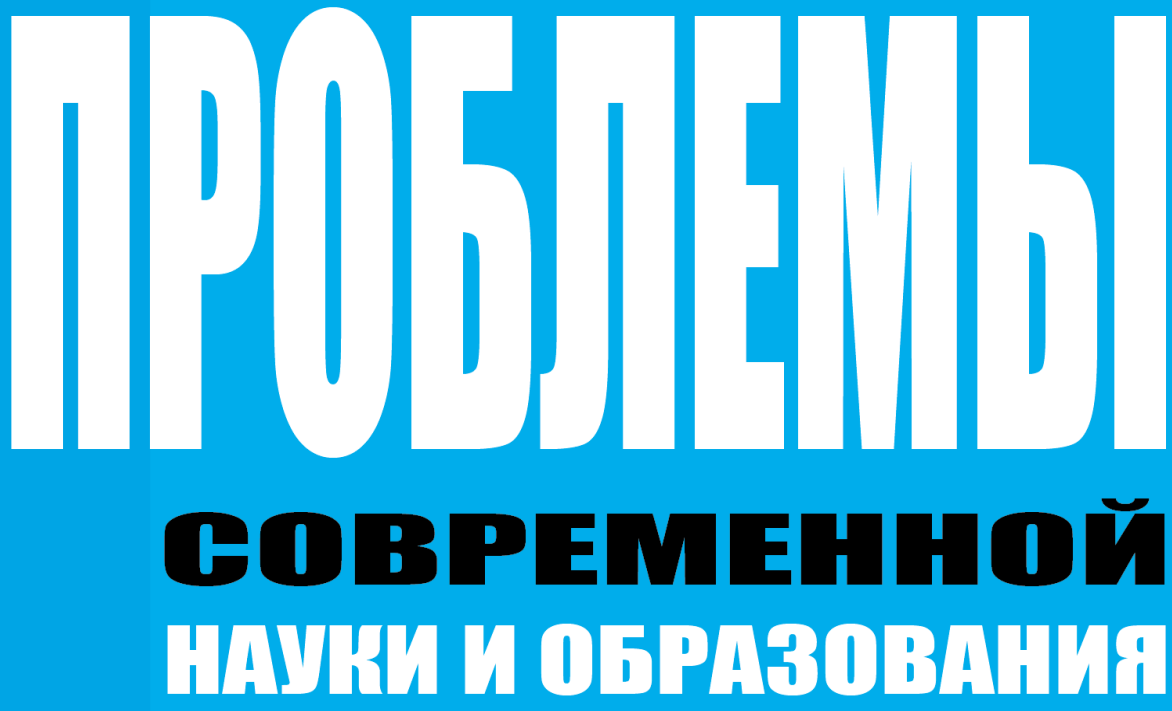
PROBLEMS OF MODERN SGIENGE AND EDUGATION DOI: 10.20861/2304-2338-2017-99 


\title{
PROBLEMS OF MODERN SCIENCE AND EDUCATION
}

\author{
2017. № 17 (99) \\ DOI: $10.20861 / 2304-2338-2017-99$
}

\author{
EDITOR IN CHIEF \\ Valtsev S.
}

\section{EDITORIAL BOARD}

\begin{abstract}
Abdullaev K. ( $\mathrm{PhD}$ in Economics, Azerbaijan), Alieva V. ( $\mathrm{PhD}$ in Philosophy, Republic of Uzbekistan), Akbulaev N. (D.Sc. in Economics, Azerbaijan), Alikulov S. (D.Sc. in Engineering, Republic of Uzbekistan), Anan'eva E. (D.Sc. in Philosophy, Ukraine), Asaturova A. (PhD in Medicine, Russian Federation), Askarhodzhaev N. (PhD in Biological Sc., Republic of Uzbekistan), Bajtasov R. (PhD in Agricultural Sc., Belarus), Bakiko I. (PhD in Physical Education and Sport, Ukraine), Bahor T. (PhD in Philology, Russian Federation), Baulina M. (PhD in Pedagogic Sc., Russian Federation), Blejh N. (D.Sc. in Historical Sc., PhD in Pedagogic Sc., Russian Federation), Bogomolov A. (PhD in Engineering, Russian Federation), Borodaj V. (Doctor of Social Sciences, Russian Federation), Volkov A. (D.Sc. in Economics, Russian Federation), Gavrilenkova I. (PhD in Pedagogic Sc., Russian Federation), Garagonich V. (D.Sc. in Historical Sc., Ukraine), Glushhenko A. (D.Sc. in Physical and Mathematical Sciences, Russian Federation), Grinchenko V. (PhD in Engineering, Russian Federation), Gubareva T. (PhD Laws, Russian Federation), Gutnikova A. (PhD in Philology, Ukraine), Datij A. (Doctor of Medicine, Russian Federation), Demchuk N. (PhD in Economics, Ukraine), Divnenko O. (PhD in Pedagogic Sc., Russian Federation), Dolenko G. (D.Sc. in Chemistry, Russian Federation), Esenova K. (D.Sc. in Philology, Kazakhstan), Zhamuldinov V. (PhD Laws, Kazakhstan), Zholdoshev S. (Doctor of Medicine, Republic of Kyrgyzstan), Ibadov R. (D.Sc. in Physical and Mathematical Sciences, Republic of Uzbekistan), Il'inskih N. (D.Sc. Biological, Russian Federation), Kajrakbaev A. (PhD in Physical and Mathematical Sciences, Kazakhstan), Kaftaeva M. (D.Sc. in Engineering, Russian Federation), Kikvidze I. (D.Sc. in Philology, Georgia), Koblanov Zh. (PhD in Philology, Kazakhstan), Kovaljov M. (PhD in Economics, Belarus), Kravcova T. (PhD in Psychology, Kazakhstan), Kuz'min S. (D.Sc. in Geography, Russian Federation), Kulikova E. (D.Sc. in Philology, Russian Federation), Kurmanbaeva M. (D.Sc. Biological, Kazakhstan), Kurpajanidi K. (PhD in Economics, Republic of Uzbekistan), Linkova-Daniels N. (PhD in Pedagogic Sc., Australia), Lukienko L. (D.Sc. in Engineering, Russian Federation), Makarov A. (D.Sc. in Philology, Russian Federation), Macarenko T. (PhD in Pedagogic Sc., Russian Federation), Meimanov B. (D.Sc. in Economics, Republic of Kyrgyzstan), Muradov Sh. (D.Sc. in Engineering, Republic of Uzbekistan), Nabiev A. (D.Sc. in Geoinformatics, Azerbaijan), Nazarov R. (PhD in Philosophy, Republic of Uzbekistan), Naumov V. (D.Sc. in Engineering, Russian Federation), Ovchinnikov $J u$. (PhD in Engineering, Russian Federation), Petrov V. (D.Arts, Russian Federation), Radkevich M. (D.Sc. in Engineering, Republic of Uzbekistan), Rakhimbekov S. (D.Sc. in Engineering, Kazakhstan), Rozyhodzhaeva G. (Doctor of Medicine, Republic of Uzbekistan), Romanenkova Yu. (D.Arts, Ukraine), Rubcova M. (Doctor of Social Sciences, Russian Federation), Rumyantsev D. (D.Sc. in Biological Sc., Russian Federation), Samkov A. (D.Sc. in Engineering, Russian Federation), San'kov P. (PhD in Engineering, Ukraine), Selitrenikova T. (D.Sc. in Pedagogic Sc., Russian Federation), Sibircev V. (D.Sc. in Economics, Russian Federation), Skripko T. (D.Sc. in Economics, Ukraine), Sopov A. (D.Sc. in Historical Sc., Russian Federation), Strekalov V. (D.Sc. in Physical and Mathematical Sciences, Russian Federation), Stukalenko N.M. (D.Sc. in Pedagogic Sc., Kazakhstan), Subachev Ju. (PhD in Engineering, Russian Federation), Sulejmanov S. (PhD in Medicine, Republic of Uzbekistan), Tregub I. (D.Sc. in Economics, PhD in Engineering, Russian Federation), Uporov I. (PhD Laws, D.Sc. in Historical Sc., Russian Federation), Fedos'kina L. (PhD in Economics, Russian Federation), Khiltukhina E. (D.Sc. in Philosophy, Russian Federation), Cuculjan S. (PhD in Economics, Republic of Armenia), Chiladze G. (Doctor of Laws, Georgia), Shamshina I. (PhD in Pedagogic Sc., Russian Federation), Sharipov M. (PhD in Engineering, Republic of Uzbekistan), Shevko D. (PhD in Engineering, Russian Federation).
\end{abstract}

Publishing house «PROBLEMS OF SCIENCE»

Frequency: weekly

153008, Russian Federation, Ivanovo, Lezhnevskaya st., h.55, 4th floor. Phone: +7 (910) 690-15-09.

http://www.ipi1.ru/ e-mail: info@p8n.ru

Distribution: Russian Federation, foreign countries

Moscow

2017 


\section{Проблемы современной науки и образования 2017. № 17 (99)}

DOI: $10.20861 / 2304-2338-2017-99$

\section{НАУЧНО-МЕТОДИЧЕСКИЙ ЖУРНАЛ}

\section{Главный редактор: Вальцев С.В.}

\section{Периодичность:} еженедельно

Подписано в печать: 03.05.2017.

Дата выхода в свет: 05.05.2017.

\section{Формат 70х100/16.}

Бумага офсетная. Гарнитура «Таймс». Печать офсетная.

Усл. печ. л. 9,1

Тираж 1000 экз.

Заказ № 1185

\section{Территория} распространения: зарубежные страны, Российская Федерация

\section{ТИПОГРАФИЯ}

ООО «ПресСто». 153025, г. Иваново, ул. Дзержинского, 39 , строение 8

\section{ИЗДАТЕЛЬ}

ООО «Олимп»

153002, г. Иваново,

Жиделева, д. 19

\section{ИЗДАТЕЛЬСТВО}

«Проблемы науки»

Свободная цена
Заместитель главного редактора: Ефимова А.В.

\section{РЕДАКЦИОННЫЙ СОВЕТ:}

Абдуллаев К.Н. (д-р филос. по экон., Азербайджанская Республика), Алиева В.P. (канд. филос. наук, Узбекистан), Акбулаев Н.Н. (д-р экон. наук, Азербайджанская Республика), Аликулов С.P. (д-р техн. наук, Узбекистан), Ананьева Е.П. (д-р филос. наук, Украина), Асатурова А.В. (канд. мед. наук, Россия), Аскарходжаев Н.А. (канд. биол. наук, Узбекистан), Байтасов Р.Р. (канд. с.-х. наук, Белоруссия), Бакико И.В. (канд. наук по физ. воспитанию и спорту, Украина), Бахор Т.A. (канд. филол. наук, Россия), Баулина М.В. (канд. пед. наук, Россия), Блейх Н.О. (д-р ист. наук, канд. пед. наук, Россия), Богомолов А.В. (канд. техн. наук, Россия), Бородай В.А. (д-р социол. наук, Россия), Волков А.Ю. (д-р экон. наук, Россия), Гавриленкова И.В. (канд. пед. наук, Россия), Гарагонич В.В. (д-р ист. наук, Украина), Глуценко А.Г. (д-р физ.-мат. наук, Россия), Гринченко B.A. (канд. техн. наук, Россия), Губарева Т.И. (канд. юрид. наук, Россия), Гутникова А.В. (канд. филол. наук, Украина), Датий А.В. (д-р мед. наук, Россия), Демчук Н.И. (канд. экон. наук, Украина), Дивненко O.В. (канд. пед. наук, Россия), Доленко Г.Н. (д-р хим. наук, Россия), Есенова К.У. (д-р филол. наук, Казахстан), Жамулдинов В.Н. (канд. юрид. наук, Казахстан), Жолдошев С.T. (д-р мед. наук, Кыргызская Республика), Ибадов Р.М. (д-р физ.-мат. наук, Узбекистан), Ильинских Н.Н. (д-р биол. наук, Россия), Кайракбаев А.К. (канд. физ.-мат. наук, Казахстан), Кафтаева М.В. (д-р техн. наук, Россия), Киквидзе И.Д. (д-р филол. наук, Грузия), Кобланов Ж.Т. (канд. филол. наук, Казахстан), Ковалёв М.Н. (канд. экон. наук, Белоруссия), Кравцова T.М. (канд. психол. наук, Казахстан), Кузьмин С.Б. (д-р геогр. наук, Россия), Куликова Э.Г. (д-р филол. наук, Россия), Курманбаева М.С. (д-р биол. наук, Казахстан), Курпаяниди К.И. (канд. экон. наук, Узбекистан), Линькова-Даниельс Н.А. (канд. пед. наук, Австралия), Лукиенко Л.В. (д-р техн. наук, Россия), Макаров А. Н. (др филол. наук, Россия), Мацаренко Т.Н. (канд. пед. наук, Россия), Мейманов Б.К. (д-р экон. наук, Кыргызская Республика), Мурадов ШШ.О. (д-р техн. наук, Узбекистан), Набиев А.А. (д-р наук по геоинформ., Азербайджанская Республика), Назаров Р.P. (канд. филос. наук, Узбекистан), Наумов В. А. (д-р техн. наук, Россия), Овчинников ЮД. (канд. техн, наук, Россия), Петров В.O. (д-р искусствоведения, Россия), Радкевич M.B. (д-р техн. наук, Узбекистан), Рахимбеков С.М. (д-р техн. наук, Казахстан), Розыходжаева Г.А. (д-р мед. наук, Узбекистан), Романенкова Ю.В. (д-р искусствоведения, Украина), Рубцова М.В. (д-р. социол. наук, Россия), Румянцев Д.Е. (д-р биол. наук, Россия), Самков А. В. (д-р техн. наук, Россия), Саньков П.Н. (канд. техн. наук, Украина), Селитреникова Т.A. (д-р пед. наук, Россия), Сибириев В.A. (д-р экон. наук, Россия), Скрипко Т.A. (д-р экон. наук, Украина), Сопов А.В. (д-р ист. наук, Россия), Стрекалов В.Н. (д-р физ.-мат. наук, Россия), Стукаленко Н.М. (д-р пед. наук, Казахстан), Субачев Ю.В. (канд. техн. наук, Россия), Сулейманов С.Ф. (канд. мед. наук, Узбекистан), Трегуб И.В. (д-р экон. наук, канд. техн. наук, Россия), Упоров И.В. (канд. юрид. наук, д-р ист. наук, Россия), Федоськина Л.А. (канд. экон. наук, Россия), Хилтухина Е.Г. (д-р филос. наук, Россия), Цуиулян С.В. (канд. экон. наук, Республика Армения), Чиладзе Г.Б. (д-р юрид. наук, Грузия), Шамиина И.Г. (канд. пед. наук, Россия), Шарипов М.С. (канд. техн. наук, Узбекистан), Шевко Д.Г. (канд. техн. наук, Россия).

АДРЕС РЕДАКцИИ:
153008, РФ, г. Иваново, ул. Лежневская, д.55, 4 этаж Тел.: +7 (910) 690-15-09.

http://www.ipi1.ru/ e-mail:info@p8n.ru

Журнал зарегистрирован Федеральной службой по надзору в сфере связи, информационных технологий и массовых коммуникаций (Роскомнадзор) Свидетельство ПИ № ФС77-47745

Редакция не всегда разделяет мнение авторов статей, опубликованных в журнале Учредители: Вальцев Сергей Витальевич; Воробьев Александр Викторович

( Проблемы современной науки и образования / Problems of modern science and education, 2017 


\section{Содержание}

ФИЗИКО-МАТЕМАТИЧЕСКИЕ НАУКИ 6

Филатов О.В. КОЛИЧЕСТВЕННЫЙ РАСЧЁТ РЕЗУЛЬТАТОВ ПАРАДОКСАЛЬНОЙ ИГРЫ ПЕННИ (УПРАВЛЯЕМАЯ ВЕРОЯТНОСТЬ ВЫПАДЕНИЙ СЕРИЙ МОНЕТЫ) НА СТАВКАХ МИНИМАЛЬНОЙ ДЛИНЫ / Filatov O.V. QUANTITATIVE CALCULATION OF THE RESULTS OF THE PARADOXICAL GAME PENNY (CONTROLLED PROBABILITY OF LOSS OF SERIES OF COINS) AT RATES OF MINIMUM LENGTH

БИОЛОГИЧЕСКИЕ НАУКИ

Балтабаев М.Т., Карльбаева М.А. РОСТ И РАЗВИТИЕ СRАМВЕ ORIENTALIS L. В УСЛОВИЯХ ЮЖНОГО ПРИАРАЛЬЯ / Baltabayev M.T., Qarlibayeva M.A. GROWTH AND DEVELOPMENT OF CRAMBE ORIENTALIS L. IN THE CONDITIONS OF SOUTHERN ARAL SEA REGION 20

ТЕХНИЧЕСКИЕ НАУКИ 23

Токмуратов А.М., Мусабаев Т.Т. НЕЛИНЕЙНЫЕ УРАВНЕНИЯ ПОЛОГИХ ЖЕЛЕЗОБЕТОННЫХ ОБОЛОЧЕК В КОНЕЧНЫХ РАЗНОСТЯХ । Tokmuratov A.M., Musabaev T.T. NONLINEAR EQUATIONS OF LOW CONCRETE HELLS IN SMALL DIFFERENCES

Петров А.Г., Авершин А.А., Степанов Е.И. АНАЛИЗ СИСТЕМЫ ЗАЩИТЫ ОТ СКАТЫВАНИЯ ПОД УКЛОН ПОДВИЖНОГО СОСТАВА КАНАТНОЙ ОТКАТКИ ПРИ ДУБЛИРОВАНИИ ЕЕ ДОПОЛНИТЕЛЬНЫМИ УСТРОЙСТВАМИ / Petrov A.G., Avershin A.A., Stepanov E.I. ANALYSIS OF THE SYSTEM OF PROTECTION FROM ROLLING DOWN THE SLOPE, ROLLING STOCK, ROPE HAULAGE, WHEN YOU DUPLICATE THEM TO ADDITIONAL DEVICES .

Овсянникова П.А., Морозова О.А. ПРОБЛЕМЫ ПРИМЕНЕНИЯ ГИБКИХ МЕТОДОЛОГИЙ УПРАВЛЕНИЯ ПОРТФЕЛЕМ ИТ-ПРОЕКТОВ В КРУПНОЙ ОРГАНИЗАЦИИ / Ovsyannikova P.A., Morozova O.A. APPLICATION PROBLEMS OF AGILE METHODOLOGIES OF IT PROJECTS PORTFOLIO MANAGMENT IN MAJOR ORGANIZATION..

Моргунов Д.Н. ВЛИЯНИЕ НЕ ЛИНЕЙНОЙ НАГРУЗКИ НА КАЧЕСТВО ЭЛЕКТРИЧЕСКОЙ СЕТИ / Morgunov D.N. EFFЕСТ OF NON-LINEAR LOAD ON THE QUALITY OF THE ELECTRICAL NETWORK

Хангильдина А.Р. ТУРБУЛЕНТНОЕ СМЕШЕНИЕ СТОЧНЫХ ВОД И ОЗОНО-ВОЗДУШНОЙ СМЕСИ / Khangildina A.R. TURBULENT MIXING OF WASTEWATER AND OZONE-AIR BLEND

ЭКОНОМИЧЕСКИЕ НАУКИ 46

Юлдашева Н.В., Хамраева Ф.Ш. НЕКОТОРЫЕ ВОПРОСЫ СОВЕРШЕНСТВОВАНИЯ ПЕНСИОННОГО ОБЕСПЕЧЕНИЯ ОТДЕЛЬНЫХ КАТЕГОРИЙ ГРАЖДАН В РЕСПУБЛИКЕ УЗБЕКИСТАН / Yuldasheva N.V., Hamrayeva F.Sh. SOME ISSUES OF IMPROVING THE PENSION PROVISION OF CERTAIN CATEGORIES OF CITIZENS IN THE REPUBLIC OF UZBEKISTAN 
Сергунина Е.В. МЕРОПРИЯТИЯ ПО СНИЖЕНИЮ ЗАТРАТ НА ВЫПУСК ПРОДУКЦИИ НА ПРЕДПРИЯТИИ ЗАО «ХЛЕБОЗАВОД № 28» / Sergunina E.V. MEASURES TO REDUCE THE COST OF PRODUCTION AT THE ENTERPRISE CJSC "BAKERY № 28" 50

ЮРИДИЧЕСКИЕ НАУКИ

Иматов А.М. НЕКОТОРЫЕ ВОПРОСЫ СОВЕРШЕНСТВОВАНИЯ ПАРЛАМЕНТСКОГО КОНТРОЛЯ В РЕСПУБЛИКЕ КАРАКАЛПАКСТАН / Imatov A.M. SOME QUESTIONS OF PERFECTION OF PARLIAMENTARY CONTROL IN THE REPUBLIC OF KARAKALPAKSTAN 54

Быконя А.В. ЗАКОНЫ: ПОНЯТИЕ, ВИДЫ И ИХ ОСОБЕННОСТИ / Bykonya A.V. LAWS: CONCEPT, TYPES AND THEIR CHARACTERISTICS

ПЕДАГОГИЧЕСКИЕ НАУКИ

Акматкулов А.А. К ПРОБЛЕМЕ ПОДГОТОВКИ СПЕЦИАЛИСТОВ ПО ИНФОРМАЦИОННОЙ СИСТЕМЕ И ТЕХНОЛОГИИ / Akmatkulov A.A. ТО THE PROBLEM OF PREPARATION OF SPECIALISTS ON THE INFORMATIONAL SYSTEM AND TECHNOLOGY

Кюриунова В.В. МЕТОДИЧЕСКИЕ ПРИЕМЫ РАБОТЫ НА ИНТЕРАКТИВНОЙ ДОСКЕ СРЕДСТВАМИ ПРОГРАММЫ SMАRТ NOTEBOOK / Kyurshunova V.V. THE METHODICAL TECHNIQUE TO WORK WITH INTERACTIVE WHITEBOARD BY MEAN OF SMART NOTEBOOK APPLICATION

Зотова И.В., Вовк С.А. СУЩНОСТЬ И КЛАССИФИКАЦИЯ ИННОВАЦИОННЫХ ТЕХНОЛОГИЙ В РЕЧЕВОМ РАЗВИТИИ ДЕТЕЙ ДОШКОЛЬНОГО ВОЗРАСТА / Zotova I.V., Vovk S.A. ESSENCE AND CLASSIFICATION OF INNOVATIVE TECHNOLOGIES IN SPEECH DEVELOPMENT OF PRESCHOOL CHILDREN.

Зотова И.В., Могилка Д.В. ОСОБЕННОСТИ РАЗВИТИЯ КОММУНИКАТИВНЫХ И РЕЧЕВЫХ НАВЫКОВ ДЕТЕЙ СТАРШЕГО ДОШКОЛЬНОГО ВОЗРАСТА / Zotova I.V., Mogilka D.V. FEATURES OF DEVELOPMENT OF COMMUNICATIVE AND SPEECH SKILLS OF CHILDREN OF SENIOR PRESCHOOL AGE.

Красушкина А.В., Басова Д.Н. ВЛИЯНИЕ ЗРИТЕЛЬСКИХ ПРЕДПОЧТЕНИЙ СТУДЕНТОВ НА ВЫБОР ТРАЕКТОРИИ ВНЕУЧЕБНОЙ ДЕЯТЕЛЬНОСТИ / Krasushkina A.V., Basova D.N. INFLUENCE OF STUDENT'S VISUAL PREFERENCES FOR THE SELECTION OF TRAJECTORY OF NON-TRAFFIC ACTIVITIES

Зотова И.В., Зосенко Е.А. РАЗВИТИЕ ИНТЕЛЛЕКТУАЛЬНО-ЯЗЫКОВЫХ СПОСОБНОСТЕЙ ДЕТЕЙ СТАРШЕГО ДОШКОЛЬНОГО ВОЗРАСТА / Zotova I.V., Zosenko E.A. THE DEVELOPMENT OF INTELLECTUAL AND LANGUAGE ABILITIES OF CHILDREN OF SENIOR PRESCHOOL AGE 84

Киселева О.М. К ВОПРОСУ О СОДЕРЖАНИИ ПРОФЕССИОНАЛЬНОЙ ПЕРЕВОДЧЕСКОЙ КОМПЕТЕНТНОСТИ ПРИ ПОДГОТОВКЕ ПЕРЕВОДЧИКОВ ПРОФЕССИОНАЛЬНО ОРИЕНТИРОВАННЫХ TEKCTOB / Kiseleva O.M. TO THE QUESTION OF THE CONTENT OF PROFESSIONAL TRANSLATION COMPETENCE IN THE TRAINING OF TRANSLATORS OF PROFESSIONALLY ORIENTED TEXTS 
Айдарбекова А.А., Сулайманова А.А., Соодонбеков Э.Т., Миненков Г.О., Тургунбаев У.А. СОВЕРШЕНСТВОВАНИЕ СИСТЕМЫ ОКАЗАНИЯ СПЕЦИАЛИЗИРОВАННОЙ ОНКОЛОГИЧЕСКОЙ НАСЕЛЕНИЮ КЫРГЫЗСКОЙ РЕСПУБЛИКИ / Aidarbekova A.A., Sulaimanova A.A., Soodonbekov E.T., Minenkov G.O., Turgunbaev U.A. IMPROVEMENT OF THE SYSTEM OF RENDERING SPECIALIZED ONCOLOGICAL CARE TO THE POPULATION OF THE KYRGYZ REPUBLIC

Усманходжаева А.А., Высогориева О.Н., Нуруллаев Б.А. ОСОБЕННОСТИ ФУНКЦИОНИРОВАНИЯ СЕРДЕЧНО-СОСУДИСТОЙ СИСТЕМЫ У ЮНЫХ СПОРТСМЕНОВ, ЗАНИМАЮЩИХСЯ В УСЛОВИЯХ ЖАРКОГО КЛИМАТА / Usmankhodjaeva A.A., Vysogortseva O.N., Nurullayev B.A. FUNCTION OF CARDIOVASCULAR SYSTEM IN YOUNG ATHLETES INVOLVED IN HOT CLIMATES.

Филиппова Я.Д., Ившин А.А., Иванова Н.А. ФЕТАЛЬНАЯ ЭКГ (STAN) В ДИАГНОСТИКЕ ИНТРАНАТАЛЬНОЙ ГИПОКСИИ ПЛОДА / Filippova J.D., Ivshin A.A., Ivanova N.A. FETAL ECG (STAN) IN DIAGNOSTICS OF INTRANATAL HYPOXIA 102

СОЦИОЛОГИЧЕСКИЕ НАУКИ. 105

Орлова К.Е. «ПРОБЛЕМНЫЕ ВОПРОСЫ» КАК УСТАНОВКА ФОРМЫ TOK-ШOY / Orlova K.E. "PROBLEMATIC ISSUES" LIKE SETTING UP A TALK SHOW FORM

Ocunoв К.B. СПЕЦИФИКА МОЛОДЁЖНОЙ ИНТЕРНЕТ-АУДИТОРИИ / Osipov K.V. THE SPECIFICITY OF THE YOUTH OF THE INTERNET AUDIENCE 


\title{
КОЛИЧЕСТВЕННЫЙ РАСЧЁТ РЕЗУЛЬТАТОВ ПАРАДОКСАЛЬНОЙ ИГРЫ ПЕННИ (УПРАВЛЯЕМАЯ ВЕРОЯТНОСТЬ ВЫПАДЕНИЙ СЕРИЙ МОНЕТЫ) НА СТАВКАХ МИНИМАЛЬНОЙ ДЛИНЫ Филатов O.B. Email: Filatov1799@scientifictext.ru
}

Филатов Олег Владимирович - инженер-программист, ЗАО «Научно технический центр «Модуль», г. Москва

\begin{abstract}
Аннотация: в парадоксальной игре Пенни управление вероятностью выпадения сторон монеть стало реальностью. В этой статье предлагаются формуль для количественного расчёта числа побед и проигрышей для сделанных в игре Пенни ставок. Количественный расчёт вылгрышей и проигрышей ставок рассчитывается в зависимости от числа сделанных бросков монеты. Количества вылгрымей $и$ проигрышей ставки выводятся из формул, описывающих структуру случайной бинарной последовательности. Любая случайная бинарная последовательность образуется иугами из составных событий. Формуль для расчёта численностей составных событий и их иуг применимы для расчёта количественных результатов побед ставок в парадоксальной игре Пенни. В конце статьи также даны правила для расчёта прочентов побед и прочгрышей ставок, эти правила также выведень из формул описания амплитудно-частотных характеристик случайной бинарной последовательности.
\end{abstract}

Ключевые слова: элементарное событие, эл, игра Пенни, парадокс Пенни, техника управления вероятностью.

\section{QUANTITATIVE CALCULATION OF THE RESULTS OF THE PARADOXICAL GAME PENNY (CONTROLLED PROBABILITY OF LOSS OF SERIES OF COINS) AT RATES OF MINIMUM LENGTH Filatov O.V.}

\author{
Filatov Oleg Vladimirovich - Experimental Physics, Software Engineer, \\ SCIENTIFIC AND TECHNICAL CENTER «MOДУЛЬ», MOSCOW
}

\begin{abstract}
Penney's paradoxical game, managing the probability of falling sides of a coin has become a reality. In this article, we propose formulas for quantifying the numbers of wins and losses for the stakes made in the Penny game. The quantitative calculation of winnings and bet losses is calculated according to the number of coin tosses made. The amounts of wins and losses of the rate are derived from formulas describing the structure of a random binary sequence. Any random binary sequence is formed by trains from compound events. Formulas for the calculation of the numbers of composite events and their train are applicable for calculating the quantitative results of wager wins in the paradoxical Penny game. At the end of the article, the rules for calculating the percentages of wins and losing stakes are also given, these rules are also derived from the formulas for describing the amplitude-frequency characteristics of a random binary sequence.
\end{abstract}

Keywords: elementary event, el, game Penny, Penny paradox, binary sequence, probability management technique. 


\section{Введение.}

Наиболее известен вариант парадоксальной игры Пенни, когда игроки придумывают серии (поисковые шаблоны) из трёх элементарных бинарных событий $(\mathrm{L}=3$ эла), при $\mathrm{L}=3$, второй игрок выигрывает (при желании) всегда. Законы парадоксальной игры Пенни действуют и на более длинных сериях (L > 3), и на коротких сериях (шаблонах) длиной в два события ( $\mathrm{L}=2$ эла). Отличие игры со ставкой длины два, от широко известной игры со ставкой длины три, заключается в том, что у первого игрока есть дополнительный шанс на выигрыш, если второй игрок не знает секрета сочетаний выигрышных и проигрышных комбинаций в двухбитовой игре Пенни.

Анализ игры Пенни на ставках длиной в два бинарных события менее трудоёмок, так как анализируемых комбинаторных вариантов мало. В этой статье механизмы игры Пенни рассматриваются на шаблонах длиной в два элементарных события $(\mathrm{L}=2$ эла).

B таблице 1 представлены экспериментально полученные результаты конкуренции пар двухразрядных поисковых шаблонов по правилам игры Пенни. Все возможные комбинации для игрока 1 (И1 первый называет свою комбинацию) представлены в верхней, горизонтальной, строке таблицы 1.

Таблица 1. Не равная вероятность побед для серий $L=2$ в игре Пенни

\begin{tabular}{|c|c|c|c|c|c|c|}
\hline \multirow{2}{*}{\multicolumn{2}{|c|}{$\begin{array}{c}\text { Sh2, } \\
\ll И 2 » \downarrow\end{array}$}} & \multicolumn{4}{|c|}{ Комбинации игрока 1 - «И1», (Sh1) } & \\
\hline & & 00 & 01 & 10 & 11 & \\
\hline \multirow{4}{*}{ 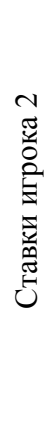 } & 00 & & $\begin{array}{l}3333183 p=1 / 2 \\
3333533 p=1 / 2\end{array}$ & $\begin{array}{l}5000055 \mathrm{p}=\mathbf{3} / \mathbf{4} \\
1666660 \mathrm{p}=1 / 4\end{array}$ & $\begin{array}{l}3333047 \mathrm{p}=1 / 2 \\
3333533 \mathrm{p}=1 / 2\end{array}$ & $\begin{array}{l}\text { «И1» } \\
\text { «И2» }\end{array}$ \\
\hline & 01 & $\begin{array}{l}3333533 \mathrm{p}=1 / 2 \\
3333183 \mathrm{p}=1 / 2\end{array}$ & & $\begin{array}{l}3333210 \mathrm{p}=1 / 2 \\
3332650 \mathrm{p}=1 / 2\end{array}$ & $\begin{array}{l}1666648 p=1 / 4 \\
5000056 p=3 / 4\end{array}$ & $\begin{array}{l}\text { «И1» } \\
\ll И 2 »\end{array}$ \\
\hline & 10 & $\begin{array}{l}1666660 p=1 / 4 \\
5000055 p=\mathbf{p} / \mathbf{4}\end{array}$ & $\begin{array}{l}3332650 \mathrm{p}=1 / 2 \\
3333210 \mathrm{p}=1 / 2\end{array}$ & & $\begin{array}{l}3333047 \mathrm{p}=1 / 2 \\
3333657 \mathrm{p}=1 / 2\end{array}$ & $\begin{array}{l}\text { «И1» } \\
\ll И 2 »\end{array}$ \\
\hline & 11 & $\begin{array}{l}3333533 \mathrm{p}=1 / 2 \\
3333047 \mathrm{p}=1 / 2\end{array}$ & $\begin{array}{l}5000056 \quad \mathbf{p}=\mathbf{3} / \mathbf{4} \\
1666648 \mathrm{p}=1 / 4\end{array}$ & $\begin{array}{l}3333657 \mathrm{p}=1 / 2 \\
3333047 \mathrm{p}=1 / 2\end{array}$ & & $\begin{array}{l}\text { «И1» } \\
\text { «И2» }\end{array}$ \\
\hline & & $\sum(\mathrm{Sh}$ & )$+\Sigma(\operatorname{Sh} 2)=N / 3$ & 3: $\quad$ F $0,5(N=2$ & & \\
\hline
\end{tabular}

Игра Пенни с двух битовыми шаблонами $(\mathrm{L}=2)$ отличается от игры с трёхбитовыми шаблонами тем, что преимущество имеет игрок, который первым называет свою комбинацию («И1»). Первый игрок («И1») может назвать комбинацию, которая при конкуренции с комбинацией второго игрока («И2»), даёт ему дополнительные шансы на победу.

Для получении дополнительных шансов на победу И1 должен назвать одну из двух комбинаций: «01» либо «10», И1 гарантированно выиграет в достаточно длинной серии таймов, если второй игрок И2 назовёт комбинацию «11» (при «01» У И1) или «00» (при комбинации «10» у И1).

Если игроку И1 нужно проиграть, то он называет комбинацию «00», либо «11». При этих комбинациях игрок И1 гарантированно проигрывает в достаточно длинной серии таймов, если второй игрок назовёт «10» либо, соответственно, «01».

Из таблицы 1 видно, что сумма выигрышей обоих игроков является величиной постоянной, которая стремится к одной трети числу бросков монеты, в среднем, на один выигрыш игроков приходятся три броска монеты.

Ниже приводится количественный расчёт для каждой из пар шаблонов таблицы 1. 


\section{Основная часть.}

Количественный расчёт побед и поражений для конкурирующих пар шаблонов: («00», «11») u («11», «00») .

Мы начинаем рассмотрение конкурирующих пар, с пары: «00»; «11», потому что для неё просто выводится формула расчёта числа выигрышей от числа бросков монеты. Но для вывода формулы познакомимся с элементами концепции экранирования [1], воздействием шаблонов друг на друга.

Поисковые шаблоны «00», «11» не оказывают друг на друга никакого экранирующего эффекта. Поясним значение слов «не оказывают друг на друга никакого экранирующего эффекта» на примере пары шаблонов оказывающих друг на друга экранирующие влияние: «01» и «11». В этой паре шаблон «01» воздействует на шаблон «11». А именно, единица «1» присутствует в обоих шаблонах: «01» и «11» и, в выпадающей комбинации «011», присутствуют оба шаблона («01» и «11»), но именно «01» разрушает (по правилам игры Пенни не допускает к реализации) шаблон «11».

В конкурирующей паре «00», «11» образующие элементарные события для каждого из шаблонов разные. Шаблон «00» не может ничего отобрать у шаблона «11», так как в шаблоне «11» нет нулей. И наоборот.

Рассмотрим в таблице 2 случайные бинарные значения. В столбце 1 содержится «0», выпавшее за ним случайное бинарное событие находится в столбце 2 и оно равно «1». Получилась комбинация «01», которая не равна ни одному из конкурирующих шаблонов («00», «11»).

Следующее выпавшее случайное бинарное значение находится в столбце 3. Значения из столбцов 2 и 3 образуют комбинацию «11», которая равна поисковому шаблону «11», поэтому победа приписывается шаблону «11». Это первая победа шаблона «11», о чём соответствует надпись (1 «11») в объединённой ячейке столбцов 2 и 3.

Следующая победа будет уже за шаблоном «00». Это первая победа шаблона «00», о чём соответствует надпись (1«00») в объединённой ячейке столбцов 5 и 6.

В таблице 2 у шаблона «11» шесть побед, у шаблона «00» четыре победы. Видно, что шаблоны «00» и «11» одерживают победы внутри составных событий $[1,2,3]{ }^{n} S$ с длиной больше единицы: $\mathrm{n} \geq 2$. Число побед шаблона внутри составного события ${ }^{n} S$ является целой частью от деления на два: (int) $\frac{n}{2}$.

Таблица 2. Серии «00»; «11» внутри составных событий ${ }^{n} S$

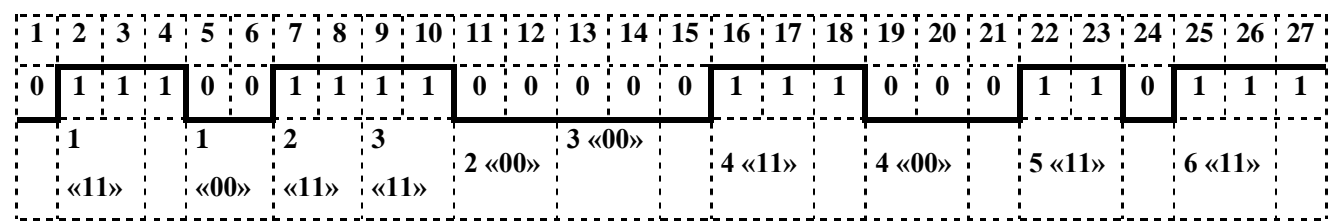

Мат ожидания чисел составных событий ${ }^{n} S$, так как они понимаются в работах [13], зависят от $N$ бросков монеты по ф.1 (теорема «О амплитудно - частотной характеристике случайной бинарной пос-ти» [6]):

$$
{ }^{n} S=\frac{N}{2^{n+1}}
$$

По ф.1 находят число составных событий ${ }^{n} S$, в которых будут найдены искомые шаблоны «00», «11». Умножая число составных событий ${ }^{n} S$ на число шаблонов, которые помещены внутри каждого составного события длины $n$ : ${ }^{n} S \cdot($ int $) \frac{n}{2}$ получим математическое ожидание суммарного числа побед ${ }^{n} V i c$ для обоих шаблонов: «00»+«11», ф.2: 


$$
{ }^{n} \text { Vic }=\frac{N}{2^{n+1}} \cdot(\text { int }) \frac{n}{2}
$$

Где: $N$ - число бросков монеты; $n$ - длина составного события ${ }^{n} S$.

Формула 2 (как и ф.1) начинает работать в довольно длинных случайных пос-ях, с числом бросков монеты $N$ более тысячи.

Таблица 2 иллюстрирует смены составных событий ${ }^{n} S$, а не работу ф.:1, 2 . В таблице 2 общее число побед шаблонов «00»+ «11» равно десяти: (“4 «00»” + “6 «11»”). Поскольку шаблоны «00», «11» не влияют друг на друга, то их выпадение равновероятно и мат ожидания: ${ }^{n} S(00)$ и ${ }^{n} S(11)$ будут одинаковыми, и равны половине ${ }^{n} S, \phi .3$ :

$$
{ }^{n} S(00)={ }^{n} S(11)=\frac{{ }^{n} S}{2}=\frac{N}{2^{n+2}}
$$

В составных событиях длины $\mathrm{n}$, число побед шаблона «00»: ${ }^{n} \operatorname{Vic}(00)$, равно числу побед шаблона «11»: ${ }^{n} \operatorname{Vic}(11)$, и равно: $\frac{1}{2} \cdot{ }^{n} V i c$.

Введём универсальное обозначение полярности: ${ }^{n} \operatorname{Vic}(X)={ }^{n} \operatorname{Vic}(00)={ }^{n} \operatorname{Vic}(11)$. Тогда число побед для каждого из рассматриваемых шаблонов будет суммой побед $\operatorname{Vic}(X)$ в составных событиях ${ }^{n} S$ всех длин $n$, ф.4:

$$
\operatorname{Vic}(X)=\frac{1}{2} \cdot \sum_{n=2}^{n \rightarrow \infty}{ }^{n} V i c=\frac{1}{2} \cdot \sum_{n=2}^{n \rightarrow \infty}\left(\frac{N}{2^{n+1}} \cdot(\text { int }) \frac{n}{2}\right)
$$

Оператор (int) нужен только для работы с нечётными $\mathrm{n}: \mathrm{n}=3 ; 5 ; 7 ; \ldots$. Избавимся от (int), введя формальный параметр $i=1,2,3, \ldots$. Параметр $i$ будем использовать в рядах: с чётными $n=2 i=2 ; 4 ; 6 ; \ldots$ и с нечётными $n=2 i+1=3 ; 5 ; 7 ; \ldots$, ф.5:

$$
\text { Vic }=\sum_{n=2}^{n \rightarrow \infty}\left({ }^{n} S \cdot(\text { int }) \frac{n}{2}\right)=\sum_{\substack{i=1 ; \\ n=2 i}}^{i \rightarrow \infty} \frac{N \cdot i}{2^{2 i+1}}+\sum_{\substack{i=1 ; \\ n=2 i+1}}^{i \rightarrow \infty} \frac{N \cdot i}{2^{2 i+2}}
$$

В первом слагаемом $\frac{N \cdot i}{2^{n+1}}$ для получения ряда чётных $\mathrm{n}$, делаем подстановку: $n=2 i$, и слагаемое принимает вид: $\sum_{\substack{i \rightarrow \infty \\ n=2 i}}^{i \rightarrow \frac{N \cdot i}{2^{2 i+1}}}$. Во втором слагаемом замена по $\mathrm{n}$ для $\frac{N \cdot i}{2^{n+1}}$ производится в виде: $n=2 i+1$, слагаемое принимает вид: $\sum_{\substack{i=1 \\ n=2 i+1}}^{i \rightarrow \infty} \frac{N \cdot i}{2^{2 i+2}} ;$ так как: $2 n+1=(2 i+1)+1=2^{2 i+2}$.

Суммируя по обоим рядам ф.5, получаем, что общее число побед шаблонов «00»+ «11» при $N$ бросках монеты равно одной трети от $N$, ф.6:

$$
\text { Vic }=\sum_{\substack{i=1 ; \\ n=2 i}}^{i \rightarrow \infty} \frac{N \cdot i}{2^{2 i+1}}+\sum_{\substack{i=1 ; \\ n=2 i+1}}^{i \rightarrow \infty} \frac{N \cdot i}{2^{2 i+2}}=\frac{2}{9} \cdot N+\frac{1}{9} \cdot N=\frac{N}{3}
$$

Учитывая, что: $\operatorname{Vic}=2 \cdot \operatorname{Vic}(X)$, а по ф.6 Vic $=N / 3$, получаем ф.7:

$$
\operatorname{Vic}(X)=\operatorname{Vic}(00)=\operatorname{Vic}(11)=N / 6
$$

Из таблицы 1 видно, что для ячеек: «11»; «00»и «00»; «11» вероятность побед шаблонов «00», «11» одинакова. Мат ожидание для каждого из этих шаблонов: $\operatorname{Vic}(00)=\operatorname{Vic}(11)=\frac{20000000}{6}=3333333$, хорошо совпадает с экспериментальными данными из таблицы 1.

Для расчёта чисел побед и поражений оставшихся пар шаблонов в таблице 1, выведем формулу расчёта математического ожидания числа встреч шаблона «01», искомого по 
правилам Пенни, в бинарной потоковой пос-ти. В нижней строке таблицы 3 пронумерованы девять ситуаций обнаружения комбинации (шаблона) «01».

Таблища 3. Примеры обнаружения серии «01» в бинарной пос-ти F0,5

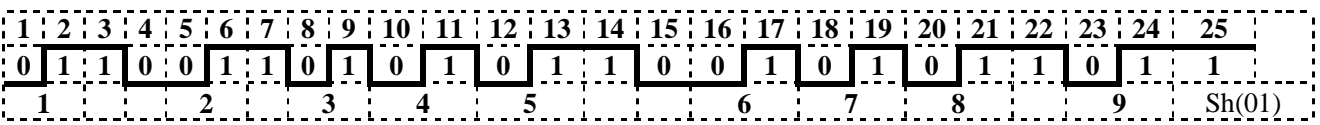

В таблице 3 показаны четыре ситуации обнаружения серии «01». Две ситуации связаны с составными событиями $[1,2,3]:{ }^{n} S$, и две с цугами $[1,2,4,5]:{ }^{n} C_{w}$. Цуги таблицы 3: ${ }^{\mathrm{n}=1} C_{(w=5)}=\ll 01010 »\left(\right.$ столбцы 8-12); ${ }^{\mathrm{n}=1} C_{(w=4)}=\ll 1010 »($ столбцы 17-20); цуга ${ }^{\mathrm{n}=1} C_{(w=1)}=\ll 0 »$, столбец 23 (цуга ${ }^{\mathrm{n}=1} C_{(w=1)}$ - вырождена в составное событие единичной длины: $\left.{ }^{n=1} S\right)$.

Математическое ожидание числа цуг длинной бинарной пос-ти находят по ф.8 $[1,2,4,5]$ :

$$
{ }^{n} C_{w N}=\frac{\left(2^{n}-1\right)^{2}}{2^{n(w+2)+1}} N
$$

Особенности обнаружения шаблона «01» в составных событиях ${ }^{n} S$.

Составное событие состоит из «1». Если составное событие состоит из «1»: ${ }^{n} S X={ }^{n} S 1$ (например, столбцы 2,3 таблицы 3), то по определению перед ним присутствует «0» (столбец 1) [1,2,3]. Это значит, что полярные составные события $n>1 S(1)$ вносят в численность шаблонов «01» вклад равный их количеству в пос-ти $[1,2,3]$, ф.9:

$$
{ }^{n>1} S X={ }^{n>1} S 0={ }^{n>1} S 1=\frac{1}{2} \cdot \sum_{n=2}^{n \rightarrow \infty} \frac{N}{2^{n+1}}=\frac{N}{8}
$$

Суммирование начинается с длины два $(n=2)$, так как при единичной длине $(n=1)$ составные события ${ }^{n} S$ вырождаются в цуги $[1,2,4,5]$ (число серий «01» в цугах рассчитывается по другой формуле).

Составное событие состоит из «0». Пример составного события из нулей: таблица 3, столбцы 4,5. В рассматриваемой модели число шаблонов «01» связано с полярными составными событиями бинарной пос-ти: ${ }^{n} S X={ }^{n} S 0={ }^{n} S 1$, ф.9. Что бы дважды не учитывать один и тот же шаблон «01» нужно определиться по каким составным событиям: ${ }^{n} S 0$ или ${ }^{n} S 1$ мы ведём расчёт численности шаблона «01». Договоримся вести расчёт через составные события, образованные из единиц «1» $\left({ }^{n} S 1\right)$, а составные события, образованные из нулей «0» $\left({ }^{n} S 0\right)$ не учитывать в расчётах. Поэтому, в рассматриваемой модели расчёта шаблонов «01», по ф.9, составные события ${ }^{n>1} S 0$ не учитывают в формулах расчёта числа серий «01».

Особенности обнаружения шаблона «01» в иугах ${ }^{1} C_{w}$.

В одной цуге может находиться несколько искомых комбинаций (шаблонов) «01». Оговорим правила распознавания и учёта шаблонов «01». С цугой из таблицы 3 : «01010», начинающейся в столбце 8, связаны три шаблона $\operatorname{Sh}(01)$, имеющие номера: $3,4,5$. Идентификация шаблонов $\operatorname{Sh}(01)$ с номерами 3 и 4, проста, то шаблон «01» с номером 5, только первым своим «0» принадлежит цуге. В пояснительной таблице 4 даны формальные ряды цуг для расчёта комбинаций»01». Таблица 4 так же содержит суммирующий составные события ${ }^{n} S$ ряд, ф. 9.

Сумма этих рядов, ф.9, однозначно вычисляет мат ожидание числа комбинаций (шаблонов) «01» в случайной бинарной пос-ти из $N$ элементарных событий.

Рассмотрим подраздел таблицы 4 «уга ${ }^{l} C_{W}$ начинается $c$ «1». Если цуга ${ }^{1} C_{w}$ начинается с «1», (пример, столбец 17 в таблице 3$)$, то по определению $[1,2,4,5]$ перед ней завершилось составное событие ${ }^{n} S 0$, что соответствует искомой 
комбинации «01». Учёт комбинаций «01» начинается с первого элементарного события цуги ${ }^{1} C_{w}$.

Число полуволн цуги чётно: $w=2 i$, при $i=1,2,3, \ldots$, пример, в таблице 3 , цуга «1010» начинается в колонке 17.

Число полуволн цуг не чётно: $w=2 i-1$, при $i=1,2,3, \ldots$, например: «1», «101».

Рассмотрим подраздел таблицы 4 «уга ${ }^{l} C_{W}$ начинается $c$ «0». Пример такой цуги ${ }^{1} C 0_{w}$, столбец 8 таблицы 3 . В подразделе раскрывается расчёт численностей цуг с чётным и нечётным числом полуволн $w$.

Таблица 4. Пояснения к формулам расчета числа встреч шаблона «01»

\begin{tabular}{|c|c|c|c|c|}
\hline & \multicolumn{2}{|c|}{ Цуга ${ }^{1} \mathrm{C}_{\mathrm{W}}$ начинается с «1» } & \multicolumn{2}{|c|}{ Цуга ${ }^{1} \mathrm{C}_{\mathrm{W}}$ начинается с «0» } \\
\hline & $\begin{array}{l}w \text { не чётное } \\
\ll . .0010100 . . »\end{array}$ & 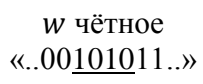 & $\begin{array}{c}w \text { чётное } \\
\text { «..11 } \underline{010100 . . »}\end{array}$ & $\begin{array}{l}w \text { не чётное } \\
« . .11 \underline{01011 . . »}\end{array}$ \\
\hline$w$ & $\sum_{\substack{i=1 ; \\
w=2 i-1}}^{i \rightarrow \infty} \frac{{ }^{1} C_{w}}{2} \cdot i$ & $\sum_{\substack{i=1 ; \\
w=2 i}}^{i \rightarrow \infty} \frac{{ }^{1} C_{w}}{2} \cdot i$ & $\sum_{\substack{i=1 ; \\
w=2 i}}^{i \rightarrow \infty} \frac{{ }^{1} C_{w}}{2} \cdot i$ & $\sum_{\substack{i=1 ; \\
w=2 i-1}}^{i \rightarrow \infty} \frac{{ }^{1} C_{w}}{2} \cdot(i-1)$ \\
\hline 1 & ${ }^{1} \mathrm{C}_{1} \cdot(i=1)$ & & & $0(i=1)$ \\
\hline 2 & & ${ }^{1} \mathrm{C}_{2} \cdot(i=1)$ & ${ }^{1} \mathrm{C}_{2} \cdot(i=1)$ & \\
\hline 3 & ${ }^{1} C_{3} \cdot(i=2)$ & & & ${ }^{1} \mathrm{C}_{3} \cdot(i=2)$ \\
\hline 4 & & ${ }^{1} \mathrm{C}_{4} \cdot(i=2)$ & ${ }^{1} \mathrm{C}_{4} \cdot(i=2)$ & \\
\hline 5 & ${ }^{1} \mathrm{C}_{5} \cdot(i=3)$ & & & ${ }^{1} \mathrm{C}_{5} \cdot(i=3)$ \\
\hline 6 & & ${ }^{1} \mathrm{C}_{6} \cdot(i=3)$ & ${ }^{1} \mathrm{C}_{6} \cdot(i=3)$ & \\
\hline 7 & ${ }^{1} \mathrm{C}_{7} \cdot(i=4)$ & & & ${ }^{1} C_{7} \cdot(i=4)$ \\
\hline 8 & & ${ }^{1} \mathrm{C}_{8} \cdot(i=4)$ & ${ }^{1} \mathrm{C}_{8} \cdot(i=4)$ & \\
\hline$\cdots$ & $\cdots$ & $\ldots$ & $\ldots$ & $\ldots$ \\
\hline & $\frac{1}{2} \cdot \frac{i \cdot N}{2^{2 i+2}}=\frac{N}{18}$ & $\frac{1}{2} \cdot \frac{i \cdot N}{2^{2 i+3}}=\frac{N}{36}$ & $\frac{1}{2} \cdot \frac{i \cdot N}{2^{2 i+3}}=\frac{N}{36}$ & $\frac{1}{2} \cdot \frac{(i-1) \cdot N}{2^{2 i+2}}=\frac{N}{72}$ \\
\hline$\Sigma(\mathrm{N})$ & 1111111 & 555556 & 555556 & 277778 \\
\hline $\begin{array}{l}\text { Сос } \\
\text { дли }\end{array}$ & $\begin{array}{l}\text { вные события } \\
n=2,3,4, \ldots \\
\text { ормула } 9\end{array}$ & $\frac{1}{2} \cdot \sum_{n=2}^{\infty} r$ & $\frac{1}{2} \cdot \sum_{n=2}^{\infty} \frac{N}{2^{n+1}}=$ & $\left.-\frac{N}{2^{2}}\right)=\frac{N}{8}$ \\
\hline & & $\mathrm{N}=20000000$ & n616; Btn618 & \\
\hline
\end{tabular}

Каждая из формул (из таблицы 4) учитывает вклад от своей поисковой ситуации. Получаемая в итоге числовая сумма будет мат ожиданием шаблона «01» при его поиске по пенни подобным правилам (при отсутствии любых конкурирующих 
шаблонов во время поиска), при $N$ бросках монеты. В результате объединения вместе пяти формул из таблицы 4, получаем ф. 10 :

$$
\begin{aligned}
\operatorname{Sh}(01)= & \sum_{\substack{i=1 ; \\
w=2 i-1}}^{i \rightarrow \infty}\left(\frac{{ }^{1} C_{w} \cdot i}{2}+\frac{{ }^{1} C_{w}}{2} \cdot(i-1)\right)+ \\
& 2 \cdot \sum_{\substack{i=1 ; \\
w=2 i}}^{i \rightarrow \infty} \frac{{ }^{1} C_{w} \cdot i}{2}+\sum_{n=2}^{\infty} \frac{{ }^{n} S}{2}=\frac{N}{4}
\end{aligned}
$$

Действительно, раскрывая суммы в ф.10, получаем: $\frac{N}{2 \cdot 9}+\frac{N}{4 \cdot 9}+\frac{N}{4 \cdot 9}+\frac{N}{8 \cdot 9}+\frac{N}{8}=$ $\frac{4+2+2+1+9}{8 \cdot 9} N=\frac{N}{4}$.

Так как шаблоны «01» и «10» симметричны, то их численности равны. И по ф.10 производится расчёт мат ожидания для любого из двух шаблонов: «01», «10».

В таблице 5, в строке «Эксперимент», даны численности экспериментально найденных шаблонов, которые искались в пос-ти случайных бинарных событий по одному (без всяких других конкурирующих шаблонов). В строках «Теория» даны числа рассчитанных по формулам мат ожиданий по отдельности для каждого из шаблонов.

Таблица 5. Поиск одного шаблона в $F 0,5\left(\mathrm{~N}=2 \cdot 10^{7}\right)$

\begin{tabular}{|c|c|c|c|c|}
\hline Шаблоны $\rightarrow$ & 00 & 01 & 10 & 11 \\
\hline «Эксперимент» & 3333533 & 5000056 & 5000055 & 3333047 \\
\hline \multirow{2}{*}{ «Теория» } & 3333333 & 5000000 & 5000000 & 3333333 \\
\cline { 2 - 5 } & $N / 6(\phi .7)$ & $N / 4(\phi .10)$ & $N / 4(\phi .10)$ & $N / 6(\phi .7)$ \\
\hline
\end{tabular}

Опираясь на полученные формулы ф.7 и ф.10 перейдём к выводу формул расчёта побед для других пар конкурирующих шаблонов в таблице 1.

Количественньй расчёт побед в парах: «00», «01», («11», «10»).

Для конкурирующей пары «00», «01» возможна одна экранирующая комбинация:

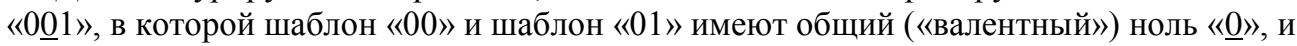
этот «와, шаблон «00» отбирает у шаблона «01». Результат расщепления комбинации $\ll 001 »:\langle 0 \underline{0} 1 » \rightarrow\langle 0 \underline{0} »+\langle 1 »$.

Рассмотрим составные события и цуги (случайной бинарной пос-ти) в которых существует цепочка расщепления: «001» $\rightarrow$ «00»+ «1».

Ситуация окончания образованного из $n$ нулей «0» $(n \geq 2)$ составного события ${ }^{n>1} S 0=\frac{1}{2} \cdot \sum_{n=2}^{n \rightarrow \infty} \frac{N}{2^{n+1}}=\frac{N}{8}$. Учитывая, что после окончания каждого $S 0$ (за каждым $S 0$ ) находится «1», получаем, что число комбинаций «...001» в случайной бинарной пости равно $N / 8$.

Из таблицы 2, столбцы 11-15, видно, что комбинации «01» не уничтожаются поисковыми шаблонами «00» в составных событиях из нечётного числа нулей. При движении поискового шаблона «00» по составному событию из пяти нулей (столбцы 11-15), он не уничтожает «валентный» ноль в столбце 15 («0000ㅁ1»). И это ноль «0» по правилам игры Пенни войдёт в число побед поискового шаблона «01». Поэтому, находя количество всех чётных составных событий ${ }^{n>1} S 0$, и вычитая его из общего числа шаблонов $\mathrm{Sh}(01)$ бинарной пос-ти $(N / 4)-ф .10$, получим число побед $\mathrm{Sh}(01)$ при конкуренции с шаблоном $\operatorname{Sh}(00)$, ф.11:

$$
\operatorname{Sh}(01)=\frac{N}{4}-\frac{1}{2} \cdot \sum_{\substack{i=1 ; \\ n=2 \cdot i}}^{\substack{i \rightarrow \infty \\ 2^{n+1}}}=\frac{N}{4}-\frac{1}{2} \cdot \frac{N}{6}=\frac{N}{6}
$$


При $N=2 \cdot 10^{7}$ число побед шаблона $\operatorname{Sh}(01)$ в конкуренции с шаблоном $\operatorname{Sh}(00)$, по ф.11 будет: $\operatorname{Sh}(01)=3333333$, что хорошо совпадает с экспериментально полученным значением в таблице 1.

Так как шаблоны «01» при использовании поисковых правил Пенни не могут влиять на шаблоны «00», то число шаблонов «00», в бинарной пос-ти, рассчитывается по ф.7: $\quad \operatorname{Sh}(00)=N / 6$. Получаем: $\operatorname{Sh}(00)=\operatorname{Sh}(01), \quad$ что подтверждается экспериментальными значениями из таблицы 1.

Пары шаблонов («00»; «01») и («11»; «10») являются идентичными относительно внутренней инверсии шаблонов [8]. Относительно внутренней инверсии структура шаблонов «01» и «10» следующая: «е $\bar{e} »-$ где «е» некоторое элементарное событие (эл), а «ер» - инверсный ему эл.

Относительно внутренней инверсии структура шаблонов «00» и «11» следующая: «ее» - где «е» некоторое элементарное событие (эл).

Исходя из свойств симметрии в спектрах, следует, что все рассуждения по выводу формул для пары («00»; «01») справедливы для пары («11»; «10»). Поэтому, для пары конкурирующих по правилам игры Пенни шаблонов: «11»; «10», справедлива ф. 12, по которой рассчитываются математические ожидания чисел выигрышей этих шаблонов:

$$
\operatorname{Sh}(11)=\operatorname{Sh}(10)=N / 6
$$

Количественный расчёт побед для пар: «00», «10», («11», «01»).

Конкурирующие шаблоны «00», «10» не равноценны, в комбинации: «1 $\underline{0} 0 » \rightarrow$ «1ㅇ》 $+\langle 0 »$ шаблон «10» отбирает валентный «ㅁ» у шаблона «00», таблица 3 столбцы 3-5. Шаблоны «10» в игре Пенни уменьшают число шаблонов «00». А шаблоны «00» не изменяют численность шаблонов «10». Численность $\operatorname{Sh}(10)$ равна численности, которая существует при его («10») одиночном (без конкурентном) поиске, таблица 5. Математическое ожидание шаблонов «10» (в игре против шаблона «00»), рассчитывается по ф.10.

Действительно, при числе элементарных событий случайной бинарной пос-ти $N=2 \cdot 10^{7}$, мат-ое ожидание численности «10» в игре Пенни, против шаблона «00», по ф.10, равно $S \mathrm{~h}(10)=N / 4=5 \cdot 10^{6}$, что хорошо совпадает с экспериментально полученным числом шаблонов в таблице 1 .

Расчёт сокращения числа шаблонов «00» под воздействием шаблонов «10».

Из таблицы 2 (столбцы: 5-6, 11-15) видно, что шаблон «00» является составной частью (фрагментами) составных событий ${ }^{n} S 0$, где $n>1$.

Шаблон «10» сократит число вхождений шаблона «00» в чётные составные

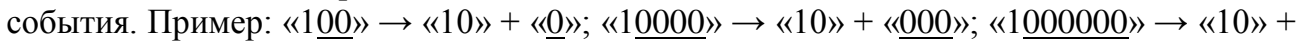
«00000»;

В то же время шаблон «10» не изменит число вхождений шаблона «00» в не

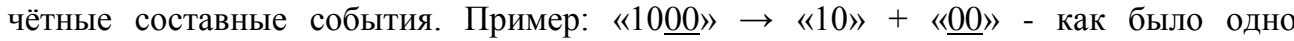

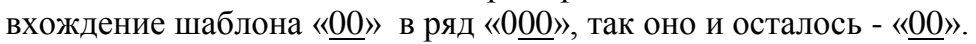

При одиночном поиске (без любых конкурирующих шаблонов), мат. ожидание шаблонов «00» в случайной бинарной пос-ти рассчитывается по ф.7: $\operatorname{Vic}(00)=N / 6$, таблица 5. После взаимодействия чётных составных событий ${ }^{n>1} S 0$ с шаблоном «10» из побед $\operatorname{Vic}(00)=N / 6$ надо вычисть число взаимодействий. Число взаимодействий чётных составных событий ${ }^{n=2 i} S 0$ с шаблоном «10» равно: $\sum_{\substack{i=1 ; \\ n=2 i}}^{i \rightarrow \infty}\left({ }^{n} S 0\right)=\frac{1}{2} \sum_{\substack{i=1 ; \\ n=2 i}}^{i \rightarrow \infty}\left({ }^{n} S\right)=$ $\frac{1}{2} \sum_{\substack{i=1 ; \\ n=2 i}}^{i \rightarrow \infty} \frac{N}{2^{2 i+1}}=\frac{N}{12}$, множитель $1 / 2$ необходим, так как: ${ }^{n} S 0+{ }^{n} S 1={ }^{n} S$ и ${ }^{n} S 0={ }^{n} S / 2$. Число побед шаблона «00» при конкуренции с «10» рассчитывается по ф.13: 


$$
\operatorname{Sh}(00)=\frac{N}{6}-\frac{1}{2} \sum_{\substack{i=1 ; \\ n=2 i}}^{i \rightarrow \infty} \frac{N}{2^{2 i+1}}=\frac{N}{6}-\frac{N}{12}=\frac{N}{12}
$$

Действительно, при числе элементарных событий случайной бинарной пос-ти $N=2 \cdot 10^{7}$, мат-ое ожидание численности шаблонов «00», в игре Пенни против шаблона «10», равно: $\operatorname{Sh}(00)=N / 12=1666666$, что хорошо совпадает с экспериментально полученной численностью в таблице 1.

Конкурирующая пара «11», «01» по инверсионной симметрии идентична только что рассмотренной паре «00»; «10», поэтому её количественные показатели то же рассчитываются по ф.10 и ф.13.

Количественный расчёт побед для конкурирующей пары: «01», «10».

Рассчитаем числа побед в последней оставшейся паре шаблонов из таблицы 1. Победы зависят от: числа краевых комбинаций соприкасающихся составных событий (ф.1); от числа цуг единичной моды (ф.8).

Количественный расчёт побед шаблона «10».Шаблоны «01» и «10» обладают внутренней инверсией, которая является признаком завершения составных событий всех длин (ф.1): ${ }^{n} S$, где $n=1,2.3, \ldots$. При $n>1$ взаимодействие шаблонов «01»и

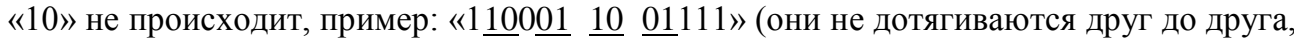
не перехлёстываются друг с другом).

Каждый переход от одного составного события к другому образует один из

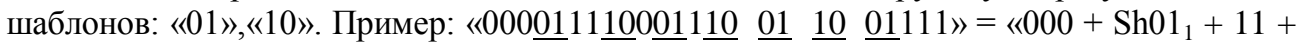
$\mathrm{Sh}_{10}{ }_{2}+0+\mathrm{ShO1}_{3}+1+\mathrm{Sh}_{10}{ }_{4}+\mathrm{Sh}_{0} 1_{5}+\mathrm{Sh}_{10}+\mathrm{Sh}_{6}+111$. Разложив на серии и поисковые шаблоны (Sh01; Sh10) бинарную пос-ть замечаем, что одно составное событие можно связывать и учитывать с одним шаблоном: $\mathrm{S}\left[000+\mathrm{Sh} 01_{1}\right]+\mathrm{S}[11+\mathrm{Sh} 10$ $2]+\mathrm{S}\left[0+\mathrm{ShO1}_{3}\right]+\mathrm{S}\left[1+\mathrm{Sh}_{0} 0_{4}\right]+\mathrm{S}\left[\mathrm{Sh01}_{5}\right]+\mathrm{S}\left[\mathrm{Sh} 10_{6}\right]+\mathrm{S}[\mathrm{Sh01} 7] \ldots$. Так как число составных событий ${ }^{n>1} S$ всех длин $n=2,3,4, \ldots$, есть сумма: $\sum_{n=2}^{\infty} \frac{N}{2^{n+1}}=\frac{N}{4}$, то число шаблонов, которые образуются этими составными событиями, то же равно $N / 4$.

Так как число составных событий образованных из нулей («0») равно числу составных событий из единиц («1»): ${ }^{n>1} S 0={ }^{n>1} S 1$, то числа побед шаблонов будет равно друг другу: $\operatorname{Vic}(01)=\operatorname{Vic}(10)$, и в два раза меньше числа составных событий, ф.14.1:

$$
\operatorname{Vic}(01)_{1}=\operatorname{Vic}(10)_{1}=\sum_{n=2}^{\infty}\left({ }^{n>1} S / 2\right)=\frac{1}{2} \cdot \sum_{n=2}^{\infty} \frac{N}{2^{n+1}}=\frac{N}{8}
$$

По ф.14.1 считается число побед, конкурирующих по правилам игры Пенни шаблонов «01» и «10», которые происходят на границах составных событий. Теперь перейдём к расчёту побед конкурирующих шаблонов: «01»; «10», которые происходят внутри цуг (при $n=1$ ), примеры: «..110101», «..001010». Как видно из примера, полярность - $X$, перед цугой составного события ${ }^{n>1} S X$, определяет, какой из шаблонов (подчёркнуты в примере) «захватит» цугу ${ }^{1} C_{w}$. В примере «...110101», окончание составного события ${ }^{n>1} S 1$ из единиц «..11» всегда образует поисковый шаблон « $\underline{10} »$. В примере: «..001010», окончание составного события ${ }^{n>1} S 0$ из нулей «..00» всегда образует поисковый шаблон «01». Так же нужно учитывать выход из зоны цуг «..010100» и «..10101011..».

Пояснения расчёта числа встреч шаблона «10» собраны в таблицу 6. Необходимые для расчёта действия будут, во многом, аналогичны действиям из раздела «Особенности обнаружения шаблона «01» в цугах ${ }^{1} \mathrm{C}_{\mathrm{w}} . »$ (таблица 4), в частности используется абстрактное целое число $i=1,2,3, \ldots$, через которое рассчитывают $w$ в ф.8.

Для примера разберём строку «w=5; $i=3$ : «11 $\underline{\mathbf{0 1 0 1 0}} 11 »$ из таблицы 6. Эта строка принадлежит ряду ф.14.2, в котором рассчитывается суммарное число побед $\operatorname{Vic}(10)_{2}$ шаблона «10», в цугах с нечётным количеством полуволн: $w=2 i-1$, где: $i=1,2,3, \ldots$ 
- абстрактное число. Строка «" ${ }^{\mathrm{n}} \mathrm{S}(« 1 »+\langle 1) \underline{\mathbf{0}} »+\langle\underline{\mathbf{1 0}} »+\langle\underline{\mathbf{1 0}} »+\langle 11 » »)$ даёт раскладку фрагмента «11 $\underline{01010} 11 »$ на количество победных ситуаций для шаблона «10».

Обозначение «" ${ }^{\mathrm{n} 1} \mathrm{~S}(« 1 »+\ll 1) \underline{\mathbf{0}} »$ отражает, что составному событию ${ }^{\mathrm{n} \gg 1} \mathrm{~S}$ из n единиц «1» принадлежит единица из первой победной комбинации «10». Количество победивших шаблонов есть множество $\{\mathrm{Sh}(10)\}$, число членов которого зависит от числа полуволн в цуге ${ }^{1} C_{w}$. Для рассматриваемого примера: «11 $\underline{01010} 11 », w=5$, поэтому: $\{\operatorname{Sh}(10)\}=(\mathrm{w}-1) / 2=(5-1) / 2=2$. Таким образом, ф.4.2 учитывает только

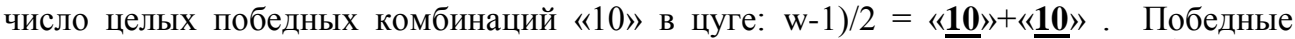
комбинации образованные из окончаний составных событий и начал цуг: «n>1 $\mathrm{S}(« 1 »+$ «1) ㅁ»» учитываются формулой ф.12.

Таблица 6. Пояснения к расчёту почскового шаблона «10»

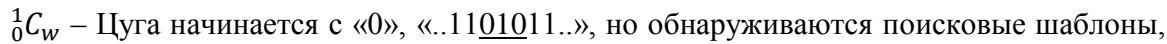
начинающиеся с «1»: «10»+... .

Подчёркнутые события относятся к текущей цуге ${ }_{0}^{1} C_{w}$.

\begin{tabular}{|c|c|}
\hline \multicolumn{2}{|l|}{$w$ - не чётное $(1,3,5, \ldots)$} \\
\hline $\mathrm{w}=1 ; i=1: 《 11 \underline{0} 11 »$ & ${ }^{\mathrm{n} \gg 1} \mathrm{~S}(« 1 »+\langle 1) \underline{\mathbf{0}} »+\langle 11 »$ \\
\hline $\mathrm{w}=3 ; i=2: 《 11 \underline{010} 11 »$ & ${ }^{\mathrm{n} \gg 1} \mathrm{~S}(\langle\ll 1\rangle+\langle 1) \underline{\mathbf{0}}\rangle+\langle\langle\underline{\underline{\mathbf{1 0}}}\rangle+\langle\langle 11 »$ \\
\hline $\mathrm{w}=5 ; i=3: \ll 11 \underline{01010} 11 »$ & ${ }^{\mathrm{n} \gg 1} \mathrm{~S}(\langle\langle 1 »+\langle 1) \underline{\mathbf{0}}\rangle++\langle\underline{\mathbf{1 0}}\rangle+\langle\langle\underline{\mathbf{1 0}}\rangle+\langle\langle 11 »$ \\
\hline $\mathrm{w}=7 ; i=4: 《 11 \underline{0101010} 11 »$ & ${ }^{\mathrm{n} \gg 1} \mathrm{~S}(\langle 1\rangle+\langle 1) \underline{\mathbf{0}}\rangle++\langle\underline{\mathbf{1 0}}\rangle+\langle\langle\underline{\mathbf{1 0}}\rangle+\langle\underline{\mathbf{1 0}}\rangle+\langle\langle\langle 11 »$ \\
\hline $\mathrm{w}=9 ; i=5: 《 1101010101011 »$ & $\left.{ }^{\mathrm{n}\rangle} \mathrm{S}(\langle\ll 1\rangle+\langle 1) \underline{\mathbf{0}}\rangle+\langle\underline{\mathbf{1 0}}\rangle\right\rangle+\langle\underline{\mathbf{1 0}}\rangle+\langle\langle\underline{\mathbf{1 0}}\rangle+\langle\underline{\mathbf{1 0}}\rangle+\langle\langle 11\rangle$ \\
\hline $\begin{array}{c}w=2 i-1 \\
2 \cdot \operatorname{Sh}(10)+1=w\end{array}$ & $\{\operatorname{Sh}(10)\}=f(\mathrm{w})=\frac{\mathrm{w}-1}{2}=i-1$ \\
\hline $\operatorname{Vic}(10)_{2}=\sum_{\substack{i=1 ; \\
w=2 i-1}}^{i \rightarrow \infty}$ & $\frac{{ }^{1} C_{w}}{2} \cdot(i-1)=\frac{N}{72}$ \\
\hline \multicolumn{2}{|l|}{$w$ - чётное $(2,4,6, \ldots)$} \\
\hline $\mathrm{w}=2: 《 11 \underline{01} 00 »$ & $i=1:\langle 1 »+\mathrm{S} « 10 »+\langle\underline{\mathbf{1 0}} »+\langle\langle 0 »$ \\
\hline $\mathrm{W}=4: 《 11 \underline{\mathbf{0 1 0 1}} 00 »$ & $i=2:\langle 1 »+\mathrm{S}\langle\langle 10 »\rangle+\langle\underline{\mathbf{1 0}}\rangle+\langle\underline{\mathbf{1 0}}\rangle+\langle\langle 0\rangle\rangle$ \\
\hline $\mathrm{w}=6: \ll 11 \underline{010101} 00 »$ & $i=3:\langle 1\rangle+\mathrm{S}\langle\langle 10\rangle+\langle\underline{\mathbf{1 0}}\rangle+\langle\langle\underline{\mathbf{1 0}}\rangle+\langle\underline{\mathbf{1 0}}\rangle\rangle+\langle 0\rangle\rangle$ \\
\hline $\mathrm{w}=8: « 11 \underline{01010101} 00 »$ & $i=4:\langle 1\rangle\rangle+\mathrm{S}\langle\langle 10\rangle+\langle\underline{\mathbf{1 0}}\rangle\rangle+\langle\underline{\mathbf{1 0}}\rangle+\langle\underline{\mathbf{1 0}}\rangle\rangle+\langle\underline{\mathbf{1 0}}\rangle\rangle+\langle 0\rangle\rangle$ \\
\hline $\mathrm{w}=10: \ll 11 \underline{0101010101} 00 »$ & $i=5:\langle 1\rangle+\mathrm{S}\langle\langle 10 »\rangle+\underline{\mathbf{1 0}}+\langle\underline{\mathbf{1 0}}\rangle\rangle+\langle\underline{\mathbf{1 0}}\rangle++\langle\underline{\mathbf{1 0}}\rangle\rangle+\langle\underline{\mathbf{1 0}}\rangle\rangle+\langle 0\rangle\rangle$ \\
\hline$w=2 i$ & $\operatorname{Sh}(10)=i$ \\
\hline $\operatorname{Vic}(10)_{3}=\sum_{\substack{i=1 \\
w=2}}$ & $\frac{{ }^{1} C_{w}}{2} \cdot i=\frac{N}{36}$ \\
\hline
\end{tabular}

Во второй части таблицы 6 поясняется получение сумм ряда, ф.14.3, с чётным числом полуволн в цугах: $w=2 i$.

Таким образом, число побед шаблона «10» (при конкуренции с шаблоном «01») будет рассчитываться как сумма трёх формул: ф.14.1, ф.14.2, ф.14.3: $\operatorname{Vic}(10)=$ $\operatorname{Vic}(10)_{1}+\operatorname{Vic}(10)_{2}+\operatorname{Vic}(10)_{2}$, по формуле ф.14.4: 


$$
\begin{gathered}
\operatorname{Vic}(10)=\frac{1}{2} \cdot \sum_{n=2}^{\infty} \frac{N}{2^{n+1}}+\sum_{\substack{i=1 ; \\
w=2 i-1}}^{i \rightarrow \infty} \frac{{ }^{1} C_{w}}{2} \cdot(i-1)+\sum_{\substack{i=1 ; \\
w=2 i}}^{i \rightarrow \infty} \frac{{ }^{1} C_{w}}{2} \cdot i \\
=N / 8+N / 72+N / 36=N / 6
\end{gathered}
$$

Пример. В случайной бинарной пос-ти $N=2 \cdot 10^{7}$ рассчитаем по ф.14.4 мат ожидание побед шаблона «10»: $\operatorname{Vic}(10)=2 \cdot 10^{7} / 6=3333333$ - полученный результат хорошо совпал с экспер-ми данными таблицы 1.

Количественный расчёт побед шаблона «01».Для расчёта числа побед шаблона «01» (при его конкуренции с шаблоном «10») воспользуемся фундаментальной симметрией - равенством друг другу количеств нулей «0» и единиц «1». Замечаем, что заменив в примерах для шаблона «10» единицы на нули $1 \rightarrow 0$, а нули на единицы $0 \rightarrow 1$, мы получаем ситуации для расчёта числа побед шаблона «01»: «11 $\underline{\mathbf{0 1 0 1 0}} 11 » \rightarrow$ «001010100». Значит, верно, что все рассуждения для нахождения числа побед шаблонов «10» применимы для нахождения числа побед шаблонов «01»: $\operatorname{Vic}(01)=$ $\operatorname{Vic}(10)$. Следовательно, число побед шаблонов «01» рассчитываются по ф.14.4.

\section{Обсуждение.}

Из формул распределений составных событий ф.1[1,2,3,6] и цуг ф.8 $[1,2,4,5]$, были получены формулы расчёта числа побед (поражений) в парах шаблонов длины 2 , конкурирующих по правилам игры Пенни. Соберём в таблице 7 все эти формулы.

\begin{tabular}{|c|c|c|c|c|c|c|c|c|c|}
\hline \multirow{2}{*}{\multicolumn{2}{|c|}{$\begin{array}{c}\text { Sh2, } \\
\ll И 2 » \downarrow\end{array}$}} & \multicolumn{7}{|c|}{ Комбинации игрока 1 - «И1», (Sh1) } & \\
\hline & & \multicolumn{2}{|c|}{00} & \multicolumn{2}{|c|}{01} & \multicolumn{2}{|c|}{10} & 11 & \\
\hline \multirow{4}{*}{ 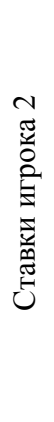 } & 00 & $N / 6$ & (ф. 7) & $\begin{array}{l}N / 6 \\
N / 6\end{array}$ & $\begin{array}{l}(\phi .7) \\
(\Phi .11)\end{array}$ & $\begin{array}{c}N / 4 \\
N / 12\end{array}$ & $\begin{array}{l}(\phi .10) \\
(\phi .13)\end{array}$ & $\begin{array}{ll}N / 6 & \text { (ф.7) } \\
N / 6 & \text { (ф.7) }\end{array}$ & $\begin{array}{l}\text { «И1» } \\
\text { «И2» }\end{array}$ \\
\hline & 01 & $\begin{array}{l}N / 6 \\
N / 6\end{array}$ & $\begin{array}{l}(\Phi .7) \\
(\Phi .11)\end{array}$ & $N / 4$ & $(\phi .10)$ & $\begin{array}{l}N / 6 \\
N / 6\end{array}$ & $\begin{array}{l}(\Phi .14 .4) \\
(\Phi .14 .4)\end{array}$ & $\begin{array}{cc}N / 12 & \text { (ф.13) } \\
N / 4 & \text { (ф.10) }\end{array}$ & $\begin{array}{l}\text { «И1» } \\
\text { «И2» }\end{array}$ \\
\hline & 10 & $\begin{array}{c}N / 12 \\
N / 4\end{array}$ & $\begin{array}{l}(\phi .13) \\
(\phi .10)\end{array}$ & $\begin{array}{l}N / 6 \\
N / 6\end{array}$ & $\begin{array}{l}(\Phi .14 .4) \\
(\Phi .14 .4)\end{array}$ & $N / 4$ & $(\phi .10)$ & $\begin{array}{ll}N / 6 & (\phi .7) \\
N / 6 & (\Phi .11)\end{array}$ & $\begin{array}{l}\text { «И1» } \\
\text { «И2» }\end{array}$ \\
\hline & 11 & $\begin{array}{l}N / 6 \\
N / 6\end{array}$ & $\begin{array}{l}(\phi .7) \\
(\phi .7)\end{array}$ & $\begin{array}{l}N / 4 \\
N / 12\end{array}$ & $\begin{array}{l}(\phi .10) \\
(\phi .13)\end{array}$ & $\begin{array}{l}N / 6 \\
N / 6\end{array}$ & $\begin{array}{l}(\Phi .7) \\
(\Phi .11)\end{array}$ & $(\phi .7)$ & $\begin{array}{l}\text { «И1» } \\
\text { «И2» }\end{array}$ \\
\hline & & & & Sh1 $1+S$ & $2=N / 3$ & $0,5(N$ & $\left.2 \cdot 10^{7}\right)$ & & \\
\hline
\end{tabular}

Таблица 7. Таблица выведенных формул для серий $L=2$ в игре Пенни»

Будем обозначать в шаблонах: «01», «10» первое элементарное событие символом $\boldsymbol{e}$, инверсное ему второе событие, как е с чертой наверху $\overline{\boldsymbol{e}}: e \overline{\boldsymbol{e}}$. Шаблоны без инверсией внутри: «00», «11» будем обозначать $е e$.

Из таблицы 7 видно, что при без конкурентном поиске число шаблонов структуры ее стремится к $N / 6$, ф.15.1:

$$
\mathrm{M}(e e)=N / 6
$$

Из таблицы 7 видно, что при без конкурентном поиске число шаблонов $e \bar{e}$ стремится к $N / 4$, ф.15.2:

$$
\mathrm{M}(e \bar{e})=N / 4
$$


Попытаемся дать объяснение формул из таблицы 7 при помощи идеи валентности. Под валентностью понимается отбор по правилам игры Пенни более «сильным» шаблоном у более «слабого» элементарного события - е.

Пример. Шаблоны: «10», «01» конкурируют за элементарное событие «예 в серии

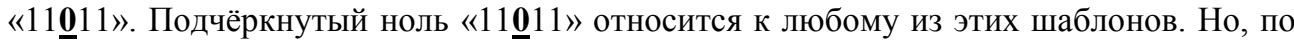
правилам игры Пенни, он будет задействован для образования более «сильного» шаблона «10», а шаблон «01» не «родиться».

Из таблицы 1 видно, что для любой конкурирующей пары шаблонов суммарное количество побед постоянно: Sh1 + Sh2 $2 N / 3$. Объединяя это наблюдение с формулой ф.15.1 получаем ф.15.3:

$$
\left\{\begin{array}{l}
\mathrm{A}(e e)=\mathrm{M}(e e)=N / 6 \\
\mathrm{M}(e e)+\mathrm{D}(e \bar{e})=N / 3
\end{array}\right.
$$

Где: $\mathrm{A}(e e)$ - обозначает, что акцептором является структура $e е$; так как структура $e e$ более сильная, то она полностью сохраняет всю свою численность $\mathrm{M}(e е)$ - ф.15.1, которую рассчитывают по ф.7; $\mathrm{D}(e \bar{e})$ - численность шаблонов - доноров со структурой $e \bar{e}$.

Из ф.15.3 численность шаблонов - доноров со структурой $e \bar{e}: \mathrm{D}(e \bar{e})=N / 3-$ $\mathrm{M}($ eе $)=N / 6$. Пример. Дана конкурирующая пара: $(\mathrm{Sh} 1=« 00 » ; \mathrm{Sh} 2=« 01 »)$. Шаблон «01» (донор - отдаёт валентный эл), его численность зависит от «00» (акцептор А(eе)

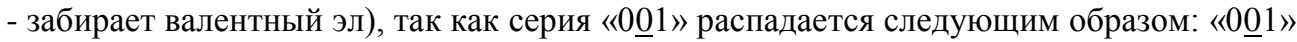
$\rightarrow$ «0ㅛ》 + «1». Так как $\operatorname{Sh} 1(00)$ - не зависим, то его численность равна численности при его без конкурентном поиске, ф.15.1: $\operatorname{Sh} 1(e e)=N / 6 ; \quad \operatorname{Sh} 2(01)=N / 3-N / 6=$ $N / 6$.

Если акцептором (забирающей) является структура $e \bar{e}$, то ф.15.4:

$$
\left\{\begin{array}{l}
\mathrm{A}(e \bar{e})=\mathrm{M}(e \bar{e})=N / 4 \\
\mathrm{M}(e \bar{e})+\mathrm{D}(e e)=N / 3
\end{array}\right.
$$

Где: $\mathrm{A}(e \bar{e})$ - обозначает, что акцептором является структура $e \bar{e}$; так как структура $e \bar{e}$ более сильная, то она полностью сохраняет всю свою численность $\mathrm{M}(e \bar{e})$ - ф.15.2, которую рассчитывают по ф.10 для без конкурентного поиска; $\mathrm{D}(e е)$ - численность шаблонов - доноров со структурой $е e$.

Из ф.15.4 численность шаблонов - доноров со структурой $e e: \mathrm{D}(e e)=N / 3-$ $\mathrm{M}(e \bar{e})=N / 12$. Пример. В конкурирующей паре («10»; «00») шаблон «00» донор отдаёт валентный эл, его численность зависит от «10». Шаблон «10» акцептор -

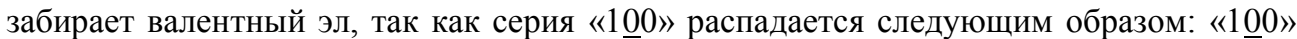
$\rightarrow 《 1 \underline{0} »+« 0 »$. Так как $\mathrm{Sh}(10)-$ не зависим, и имеет внутри себя инверсию, то по ф.15.4: $\quad \operatorname{Sh}(e \bar{e})=N / 4 . \quad \operatorname{Sh} 2+\operatorname{Sh} 1=\operatorname{Sh}(00)+N / 4=N / 3 ; \quad \operatorname{Sh}(00)=N / 3-N / 4=$ $N / 12$. При $N=2 \cdot 10^{7}$ значение $\operatorname{Sh}(00)=1666666$. Вероятность победы $\mathrm{p}(\operatorname{Sh}(00))=$ $\operatorname{Sh}(00) /(\operatorname{Sh}(00)+\operatorname{Sh}(10))=N / 12:(N / 12+N / 4)=N / 12: 4 N / 12=1 / 4$.

В конкурирующей паре со структурой шаблонов $e e:$ «00», «11»- нет ни донора, ни акцептора, ф.7. Поэтому для обоих её шаблонов справедлива ситуация, ф.15.1. Шаблоны: «00»; «11» не зависят друг от друга, поэтому: $\operatorname{Sh}(00)=\operatorname{Sh}(11)=N / 6$. Вероятность победы: $\mathrm{p}(\mathrm{Sh} 1)=\mathrm{Sh} 1 /(\mathrm{Sh} 1+\mathrm{Sh} 2)=1 / 2$.

В конкурирующей паре с внутренней структурой $e \bar{e}:$ «01»; «10» каждый шаблон зависит от другого, так как серии «ㅁ10», «1미» распадаются следующим образом: $\langle 0 \underline{10} \gg \rightarrow\langle 0 \underline{1} »+\langle 0 »($ шаблон «01

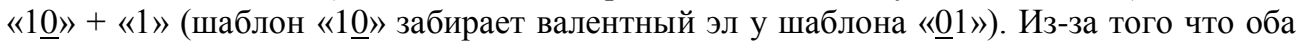
конкурирующих шаблона являются донорами, справедлива формула ф.15.5:

$$
\mathrm{D}(e \bar{e})+\mathrm{D}(e \bar{e})=N / 3
$$

Из ф.15.5 следует, численность каждого шаблона: Sh1 + Sh2 = 2 $\operatorname{Sh} 1=2 \cdot \operatorname{Sh} 2=$ $N / 3$. Отсюда: $\mathrm{D}(e \bar{e})=N / 6, \phi .14 .4$. 
Из выше сказанного следует, что число побед у акцепторного шаблона равно числу встреч этого же шаблона в пос-ти, при его без конкурентном поиске: $\mathrm{A}=\mathrm{M}$. Если этот шаблон становится донором, то его число побед в качестве донора будет меньше, чем число его встреч при его без конкурентном поиске: M > D.

Интересно заметить, что численности побед $\operatorname{Vic}\left(S \mathrm{~h}_{\mathrm{X}}\right)$ конкурирующих пар шаблонов таблицы 7 получаются из вероятностей таблицы 1 путём умножения каждой вероятности из таблицы 1 на сумму шаблонов пары, ф.16:

$$
\operatorname{Vic}\left(S \mathrm{~h}_{\mathrm{X}}\right)=p_{\mathrm{X}}(\operatorname{Sh} 1+S \mathrm{~h} 2)=p_{\mathrm{X}} \cdot N / 3
$$

Где: $\mathrm{X}$ - номер шаблона в паре $(1 ; 2) ; p_{\mathrm{X}}$ - вероятность победы шаблона $S \mathrm{~h}_{\mathrm{X}}$.

Сумма всех частот равна четырём. Введём по аналогии с частотами мизеса [8], частоты пенни $f\left(S h_{\mathrm{X}}\right)$, разделив в ф.16 число побед каждого шаблона $\operatorname{Vic}\left(S \mathrm{~h}_{\mathrm{X}}\right)$ на число элементарных событий (эл) пос-ти $-N$, ф.17:

$$
f\left(S h_{\mathrm{X}}\right)=\operatorname{Vic}\left(S \mathrm{~h}_{\mathrm{X}}\right) / N=p_{\mathrm{X}} / 3
$$

Где: $p_{\mathrm{X}}$ - вероятность победы для каждого шаблона из таблицы 1 . Всего в таблице 1 находятся: 16 вероятностей $\mathrm{p}=1 / 2 ; 4$ вероятности $\mathrm{p}=1 / 4 ; 4$ вероятности $\mathrm{p}=3 / 4$. После деления значений соответствующих вероятностей на три, ф.17, с последующим суммированием получившихся частот пенни $\Sigma f_{\mathrm{X}}$, получаем, что сумма частот равна четырём, ф.18:

$$
\Sigma\left(p_{\mathrm{X}} / 3\right)=\Sigma f\left(S \mathrm{~h}_{\mathrm{X}}\right)=\frac{16}{6}+\frac{4}{12}+\frac{4}{4}=4
$$

Объединим выше приведённые формулы в систему ф.19:

$$
\left\{\begin{array}{c}
p_{1}+p_{2}=1 ; \\
\Sigma f\left(S h_{\mathrm{X}}\right)=4 \\
\operatorname{Vic}\left(S \mathrm{~S}_{\mathrm{X}}\right)=p_{\mathrm{X}} \cdot N / 3 ; \\
\operatorname{Sh} 1+\operatorname{Sh} 2=N / 3 ;
\end{array}\right.
$$

В статье была рассмотрена парадоксальная игра Пенни на шаблонах длиной два эла. При некотором изменений правил игры Пенни, а именно, два потока конкурируют между собой на шаблонах в два эла, появляется возможность не только управлять вероятностями обнаружения серий, но и угадывать, с вероятностью не равной 0.5 , какой стороной выпала монета [7].

\section{Выводы.}

Эффект экранирования одним конкурирующим шаблоном другого шаблона, заключающийся в одновременном обладании шаблонами валентных элементарных событий (события принадлежит сразу двум конкурирующим ставкам - шаблонам). Этот эффект экранирования полностью описывает процесс известный как парадоксальная игра Пенни.

В игре Пенни со ставками длиной в два элементарных события преимущество имеет игрок, который первый называет свою ставку (поисковый шаблон, серию).

Математическое ожидание выигрышей каждой ставки и вероятности её выигрыша (проигрыша) связано с числом бросков монеты, эти параметры выведены из двух формул. Первая формула описывает распределение составных событий в зависимости от их длин в случайной бинарной последовательности. Вторая формула определяет численность цуг, которые образуют составные события в последовательности.

Сумма выигрышей обоих шаблонов является величиной постоянной, которая стремится к одной трети числу бросков монеты. Поэтому, в среднем, на один выигрыш приходится три броска монеты.

Введено разделение конкурирующих шаблонов по признаку внутренней инверсии. 
Введено понятие частоты пенни, которое родственно вероятности выигрыша шаблона.

Дано акцепторно-донорное объяснение игры Пенни для шаблонов длиной $\mathrm{L}=2$.

Число побед у акцепторного шаблона равно числу его встреч в пос-ти, при его безконкурентном поиске: $\mathrm{A}=\mathrm{M}$. Если этот шаблон становится донором, то его число побед в качестве донора будет меньше, чем число его встреч при его безконкурентном поиске: $\mathrm{D}<\mathrm{M}$.

\section{Сиисок литературы / References}

1. Филатов О.В., Филатов И.О., Макеева Л.Л. и др. «Потоковая теория: из сайта в книгу». Москва. «Век информации», 2014. С. 200.

2. Филатов О.В., Филатов И.О. «Закономерность в выпадении монет - закон потоковой последовательности». Германия, Издательский Дом: LAPLAMBERT Academic Publishing, 2015. C. 268.

3. Филатов О.В., Филатов И.О. Статья «О закономерностях структуры бинарной последовательности». «Журнал научных публикаций аспирантов и докторантов», 2014. № 5 (95). С. 226-233.

4. Филатов О.В., Филатов И.О. Статья «О закономерностях структуры бинарной последовательности (продолжение)». «Журнал научных публикаций аспирантов и докторантов», 2014. № 6 (96). С. 236-245.

5. Филатов О.В., Филатов И.О. Статья «О закономерностях структуры бинарной последовательности (продолжение 2)», Журнал научных публикаций аспирантов и докторантов, 2014. № 7 (97). С. 98-108.

6. Филатов O.B. Статья «Теорема «Об амплитудно-частотной характеристике идеальной бинарной случайной последовательности». «Проблемы современной науки и образования», 2015 г. № 1 (31). С. 5-11.

7. Филатов О.В. Статья «Техника управления вероятностью обнаружения элементарных событий - «0», «1» (аналоги сторон монеты) через псевдозапутывание случайных последовательностей по правилам парадоксальной игры Пенни». «Проблемы современной науки и образования», 2017 г. № 10 (92). C. $10-18$.

8. Филатов О.В. Статья «Managed probability of Penny series against classical probability series of equal length. Not a typical conversion Mises. / Управляемая вероятность выпадения серий Пенни против классической вероятности выпадения серий равной длины. Не типичное преобразование Мизеса», журнал «Проблемы современной науки и образования / Problems of modern science and education», № 29 (71), 2016 г.

9. [Электронный ресурс]: Авторский сайт со статьями. Режим доступа: http://kodpi.net/ (дата обращения: 03.05.2017). 


\title{
РОСТ И РАЗВИТИЕ СRAMВЕ ORIENTALIS L. В УСЛОВИЯХ ЮЖНОГО ПРИАРАЛЬЯ \\ Балтабаев М.T. ${ }^{1}$, Карлыбаева М.А. ${ }^{2}$ \\ Email: Baltabayev1799@scientifictext.ru

\author{
${ }^{1}$ Балтабаев Муратбай Туребаевич - кандидат биологических наук, доцент; \\ ${ }^{2}$ Карльгбаева Мияссар Абдинасыровна - студент, \\ кафедра методики преподавания биологии, \\ Нукусский государственный педагогический институт, \\ 2. Нукус, Республика Каракалпакстан
}

\begin{abstract}
Аннотация: статья посвящена изучению роста и развития Crambe orientalis L. 6 условиях Южного Приаралья. Впервые изучены рост и развитие Crambe orientalis L. 6 условиях культуры, на 1-2 и 3-м году жизни. На третьем году жизни особи хорошо развиты и имеют до 30 крупных прикорневых листьев. Длина этих листьев достигает 30-45 см, а длина стебля достигает 150-160 см. Растения имеют мощную корневую систему, длина главного корня достигает около 3 м. Начиная с третьего года вегетаџии, растения находятся на средневозрастном генеративном состоянии. Все количественные параметры растения в этом возрастном состоянии достигают своего пика. Период вегетации Crambe orientalis L. в условиях Южного Приаралья продолжается 208-227 дней.
\end{abstract}

Ключевые слова: вегетация, всхожесть, появления всходов, корневая система, репродуктивный период, генеративный побег, стержневой корень, надземная часть, ияветение, плодоночение.

\section{GROWTH AND DEVELOPMENT OF CRAMBE ORIENTALIS L. IN THE CONDITIONS OF SOUTHERN ARAL SEA REGION Baltabayev M.T. ${ }^{1}$, Qarlibayeva M.A. ${ }^{2}$}

\author{
${ }^{l}$ Ealtabayev Muratbay Torebayevich - PhD in Biology, Associate Professor; \\ ${ }^{2}$ Qarlibayeva Miyassar Abdinasirovna Atamuratovna - Student, \\ NUKUS STATE PEDAGOGICAL INSTITUTE, CHAIR THE METHODS OF TEACHING BIOLOGY, \\ NUKUS, KARAKALPAKSTAN
}

Abstract: the article is devoted to the study of the growth and development of Crambe orientalis L. in the conditions of Southern Aral Sea region. The growth and development of Crambe orientalis $L$. was studied for the first time in the conditions of culture, in the 1-2 and 3-rd year of life. On the third year of life the individuals are well developed and have about 30 large radical leaves. The length of these leaves reaches $30-45 \mathrm{~cm}$ and the stem length reaches $150-160 \mathrm{~cm}$. The plant has powerful root system and the main root has the length of about 3 meters. Since the third year of vegetation the plant is in the average age of generative state. All the quantitative parameters of the plant in this age state reach their peak. The vegetation period of Crambe orientalis L. in the conditions of Southern Aral Sea region continues 208-227 days.

Keywords: vegetation, germination, the appearance of shoots, root system, reproductive period, generative shoot, tap root, over ground part, flowering, fruiting.

УДК 582.232:581

За ростом и развитием катрана восточного наблюдали в течение 1-го, 2-го и 3-го годов вегетации. 
При осеннем и подзимнем сроках посева всходы появились в середине марта. Это, наверное, зависит от специфических условий Южного Приаралья. Первый настоящий лист в наших опытах развертывался на 1-2 недели после появления всходов.

Семядоли проростков уменьшаются в размерах и начинают засыхать в фазе 4-6 листьев. В марте отмечен сравнительно медленный рост листьев. В апреле рост увеличивается. Наиболее быстрый рост листьев мы обнаружили в мае и начале июня. А в начале июля рост прекращается. Длина листьев в это время достигает до $30 \mathrm{~cm}$. К концу первого года вегетации каждое растение имело по 4-8 прикорневых листьев. К этому времени эти листья достигают до 30см в длину и 12-15 см в ширину.

Изучены особенности роста и динамика формирования корневых систем у катрана восточного на опытном участке-1 и 2, (ОУ-1), (ОУ-2). Во время появления первого настоящего листа, длина стержневого корня составляла 8-10 см, корень имел 3 боковых корня первого порядка (15.04.2015). В фазе развития 3-4 настоящих листьев (30.04.2015) главный стержневой корень проникает на глубину 12-16 см, при этом наблюдалось образование у него значительного количества боковых корней I порядка, а в некоторых случаях и корней II порядка. Боковые корни были расположены в средней и нижней части главного корня. Корни первого порядка достигали до 7см, а корни второго порядка - до 4 см.

В середине мая (15.05.2015) в фазе развития 4-5 настоящих листьев, корневая система катрана достигла 35-42 см длины, и горизонтальное расположение ее было равно 18-22 см. В начале июня, с появлением 5-6 листьев в розетке, корневая система, еще более удлиняясь, достигла 70-75 см. Главный корень значительно утолщается, заметно увеличивается число хорошо развитых боковых корней, от которых отходят корни II и III порядка. Горизонтальное расположение корней достигало 45-48 см. Первый ярус боковых корней, находящийся в верхнем слое почвы, достигает 10-12 см и растет геотропно. Вторые ответвления корней, которые растут косогеотропно, параллельно главному корню, довольно хорошо развиты и отходят от стержневого корня на глубину 25-40 см.

Диаметр главного корня в зоне корневой шейки был равен 1,5-2 см, длина корневой системы достигла 75-80 см. На втором году более $80 \%$ особей переходят на репродуктивный период (Рис. 1).

Остальная часть особей остаются во взросло-вегетативном состоянии. У генеративных особей в апреле образуются 7-12 прикорневых листьев. Появляется генеративный побег, на котором позже образуется соцветие. В свою очередь они образуют побеги следующего порядка. К концу второго года вегетации стебель достигает 100-120 cм.

Некоторые авторы отмечают [1, 43 с., 3, 29 с.], что у катрана наблюдается гетерофилия. В наших опытах это мнение подтверждается. В конце августа - начале сентября у них опять наблюдается рост, и появляются сочные листья. На втором году развития корневая система продолжала расти и развиваться как в вертикальном, так и в горизонтальном направлениях. 


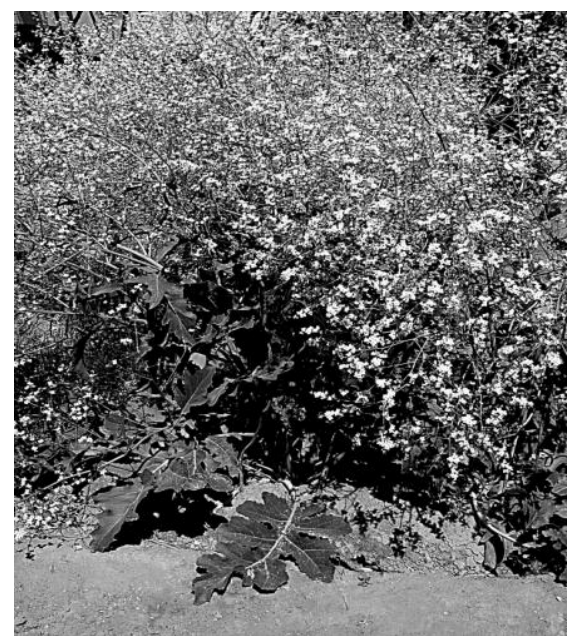

Puc. 1. Цветение C. orientalis L. в условиях культуры

В период стеблеобразования (17.04.2016) корневая система C.orientalis проникает в глубину на 150-160 см. Диаметр главного корня в зоне корневой шейки достигал 22,5 см. В фазе плодоношения (10.06.2016) диаметр главного корня в зоне корневой шейки достигает 3,0-3,5 см. В верхнем слое почвы (5-10см) образуется множество тонких нитевидных боковых корней, несколько ниже, в почвенном горизонте 20-25 см располагается первый ярус боковых корней. На глубине $50-90 \mathrm{~cm}$, а у некоторых даже в 30-50 сантиметровом горизонте почвы главный корень разветвляется на несколько частей (ответвлений) одинакового диаметра. В конце 2-го года вегетации, глубина проникновения корневой системы катрана составляет более $290 \mathrm{~cm} \mathrm{в} \mathrm{глубину,}$ надземная часть растения достигала к этому времени 110-118 см высоты [2, с. 23], что было в три раза меньше длины корней.

На третьем году жизни особи хорошо развиты и имеют до 30 крупных прикорневых листьев. Длина этих листьев достигает 30-45 см, а длина стебля достигает 150-160 см. Растения имели мощную корневую систему, длина главного корня достигала около 3 м.

Начиная с третьего года вегетации, растения находятся на средневозрастном генеративном состоянии. Все количественные параметры растения в этом возрастном состоянии достигают своего пика. Период вегетации катрана восточного в условиях Южного Приаралья продолжается 208-227 дней.

Таким образом, адаптивная особенность, отношение к характеру засоленности и механическому составу почв показало, что все показатели C. orientalis L. на OУ-1 и ОУ-2 выявляют его широкий диапазон толерантности к механическому составу почв, от легких (пески, супеси) до более тяжелых (суглинки) и к засоленности почвы по хлор-иону от $0,035 \%$ до $0,080 \%$.

\section{Сиисок литературы / References}

1. Амирханов Н.A. Катран (Crambe) в Узбекистане (вопросы систематики, распространения, биологии, интродукции, химизма). Автореф. дис... док.биол.наук. Ташкент, 1974. 43 с.

2. Балтабаев M.T. Био-экологические особенности Crambe orientalis L. в условиях южного Приаралья.: Автореф.дис... канд. биол. наук. Ташкент, 2010. 23 с.

3. Шомуродов Х.Ф. Биологические особенности кормовых растений на СевероЗападных адырах Туркестанского хребта. Автореф. дисс...канд. биол. наук. Ташкент, 1997. 29 с. 


\title{
НЕЛИНЕЙНЫЕ УРАВНЕНИЯ ПОЛОГИХ ЖЕЛЕЗОБЕТОННЫХ ОБОЛОЧЕК В КОНЕЧНЫХ РАЗНОСТЯХ Токмуратов A.M. ${ }^{1}$, Мусабаев T.T. ${ }^{2}$ Email: Tokmuratov1799@scientifictext.ru
}

\author{
${ }^{1}$ Токмуратов Абдухалык Маженович - кандидат технических наук, доиент, \\ кафедра механики и машиностроения, \\ Южно-Казахстанский государственный университет, г. Шымкент; \\ ${ }^{2}$ Мусабаев Турлыбек Туркпенович - доктор технических наук, профессор, директор, \\ Евразийский технологический институт, \\ Евразийский национальный университет им. Н. Гумилева, г. Астана, \\ Республика Казахстан
}

Аннотация: в статье приводятся уравнения гибких пологих железобетонных оболочек с учетом нелинейных деформаций, записанные в конечных разностях. Все жесткостные характеристики оболочки принимаются переменными как по поверхности, так и по толщине оболочки. Разрешающие дифференщиальнье уравнения с помощью разностньх операторов приводятся к системе алгебраических уравнений.

Для случая шарнирного опирания оболочки при сетке $8 x 8$ выведена система из 98 уравнений, которая решается методом приближений нелинейной теории пластичности. Ключевые слова: железобетонные оболочки, дифференциальные уравнения, нелинейные деформации, конечные разности.

\section{NONLINEAR EQUATIONS OF LOW CONCRETE HELLS IN SMALL DIFFERENCES Tokmuratov A.M. ${ }^{1}$, Musabaev T.T. ${ }^{2}$}

\author{
Tokmuratov Abdukhalyk Mazhenovich - PhD, Associate Professor, \\ DEPARTMENT OF MECHANICS AND MECHANICAL ENGINEERING, \\ SOUTH KAZAKHSTAN STATE UNIVERSITY, SHYMKENT; \\ Musabaev Turlybek Turkpenevich - Doctor of Technical Sciences, Professor, Director, \\ EURASIAN INSTITUTE OF TECHNOLOGY, EURASIAN NATIONAL UNIVERSITY, ASTANA, \\ REPUBLIC OF KAZAKHSTAN
}

Abstract: the paper presents the equations of flexible shallow reinforced concrete shells with allowance for nonlinear deformations recorded in finite differences. All the stiffness characteristics of the shell are assumed to be variable both over the surface and the thickness of the shell. Solving differential equations with the aid of difference operators are reduced to a system of algebraic equations. For the case of pivot bearing shells under the grid 8x8, a system of 98 equations is calculated by the approximation method of non-linear theory of plasticity.

Keywords: ferroconcrete shells, differential equations, nonlinear deformations, small differences.

УДК 69.04

В работе [1] выведены разрешающие уравнения пологих гладких железобетонных оболочек с учетом физической и геометрической нелинейности. Приведем эти уравнения в развернутом виде:

$$
\begin{gathered}
D_{4} \cdot \frac{d^{4} F}{d x^{4}}+D_{9} \cdot \frac{d^{4} F}{d y^{4}}+D_{14} \cdot \frac{d^{4} F}{d x^{2} d y^{2}}+\left(\frac{d^{2} D 4}{d x^{2}}+\frac{d^{2} D 8}{d y^{2}}\right) \cdot \frac{d^{2} F}{d x^{2}}+\left(\frac{d^{2} D 5}{d x^{2}}+\frac{d^{2} D 9}{d y^{2}}\right) \cdot \frac{d^{2} F}{d y^{2}}+\frac{d D 4}{d x} . \\
\frac{d^{3} F}{d x^{3}}+\frac{d D 9}{d y} \cdot \frac{d^{3} F}{d y^{3}}+\frac{d D 812}{d y} \cdot \frac{d^{3} F}{d y d x^{2}}+\frac{d D 512}{d x} \cdot \frac{d^{3} F}{d x d y^{2}}+D 6 \cdot \frac{d^{4} W}{d x^{4}}+D 11 \cdot \frac{d^{4} W}{d y^{4}}+
\end{gathered}
$$




$$
\begin{gathered}
D_{15} \cdot \frac{d^{4} W}{d x^{2} d y^{2}}+\left(\frac{d^{2} D 6}{d x^{2}}+\frac{d^{2} D 10}{d y^{2}}\right) \cdot \frac{d^{2} W}{d x^{2}}+\left(\frac{d^{2} D 7}{d x^{2}}+\frac{d^{2} D 11}{d y^{2}}\right) \cdot \frac{d^{2} W}{d y^{2}}+2 \cdot\left(\frac{d^{2} D 13}{d x d y} \cdot \frac{d^{2} W}{d x d y}\right. \\
\left.+\frac{d D 6}{d x} \cdot \frac{d^{3} W}{d x^{3}}+\frac{d D 11}{d y} \cdot \frac{d^{3} W}{d y^{3}}+\frac{d D 1013}{d y} \cdot \frac{d^{3} W}{d y d x^{2}}+\frac{d D 713}{d x} \cdot \frac{d^{3} W}{d x d y^{2}}\right)+\left(k_{l}+\frac{d^{2} W}{d x^{2}}\right) \cdot \frac{d^{2} F}{d y^{2}}+ \\
\left(k_{2}+\frac{d^{2} W}{d y^{2}}\right) \cdot \frac{d^{2} F}{d x^{2}}-2 \cdot \frac{d^{2} W}{d x d y} \cdot \frac{d^{2} F}{d x d y}+q(x, y)=0 ; \\
B_{5} \cdot \frac{d^{4} F}{d x^{4}}+B_{2} \cdot \frac{d^{4} F}{d y^{4}}+B_{14} \cdot \frac{d^{4} F}{d x^{2} d y^{2}}+\left(\frac{d^{2} B 5}{d x^{2}}+\frac{d^{2} B 1}{d y^{2}}\right) \cdot \frac{d^{2} F}{d x^{2}}+\left(\frac{d^{2} B 9}{d x^{2}}+\frac{d^{2} B 2}{d y^{2}}\right) \cdot \frac{d^{2} F}{d y^{2}}+\frac{d^{2} B 8}{d x d y} . \\
\frac{d^{2} F}{d x d y}+2 \cdot\left(\frac{d B 5}{d x} \cdot \frac{d^{3} F}{d x^{3}}+\frac{d B 2}{d y} \cdot \frac{d^{3} F}{d y^{3}}+\frac{d B 98}{d y} \cdot \frac{d^{3} F}{d y d x^{2}}+\frac{d B 18}{d x} \cdot \frac{d^{3} F}{d x d y^{2}}\right)+B 6 \cdot \frac{d^{4} W}{d x^{4}}+ \\
B_{4} \cdot \frac{d^{4} W}{d y^{4}}+B_{15} \cdot \frac{d^{4} W}{d x^{2} d y^{2}}+\left(\frac{d^{2} B 6}{d x^{2}}+\frac{d^{2} B 3}{d y^{2}}\right) \cdot \frac{d^{2} W}{d x^{2}}+\left(\frac{d^{2} B 7}{d x^{2}}+\frac{d^{2} B 4}{d y^{2}}\right) \cdot \frac{d^{2} W}{d y^{2}}- \\
\frac{d^{2} W}{d x d y} \cdot \frac{d^{2} B 10}{d x d y}+2 \cdot\left(\frac{d B 6}{d x} \cdot \frac{d^{3} W}{d x^{3}}+\frac{d B 3}{d y} \cdot \frac{d^{3} F}{d y^{3}}+\frac{d B 310}{d y} \cdot \frac{d^{3} W}{d y d x^{2}}+\frac{d B 710}{d x} \cdot \frac{d^{3} W}{d x d y^{2}}\right) \\
+\frac{d^{2} W}{d x^{2}} \cdot \frac{d^{2} W}{d y^{2}}-\left(\frac{d^{2} W}{d x d y}\right)^{2}+k_{l} \cdot \frac{d^{2} W}{d y^{2}}+k_{2} \cdot \frac{d^{2} W}{d x^{2}}=0 .
\end{gathered}
$$

Здесь, $D_{i}, B_{i}$ - жесткостные характеристики, имеющие сложную структуру и подробно описаны в [1]. Решения этих уравнений в работе [1] выполнены с помощью тригонометрических аппроксимирующих функций усилий $\mathrm{F}(\mathrm{x}, \mathrm{y})$ и прогибов $\mathrm{W}(\mathrm{x}, \mathrm{y})$.

В данной работе предлагается разрешение вышеназванных уравнений с помощью метода конечных разностей (метод сеток) [3].

Рассматривается пологая оболочка (рис. 1) прямоугольная в плане с размерами 2a х $2 b$, на которую по всей поверхности действует вертикальная равномерная нагрузка

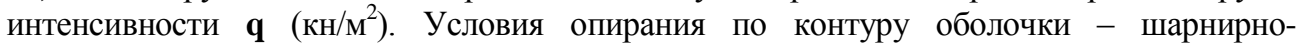
подвижные. Поверхность оболочки разбивается на сетку размером 8 х8 (рис. 2). Как видно из уравнений (1), по поверхности оболочки (х,y) переменными параметрами являются не только основные неизвестные функции $\mathrm{F}$ и $\mathrm{W}$, но и жесткостные характеристики $D_{i}, B_{i}$. Ценность и сложность предлагаемых уравнений (1) и заключается в том, что конечноразностной аппроксимации подвергаются все параметры:

F, W, $D_{i}$ и $B_{i}$.

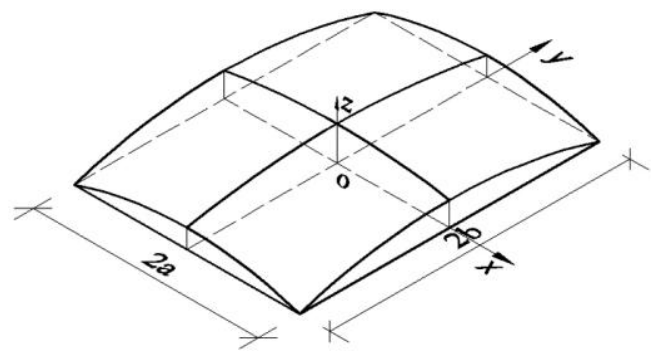

Рис. 1. Пологая оболочка

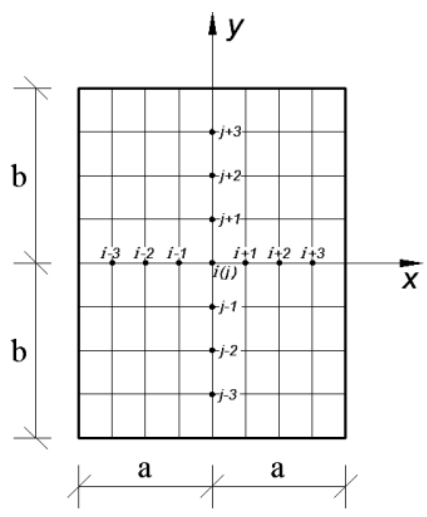

Рис. 2. Поверхность оболочки, разбитая на сетку размером $8 x 8$ 
В предлагаемой задаче используются разностные операторы [3] от 1-го до 4 -го порядков, включая и смешанного типа:

$$
\frac{d S}{d x} ; \frac{d S}{d y} ; \frac{d^{2} S}{d x^{2}} ; \frac{d^{2} S}{d y^{2}} ; \frac{d^{3} S}{d x^{3}} ; \frac{d^{3} S}{d y^{3}} ; \frac{d^{4} S}{d x^{4}} ; \frac{d^{4} S}{d y^{4}} ; \frac{d^{2} S}{d x d y} ; \frac{d^{4} S}{d x^{2} d y^{2}} ; \frac{d^{3} S}{d x^{2} d y} ; \frac{d^{3} S}{d x d y^{2}} .
$$

Для центральной точки поверхности оболочки - $\mathrm{O}(\mathrm{i}, \mathrm{j})$ (рис. 2) производные любой функции $\mathrm{S}(\mathrm{x}, \mathrm{y})$ запишутся следующими разностными операторами:

$$
\begin{gathered}
\frac{d S}{d x}=\left[\mathrm{S}_{(\mathrm{i}+1), \mathrm{j}}-\mathrm{S}_{(\mathrm{i}-1), \mathrm{j}}\right] / \Delta \mathrm{X} ; \quad \frac{d S}{d y}=\left[\mathrm{S}_{\mathrm{i},(\mathrm{j}+1)}-\mathrm{S}_{\mathrm{i},(\mathrm{j}-1)}\right] / \Delta \mathrm{y} ; \\
\frac{d^{2} S}{d x^{2}}=\left[\mathrm{S}_{(\mathrm{i}+1), \mathrm{j}}-2 \cdot \mathrm{S}_{\mathrm{i}, \mathrm{j}}+\mathrm{S}_{(\mathrm{i}-1), \mathrm{j}}\right] /(\Delta \mathrm{X})^{2} ; \quad \frac{d^{2} S}{d y^{2}}=\left[\mathrm{S}_{\mathrm{i}, \mathrm{j}+1)}-2 \cdot \mathrm{S}_{\mathrm{i}, \mathrm{j}}+\mathrm{S}_{\mathrm{i},(\mathrm{j}-1)}\right] /(\Delta \mathrm{y})^{2} ; \\
\frac{d^{2} S}{d x d y}=\left[\mathrm{S}_{(\mathrm{i}+1),(\mathrm{j}+1)}-\mathrm{S}_{(\mathrm{i}+1),(\mathrm{j}-1)}-\mathrm{S}_{(\mathrm{i}-1),(\mathrm{j}+1)}+\mathrm{S}_{(\mathrm{i}-1),(\mathrm{j}-1)}\right] /(\Delta \mathrm{y} \Delta \mathrm{x}) ; \\
\frac{d^{4} S}{d x^{4}}=\left[\mathrm{S}_{(\mathrm{i}+2), \mathrm{j}}-4 \cdot \mathrm{S}_{(\mathrm{i}+1), \mathrm{j}}+6 \cdot \mathrm{S}_{\mathrm{i}, \mathrm{j}}-4 \cdot \mathrm{S}_{(\mathrm{i}-1), \mathrm{j}}+\mathrm{S}_{(\mathrm{i}-2), \mathrm{j}}\right] /(\Delta \mathrm{x})^{4} ; \\
\frac{d^{4} S}{d y^{4}}=\left[\mathrm{S}_{\mathrm{i},(\mathrm{j}+2)}-4 \cdot \mathrm{S}_{\mathrm{i},(\mathrm{j}+1)}+6 \cdot \mathrm{S}_{\mathrm{i}, \mathrm{j}}-4 \cdot \mathrm{S}_{\mathrm{i},(\mathrm{j}-1)}+\mathrm{S}_{\mathrm{i},(\mathrm{j}-2)}\right] /(\Delta \mathrm{y})^{4} ; \\
\frac{d^{4} S}{d x^{2} d y^{2}}=\mathrm{S}_{(\mathrm{i}+1),(\mathrm{j}+1)}-2 \cdot \mathrm{S}_{(\mathrm{i}+1), \mathrm{j}}+\mathrm{S}_{(\mathrm{i}+1),(\mathrm{j}-1)}-2 \cdot\left[\mathrm{S}_{\mathrm{i},(\mathrm{j}+1)}-2 \cdot \mathrm{S}_{\mathrm{i}, \mathrm{j}}+\mathrm{S}_{\mathrm{i}, \mathrm{j}-1)}\right]+\mathrm{S}_{(\mathrm{i}-1),(\mathrm{j}+1)} \\
-2 \cdot \mathrm{S}_{(\mathrm{i}-1), \mathrm{j}}+\mathrm{S}_{(\mathrm{i}-1),(\mathrm{j}-1)} /\left[(\Delta \mathrm{X})^{2}(\Delta \mathrm{y})^{2}\right] ; \\
\frac{d^{3} S}{d x^{3}}=\left[\mathrm{S}_{(\mathrm{i}+2), \mathrm{j}}-2 \cdot \mathrm{S}_{(\mathrm{i}+1), \mathrm{j}}+2 \cdot \mathrm{S}_{(\mathrm{i}-1), \mathrm{j}}-\mathrm{S}_{(\mathrm{i}-2), \mathrm{j}}\right] /(\Delta \mathrm{X})^{3} ; \\
\frac{d^{3} S}{d y^{3}}=\left[\mathrm{S}_{\mathrm{i},(\mathrm{j}+2)}-2 \cdot \mathrm{S}_{\mathrm{i},(\mathrm{j}+1)}+2 \cdot \mathrm{S}_{\mathrm{i},(\mathrm{j}-1)}-\mathrm{S}_{\mathrm{i}, \mathrm{j}-2)}\right] /(\Delta \mathrm{y})^{3} ; \\
\frac{d^{3} S}{d x^{2} d y}=\left[\mathrm{S}_{(\mathrm{i}+1),(\mathrm{j}-1)}-2 \cdot \mathrm{S}_{\mathrm{i},(\mathrm{j}-1)}+2 \cdot \mathrm{S}_{\mathrm{i}, \mathrm{j}+2)}-\mathrm{S}_{(\mathrm{i}-1),(\mathrm{j}-1)}\right] /\left[(\Delta \mathrm{x})^{2} \Delta \mathrm{y}\right] ; \\
\frac{d^{3} S}{d x d y^{2}}=\left[\mathrm{S}_{(\mathrm{i}-1),(\mathrm{j}+1)}-2 \cdot \mathrm{S}_{(\mathrm{i}-1), \mathrm{j}}+2 \cdot \mathrm{S}_{(\mathrm{i}+2), \mathrm{j}}-\mathrm{S}_{(\mathrm{i}+1),(\mathrm{j}+1)}\right] /\left[(\Delta \mathrm{y})^{2} \Delta \mathrm{x}\right]
\end{gathered}
$$

где $\Delta \mathrm{x}=\mathrm{a} / 4 ; \Delta \mathrm{y}=\mathrm{b} / 4$.

Применяя разностные операторы (2) к уравнениям (1) для центральной точки $\mathrm{O}(\mathrm{i}, \mathrm{j})$, получим систему 2-х алгебраических уравнений :

$$
\begin{gathered}
\mathrm{c}_{1} \cdot \mathrm{F}_{(\mathrm{i}-2)}+\mathrm{c}_{2} \cdot \mathrm{F}_{(\mathrm{i}-1)}+\mathrm{c}_{3} \cdot \mathrm{F}_{\mathrm{i}}+\mathrm{c}_{4} \cdot \mathrm{F}_{(\mathrm{i}+1)}+\mathrm{c}_{5} \cdot \mathrm{F}_{(\mathrm{i}+2)}+ \\
+\mathrm{c}_{6} \cdot \mathrm{W}_{(\mathrm{i}-2)}+\mathrm{c}_{7} \cdot \mathrm{W}_{(\mathrm{i}-1)}+\mathrm{c}_{8} \cdot \mathrm{W}_{\mathrm{i}}+\mathrm{c}_{9} \cdot \mathrm{W}_{(\mathrm{i}+1)}+\mathrm{c}_{10} \cdot \mathrm{W}_{(\mathrm{i}+2)}=-\mathrm{q}(\mathrm{x}, \mathrm{y}) \\
\mathrm{e}_{1} \cdot \mathrm{F}_{(\mathrm{i}-2)}+\mathrm{e}_{2} \cdot \mathrm{F}_{(\mathrm{i}-1)}+\mathrm{e}_{3} \cdot \mathrm{F}_{\mathrm{i}}+\mathrm{e}_{4} \cdot \mathrm{F}_{(\mathrm{i}+1)}+\mathrm{e}_{5} \cdot \mathrm{F}_{(\mathrm{i}+2)}+ \\
+\mathrm{e}_{6} \cdot \mathrm{W}_{(\mathrm{i}-2)}+\mathrm{e}_{7} \cdot \mathrm{W}_{(\mathrm{i}-1)}+\mathrm{e}_{8} \cdot \mathrm{W}_{\mathrm{i}}+\mathrm{e}_{9} \cdot \mathrm{W}_{(\mathrm{i}+1)}+\mathrm{e}_{10} \cdot \mathrm{W}_{(\mathrm{i}+2)}=0
\end{gathered}
$$

Здесь, коэффициенты с,e содержат жесткостные и геометрические параметры оболочки.

Уравнения, подобные системе (3) записываются для всех 49 точек сетки (рис. 2). Таким образом, получается система 98 алгебраических уравнений относительно функций $\mathbf{F}$ и $\mathbf{W}$. Значения этих функций в контурных и законтурных точках определяются из условий опирания кромок оболочки: $\mathrm{W}=0 ; \frac{d^{2} F}{d x^{2}}=0 ; \frac{d^{2} F}{d y^{2}}=0$.

Значения жесткостных параметров $D_{i}, B_{i}$ в контурных и законтурных точках сетки принимаются равными нулю.

Как и любая физически нелинейная задача теории пластичности данная задача не имеет прямого решения. Для ее решения применяется метод переменных параметров упругости [4], с пересчетом на каждом шаге приближений жесткостных характеристик $D_{i}, B_{i}$ и решения системы из 98 алгебраических уравнений

Предлагаемый алгоритм решения изгиба пологой железобетонной оболочки заключается в следующем: В линейной постановке решается система алгебраических уравнений 98-го порядка и определяются значения функций $\mathrm{F}$ и $\mathrm{W}$ для каждой точки сетки. Используя жесткостные коэффициенты упругой болочки, вычисляются величины деформаций, напряжений и их интенсивности $\square_{\mathrm{i}}, \square_{\mathrm{i}}$ в каждой заданной точке по толщине и поверхности оболочки.

1. По известной диаграмме мгновенного деформирования бетона $\square_{\mathrm{i}} \sim \square_{\mathrm{i}}$

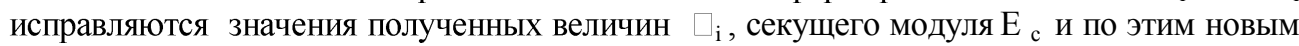
значениям параметров деформаций вычисляются жесткостные коэффициенты $D_{i}, B_{i}$. 
2. Получив, таким образом, новое поле жесткостей снова решается система 98 уравнений и по полученным значениям $\mathrm{F}$ и $\mathrm{W}$ процесс переходит на следующий шаг.

Процесс последовательных приближений продолжается до достижения заданной точности (по прогибам, напряжениям или другим параметрам).

Необходимо отметить, что для расчета в конечных разностях оболочек с жестко заделанными кромками лучше использовать разрешающие уравнения теории гибких пологих оболочек в перемещениях $\mathrm{U}, \mathrm{V}, \mathrm{W}$. Только в этом случае будут наиболее корректно учтены граничные условия по кромкам оболочки. Эта задача будет представлена авторами в последующих публикациях.

\title{
Сиисок литературы / References
}

1. Токмуратов А.М. Расчет пологих железобетонных оболочек с учетом нелинейной ползучести материала // Расчет строительных конструкций на статические и динамические нагрузки: межвуз. темат. сб. тр. Ленинград: Изд-во ЛИСИ, 1985. C. $59-68$.

2. Мусабаев T.T., Эм Э.В. Нелинейная модель расчета неупругих железобетонных балок // 1-й международный Джолдасбековский симпозиум: тезисы докладов (Алматы, 24 июня-25июня 2011). Алматы: Изд-во КазНУ, 2011. С. 75-80.

3. Годунов С.К., Рябенький В.С. Разностные схемы (введение в теорию). М.: Наука, 1977. $440 \mathrm{c}$

4. Биргер И.А. Некоторые общие методы решения задач теории пластичности // Прикладная механика, 1951. Т. 15. Вып. 6. С. 765-770.

\section{АНАЛИЗ СИСТЕМЫ ЗАЩИТЫ ОТ СКАТЫВАНИЯ ПОД УКЛОН ПОДВИЖНОГО СОСТАВА КАНАТНОЙ ОТКАТКИ ПРИ ДУБЛИРОВАНИИ ЕЕ ДОПОЛНИТЕЛЬНЫМИ УСТРОЙСТВАМИ \\ Петров А.Г. ${ }^{1}$, Авершин А.А. ${ }^{2}$, Степанов Е.И. ${ }^{3}$ Email: Petrov226@scientifictext.ru

\footnotetext{
${ }^{1}$ Петров Александр Геннадиевич - кандидат технических наук, доцент;

${ }^{2}$ Авершин Андрей Александрович - кандидат психологических наук, дочент;

${ }^{3}$ Степанов Евгений Иванович - кандидат технических наук, доиент, кафедра горной электромеханики и транспортных систем, Луганский национальный университет им. Владимира Даля,

2. Стаханов, Украина
} \\ Стахановский учебно-научный институт горных и образовательных технологий}

\begin{abstract}
Аннотация: в работе предложень дополнительные удерживающие механизмь зашиты от скатывания под уклон, кинематически не связанные с системой защиты отдельного транспортного средства и подвижного состава в целом, не взаимодействующие с головками рельс пути на зажимание, и со шпалами пути на жесткое стопорение. Представлен конструктивный принции дублирования системы защиты от скатывания под уклон подвижного состава вагонеток одноконцевой канатной откатки. Используемые дополнительные удерживающие механизмы устанавливаются на платформы вагонеток подвижного состава.
\end{abstract}

Ключевые слова: удерживающий механизм; защита; скатывание под уклон; транспортное средство; подвижный состав; рельсовый путь. 


\title{
ANALYSIS OF THE SYSTEM OF PROTECTION FROM ROLLING DOWN THE SLOPE, ROLLING STOCK, ROPE HAULAGE, WHEN YOU DUPLICATE THEM TO ADDITIONAL DEVICES Petrov A.G. ${ }^{1}$, Avershin A.A. ${ }^{2}$, Stepanov E.I. ${ }^{3}$
}

\author{
${ }^{I}$ Petrov Alexander Gennadievich - Candidate of technical Sciences, associate Professor; \\ ${ }^{2}$ Avershin Andrey Aleksandrovich - Candidate of psychological Sciences, associate Professor; \\ ${ }^{3}$ Stepanov Evgeny Ivanovich - Candidate of technical Sciences, associate Professor, \\ DEPARTMENT OF MINING ELECTROMECHANICS AND TRANSPORT SYSTEMS \\ (AIRCRAFT AND VEHICLE), \\ STAKHANOV EDUCATIONAL AND SCIENTIFIC INSTITUTE OF MINING AND EDUCATIONAL \\ TECHNOLOGY AFFILIATED WITH DALIA LUGANSK STATE UNIVERSITY, \\ STAKHANOV, UKRAINE
}

\begin{abstract}
: proposed additional restraint mechanisms to protect from rolling downhill, kinematically not associated with a system of protection separate vehicle and rolling stock as a whole, does not interact with the rail heads way on pinching, and to the sleepers of the way on hard lock. Presents the structural principle of the duplication system of protection from rolling downhill rolling stock trolleys one-ended rope haulage. Used additional restraint mechanisms are mounted on platforms of trolleys rolling stock.
\end{abstract}

Keywords: retention mechanism; protection; rolling downhill; vehicle; rolling stock; track.

УДК 622.625. (088.8)

Введение и постановка проблемы. Условия горного производства диктуют архитектуру построения технических систем, особенно связанную с проблемой безопасности ведения очистных и подготовительных работ в угольной промышленности. Глубина залегания пластов ведет к необходимости углубления вертикальных стволов, а это сложный и затратный способ. Использование действующих и оснащение оборудованием вновь созданных наклонных выработок обусловливает поиск технических и конструктивных решений, повышающих надежность систем улавливания и защиты от скатывания под уклон подвижного состава канатной откатки. Верхний и нижний горизонты угледобывающего участка технологически связаны между собой наклонной выработкой, оборудованной концевой откаткой, по которой подвижный состав грузовых вагонеток транспортирует основные грузы, материалы и механизмы. При эксплуатации откатки возможны аварийные ситуации с тяжелыми последствиями: расстыковка прицепного устройства подъемного каната с головной вагонеткой состава, обрыв каната, разрыв сцепок между вагонетками. Во всех случаях состав или его часть, наращивая скорость, скатывается вниз, производя по пути разрушения и угрожая жизни людей, работающих на нижнем горизонте. Устранение последствий аварии требует значительных финансовых и материальных затрат, а также остановки участка на период ремонта, что нарушает график выполнения основных работ.

Для обеспечения безопасных условий эксплуатации откатки состав вагонеток оснащают улавливающим приспособлением, способным удержать его на уклоне при возникновении нестандартных ситуаций. В повседневной практике для этих целей применяют различные устройства. Существуют два основных вида улавливающих механизмов: взаимодействующих со шпалами рельсового пути и зажимающих головки рельсов. В зависимости от конструкции они выполняют либо плавную, либо жесткую остановку состава. Жесткая остановка реализуется с помощью шарнирно соединенных с рамой улавливающего приспособления тормозных плужков, упирающихся в рабочем положении в шпалу рельсового пути. Резкое торможение состава - основной недостаток подобных конструкций. Большие динамические нагрузки способствуют сходу вагонеток с рельсов, их развороту, капотированию, а 
удары о стенки выработки разрушают ее крепь и смонтированное оборудование. Плавная остановка состава происходит за счет протягивания с усилием сквозь амортизационное устройство тормозного каната, который сматывается с бобины, оснащенной фрикционными муфтами. Канат и тормозные элементы входят в комплект оборудования улавливающего приспособления системы защиты от скатывания под уклон. Инерционность системы все же сохраняет значительные динамические нагрузки и в выработках с большим углом наклона возможен отрыв и сход транспортных средств с рельсового пути. Например, по данным МакНИИ, в угольной промышленности при эксплуатации канатной откатки ежегодно происходит в среднем 20 несчастных случаев [1, 2]. Более половины из них обусловлено неуправляемым скатыванием подвижного состава под уклон, хотя эти составы были оборудованы системами защиты и улавливания от скатывания.

Поэтому разработка дополнительных (новых) мероприятий, технических решений и технических средств защиты на шахтном транспорте, дублирующих основные элементы (системы) защиты и повышающих надежность работы транспортных магистралей, особенно при транспортировании людей, является актуальной. Это снижает и практически исключает аварийные ситуации при транспортировании, как грузов, так и людей канатной откаткой в наклонных выработках.

Данная работа является продолжением исследований по выяснению возможности применения «независимых» дополнительных устройств и приспособлений для дублирования системы защит от скатывания под уклон подвижного состава, проведенных в статье [3].

Анализ публикаций. Системы улавливания и защиты от скатывания под уклон подвижного состава канатной откатки напрямую или косвенно связаны конструктивно с составом вагонеток. Согласно [2] можно проследить их кинематическую связь. Техническая система концевой откатки состоит из рельсового пути наклонной выработки, лебедки подъемной установки, подвижного состава вагонеток с тормозной тележкой, на ходовой платформе которой установлены тормозной механизм с прицепным устройством и удерживающей лебедкой, прицепленным к тяговому канату лебедки подъемной установки через прицепное устройство тормозного механизма и сцепленным канатом удерживающей лебедки с ходовой платформой последней вагонетки состава, улавливающих барьеров типа «гильотина» и аппаратуры автоматизации. В случае обрыва тягового каната или прицепного устройства, торможение осуществляется колесными парами тормозной тележки, вследствие чего из-за низкого коэффициента трения между колесом и рельсом, вагонетки состава могут «пролетать» значительные расстояния, прежде чем будут уловлены улавливающими барьерами (то есть прежде, чем сработают элементы аппаратуры автоматизации). При торможении части состава, при обрыве сцепного устройства между вагонетками, она удерживается канатом удерживающей лебедки и может набрать большую скорость скатывания. Датчик контроля числа вагонеток в составе - исполнительный элемент опускания барьера не сработает и аварийная часть состава не будет уловлена ближайшим барьером, а «проскочит» к другому ниже установленному барьеру, и даже, если и будет уловлена этим барьером, то масштаб аварии окажется значительным (сход с рельсов состава, опрокидывание вагонеток, разрушение крепления и улавливающего барьера, травмирование людей), что обусловливает тенденцию к увеличению количества устанавливаемых улавливающих барьеров в наклонной выработке для поддержания необходимого уровня безопасности при эксплуатации канатной откатки в угольной шахте. Кроме этого, изза специфических условий эксплуатации в подземных выработках аппаратуры автоматизации возможен выход из строя ее элементов (блоков, устройств, технических средств управления и так далее), а также обесточиванию части или всего комплекта аппаратуры автоматизации, то перечисленные негативные факторы могут также оказаться масштабными. 
Кинематическая связь систем защиты с основной конструкцией отдельно взятого транспортного средства в составе вагонеток представлена в типовом устройстве [4]. Это устройство включает в себя состав вагонеток, ходовую тележку с тормозным механизмом и амортизирующий механизм с тормозными канатами, закрепленными на ходовой тележке и вагонетках состава, транспортное средство также имеет сцепкурасцепитель, кинематически связанный с тормозным механизмом и головной вагонеткой. Такое выполнение, разгружает амортизирующий механизм от тягового усилия, однако не предусматривает возможность наезда на препятствие впереди, при этом при торможении верхняя часть устройства под действием сил инерции может сойти с рельсового пути. В другом транспортном средстве конструктивно выполненном в виде кузова, рамы, ходовой тележки, тормозной системы с кареткой и включателем [5] отсутствует механизм торможения при подходе к препятствию на рельсовом пути, а также механизм удерживания этого транспортного средства на рельсовом пути при экстренной остановке. В компоновочном конструктивном сочетании, включающем кузов, раму, ходовые тележки, тормозную систему с кареткой и включателем и предохранительный упор, размещенный в направляющих рамы аналогичного транспортного средства [6], также отсутствует механизм удержания на рельсовом пути при срабатывании тормозной системы при аварийной, экстренной остановке, т.к. под действием сил инерции транспортное средство может сойти с рельсового пути даже при заклинивании рельса захватами каретки. Верхняя часть устройства под действием сил инерции - инерционности «подпрыгивает», что может привести к сходу устройства с рельсового пути.

Формулирование задачи. В основу поставлена задача исключить масштабные аварийные ситуации в наклонных выработках при транспортировке полезного ископаемого канатной откаткой при обрыве тягового каната, прицепного устройства или сцепного устройства в самом составе, за счет торможения и надежного удержания состава или части состава при скатывании под уклон без набора скорости скатывания дополнительными удерживающими механизмами, не взаимодействующими со шпалами рельсового пути и не зажимающими головки рельсов.

Материалы и результаты исследований. В работе представлен конструктивный принцип дублирования систем защиты от скатывания под уклон подвижного состава вагонеток одноконцевой канатной откатки. Используются дополнительные удерживающие механизмы которые устанавливаются на платформы вагонеток подвижного состава. Эти механизмы кинематически не связаны с системой защиты от скатывания как отдельного транспортного средства так и состава в целом и не взаимодействуют со шпалами рельсового пути, и не зажимают головки рельсов. Технические решения конструктивного исполнения дополнительных удерживающих механизмов защищены патентами [7,8].

На основе технического решения, заложенного в патенте [7], на рисунке 1 представлена разработанная технологическая схема канатной откатки с системой улавливания и защит от скатывания под уклон подвижного состава с «дублирующими» элементами; на рисунке 2 показан вид А (Вид сбоку) подвижного состава вагонеток; на рисунке 3 показано: (а) - сечение А-А на рис. 2; (б) - сечение В-В; (c) - сечение Б-Б; на рисунке 4 показано: (а) - блок-схема функциональной взаимосвязи аппаратуры автоматизации; (б) - «фрагмент» схемы защиты от обрыва каната. Нумерация обозначений во всех приведенных схемах работы одна и та же.

Устройство канатной откатки с системой улавливания и защиты от скатывания под уклон подвижного состава состоит из рельсового пути наклонной выработки $1 \mathrm{c}$ верхней приемно-отправочной площадкой 2 (ПОП) и нижней ПОП 3, подъемной установки, подвижного состава вагонеток с тормозной тележкой 4, на ходовую платформу которой установлены тормозной механизм 5 с прицепным устройством (на чертеже не показано) и удерживающая лебедка 6 , прицепленным к тяговому канату 7 лебедки 8 подъемной установки, установленной в камере 9, через прицепное 
устройство тормозного механизма 5, улавливающих 10 барьеров типа «гильотина», установленных по всей длине наклонной выработки 1 и аппаратуры автоматизации, в комплект которой входят:

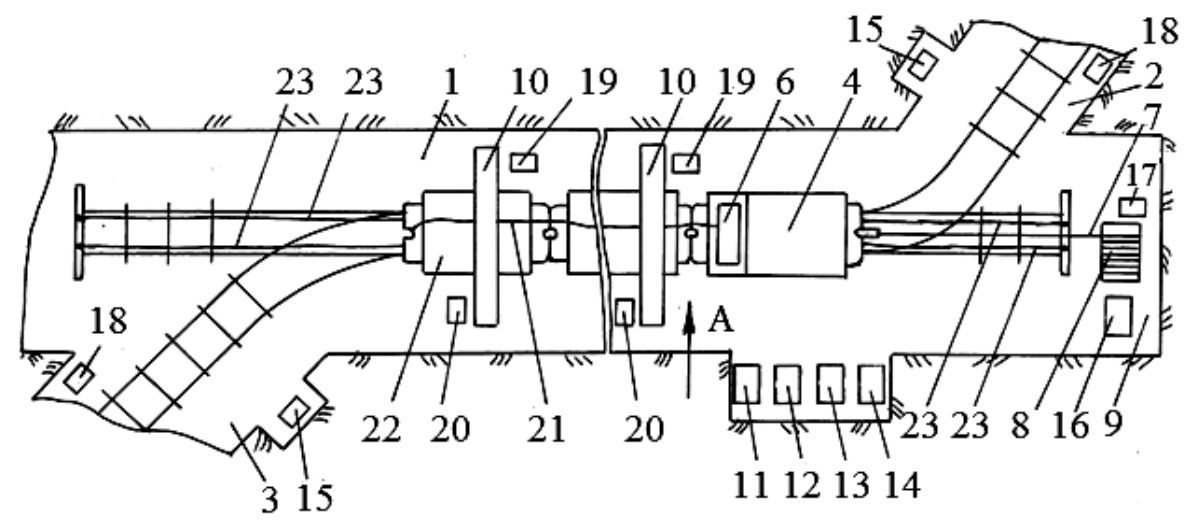

Рис. 1. Технологическая схема канатной откатки с системой улавливания и защиты от скатывания под уклон подвижного состава вагонеток

Основные блоки - исполнительный блок 11, блок 12 сигнализации и индикации, блок 13 приемника информации о скорости подвижного состава, блок 14 контроля числа вагонеток (задатчик), установленные в нише наклонной выработки; вспомогательные блоки - блоки 15 включение световой и звуковой сигнализации, блок 16 преобразования информации, блок 17 отключения аппаратуры управления лебедкой 8 подъемной установки и технические средства управления - датчик скорости ДС и передатчик информации о скорости состава ПС, установленные на тормозной тележке (на чертеже не показано), устройства 18 считываний числа вагонеток в составе, датчики 19 контроля числа вагонеток в составе, исполнительные элементы 20 опусканий улавливающего барьера. Канатом 21 удерживающей лебедки 6 тормозной тележки сцепленный также с ходовой платформой последней вагонетки 22 состава, который выполняет функции как тормозной тележки так и «балластной». На верхнее строение рельсового пути наклонной выработки уложены предохранительные канаты 23, закрепленные на концах рельсового пути (на чертеже не указаны) с надетыми на них полыми зажимами 24. Зажимы закреплены в нижних частях ходовых платформ тормозной тележки и балластной вагонетки 22, например, сваркой, болтовым соединением, хомутами. Часть полости зажимов 24 имеет форму конической поверхности 25 и снабжена коническими сегментами 26, а часть полости зажимов имеет форму цилиндрической поверхности с большим и меньшим диаметром.

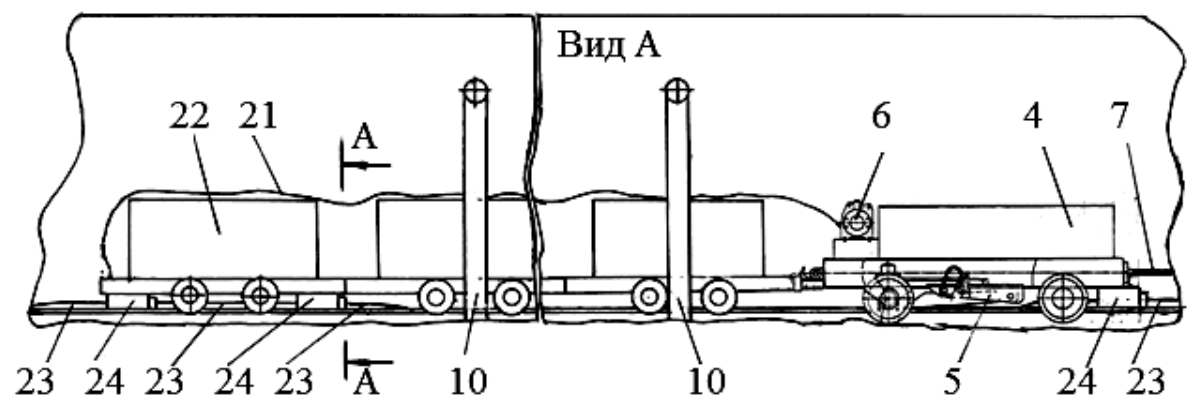

Рис. 2. Вид сбоку подвижного состава вагонеток (Вид А на рис. 1) 
Полость 27 с цилиндрической поверхностью большего диаметра снабжена упругим элементом 28, а полость 29 с цилиндрической поверхностью меньшего диаметра снабжена полым винтом 30, установленным с возможностью радиального и аксиального перемещения в этой полости.

В зажимах конические сегменты 26 прижаты упругим элементом 28 через шайбу 31 к поверхности предохранительного каната 23 и цилиндрической частью 32 своей поверхности, а к конической поверхности 25 зажима и к торцу полого винта 30 конической частью 33 своей поверхности и меньшим основанием, соответственно. Конические сегменты 26 могут быть выполнены из дерева, специальных пластмасс, мягких металлов и так далее. Стрелочные переводы верхней ПОП 2 и нижней ПОП 3 на наружной нити переводной кривой имеют стыки (на чертеже не показаны), в которые укладываются предохранительные канаты 23 тормозным тележкой и «балластным» вагонеткой 22 при формировании подвижного состава для движения по наклонной выработке вверх или вниз.

В системе «барьер» в улавливающих барьерах 10 используется металлическая или другая, такая, что отвечает требованиям прочности сетка (на чертеже не показано). При движении состава с грузом по наклонной выработке вверх информация о его скорости от установленного на тормозном барабане датчика скорости ДС и передатчика ПС передается в блок 13, откуда поступает в блок 11. В случае обрыва тягового каната 7 или прицепного устройства срабатывает тормозной механизм 5 тормозного тележки и начинается торможение состава. Скорость состава при этом превышает допустимую и блок 11 дает команду на исполнительный элемент 20 для опускания ниже установленного улавливающего барьера 10. Одновременно блок 11 подает команду в блок 12, который формирует сигналы на включение блоков 15 и 16, а также подает сигнал в блок 17. Лебедка 8 подъемной установки останавливается, а состав улавливается в ближайшим улавливающим барьером 10. В случае обрыва сцепного устройства (на чертеже не показано) при подходе к нижней ПОП груженого состава (перед формированием состава в наклонной выработке) устройство 18 считывает число вагонеток в составе, которое передается в блок 14 (задатчик). В наклонной выработке в местах установки улавливающих барьеров 10 установлены датчики 59. При обрыве сцепного устройства часть состава, что отцепилась, опускается ниже 6 за основной состав на величину напуска каната 21 удерживающей лебедки 6 тормозного тележки. Ближайший датчик 19 передает в блок 14 информацию о прохождении части состава. Блок 14 фиксирует несоответствие полученной информации с ранее полученной от устройства 18 и подает сигнал в блок 11 на остановку лебедки 8 (блок 17), опускание ниже установленного улавливающего барьера 10 (исполнительный элемент 20) включение световой и звуковой сигнализации (блоки 15 и 16).

В случае использования в системе (рис. 3) предохранительных канатов 23 с надетыми на них полыми зажимами 24, закрепленными к нижним частям платформ тормозного тележки 4 и балластной вагонетки 22, последовательность функционирования системы не меняется. 


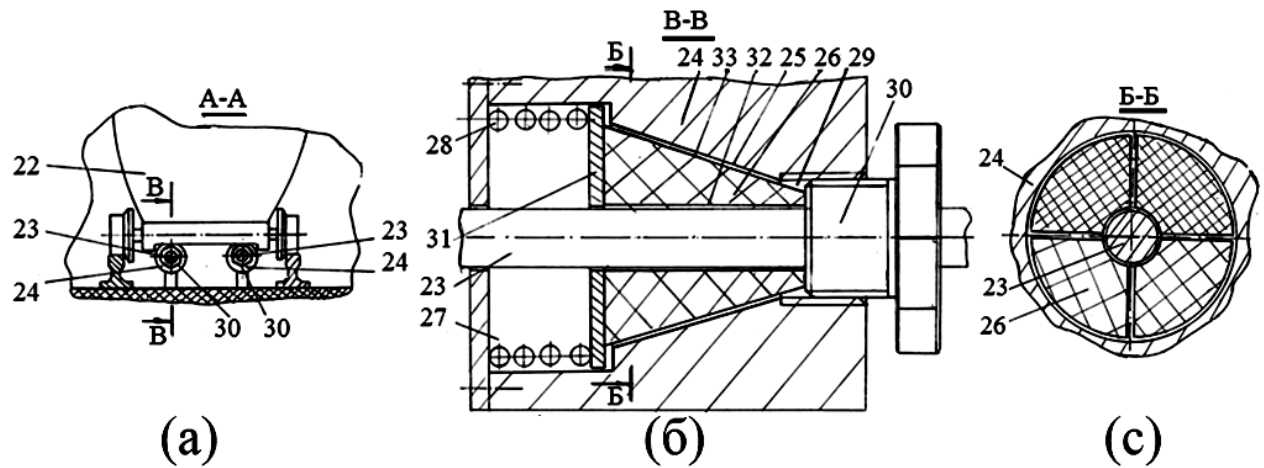

Рис. 3. Поперечное сечение: (а) - по А-А на рис. 2;(б) - по B-B; (c) - по Б-Б

При движении груженого состава вверх по наклонной выработке полый винт с зажимов 24 устанавливается так, что его торец не соприкасается с нижним основанием конических сегментов 26. Сегменты скользят по поверхности предохранительного каната 23, сжимая упругий элемент 28 , и в зажиме не происходит «расклинивание» этими сегментами поверхности каната. При обрыве тягового каната 7, прицепного устройства или сцепных устройств в составе происходит скатывание состава и расклинивание (заклинивания) коническими сегментами 26 поверхности предохранительного каната 23 в зажимах 24 (т. е. цилиндрической частью 32 сегменты зажимают поверхность предохранительного каната 23). Происходит резкое торможение всего состава в случае обрыва тягового каната 7 или прицепного устройства, зажимами 24 тормозного тележки и балластной вагонетки 22 или части состава, в случае обрыва сцепного устройства в составе, зажимами 24 балластной вагонетки 22 и содержание состава или части состава на предохранительных канатах 23. При движении ненагруженного состава вниз по наклонной выработке полый винт с зажимов 24 устанавливается так, чтобы его торец соприкасался с нижними основаниями конических сегментов 26, сжимая в полости 27 упругий элемент 28. В этом случае заклинивания поверхности предохранительного каната 23 коническими сегментами 26 не состоится, поскольку сегменты 26 не перемещаются на расклинивание (заклинивания).

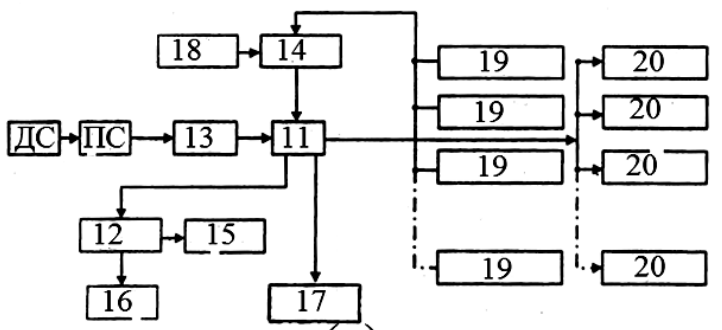

(a)

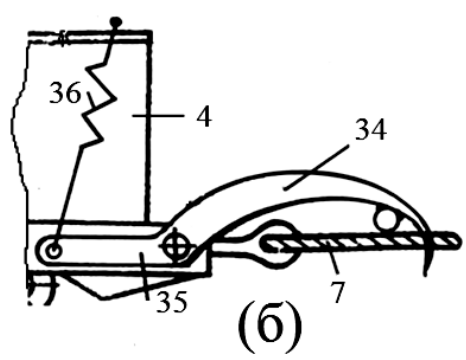

(6)

Рис. 4. (а) - блок-схема взаимосвязи комплекта аппаратуры автоматизации;

(б) - «фрагмент» схемы взаимосвязи тягового каната с дополнительным удерживаюшим механизмом

В случае использования устройства, конструктивное исполнение которого приведено в работе [3] и исходя из технического решения изложенного в патенте [8], «дублирование» защиты от обрыва каната 7, этим дополнительным удерживающим механизмом, будет осуществляться следующим образом. Согласно схеме на рисунке 4, к ходовой платформе тележки 4 крепится специальный зацеп 34 с приводным 
рычагом 35 и упругим элементом 36, с возможностью углового перемещения относительно ходовой платформы. Зацеп 34 связан (взаимодействует) с тяговым канатом 7 «контактно», с тормозной тележкой 4 посредством упругого элемента 36 через приводной рычаг 35 . В случае обрыва тягового каната 7 срабатывает тормозной механизм 5 системы защиты и одновременно под действием собственного веса и упругого элемента 36 зацеп 34 перемещается (угловое перемещение) и зацепляется за верхнее строение рельсового пути, за шпалы, удерживая тормозную тележку 4 состава вагонеток на рельсовом пути. Удержание тележки 4 осуществляется не жестким стопорением в шпалу специальным зацепом 34, а зацеплением его за шпалы с «гашением» иннерционности подвижного состава.

Выводы. Таким образом, обеспечив систему улавливания и защиты от скатывания под уклон подвижного состава предохранительными канатами с надетыми на них полыми зажимами, закрепленными в нижних частях ходовых платформ, например первой и последней вагонетки подвижного состава, которые выполняют функции «балластных», позволит повысить надежность работы канатной откатки в наклонных выработках. За счет удержания в зажимах, всего состава или части состава, на предохранительных канатах при скатывании его под уклон в случае обрыва тягового каната, прицепного устройства или сцепного устройства. Выполнение полости зажимов различной формы поверхностей и размерности с размещением в них конических сегментов, упругого элемента и полого винта, позволит осуществлять зажим поверхности предохранительного каната, исключив тем самым набор скорости скатывания «аварийного» состава при движении состава с грузом без взаимодействия с шпалами рельсового пути и без взаимодействия с головками рельс. А также закреплять эти зажимы к ходовым платформам любой вагонетки состава, осуществляя при необходимости быструю замену конических сегментов в качестве тормозных элементов. Постоянное «контактирование» тягового каната со специальным зацепом, при его обрыве, позволяет гасить инерционность технической системы (подвижного состава вагонеток), за счет «зацепления» за шпалы рельсового пути (не стопорение в шпалу), снижая тем самым динамические нагрузки, способствующие отрыву и сходу с рельсового пути подвижного состава.

Исследования, приведенные в статье [3], являются продолжением и в этой работе и могут быть полезны при проведении прогнозных и поисковых НИР, направленных на разработку новых технических решений, повышающих надежность работы канатной откатки, на стадии формулирования исходных технических требований к техническому заданию.

\section{Сиисок литературы / References}

1. Гриф Б.В., Горчаков С.П. Охрана труда в угольной промышленности. М.: Недра, 1988.

2. Деревянский В.Ю., Бирюков В.В. Автоматизированный комплекс улавливания вагонеток «АКУЛА» // Уголь Украины, 2009. № 3. С. 18-20.

3. Петров А.Г. Дублирование тормозной системы устройства для транспортирования людей по наклонным выработкам / А.Г. Петров, А.А. Авершин, Е.И. Степанов // Научно-теоретический журнал «Наука и образование сегодня». М.: Изд-во «Проблемы науки» г. Иваново, 2017. № 2 (13). С. 12-14.

4. Авторское свидетельство СССР № 569728. Е 21 F 13/04, 1974.

5. Авторское свидетельство СССР № 352028. Е 21 F 13/04, 1960.

6. Авторское свидетельство СССР № 688647. Е 21 F 13/04, 1979.

7. Пат. 69120 Україна, МПК Е21F 13/00. Система уловлювання та захисту від скочування під уклон рухомого состава канатної відкатки / Степанов Є.I., Романенко В.П., Хаджиков М.Р., Амірахов А.А.; заявник і патентовласник УІПА. №u201110120; заявл. 16.08.2011; опубл. 25.04.2012, бюл. № 8. 
8. Пат. 94981 Україна, МПК Е21F 13/04; В61Д 11/00. Пристрій для транспортування людей по нахиленим виробкам / Петров О.Г., Фіногєєва Т.Є., Степанов Є.І.; заявник i патентовласник УІПА. №U201406156; заявл. 04.06.2014; опубл. 10.12.2014, бюл. № 23.

\section{ПРОБЛЕМЫ ПРИМЕНЕНИЯ ГИБКИХ МЕТОДОЛОГИЙ УПРАВЛЕНИЯ ПОРТФЕЛЕМ ИТ-ПРОЕКТОВ В КРУПНОЙ ОРГАНИЗАЦИИ \\ Овсянникова П.А. ${ }^{1}$, Морозова О.А. ${ }^{2}$ \\ Email: Ovsyannikova226@scientifictext.ru \\ ${ }^{\text {I } О в с я н н и к о в а ~ П о л и н а ~ А л е к с е е в н а ~-~ с т у д е н т ~ м а г и с т р а т у р ы ; ~}$ \\ ${ }_{2}^{2}$ Морозова Ольга Анатольевна - кандидат технических наук, доцент, кафедра бизнес-информатики, факультет прикладной математики и информатики, Финансовый университет при Правительстве Российской Федерации,}

$$
\text { г. Москва }
$$

Аннотация: в статье проведен анализ портфельного управления ИТ-проектами и его основные задачи в рамках компании, описываются основные подходы к применению гибких методологий управления портфелем ИТ-проектов в организаиии, влияние системь управления портфелем на стратегию и развитие компании, проанализированы основные преимущества в условиях постоянно изменяющейся внешней $u$ внутренней среды, возможные трудности, с которыми могут сталкиваться крупные компании при трансформации своего бизнеса, а также даны основные рекомендации при планировании перехода к гибкой организации.

Ключевые слова: гибкие методологии, Agile, управление портфелем, ИТ-проект, крупная организация, стратегия организациии.

\section{APPLICATION PROBLEMS OF AGILE METHODOLOGIES OF IT PROJECTS PORTFOLIO MANAGMENT IN MAJOR ORGANIZATION Ovsyannikova P.A. ${ }^{1}$, Morozova O.A. ${ }^{2}$ \\ ${ }^{1}$ Ovsyannikova Polina Alekseevna - Graduate student; \\ ${ }^{2}$ Morozova Olga Anatolevna - PhD, Associate Professor, DEPARTMENT BUSINESS INFORMATICS, \\ FINANCIAL UNIVERSITY UNDER THE GOVERNMENT OF THE RUSSIAN FEDERATION, MOSCOW}

Abstract: the article analyzes the portfolio management of IT projects and its main tasks within the company, describes the main approaches to the application of flexible methodologies for managing the portfolio of IT projects in the organization, the impact of the portfolio management system on the company's strategy and development, analyzed the main advantages in the constantly changing external and Internal environment, possible difficulties that large companies may face when transforming their business, and also gives the main recommendations for the planned and the transition to a flexible organization. Keywords: agile methodology, Agile, portfolio management, IT project, large organization, organization strategy. 
При анализе различных методологий управления проектами, отраженных в стандартах [24, с. 78], можно прийти к выводу, что все они имеют единую основу, которая представляет собой возможность применения определённых процессов управления проектами к каждому пункту проекта и дает руководителям проекта инструмент, достаточный для управления проектом. Но редко когда организация занимается реализацией лишь одного проекта. Обычно имеется целый ряд проектов, реализация которых направлена на достижение стратегических целей компании. Таким образом, организация сталкивается с необходимость управления несколькими проектами одновременно. Для решения задачи управления скоупом проектов и были разработаны методы и инструменты управления программами и портфелями проектов.

Процесс управления Портфелем направлен на получение дополнительного эффекта от совместной и скоординированной реализации всей совокупности программ и проектов и общего повышения зрелости проектного управления, что позволит:

- повысить отдачу от использования финансов и ресурсов в проектной деятельности;

- исключить дублирование работ в проектах;

• исключить нецелевые расходы/затраты в проектной деятельности;

- оптимизировать использование персонала Банка в проектах;

- сократить сроки реализации проектов.

Правильный выбор и успешная реализация портфелей проектов являются связующим звеном между стратегическим планированием и управлением проектами. В такой среде руководящее звено организаций имеет всю необходимую информацию для поиска оптимального способа использования ресурсов, фокусируясь только на «реально выполнимых» проектах, соответствующих стратегическим целям. На рисунке 1 представлены место и роль управления портфелем проектов в организационной системе управления компании [3, с. 357].

Управление портфелем отвечает за трансформацию стратегии, изменений, инноваций в значимую ценность для организации, и должны делать это своевременно и в гибкой манере [1, с. 25].

Организационная гибкость - это способность компании отвечать на вызовы окружающей среды, реагировать на неожиданные внутренние изменения и конфликты, приспосабливаться к новым условиям и возможностям. Сюда можно отнести появление новых технологий, конкурентов, рынков и потребностей. Гибкость организации напрямую влияет на её прибыльность.

Гибкость на организационном уровне, на уровне портфеля, как и на уровне проекта требует, чтобы во всех аспектах предприятия, была реакция на изменения и риски в условиях сотрудничества и адаптивности. Создавая стратегическую гибкость и гибкость портфеля, можно дать возможность организации направить бизнес к успеху.

По результатам ежегодного отчета «РMI's Pulse of the Profession: Capturing the Value of Project management» [8] Project Management Institute можно сделать вывод, что проекты гибких организаций чаще достигают поставленных целей (75\% против $56 \%$ у негибких организаций), чаще завершаются вовремя (65\% против 40\%) и укладываются в бюджет (67\% против $45 \%)$.

Тем не менее, мы можем спросить: Почему портфели проектов должны быть гибкими? Ответ заключается в том, что в сфере организации, мы должны быть в состоянии предвидеть необходимость изменения и быть в состоянии приспособиться к ним, не создавая хаос в организации. Организация не должна вставать перед проблемой, но она должна быть в состоянии предвидеть ее, внести необходимые коррективы. 
В настоящее время гибкость больше относится к процессу разработки, существует множество методологий и рекомендаций для ее реализации в организации и при разработке в ходе ИТ проектов. Про гибкое портфельное управление существует не так много работ.

Описание фреймворков метода Agile, применяемых к портфельному управлению, было сформировано Леффингуэллом, Кребсом и Vähäniitty et al.

Леффингуэлл [8, с. 153] в своей книге и фреймворке описывает определение Scaled Agile Framework (SAFe) и несколько методов для осуществления гибких методов в масштабах предприятия. Он делит свой фреймворк на уровни: портфель, программы и команды. На уровне портфеля команда управления портфелем поддерживает целостность портфельного видения, распределяет ресурсы, чтобы оценить потоки создания ценности через инвестиции, определяет и устанавливает приоритеты портфельного бэклога и технологических инициатив в области развития. На программном уровне менеджер по продукту постоянно взаимодействует с командой управления портфелем и участвует в процессе принятия решений о приоритетах бэклога программы. На уровне команды, около 5-10 agile команд ответственны за осуществление и реализацию проектов, следуя практикам гибкой методологии управления проектами, которые предусмотрены, например, методологией Scrum.

Кроме того, он определяет четыре основные преимущества фреймворка:

1 - Выравнивание (стратегии от бэклога портфеля вплоть до соответствующего бэклога команды).

2 - Качество кода (обеспечивается за счет количества повторений).

3 - Прозрачность (чтобы построить доверие и обеспечить лучшее принятие решений).

4 - Выполнение программы (успешное выполнение всей программы).

В своей книге Кребс предлагает динамически управляемый портфель, основанный на принципах Agile и с гибкой финансовой моделью. Он делит все управление портфелем на управление портфелем проектов, ресурсов (например, персонала) и активов (например, систем, приложений) и в то же время предлагает использовать информационную панель для оценки ситуации в целом и принимать прогресс, качество и боевой дух команды в качестве ключевых показателей для отдельных проектов.

Кребс также раскладывает трудности управления портфелем на 3 вектора:

1- Портфель проектов: слишком много активных проектов и неправильное сочетание проектов;

2- ресурсный портфель: отсутствие видения, слишком много проектов, в то время как не хватает ресурсов, а также отсутствие обратной связи;

3- портфель активов: устаревшие унаследованные системы и занижение общей стоимости владения.

По его словам, внедрение офисов управлению проектами (РМО) и прозрачность ресурсов являются ключевыми для гибкого управления проектами.

Vähäniitty говорит o agile управлении портфелем проектов в условиях малой компании по разработке программного обеспечения. Он предлагает Фреймворк для объединения принятия решений бизнеса и развития через три ключевых процесса (управление портфелем развития, роадмеппинге продукта и планировании релизов) распределенных между тремя основными акторами (топ-менеджмент, менеджеры по стратегическим релизам и менеджеры по разработке ПО).

По его словам, основными шагами в создании гибкой системы управления портфелем являются:

1- создание общедоступного приоритизированного списка всех текущих мероприятий;

2- убедиться, что системы стимулирования не поддерживают локальную оптимизацию; 
3- назначить руководящую группу, которая будет регулярно встречаться и принимать решение о приоритетах и ресурсообеспечении.

Крупные организации могут вести одновременно до 500 и более проектов. Связь каждого из них с КПЭ организации и их стратегическими целями непосредственно влияет на успешность всей организации. Необходимо умело распределять бюджеты и ресурсы. В условия стандартного портфельного управления планирование делается на срок от полугода до года, что в условиях крайней изменчивости как внешней так и внутренней среды организации может привести к упущению конкурентных преимуществ, недополучению прибыли или трате бюджета на неприбыльные или убыточные проекты. Но сложность краткосрочного планирования заключается в невозможности отслеживания всех малейших изменений в портфеле. Необходимо постоянно консолидировать информацию с множества функциональных подразделений, соотносить цели проектов и программ с целями организации, а также отслеживать ресурсообеспечение всего портфеля.

Но, несмотря на все трудности можно сказать, что гибкость организации это неотъемлемая черта управления необходимая для развития и процветания компании в современных условиях [2, с. 14].

Стеттина и Хорст $[14$, с. 53] использовали полуструктурированные интервью для сравнения компаний, занимающихся традиционным управлением портфелем с компаниями, которые практикуют гибкую методику управление портфелем. Они выяснили, что гибкое управление портфелем ведет к:

1- Прозрачность ресурсов и рабочих элементов, повышение доверия к принятию решений и распределению ресурсов.

2- Сотрудничество, тесное сотрудничество на основе взаимодействия позволяет частые итерации обратной связи.

3- Стремление к стратегически управляемому портфелю.

4- Ориентация команды, устранение проблем в распределении ресурсов и создание потенциала в командах.

Таким образом, можно вывести некоторые рекомендации для тех, кто стремится содействовать созданию гибкого подхода к финансированию портфеля проектов, управлению изменениями и управлению в целом.

Во-первых, быть в курсе процессов организации и умонастроений, которые формируют эти процессы [13, с. 45]. Вместо того чтобы просто выполнять процесс, потому что «это просто должно быть так», бросить вызов предположению, лежащие в основе - это либо усилит его значение или запустит процесс быстрого значимого изменения. Томас и Бэкер обнаружили, что принципы Agile, связанные с улучшением процесса, могут иметь дополнительное преимущество в этом контексте. В частности, привычка введения частых небольших улучшений (по нарастающей и итеративным способом) стремится обеспечить, чтобы процессы не становятся слишком устаревшими.

Во-вторых, необходимо быть вовлеченным в лидерские сообщества организации (как в ИТ, так и в бизнесе). Вместо того, чтобы надеяться на то, что они признают свои собственные устаревшие процессы и умонастроения, необходимо направлять их, чтобы определить, что работает хорошо и где существуют проблемы, и умышленно и намеренно внести изменения. Довольно часто, лидеры слишком вовлечены в процесс и его сложности (накопленный за эти годы), чтобы увидеть какой-либо другой способ работы. Необходимо создать благоприятные условия, чтобы сделать шаг назад и посмотреть на сложности, с альтернативных точек зрения (например, ограничений) и продолжить с новым набором идей.

В-третьих, нужно быть терпеливым в процессе приспособления гибкого подхода к финансированию, управлению изменениями и управлению в целом через корпоративную сеть предприятия. Вместо того, чтобы изменить все сразу, советуется сначала выбрать и взаимодействовать с одной или двумя бизнес-единицами, проанализировать результаты, а затем применить эти достижения уже к другому 
набору бизнес-единиц [6, с. 21]. В то время как все бизнес-единицы являются вариациями унаследованных процессов и менталитетов, каждый из них достаточно уникален, поэтому единый подход недостаточен и неприменим. Приняв и адаптировав гибкие методы в рамках каждого бизнес-единицы (и в общем, одна бизнес-единица за другой) можно получить возможность гибкого финансирования и управления портфелем и улучшить бизнес-ИТ выравнивание.

\section{Сиисок литературы / References}

1. Белозеров А. Управление портфелем проектов. Новые методологические подходы и инструменты (2015). [Электронный ресурс]. Режим доступа: http://www.iteam.ru/publications/project/section_38/article_3258/ (дата обращения 01.06.2016 г.).

2. Сценарии инновационного развития и глобализации российской отрасли информационных технологий. РВК, 2015.

3. Blichfeldt B.S., Eskerod P. Project portfolio management - There's more to it than what management enacts. International Journal of Project Management 26 (2008). 357-365.

4. Dickinson M.W., Thornton A.C., Graves S. Technology portfolio management: Optimizing interdependent projects over multiple time periods. IEEE Transactions on Engineering Management 48, (2011).

5. Gartner PPM Summit: Key Learnings for Every PMO 2016. [Электронный ресурс]: Innotas. Режим доступа: http://blog.innotas.com/gartner-ppm-summit-key-learningsevery-pmo/ (дата обращения: 20.06.2016).

6. Jordan A. (2015, June 18). Preparing for strategic agile. [Электронный ресурс]: Innotas. Режим доступа: Projectmanagement.com./ (дата обращения: 03.04.2017).

7. Hoda R., Kruchten P., Noble J., Marshall S., 2010. Agility in context. Proceedings of the ACM International Conference on Object Oriented Programming Systems Languages and Applications. ACM. NY. USA. P. 74-88.

8. Leffingwell D., 2011. Agile Software Requirements: Lean Requirements Practices for Teams, Programs, and the Enterprise (Agile Software Development Series). P. 132.

9. Project Management Institute. (2015. September). Pulse of the profession ${ }^{\circledR}$ : Capturing the value of project management through organizational agility. Newtown Square, PA: Author.

10. Project Management Institute. (2015b, November). Thought leadership series. The practitioner's perspective: Winning through project portfolio management. Newtown Square, PA: Author.

11. Raczka M. (2015, August). Becoming agile. One organization's experience with adopting agile practices proves instructive — and profitable. . PM Network ${ }^{\circledR} 29$ (8). 70.

12. Conboy K., 2009. Agility from first principles: reconstructing the concept of agility in information systems development. Info. Sys. Res. 20. 329-354.

13. Sull D. (2009, December). McKinsey Quarterly. Competing through organizational agility. Three distinct types of agility-strategic, portfolio, and operational- help companies compete.

14. Stettina C.J., Heijstek W., 2011. Five agile factors: helping self-management to selfreflect. Proceedings of European Software Process Improvement Conference (EuroSPI 2011), Roskilde, Denmark.

15. Thiry M. (2015, November). Agility is not just for projects. Crafting the agile organization. PMI Global Congress 2015-EMEA, London. UK.

16. PMI Thought Leadership Series Implementing the Project Portfolio: A Vital C-Suite, Project Management Institute, 2015.

17. PMI Thought Leadership Series Delivering on Strategy: The Power of Project Portfolio Management, Project Management Institute, 2015. 
18. PMI Thought Leadership Series The Practitioner's Perspective: Winning through Project Portfolio Management, Project Management Institute, 2015.

19. Project Portfolio Management Predictions for 2016. [Электронный pecypc]: Innotas. Режим доступа: http://blog.innotas.com/project-portfolio-management-predictions2016/ (дата обращения: 20.06.2016).

20. Rautiainen K., von Schantz J., Vahaniitty J., 2011. Supporting Scaling Agile with Portfolio Management: Case paf.com. IEEE Computer Society, Washington. DC. USA 1-10. Reyck. B. Grushka-Cock.

21. The Project and Portfolio Management Landscape. Innotas, 2016.

22. The Standard for Portfolio Management. Project Management Institute, 2006. 78 p.

23. The State of Project Portfolio Management (PPM), PM Solutions Research, 2013.

24. Thummadi B.V., Shiv O., Lyytinen K., 2011. Enacted Routines in Agile and Waterfall Processes. AGILE, IEEE Computer Society 67-76.

\title{
ВЛИЯНИЕ НЕ ЛИНЕЙНОЙ НАГРУЗКИ НА КАЧЕСТВО ЭЛЕКТРИЧЕСКОЙ СЕТИ Моргунов Д.Н. Email: Morgunov1799@scientifictext.ru
}

\author{
Моргунов Денис Николаевич - аспирант, \\ кафедра электроснабжения железнодорожного транспорта, \\ факультет систем обеспечения движения поездов, \\ Самарский государственный университет путей сообщения, г. Самара
}

\begin{abstract}
Аннотация: двадиать первый век - время новых технологий, повсеместно в компьютерной, оргтехнике и в светотехническом оборудовании используются малогабаритные импульсные источники питания. Применение импульсных источников оказывает серьезное влияние на работу электрооборудования, подключенного к одной с ними электрической сети. В статье раскрывается понятие не линейной нагрузки. Рассматривается влияние высших гармоник на трансформатор и сеть электроснабжения. Приведень решения исключения эмиссии гармонических составляющих.
\end{abstract}

Ключевые слова: электроприемник, не линейная нагрузка, импульсный источник питания, гармоника, трансформатор, эмиссия, ток, напряжении.

\section{EFFECT OF NON-LINEAR LOAD ON THE QUALITY OF THE ELECTRICAL NETWORK Morgunov D.N.}

\author{
Morgunov Denis Nikolayevich - Graduate Student, \\ DEPARTMENT ELECTRICITY SUPPLY OF RAILWAY TRANSPORT, \\ FACULTY OF TRAINS PROVISION SYSTEM, \\ SAMARA STATE TRANSPORT UNIVERSITY, SAMARA
}

\begin{abstract}
: twenty-first century - the time of new technologies, everywhere in computer, office equipment and lighting equipment small-sized switching power supplies are used. The use of pulsed sources has a serious impact on the operation of electrical equipment connected to the same electrical network. The notion of non-linear loading is disclosed in the article. The effect of higher harmonics on the transformer and the power supply network is considered. Solutions for the elimination of emission of harmonic components are given.
\end{abstract}

Keywords: electric receiver, non-linear load, switching power supply, harmonic, transformer, emission, current, voltage. 
В недавнем прошлом значительная часть электрической энергии использовалась потребителями с линейной вольтамперной характеристикой .....

\section{Влияние не линейной нагрузки на качество электрической сети.}

В 2016 году доля потребления Российскими железными дорогами электроэнергии в Российской федерации составила 4,5\%, из них $86 \%$ отводится на тягу поездов, $11 \%$ эксплуатационные нужды и 4\% прочее потребление (сторонние потребители не связанные с деятельностью компании)

В эксплуатационные расходы входит, в основной своей части, станочный парк, отопление, освещение и офисная техника.

Энергетическая стратегия ОАО «РЖД» на период до 2010 года и на перспективу до 2030 года, утвержденная распоряжением ОАО «РЖД» 11 февраля 2008 г. № 269p включает в себя 2 основных направления.

- значительное снижение удельного расхода топливно-энергетических ресурсов (далее - ТЭР) во всех сферах деятельности ОАО «РЖД»;

- оптимизация энергетических затрат в стационарной энергетике;

Оптимизация энергетических затрат необходима и если взять освещение хотя бы одной станции - (жигулевское море) наглядно видно, что экономия реально возможна путем модернизации.

Пример - средний годовой расход электроэнергии на освещение ст. Жигулевское море составляет порядка 530000 кВт*ч, что в переводе в рубли 1,637 миллиона рублей, если рассматривать в масштабах сети дорог из расчета, что всего в компании около 4000 станций то видно колоссальные затраты исчисляемые миллиардами. Применение энергосберегающих технологий (в данном случае светодиодных светильников) дает возможность снизить затраты в 3, а то и 7 раз, но необдуманное, массовое применение светодиодных светильников может дать и отрицательный результат, вплоть до массового выхода из строя электроустановок.

Различаются несколько видов электроприемников - именуемых как нагрузка, линейные и нелинейные сопротивления. Первым относятся наиболее знакомые лампы накаливания, нагревательные элементы, и другие резистивные нагрузки сопротивление которых не зависит от тока или приложенного к ним напряжения, ко вторым более сложные устройства, сопротивление которых зависит от протекающего по ним тока или приложенного напряжения.

В недалеком прошлом большая часть электрической энергии потреблялась линейными нагрузками, с конца 90-х годов резко увеличилась доля нелинейных электропотребителей. В первую очередь это персональные компьютеры и файлсерверы, принтеры, блоки бесперебойного питания, газоразрядные лампы другое офисное оборудование, также не составили исключения набирающие популярность светодиодные светильники, и светодиодные лампочки.

Россия столкнулась с новой серьезнейшей проблемой. Ее суть в том, что сети электроснабжения 0,4 кВ в зданиях, оснащенных компьютерной техникой, «заражены» высшими по отношению к промышленной частоте (50 Гц) гармониками.

В случаях, когда мощность нелинейных электропотребителей не превышает 10-15\%, каких-либо особенностей в эксплуатации системы электроснабжения не возникает. При превышении указанного предела появляются различные проблемы в эксплуатации [2].

Дело в том, что для электропитания перечисленного электронного оборудования используются встроенные импульсные источники питания, представляющие собой нелинейные нагрузки, сопротивление которых изменяется с течением времени. Они отличаются от прежних тем, что традиционный понижающий трансформатор и диод заменены на схему управления выпрямлением поступающего из сети тока.

Преимуществом такой схемы - для производителя оборудования - является значительное снижение размеров, стоимости и массы. Источник питания может 
изготавливаться практически любого форм-фактора. Недостатком - является то, что кроме преобразования переменного тока сети в выпрямленный ток, источник питания создает импульсы тока, содержащие большое количество гармоник третьего и более высокого порядков и значительные высокочастотные составляющие. Эти токи по сути являются несинусоидальным периодическим сигналом, который можно представить в виде суммы постоянной величины и бесконечного ряда синусоидальных сигналов с кратными частотами. На рис. 1 кривая тока, потребляемого импульсным источником, разложена в гармонический ряд. Очень хорошо видно, что третья гармоника исследуемого тока по величине составляет больше $80 \%$ от величины основной гармоники частотой 50 Гц.

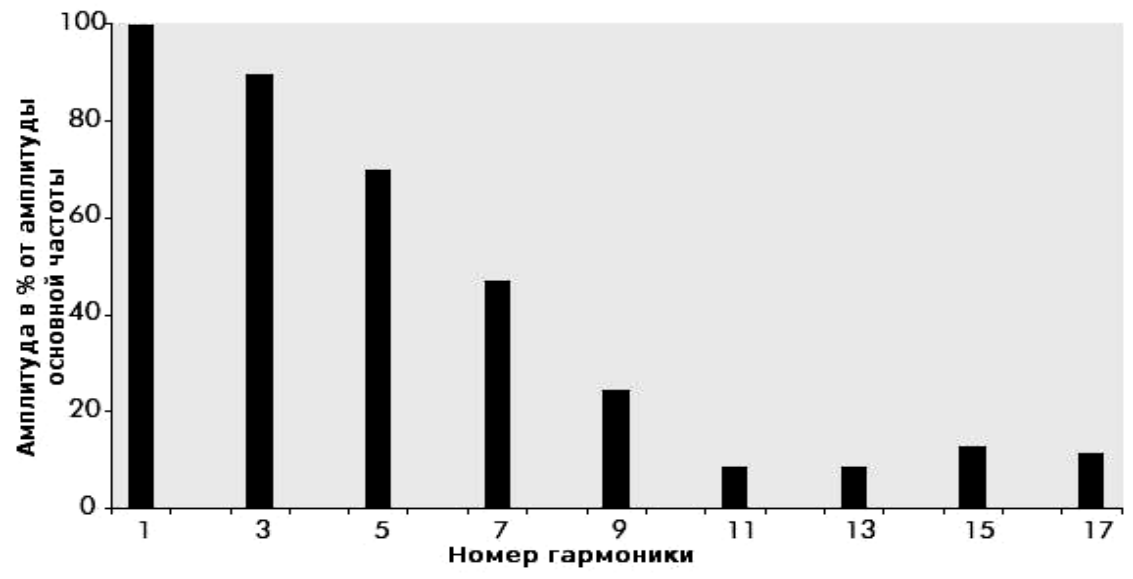

Рис. 1. Спектр гармоник типового ИП (гистограмма)

Гармоники порождаются нелинейными нагрузками, т.е. нагрузками, потребляющими ток с формой волны, отличающейся от формы волны питающего напряжения.

Примеры нелинейных нагрузок:

- промышленное оборудование (сварочные машины, электродуговые печи, индукционные печи и выпрямители);

- преобразователи частоты для асинхронных двигателей или двигателей постоянного тока;

- источники бесперебойного питания;

- офисное оборудование (компьютеры, фотокопировальные машины, серверные и др.);

- бытовые электроприборы (телевизоры, микроволновые печи, люминесцентные лампы);

- светодиодные светильники и лампы.

Нелинейные нагрузки потребляют токи гармоник, которые поступают в распределительную сеть. Гармоники напряжения вызываются протеканием токов гармоник по сопротивлениям питающих цепей (по трансформатору и распределительной сети) [3].

Влияние высших гармоник на сети очень велики, весьма вероятны перегрев и разрушение нулевых рабочих проводников кабельных линий вследствие их перегрузки токами третьей гармоники, когда токи в нулевых рабочих проводниках значительно превосходят токи фазных проводников, а защита от токовых перегрузок в цепях нулевых проводников не предусмотрена [1]. Необходимо также отметить ускоренное старение изоляции при повышении рабочей температуры токонесущих проводников. Нулевой рабочий проводник не защищен от перегрева автоматическими выключателями либо предохранителями [1]. 
Старые системы электроснабжения проектировались только под линейную нагрузку, т. е. потребляемый электроприемниками ток в своем гармоническом составе содержал лишь основную гармонику (50 Гц). Следовательно, ток в нулевом рабочем проводнике не мог превосходить ток в наиболее нагруженной фазе (защита, установленная на фазных проводниках, одновременно предохраняла от перегрева и нулевой рабочий проводник).

Нечетные гармоники в трехфазных цепях сдвинуты на 360 градусов друг к другу, совпадают по фазе и образуют нулевую последовательность. Нечетные гармоники, кратные третьей, суммируются в проводнике нейтрали (рис. 2).

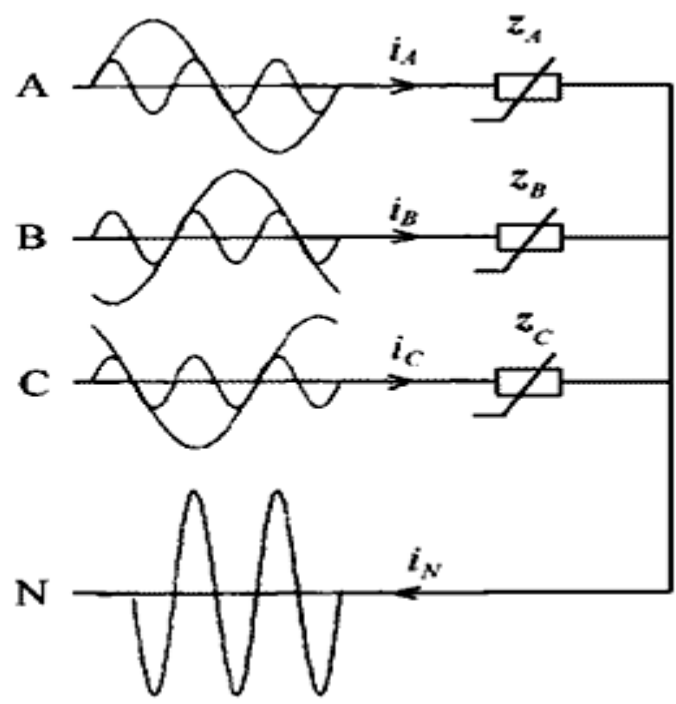

Рис. 2. Прочесс формирования тока нейтрали при нелинейной нагрузке [4]

Полная загрузка трансформатора наступает при использовании лишь $50 \%$ его номинальной мощности. Большинство производителей светодиодного оборудования уверяют, что проблема эмиссии гармонических составляющих (влияния на сети электроснабжения) в современном оборудовании решена путем установки в ИИП корректора коэффициента мощности (широтно-импульсная модуляция). Целью было сделать так, чтобы нагрузка источника питания выглядела как резистивная нагрузка, следовательно, входной ток имел синусоидальную форму и совпадал по фазе с приложенным напряжением. Это достигается за счет импульсного извлечения входного тока (как высокочастотного сигнала треугольной формы), из которого с помощью входного фильтра выделяется синусоида. Действительно коэффициент мощности увеличивается с 0,5 до 0,97 , более того прибор освещения действительно соответствует нормам эмиссии, но в тоже время приборы оборудованные ККМ (согласно требованиям госта), подключенные к трехфазной сети и имеющие высокий коэффициент, в группе оказывают не меньшее влияние на сеть. Данные явления с сочетанием светодиодного освещения мало изучены в виду того, что массовый характер светодиодного освещения наблюдается в последние 3 года с нарастающим. Светодиодный светильник как штучное изделие не представляет никакой опасности для электрической сети. Большинство производителей светотехнических изделий не занимаются проектными и электромонтажными работами, и как следствие не несут ответственности за качество электрической энергии применительно к комплексу работ. Особенно необходимы данные исследования для проектных институтов применительно к новым объектам и реконструкции существующих. 
На сегодняшний день найдены возможные пути решения проблемы, это изменение схемы электроснабжения Ү/Д, применение разделительных трансформаторов, применение источников малой мощности без коррекции мощности.

\title{
Сиисок литературы / References
}

1. Москва: Научно-технический центр по безопасности в промышленности «Правила устройства электроустановок», 2007. 584 с.

2. [Электронный peсурс]: Электротехника. Режим доступа: http://www.klmgroup.ru/ru/ enegineers/articles/vliyanie-garmonik-napryazheniya-i-toka/ (дата обращения: 13.03.2017).

3. [Электронный

pecypc]:

ВИКиЭлектро.

Режим

доступа: http://ru.electricalinstallation.org/ruwiki/ (дата обращения: 16.03.2017).

4. [Электронный ресурс]: Тенси плюс. Режим http://www.tensy.ru/article01.html/ (дата обращения: 25.03.2017).

доступа:

\section{ТУРБУЛЕНТНОЕ СМЕШЕНИЕ СТОЧНЫХ ВОД И ОЗОНО-ВОЗДУШНОЙ СМЕСИ Хангильдина A.P. Email: Khangildina1799@scientifictext.ru}

\author{
Хангильдина Адиля Рустэмовна - магистрант, \\ кафедра газохимии и моделирования химико-технологических прочессов, \\ Уфимский государственныій нефтяной технический университет, г. Уфа
}

\begin{abstract}
Аннотация: рассмотрен метод очистки сточных вод от трудноокисляемых загрязняющих веществ в мембранном реакторе, в котором совмещены прочессы мембранного разделения и каталитического окисления. В иелях полного смешения фаз предложен метод интенсификации растворения газов-окислителей в сточных водах путем использования трубчатого турбулентного аппарата диффузор-конфузорной конструкиии. В среде программирования Delphi 7 произведен расчет трубчатого турбулентного аппарата, показана возможность эффективного использования турбулентного аппарата диффузор-конфузорной конструкиии при смешении газовокислителей и сточных вод. Определены геометрические параметры аппарата.
\end{abstract}

Ключевые слова: очистка сточных вод, смешение газо-жидкостной смеси, трубчатый турбулентный аппарат, диффузор-конфузорная конструкция, перепад давления.

\section{TURBULENT MIXING OF WASTEWATER AND OZONE-AIR BLEND Khangildina A.R.}

\author{
Khangildina Adilya Rustemovna - Undergraduate, \\ DEPARTMENT OF GAS CHEMISTRY AND MODELING OF CHEMICAL PROCESSES, \\ UFA STATE PETROLEUM TECHNOLOGICAL UNIVERSITY, UFA
}

\begin{abstract}
: the method of wastewater treatment from hardly oxidizable contaminants in a membrane reactor in which processes of membrane separation and catalytic oxidation are combined was considered. For complete mixing of the phases there was proposed a method for intensifying the dissolution of oxidant gases in wastewater by using a tubular turbulent apparatus with diffuser-confusor construction. The tubular turbulent apparatus was calculated by the Delphi 7 programming environment and the possibility of effectively using of the
\end{abstract}


tubular turbulent apparatus with diffuser-confusor construction for mixing oxidant gases and wastewater was shown. The geometrical parameters of the apparatus are determined.

Keywords: wastewater treatment, gas-liquid mixture, tubular turbulent apparatus, diffuserconfuser design, pressure drop.

УДК 665.663

Для очистки сточных вод от трудноокисляемых загрязняющих веществ был разработан мембранный реактор, в котором совмещены процессы мембранного разделения и каталитического окисления $[1,2]$. Очищаемая от загрязняемых примесей вода из сырьевой емкости насосом подается под рабочим давлением трансмембранного фильтрования в сатуратор. С помощью эжектора в сатуратор поступают окислители в виде газов, например, кислород или его смесь с озоном. Из сатуратора после полного насыщения обрабатываемой жидкости окисляющим газом газонасыщенная реакционная смесь поступает в реактор с каталитически активными мембранами.

В разработанных схемах первым этапом является насыщение сточных вод газомокислителем путем их смешивания и отстаивания в сатураторе. Сатуратор - это емкостной аппарат, рассчитанный на определенное время пребывания в нем пузырьков газа и жидкости. Растворение газа в аппарате происходит в результате процессов межфазного переноса и диффузии компонентов. Однако в сатураторе не обеспечивается полное смешение фаз, существуют застойные зоны, в результате плохого диспергирования мала поверхность контакта фаз. Следовательно, сатуратор является достаточно пассивным аппаратом, который необходимо усовершенствовать либо применить другие более эффективные методы, позволяющие интенсифицировать процессы межфазного массообмена.

Существует множество методов интенсификации процессов смешения газожидкостной смеси. В таком качестве хорошо себя проявили трубчатые турбулентные аппараты диффузор-конфузорной конструкции [3]. Общий вид трубчатого турбулентного аппарата диффузор-конфузорной конструкции приведен на рисунке.

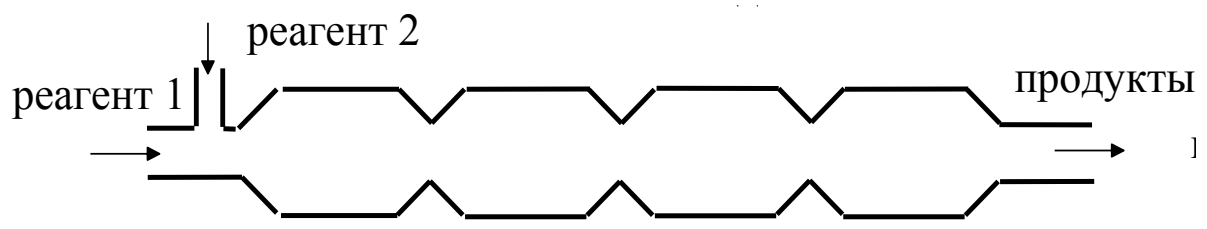

Рис. 1. Общий вид трубчатого турбулентного аппарата диффузор-конфузорной конструкиии

При прохождении потока жидкости через сужение аппарата, а затем через расширение, в потоке жидкости возникают вихреобразования, кавитации и отрывные течения. Возникающие в потоке эффекты воздействуют на частицы газа и жидкости и способствуют их интенсивной гомогенизации и дроблению, срыву пограничных слоев со стенок аппарата.

Изменение скорости движения потоков в аппаратах диффузор-конфузорной конструкции и соотношения диаметра диффузора $\mathrm{d} д$ к диаметру конфузора $\mathrm{d \kappa}(\mathrm{d} д / \mathrm{d} \kappa)$ является эффективным способом воздействия на характер диспергирования и качество получаемых эмульсий.

Рассмотрен метод интенсификации растворения газов-окислителей при очистке сточных вод в мембранных реакторах каталитического окисления путем использования трубчатого турбулентного аппарата диффузор-конфузорной конструкции перед сатуратором.

Для анализа работы установки в среде программирования Delphi 7 проведен расчет трубчатого турбулентного аппарата диффузор-конфузорной конструкции по методике, приведенной в работах $[3,4]$. Геометрические параметры аппарата также были выбраны на основе экспериментальных исследований, приведенных в работах $[4,5]$. 
Расчеты процесса турбулизации смеси «вода-газ» были проведены со следующими исходными данными: давление в аппарате $0,6 \mathrm{MПа,} \mathrm{температура} 50^{\circ} \mathrm{C}$, плотность

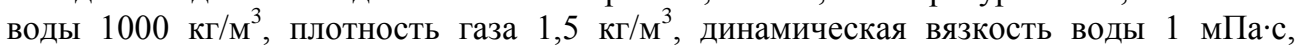
динамическая вязкость газа 0,0185 мПа·с.

Расчеты показали, что при числе диффузор - конфузорных секций равном 8, диаметре диффузора dд равном 0,048 м, диаметра конфузора dк равном 0,016 м и объемных расходах газа и жидкости по $0,000278 \mathrm{~m} / \mathrm{c}$, осуществляется полное перемешивание газо-жидкостной смеси, способствующее эффективному межфазному массообмену. Перепад давления в аппарате составил 0,017 МПа, что находится в допустимых пределах.

Таким образом, трубчатый турбулентный аппарат диффузор-конфузорной конструкции может эффективно использоваться при смешении газов-окислителей и сточных вод.

\section{Список литературы / References}

1. Ягафарова Г.Г., Аминова А.Ф., Сухарева И.А., Хангильдина А.Р., Хангильдин Р.И. Разработка метода очистки сточных вод от трудноокисляемых органических соединений // Вода: химия и экология, 2016. № 1. С. 24-29.

2. Патент РФ №2572132 Установка для очистки воды каталитическим окислением / Хангильдин Р.И., Баландина А.Г., Шундеева Е.В., Мартяшова В.А, Фаттахова А.М., Хангильдина А.Р. // Патентообладатель ФГБОУВПО УГНТУ. № 2014109757/05 заявл. 13.03.2014; опубл. 27.12.2015. Бюлл. № 36 .

3. Умергалин Т.Г., Шевляков Ф.Б., Захаров В.П., Баулин О.А. Гидродинамические особенности работы трубчатых турбулентных аппаратов применительно к извлечению высококипящих углеводородов из попутного нефтяного газа // Башкирский химический журнал, 2011. Т. 18. № 2. С. 156-161.

4. Мурзабеков Б.Е., Шевляков Ф.Б., Умергалин Т.Г., Захаров В.П. Отмывка газового конденсата от солей в трубчатом турбулентном аппарате диффузор-конфузорной конструкции // Вестник Башкирского университета, 2012. Т. 17. № 1. С. 36-38.

5. Шевляков Ф.Б., Захаров В.П., Каеем Д.Х., Умергалин Т.Г. Совершенствование процесса доизвлечения высококипящих углеводородов попутного нефтяного газа в турбулентных аппаратах диффузор-конфузорной конструкции // Вестник Башкирского университета, 2008. Т. 13. № 4. С. 916-918. 


\title{
НЕКОТОРЫЕ ВОПРОСЫ СОВЕРШЕНСТВОВАНИЯ ПЕНСИОННОГО ОБЕСПЕЧЕНИЯ ОТДЕЛЬНЫХ КАТЕГОРИЙ ГРАЖДАН В РЕСПУБЛИКЕ УЗБЕКИСТАН Юлдашева Н.В. ${ }^{1}$, Хамраева Ф.Ш. ${ }^{2}$ Email: Yuldasheva1799@scientifictext.ru \\ ${ }^{1}$ Юлдашева Надира Викторовна - стариий преподаватель; \\ ${ }^{2}$ Хамраева Фируза Шодибековна - преподаватель, кафедра пенсионного дела, \\ Ташкентский финансовый институт, \\ 2. Ташкент, Республика Узбекистан
}

\begin{abstract}
Аннотация: в приведённой статье рассматривается сущность системь пенсионного обеспечения, особенности и этапы становления и развития системь государственного пенсионного обеспечения в Республике Узбекистан, приведень данные по прогнозу демографических показателей, а также проделан анализ финансовых показателей деятельности внебюджетного Пенсионного фонда при Министерстве финансов Республики Узбекистан за ряд лет, в частности источники формирования доходов фонда и направления расходования средств фонда, подведень итоги и выявлены недостатки действующей системы пенсионного обеспечения в Республике Узбекистан.
\end{abstract}

Ключевые слова: пенсионная система, пенсионное страхование, Пенсионный фонд, пенсионеры, доходы фонда, отчисления работодателя, страховые взносы граждан, расходы фонда, расходьл на выплату пенсий неработающим и работающим пенсионерам, социальные пособия.

\section{SOME ISSUES OF IMPROVING THE PENSION PROVISION OF CERTAIN CATEGORIES OF CITIZENS IN THE REPUBLIC OF UZBEKISTAN Yuldasheva N.V. ${ }^{1}$, Hamrayeva F.Sh. ${ }^{2}$ \\ ${ }^{I}$ Yuldasheva Nadira Victorovna - Senior Lecturer; \\ ${ }^{2}$ Hamrayeva Firuza Shodibekovna - Lecturer, DEPARTMENT OF PENSION WORK, TASHKENT FINANCIAL INSTITUTE, TASHKENT, REPUBLIC OF UZBEKISTAN}

\begin{abstract}
: this article provides the nature of the pension system, the features and stages of the establishment and development of the state pension system in the Republic of Uzbekistan, presents data on the forecast of demographic indicators, and analyzes the financial performance of the extra-budgetary Pension Fund under the Ministry of Finance of the Republic of Uzbekistan for a number of years, in particular the sources of the fund's income formation and the direction of spending of the fund's resources, the results are summed up and the shortcomings of the current pension system in the Republic of Uzbekistan are revealed.

Keywords: pension system, pension insurance, the Pension fund, pensioners, income of fund, expel of the employer, insurance premiums of citizens, expenses of fund, expenses on payment of pensions to the unemployed and the working pensioners, social benefits.
\end{abstract}


Одним из основных принципов разработанной узбекской модели развития является сильная социальная политика, в то время как одним из её важных элементов выступает система пенсионного обеспечения. Процесс поэтапного перехода к рыночным отношениям потребовал адекватного реформирования пенсионной системы, которая последовательно была преобразована из централизованной системы государственного пенсионного обеспечения в систему обязательного пенсионного страхования, способную самостоятельно, при координации государства, адаптироваться к механизмам рыночного развития [1].

Пенсионная система независимого Узбекистана прошла опредёленное историческое развитие. Исторические истоки возникновения системы пенсионного обеспечения республики относят к XX веку, то есть веком спустя после возникновения систем пенсионного обеспечения в таких развитых странах как Германия, Дания, Великобритания, Швеция [2].

Изучая множество учебной и историко-познавательной литературы по становлению и развитию системы пенсионного обеспечения республики многие авторы сходятся на той точки зрения, что система пенсионного обеспечения Республики Узбекистан в своём развитии прошла 5 этапов: первый этап (19171956 гг.); второй этап (1956 - 1990 гг.); третий этап (1991 - 1993 гг.); четвёртый этап (1994 - 2001); пятый этап (2002 - по настоящее время).

Система пенсионного обеспечения Республики Узбекистан на современном этапе экономического развития представляет собой двухуровневую систему. Первый уровень - система государственного пенсионного обеспечения, основанная на распределительном принципе (солидарность поколений, второй уровень - система накопительного пенсионного обеспечения.

За годы независимости прошли существенные реформы в системы пенсионного обеспечения республики, а в частности в деятельности Пенсионного фонда. Особое внимание было уделено обеспечению финансовой стабильности, совершенствованию нормативно-правовой базы, улучшению материально-технической базы территориальных подразделений Пенсионного фонда. В целях дальнейшего развития пенсионной системы Кабинетом Министров Республики Узбекистан была утверждена программа Комплекса «Стабильное развитие системы государственного пенсионного обеспечения на 2012 - 2016 гг., улучшение условий по предоставлению гарантий гражданам по государственным пенсиям посредством создания благоприятной социальной среды».

На сегодняшний день общее количество лиц пенсионного возраста в республике составляет свыше 3 млн. человек. В Узбекистане темпы прироста пожилого населения значительно ниже, чем в других странах. Прогноз демографических показателей подтверждает мнение, что после 2016 года ожидается существенное изменение структуры населения за счёт постепенного роста населения старших возрастных групп с 6\% в 2003 году до $8.5 \%$ в 2020 году [3].

Как показывают данные таблицы, в 2003 году при общей численности населения 25928 тыс. чел. доля населения старше 60 лет составляла $6.03 \%$, в 2017 году при общей численности населения 30845 тыс. чел доля их доля составила $7.41 \%$. В последние годы наблюдается увеличение средней продолжительности жизни населения. Так средняя продолжительность жизни женщин в республике составляет 78 лет, а мужчин 73 года. 
Таблища 1. Прогноз демографических показателей (тыс. чел.)*

\begin{tabular}{|c|c|c|c|c|c|c|}
\hline \multirow{2}{*}{ Год } & \multicolumn{4}{|c|}{ Население } & \multirow{2}{*}{$\begin{array}{c}\text { Коэффициент роста } \\
\text { населения }\end{array}$} & \multirow{2}{*}{$\begin{array}{c}\text { Процент } \\
\text { населения 60+ }\end{array}$} \\
\hline & всего & $<16$ & $16-59$ & $60+$ & & \\
\hline 2003 & 25928 & 11833 & 12532 & 1562 & $1,19 \%$ & $6,03 \%$ \\
\hline 2004 & 26224 & 11703 & 12991 & 1530 & $1,14 \%$ & $5,84 \%$ \\
\hline 2005 & 26512 & 11536 & 13458 & 1518 & $1,10 \%$ & $5,72 \%$ \\
\hline 2006 & 26813 & 11373 & 13913 & 1528 & $1,14 \%$ & $5,70 \%$ \\
\hline 2007 & 27129 & 11228 & 14355 & 1546 & $1,18 \%$ & $5,70 \%$ \\
\hline 2008 & 27459 & 11110 & 14781 & 1568 & $1,22 \%$ & $5,71 \%$ \\
\hline 2009 & 27805 & 11003 & 15189 & 1613 & $1,26 \%$ & $5,80 \%$ \\
\hline 2010 & 28162 & 10883 & 15609 & 1671 & $1,29 \%$ & $5,93 \%$ \\
\hline 2011 & 28530 & 10766 & 16029 & 1735 & $1,31 \%$ & $6,08 \%$ \\
\hline 2012 & 28906 & 10676 & 16427 & 1803 & $1,32 \%$ & $6,24 \%$ \\
\hline 2013 & 29287 & 10617 & 16797 & 1873 & $1,32 \%$ & $6,40 \%$ \\
\hline 2014 & 29674 & 10567 & 17152 & 1955 & $1,32 \%$ & $6,59 \%$ \\
\hline 2015 & 30065 & 10532 & 17483 & 2050 & $1,32 \%$ & $6,82 \%$ \\
\hline 2016 & 30457 & 10533 & 17765 & 2159 & $1,30 \%$ & $7,09 \%$ \\
\hline 2017 & 30845 & 10576 & 17984 & 2285 & $1,27 \%$ & $7,41 \%$ \\
\hline 2018 & 31226 & 10644 & 18160 & 2422 & $1,24 \%$ & $7,76 \%$ \\
\hline 2019 & 31598 & 10716 & 18316 & 2566 & $1,19 \%$ & $8,12 \%$ \\
\hline 2020 & 31958 & 10788 & 18451 & 2719 & $1,14 \%$ & $8,51 \%$ \\
\hline
\end{tabular}

*Источник: данные приведены по [3].

Государственное пенсионное обеспечение в Республике осуществляется за счёт Внебюджетного Пенсионного фонда Республики Узбекистан, который формируется за счёт обязательных отчислений работодателей, социальных взносов работников и иных поступлений.

Так анализируя динамику исполнения доходной части Пенсионного фонда можно привести следующие данные: более $50 \%$ доходной базы формируют отчисления работодателей (т.е. единый социальный платёж), около $15 \%$ доходов фонда приходится на социальные взносы работодателей, обязательные отчисления работодателей от объёма реализации продукции от $8-14 \%$, иные доходы порядка $8 \%$, остаток на начало года порядка $15 \%$.

Ниже в таблице приведена динамика расходов внебюджетного Пенсионного фонда Республики Узбекистан за 2013 - 2016 гг.

Как видно из таблицы за период с 2013 - 2016 гг. темпы роста расходов фонда составили $175.8 \%$. Основную долю расходов составляют расходы Пенсионного фонда по выплате пенсий неработающим пенсионерам. Так на данный вид расхода приходится в среднем около 80-83\% всех расходов фонда. На финансирование расходов по выплате пенсий работающим пенсионерам приходится около $3 \%$. 
Таблииа 2. Динамика расходов внебюджетного Пенсионного фонда при Министерстве финансов Республики Узбекистан за 2013 - 2016 г2.*

\begin{tabular}{|c|c|c|c|c|c|c|c|c|}
\hline \multirow{2}{*}{ Показатели } & \multicolumn{2}{|c|}{$\mathbf{2 0 1 3}$ год } & \multicolumn{2}{c|}{$\mathbf{2 0 1 4}$ год } & \multicolumn{2}{c|}{$\mathbf{2 0 1 5}$ год } & \multicolumn{2}{c|}{ 2016 год } \\
\cline { 2 - 9 } сумма & \% & сумма & \% & сумма & \% & сумма & \% \\
\hline Расходы & 10302,1 & 100 & 13013,7 & 100 & 16557,0 & 100 & 18113,3 & 100,0 \\
\hline $\begin{array}{c}\text { Расходы по } \\
\text { выплате пенсий } \\
\text { неработающим } \\
\text { пенсионерам }\end{array}$ & 9097,9 & 88,3 & 11191,9 & 86,0 & 12838,1 & 77,5 & 14779,6 & 81,6 \\
\hline $\begin{array}{c}\text { Расходы по } \\
\text { выплате пенсий } \\
\text { работающим } \\
\text { пенсионерам }\end{array}$ & 317,4 & 3,1 & 426,6 & 3,3 & 474,8 & 2,9 & 484,3 & 2,7 \\
\hline $\begin{array}{c}\text { Пособия } \\
\text { престарелым и } \\
\text { нетрудоспособным } \\
\text { гражданам, } \\
\text { пособия на } \\
\text { погребение и } \\
\text { другие выплаты }\end{array}$ & 20,5 & 0,2 & 29,1 & 0,2 & 105,2 & 0,6 & 152,1 & 0,8 \\
\hline Прочие расходы & 2,1 & 0,0 & 2,4 & 0,0 & 2,8 & 0,0 & 3,0 & 0,0 \\
\hline $\begin{array}{c}\text { Остаток на начало } \\
\text { года }\end{array}$ & 864,2 & 8,4 & 1363,7 & 10,5 & 3136,1 & 19,0 & 2694,3 & 14,9 \\
\hline
\end{tabular}

*Источник: данные Министерства финансов Республики Узбекистан.

Таким образом, подводя итоги вышесказанному хотелось выделить следующие недостатки системы государственного пенсионного обеспечения в Республике Узбекистан: наличие множества льготных пенсий, нет взаимозависимости размеров пенсий от продолжительности участия в формировании Пенсионного фонда, то есть необходимо внедрение в практику понятия «страховой стаж», а также пересмотр выхода на пенсию и выравнивание условий на пенсионное обеспечение для мужчин и женщин.

\section{Сиисок литературы / References}

1. Умурзаков Б.Х. Социально-экономическая сущность пенсионных взносов и налоговых платежей населения// Материалы республиканской научнопрактической конференции «Перспективы развития системы пенсионного обеспечения». Т.: «Университет», 2014. С. 3-7.

2. Юлдашева Н.В., Турсунов Ж.П. История возникновения и становления пенсионных стран мира // Проблемы современной науки и образования, 2017. № 4 (86). C. 40-43.

3. Умурзаков Б.Х. Социальные и демографические особенности совершенствования пенсионного обеспечения Узбекистана.// Материалы республиканской научнопрактической конференции «Финансирование пенсионной системы: зарубежный опыт и перспективы совершенствования». Т.: ТФИ, 2017. С. 7-11. 


\title{
МЕРОПРИЯТИЯ ПО СНИЖЕНИЮ ЗАТРАТ НА ВЫПУСК ПРОДУКЦИИ НА ПРЕДПРИЯТИИ ЗАО «ХЛЕБОЗАВОД № 28» \\ Сергунина E.B. Email: Sergunina1799@scientifictext.ru
}

Сергунина Евгения Викторовна - студент, факультет экономики и финансов,

Российский государственный аграрныий университет

Московская сельскохозяйственная академия им. К.А. Тимирязева, г. Москва

\begin{abstract}
Аннотация: в рамках представленной статьи проанализированы мероприятия, которые способствуют снижению затрат на выпуск продукции на примере конкретного предприятия - $3 A O$ «Хлебозавод № 28». Проведен анализ рентабельности экономного расхода сырья на предприятии, снижения текущих затрат в современных условиях. Также разработаны рекомендачионные меры, которые способны стимулировать снижение затрат на предприятии. Даны числовые показатели экономической эффективности применения рекомендационных мер. Сделань выводы, касаемо необходимости применения мероприятий по снижению затрат на предприятии 3 АО «Хлебозавод № 28».
\end{abstract}

Ключевые слова: снижение затрат, рекомендации, сырьевая база, производство, управление ресурсами.

\section{MEASURES TO REDUCE THE COST OF PRODUCTION AT THE ENTERPRISE CJSC "BAKERY № 28" Sergunina E.V.}

\author{
Sergunina Eugenia Victorovna - Student, \\ FACULTY OF ECONOMICS AND FINANCE, \\ RUSSIAN STATE AGRARIAN UNIVERSITY \\ MOSCOW AGRICULTURAL ACADEMY NAMED AFTER K.A. TIMIRYAZEV, MOSCOW
}

\begin{abstract}
: within the framework of the presented article, measures are analyzed that reduce the cost of production by the example of a particular enterprise - CJSC "Bakery № 28". The analysis of profitability of economical consumption of raw materials for enterprises, reducing current costs in modern conditions is carried out. Also, recommendatory measures have been developed that can stimulate the reduction of costs in the enterprise. Numerical indicators of economic efficiency of application of recommendation measures are given. Conclusions are drawn regarding the need to apply measures to reduce costs at the enterprise CJSC "Bakery № 28".
\end{abstract}

Keywords: cost reduction, recommendations, raw materials base, production, resource management.

УДК 338.984

Важнейшим показателем экономической деятельности любого предприятия является прибыль. Она зависит, в основном, от цены продукции и затрат на ее производство. Проблемы снижения затрат на предприятии, поиска путей их решения являются сложными и интересными вопросами современной экономики предприятия [1].

Актуальность выбранной темы обусловлена тем, что управление затратами означает, прежде всего поиск возможностей снижения себестоимости (текущих) затрат, что является важнейшим фактором развития экономики предприятия. От их уровня зависят финансовые результаты деятельности и финансовое состояние хозяйствующих субъектов.

Для обеспечения экономного расхода сырья на предприятии должен осуществляться строгий контроль количественных показателей технологического процесса. Увеличение 
затрат и потерь указывают на недостатки в организации и ведении производственного процесса, а устранение их приводит к экономии сырья [2].

Таким образом, на предприятии можно предложить ряд мероприятий по снижению затрат:

\section{1. Снизить потери при транспортировке муки.}

Потери муки в зависимости от объема склада, способа хранения различны и могут достигать от 0,2 до $1 \%$ от объема муки. Из существующих способов хранения муки (тарный и бестарный) - наиболее эффективным является бестарный. Однако при этом способе потери муки в результате распыла из-за негерметичности соединений элементов трубопроводов и оборудования могут достигать 0,6-0,8\%.

Потери при тарном хранении выше в 3-4 раза и вызываются:

- распылом муки,- остатком ее в мешках (40-50 г на 1 мешок);

- загрязнением муки, попавшей на пол.

Для снижения потерь в тарных складах необходимо аккуратно засыпать муку, выворачивая и стряхивая мешки над приемной воронкой; устанавливать пылесосы над загрузочной воронкой; предохранять мешки с мукой от повреждения и намокания. Необходимо обеспечивать герметизацию оборудования в мучных линиях, а лучше производство оборудовать мукопроводами.

\section{2. Уменьшение затрат муки при разделке теста.}

Затраты муки на разделку вызваны тем, что при замесе вода на эту часть муки не рассчитывается и не добавляется, что приводит к некоторому снижению выхода хлеба. Затраты в перерасчете на муку составляют 0,6-0,8\%. Некоторые виды хлеба (Рижский) должны иметь мучнистую корку, что требует на разделку значительного расхода муки.

Основным затруднением при механизированном производстве хлеба является прилипание теста к рабочим поверхностям тесторазделочных машин, транспортерным лентам, расстойных устройств. Это вызывает необходимость на всех участках применять подсыпку мукой или смазку маслом, сто приводит к дополнительным непроизводительным затратам сырья. Обработка таких поверхностей водоотталкивающими материалами в сочетании с обдувкой теплым воздухом способствует снижению потерь муки при разделке теста до $0,08 \%$. Технология обработки полимерными материалами оборудования, в основном, сводится к способам крепления пластин фторопласта к деталям машин, гидрофобизации тканей и транспортерных лент кремний-органической жидкостью, нанесения этой жидкости на металлические детали.

Внедрение полимерных материалов улучшает санитарное состояние цехов, снижает загрязненность воздуха мучной пылью, а также сокращает расход муки на подсыпку. Облегчается труд рабочих, улучшается качество продукции.

\section{3. Снижение упека хлебных изделий.}

Большой удельный вес в потерях составляет упек хлебобулочных изделий. В среднем при выпечке подовых изделий упек составляет 7-8,5\% массы теста, или 11-13\% к массе переработанной муки. Снижение упека на 0,5\% экономит около 2,5 кг муки на 1 т хлеба. Для снижения упека поддерживают рациональный режим выпечки изделий, обеспечивают достаточное увлажнение заготовок в начале выпечки и опрыскивание изделий перед выходом из печи (последняя операция снижает упек на $0,05 \%$ ).

С целью экономии материальных ресурсов необходимо не только снижать упек, но и выравнивать его на люльке или поду печи. Неравномерность упека приводит к утолщению корок изделий, слишком темной колеровке их поверхностей, т.е. к излишним затратам и соответственно к уменьшению выхода хлеба. Одним из способов выравнивания упека, является экранирование греющих поверхностей в печи укладкой асбестовых листов на место с избыточной теплоотдачей.

Существенным фактором, влияющим на величину упека подовых изделий, является увлажнение тестовых заготовок в начальной зоне выпечки и относительная влажность среды в различных зонах пекарной камеры. При повышенном упеке 
целесообразно применять водяное опрыскивание тестовых заготовок или готовой продукции при выходе из печи. При выпечке изделий наряду с увлажнением тестовых заготовок необходимо достаточное паровое увлажнение среды пекарной камеры. Расход пара при этом должен составлять примерно 200-250 кг на 1 т. продукции. Тепловой режим печи является определяющим фактором величины упека. Выпечку целесообразно проводить в условиях наиболее высокой температуры $\left(270-300^{\circ} \mathrm{C}\right)$, а затем при температуре $180-200^{\circ} \mathrm{C}$.

\section{4. Снижение усушки хлебных изделий.}

На хлебопекарных предприятиях пшеничный хлеб может храниться от момента выпечки до отправки в торговую сеть до 10 часов, а ржаной - до 14 часов. За этот срок в хлебе происходит потеря влаги за счет разности температур изделий и окружающей среды. Чем больше разность температур хлеба и окружающего воздуха, тем выше усушка.

Для снижения усушки горячие изделия необходимо быстро охладить. Краткосрочное хранение изделий рекомендуется организовать в закрывающихся вагонетках или закрытых камерах согласно технологической инструкции по увеличению сроков сохранения хлеба в свежем виде. Применение камер для хранения хлеба с кондиционированием воздуха приводит к значительному снижению усушки (до 1-1,5\%), а закрытых вагонеток или контейнеров (до 1,5-2\%) за 10-18 часов хранения.

Уменьшение усушки является важным мероприятием в ликвидации внепроизводственных затрат. Снижение усушки на 1\% повышает выход хлеба на 1,7\%.

\section{5. Вторичная переработка брака.}

Потери от переработки брака $(0,02-0,03 \%$ к массе муки) обусловлены тем, что часть продукции при этом идет в отходы (подгоревшие изделия, загрязненные и др.).

Потери от крошек и лома вызываются неисправным состоянием хлебных форм, деформацией изделий при выбивке из форм, транспортировке и укладке в лотки.

Отходы ржаного хлеба (черствый хлеб или хлеб с дефектом) используют в виде мочки, добавляемой затем в тесто. Такой хлеб тщательно осматривают, горелые корки срезают. Затем хлеб замачивают в воде и измельчают на мочкотерке до однородной массы влажностью 70-80\% . Затем мочка поступает через жидкостные дозаторы на замес теста. Максимальная дозировка мочки для теста из ржаной и ржано-пшеничной обойной муки $10 \%$ (от общего расхода муки), из муки пшеничной обойной - 5\%, из муки пшеничной 2 сорта - 2,5\%. Мочку добавляют также в хлеб из муки обдирной и муки смешанной валки.

В тесто из пшеничной муки первого и высшего сорта мочку не добавляют, т.к. оно затемняет мякиш и повышает кислотность изделия. Добавление мочки в определенных пределах ускоряет брожение и созревание теста и улучшает качество хлеба.

На некоторых предприятиях отходы хлеба, подлежащего переработке, не замачивают в воде, а измельчают в крошку, которую тоже добавляют в тесто. Хлебную крошку нужно расходовать на те сорта изделий, из которых она получена. Для использования крошку тщательно осматривают, чтобы не допустить в переработку горелую или загрязненную. Перед употреблением ее просеивают. Обычная дозировка хлебной крошки для хлеба, батонов, булок 2-3 кг на 100 кг муки в тесте. Мочка и крошка должны быть израсходованы не позже, чем через 24 часа после приготовления [3].

Средние потери муки при производстве хлеба на основных операциях приведены в таблице 1.

Таблица 1. Средние потери муки при производстве хлеба

\begin{tabular}{|c|c|}
\hline Операция & Потери, \% (к массе муки) \\
\hline $\begin{array}{c}\text { Транспортирование муки, способы } \\
\text { хранения }\end{array}$ & $0,2-1,0$ \\
\hline Приготовление теста & $2,5-3,3$ \\
\hline Разделка теста & $0,6-0,8$ \\
\hline
\end{tabular}


Экономия сырья при производстве хлеба имеет огромное значение, так как стоимость сырья является основным элементом себестоимости изделий (около 80$85 \%$ суммы всех затрат).

\section{Список литературы}

1. Сергеев И.В. Экономика предприятия: учебное пособие для бакалавров / И.В. Сергеев. 5-е издание, исправленное и дополненное./ М: Юрайт, 2013. 671 с.

2. Мармузова Л.В. Технология хлебопекарного производства. М.: Издательский центр «Академия», 2013. 288 с.

3. Хамельман Джеффери. Хлеб. Технология и рецептуры. Пер. с англ. О.П. Четвериковой. СПб.: Профессия, 2012. 432 с. 


\title{
НЕКОТОРЫЕ ВОПРОСЫ СОВЕРШЕНСТВОВАНИЯ ПАРЛАМЕНТСКОГО КОНТРОЛЯ В РЕСПУБЛИКЕ КАРАКАЛПАКСТАН \\ Иматов A.M. Email: Imatov1799@scientifictext.ru
}

Иматов Азат Маратович - стариий научный сотрудник-соискатель, кафедра правоведения,

Каракалпакский государственный университет им. Бердаха, г. Нукус, Республика Каракалпакстан

\begin{abstract}
Аннотация: в этой статье анализируются некоторые теоретические и правовые вопросы совершенствования парламентского контроля в Республике Каракалпакстан. Проанализированы теоретические подходы к понятию, сущности и особенностям контрольной деятельности в иелом, а также государственного и парламентского контроля. Также в статье рассматриваются и анализируются формы парламентского контроля в Республике Каракалпакстан. Дается оиенка эффективности осуществления парламентского контроля парламентом Каракалпакстана на современном этапе развития страны. Затрагиваются вопросы о направлениях совершенствования парламентского контроля.
\end{abstract}

Ключевые слова: Жокаргы Кенес Республики Каракалпакстан, парламентский контроль, формы парламентского контроля, закон, государственный контроль.

\section{SOME QUESTIONS OF PERFECTION OF PARLIAMENTARY CONTROL IN THE REPUBLIC OF KARAKALPAKSTAN Imatov A.M.}

\author{
Imatov Azat Maratovich - Senior scientific researcher, \\ LAW DEAN AT THE KARAKALPAK STATE UNIVERSITY AFTER THE NAME OF BERDAKH, \\ NUKUS, REPUBLIC OF KARAKALPAKSTAN
}

\begin{abstract}
: in this article was analyzed some theoretical and legal problems on improving parliamental control in the Republic of Karakalpakstan. The authors analyze the theoretical approaches towards nature, definition and specificities of the control activities in general, and state and parliamentary control in particular. Also, the article examines and analyzes the forms of parliamentary control in the Republic of Karakalpakstan.The assessment of the effectiveness of the execution of the Parliament control by the Parliament of Karakalpakstan on the modern stage of the country's development is given. The problems of the trends of the improvement of the Parliament control are touched.
\end{abstract}

Keywords: Jokargy Kenges of Karakalpakstan, parliamental control, forms of parliamental control, law, state control.

УДК 342.533

Как известно, одним из самых действенных влияний парламента на жизнедеятельность общества оказывает его деятельность в сфере контроля. В ряде юридических литературы дискуссионным является вопрос о соотношении парламентского и общественного контроля. Некоторые ученые трактуют парламентский контроль как основную форму государственного [1, 72]. Существует мнение, что парламентский контроль носит политический характер и является его разновидностью. «Необходимо иметь в виду, - пишет Н.М. Добрынин, - что парламентский контроль часто называют политическим, в том смысле, что контрольные полномочия парламента основываются не только на его собственных правах, установленных законодательством, 
но и на мнении избирателя, которые выражают верховную власть любого демократического государства» $[2,16]$. Думается, что парламентский контроль не является сугубо государственным. Он представляет собой опосредованную форму общественного контроля, своего рода «мостик» между общественным и государственным контролем. Иными словами является наиболее организованной, структурированной, методически отработанной его частью.

Следует отметить, что в Каракалпакстане конституционно закреплен принцип разделения власти [3]. Согласно статье 68 Конституции Республики Каракалпакстан, высшим государственным представительным органом власти является Жокаргы Кенес Республики Каракалпакстан, осуществляющий законодательную власть. В Конституции и законодательстве предусматривается, что от имени народа Каракалпакстана может выступать только избранный им Жокаргы Кенес республики, никакая часть общества, политическая партия, общественное объединение, движение или отдельное лицо не могут выступать от имени народа Республики Каракалпакстан [4].

Обращаясь к зарубежному опыту законодательного закрепления норм в сфере парламентского расследования, можно выделить ст. 53 Конституции Австрии, ст. 56 Конституции Бельгии, ст. ст. 44 и 45a2 Конституции ФРГ, ст. 68 Конституции Греции, ст. 51 Конституции Дании, ст. 76 Конституции Испании, ст. 82 Конституции Италии, ст. 64 Конституции Люксембурга, ст. 181 Конституции Португалии, гл. 4 Конституции Швеции, ст. 62 Конституции Японии. В Российской Федерации же принят отдельный Закон «О парламентском расследовании».

Согласно принятой в апреле 2014 года поправке к Конституции Республики Каракалпакстан, парламент страны Жокаргы Кенес Республики Каракалпакстан вправе осуществлять парламентского контроля [5]. Но отсутствие единого отдельного нормативно-правового акта, направленного на регулирование правовых основ контрольно-аналитической деятельности парламента приводило к многим организационным и правовым проблемам. Поэтому в целях систематизации, кодификации правовых норм законодательных актов, регулирующих парламентский контроль, создания действенного механизма основных положений Конституции, повышения эффективности правового регулирования контрольно-аналитической деятельности двухпалатного парламента в качестве важного направления реализуемых конституционных реформ принятие 28 декабря 2016 года Жокаргы Кенесом Закона Республики Каракалпакстан «О парламентском контроле» имеет огромное значение [6].

На сегодняшний день в нашей стране реализуются следующие виды парламентского контроля (в ст. 5 Закона «О парламентском контроле»):

- принятие Государственного бюджета Республики Каракалпакстан, а также рассмотрение хода исполнения Государственного бюджета;

- рассмотрение отчета Председателя Совета Министров Республики

Каракалпакстан по отдельным актуальным вопросам социально-экономического развития страны;

- рассмотрение ежегодного доклада Совета Министров Республики Каракалпакстан по важнейшим вопросам социально-экономической жизни страны;

- заслушивание на заседаниях Жокаргы Кенеса информации членов правительства по вопросам их деятельности;

- заслушивание отчета Прокурора Республики Каракалпакстан;

- заслушивание отчета председателя Государственного комитета Республики Каракалпакстан по охране природы;

- заслушивание отчета председателя Главного управления Центрального банка Республики Узбекистан по Республике Каракалпакстан;

- парламентский запрос;

- запрос депутата Жокаргы Кенеса;

- заслушивание комитетами Жокаргы Кенеса состояния исполнения сообщений руководителей органов государственной власти и управления; 
- изучение комитетами Жокаргы Кенеса состояния исполнения законодательных актов, правоприменительной практики и осуществления ими мониторинга за принятием подзаконных актов [7].

Кроме того, полагаем, что в целях дальнейшего повышения престижа парламента в системе государственной власти и обеспечения полного выражения воли народа уместно воплотить в действие следующие виды контрольно-аналитической деятельности, сформированных мировым опытом:

- рассмотрение вопроса предъявления Председателю Совета Министров Республики Каракалпакстан вотума недоверия;

- правительственный час (час обращения с вопросами к правительству);

- парламентское расследование.

Надеемся, что это предложение, разработанное в рамках исследования, способствует усилению влияния и повышению роли парламента в жизнедеятельности общества и государства, укреплению его контрольной деятельности, созданию целостной системы правовых основ, созданию для депутатов благоприятных условий в этой сфере, координации их взаимной деятельности. В заключение приводим следующие слова Президента Республики Узбекистан Шавката Мирзиеева: «Руководители всех уровней должны глубоко осознать одну истину: не народ служит государственным органам, а государственные органы должны служить народу... С этой точки зрения изучение социальных настроений, общения с людьми и обеспечение интересов человека тесно взаимосвязаны» [9].

\section{Сиисок литературы / References}

1. Беляев В.П. Контроль и надзор в Российском государстве. М., 2005. С. 72.

2. Добрынин Н.М. Общественный контроль и власть: Политико-правовое и историческое исследование // Российский юридический журнал, 2006. № 1. Ст. 16.

3. Статья 11 Конституции Республики Каракалпакстан. [Электронный ресурс]. Режим доступа: http://parliamentrk.gov.uz/uz/dokumenti/konstitucija-respublikikarakalpakstan/ (дата обращения: 09.04.2017.)

4. Статья 10 Конституции Республики Каракалпакстан. [Электронный ресурс]. Режим доступа: http://parliamentrk.gov.uz/uz/dokumenti/konstitucija-respublikikarakalpakstan/ (дата обращения: 09.04.2017.)

5. Ведомости Жокаргы Кенеса Республики Каракалпакстан, 2014. № 9. Ст. 18.

6. Ведомости Жокаргы Кенеса Республики Каракалпакстан, 2016. № 3. Ст. 139.

7. Ведомости Жокаргы Кенеса Республики Каракалпакстан, 2016. № 3. Ст. 140.

8. Мирзиеев Ш.М. Доклад на торжественном собрании, посвященном 24-й годовщине принятия Конституции Республики Узбекистан. [Электронный ресурс]. Режим доступа: www.uza.uz/ (дата обращения: 07.01.2017). 


\title{
ЗАКОНЫ: ПОНЯТИЕ, ВИДЫ И ИХ ОСОБЕННОСТИ Быконя A.B. Email: Bykonya1799@scientifictext.ru
}

\author{
Быконя Артём Васильевич - студент, \\ Институт финансовой и экономической безопасности \\ Национальный исследовательский ядерный университет «МИФИ», г. Москва
}

\begin{abstract}
Аннотация: в современных условиях большинство людей знает, что закон обладает высшей юридической силой, но о том, что существуют различные его виды, не многие знают, поэтому иелесообразно об этом рассказать. В данной статье речь идет о том, что такое «закон», есть ли разница между нормативным правовым актом и законом, какие его разновидности существуют, в чем их особенность, каким образом выстроена российская правовая система, в чем состоят особенности федеральных конституцчинных законов и других видов законов в зависимости от основания классификации.
\end{abstract}

Ключевые слова: понятие «закон», виды законов, нормативный правовой акт, конституциионные законы, обыкновенные законы, российская правовая система.

\section{LAWS: CONCEPT, TYPES AND THEIR CHARACTERISTICS Bykonya A.V.}

\author{
Bykonya Artyom Vasilevich-Student, \\ INSTITUTE OF FINANCIAL AND ECONOMIC SECURITY, \\ NATIONAL RESEARCH NUCLEAR UNIVERSITY "MEPHI", MOSCOW
}

\begin{abstract}
Supreme legal force, but that there are different types, not known to many, so it is advisable to talk about it. In this article we are talking about what "the law", is there a difference between a normative act and a law what varieties there are, what are their features, how built the Russian legal system, what are the features of Federal constitutional laws and other laws depending on the grounds of classification.
\end{abstract}

Keywords: concept of law, kinds of laws, normative legal act, constitutional laws, ordinary laws, the Russian legal system.

УДК 340

Закон - это нормативный правовой акт, принятый представительным законодательным органом власти в особом порядке, регулирующий наиболее важные общественные отношения и обладающей высшей юридической силой [2].

В свою очередь, возникает вполне логичный вопрос: что же такое нормативный правовой акт? Нормативный правовой акт - акт правотворческих органов государства, который содержит нормы права, принимается в особом порядке, в конкретной письменной форме и состоит в отношениях соподчиненности с другими актами.

Необходимо отметить, что закон имеет ряд принципиальных отличий от нормативного правового акта (в дальнейшем - НПА):

1. Закон, следуя из определения, обладает высшей юридической силой, в силу этого он занимает ведущее место в системе законодательства и никакие другие акты не могут вступать с ним в противоречие;

2. Закон регулирует общественные отношения первично, то есть для которых впервые устанавливаются правовые рамки, например, земельные отношения;

3. Закон действует прямо и непосредственно;

4. Закон должен исполняться, а для того, чтобы это осуществилось, он обладает большими финансовыми и материальными ресурсами; 
5. Закон эффективно обеспечивается. Возникает вопрос: каким образом? Государство устанавливает общий надзор прокуратуры за соблюдением законности.

6. По сравнению с другими актами, к закону в стадии его подготовки, а в дальнейшем и обсуждения предъявляются более строгие требования.

Перечислим основные признаки закона:

1. Принимается представительными органами или населением [1].

2. Регулирует наиболее важные общественные отношения, к примеру, порядок образования и деятельности органов государства, права, свободы и обязанности человека и гражданина и т.д.

3. Первостепенно в сравнении с другими НПА.

4. Обладает высшей юридической силой.

5. Имеет строго выверенную процедуру создания, которая закреплена в законодательстве.

Рассматривая российскую правовую систему в настоящее время, выделяют следующие виды законов:

1. Первостепенное значение по своей юридической силе, конечно же, принадлежит основному закону нашей страны - Конституции РФ. Никакие другие акты в нашей стране не могут противоречить ей.

2. Федеральные конституционные законы (ФКЗ). К их основным особенностям относятся:

А) они являются продолжением конституционных норм и помогают избегать частых поправок в текст Конституции РФ;

Б) по сравнению с другими законами обладают повышенной стабильностью и более широкой сферой действия;

В) регулируют основополагающие, устойчивые общественные отношения;

Г) обладают по сравнению с текущими законами более высшую юридическую силу.

3. Закон о поправке к Конституции РФ. Этот вид закона выделен решением Конституционного Суда РФ от 31 октября 1995 г. о толковании статьи 136 Конституции РФ. Этот закон обладает особой юридической силой и принимается в порядке, предусмотренном для ФКЗ.

4. Самая распространенная форма закона - Кодексы. Они содержат в систематизированном виде все или большинство норм, регулирующих однородные общественные отношения. Следует отметить, что кодексы не имеют более высокой юридической силы, чем другие законы того же уровня.

5. Законы о ратификации и денонсации международных договоров. К особенностям относятся:

- предмет регулирования точно определен;

- особая процедура принятия.

6. Модельные законы (появились после создания СНГ). Этот вид законов носит рекомендательный характер, служат ориентиром для законодательства государств членов СНГ при регулировании определенных сфер общественных отношений.

7. Делегированное законодательство - новый вид для России и на федеральном уровне не использовался. Но в региональном законодательстве этот вид законов предусмотрен.

Суть делегированных законов состоит в том, что законодательные (представительные) органы государства делегируют исполнительным органам право принимать акты в форме законов.

8. Законы, принимаемые путем референдума. Особенность данного вида законов состоит в том, что они обладают высшей юридической силой и тот факт, что они могут быть отменены только на референдуме.

Если говорить в целом о видах законов, то всё зависит по какому основания проводить рассмотрение. В зависимости от значимости содержащихся в них норм законы бывают конституционными и обыкновенными, или текущими, как их иногда называют [3]. В зависимости от государства в которой действуют эти законы, то в одних странах, 
например в РФ, конституционные законы - это те, которые касаются изменений, вносимых в Конституцию, а, если взять ряд других стран, то это законы, которые издаются по вопросам, касающимся Конституции. В свою очередь, обыкновенные законы - это нормативные акты, которые регулируют обособленные общественные отношения. Они издаются в форме кодексов, уставов и текущих законов.

Если рассматривать законы по отраслевой принадлежности, то выделяют законы, касающиеся той или иной отрасли права. Например, законы, содержащие нормы административного права и т.д.

В зависимости от объема и объекта регулирования выделяют общие и специальные законы. Общие, то есть те, которые регулируют целую область (сферу) общественных отношений в целом, как правило, это кодексы. Например, Уголовный кодекс Российской Федерации. Специальные - те, которые регулируют часть общественных отношений, если сравнивать их с общими, то они будут составлять узкую часть, а общие законы - широкую. Например, «Патентный закон».

В зависимости от срока действия все законы делятся на постоянные, временные, чрезвычайные.

В зависимости от адресатов те законы, которые действуют в отношении всех граждан, называются общими, а те, которые касаются отдельных социальных групп или классов, называются специальными.

\section{Сиисок литературы / References}

1. Кожевников В.В., Коженевский В.Б., Рыбаков В.А. Теория государства и права. М.: Проспект, 2017. 464 с

2. Морозова Л.А. Теория государства и права. 5-е изд. М.: Норма: ИНФРА-М, 2017. $464 \mathrm{c}$.

3. Марченко М.Н. Теория государства и права. 2-е изд. М.: Проспект, 2017. 656 с. 


\title{
К ПРОБЛЕМЕ ПОДГОТОВКИ СПЕЦИАЛИСТОВ ПО ИНФОРМАЦИОННОЙ СИСТЕМЕ И ТЕХНОЛОГИИ
}

\author{
Акматкулов A.A. Email: Akmatkulov1799@scientifictext.ru
}

Акматкулов Асылбек Акматкулович - доктор педагогических наук, профессор, кафедра информационных систем в экономике, инженерно-экономический факультет, Кыргызский государственный технический университет им. И. Раззакова,

\author{
г. Бишкек, Кыргызская Республика
}

\begin{abstract}
Аннотация: материаль данной статьи, представленные на рассмотрение читателей, не дают полного ответа на вопрос: "как» и «для чего» подготовить специалистов по направлению «Информационные системы и технологии» (ИСТ) в вузе. А между тем это вопрос один из главных, ибо ответ на него в значительной степени связан с уровнем развития экономики и культуры страны, результатами поисков новых путей и направлений в подготовке специиалистов высшей школы. В статье описан ряд обстоятельных моментов о том, что учебный процесс, ориентированный на пробуждение интереса будущего IT-специалиста (специалиста по информационной системе и технологии), обеспеченный необходимыми учебнометодическими и инструментальными средствами, превращает его в творческую личность, способную полученные знания профессионально использовать в конкретной производственной деятельности.
\end{abstract}

Ключевые слова: специалист по информационным системам и технологиям, ITспециалист, информационные системы и технологии, САSЕ-ссредства, «кафедра базовые предприятия».

\section{TO THE PROBLEM OF PREPARATION OF SPECIALISTS ON THE INFORMATIONAL SYSTEM AND TECHNOLOGY}

\author{
Akmatkulov A.A.
Akmatkulov Asylbek Akmatkulovich - Doctor of Pedagogical Sciences, Professor, DEPARTMENT OF INFORMATION SYSTEMS IN ECONOMICS, ENGINEERING AND ECONOMICS FACULTY, KYRGYZ STATE TECHNICAL UNIVERSITY. I. RAZZAKOV, BISHKEK, REPUBLIC OF KYRGYZSTAN

\begin{abstract}
: the materials of this article submitted to the readers do not give a complete answer to the question: "how" and "why" to prepare specialists in the direction of "Information Systems and Technologies" (ICT) at the university. And yet this is a question one of the main, because the answer to it is largely related to the level of development of the country's economy and culture, the results of the search for new ways and directions in the training of specialists in higher education. The article describes a number of detailed points about the fact that the educational process aimed at awakening the interest of the future IT specialist (specialist in the information system and technology), provided with the necessary teaching and methodological tools, turns him into a creative personality, capable of using the profession professionally in Specific production activities.
\end{abstract}

Keywords: specialist in information systems and technologies (ICT specialist, information systems and technologies, CASE-tools, "department-base enterprises".

УДК 01081.19

Проблему подготовки специалиста по направлению информационных систем и технологий (ИСТ), формирование его компетентности следует рассматривать как 
последовательный и поэтапный процесс разрешения согласования комплекса противоречий, которые задаются и определяются между социальнопрофессиональными требованиями, предъявляемыми к специалисту, и возможностями индивида, его личностным опытом в трудовой деятельности.

Средством преодоления таких противоречий выступают различные виды активности человека, когда на отдельных стадиях профессионального становления они реализуются в форме учебной или трудовой деятельности, в форме практики или познавательных действий, общения и т.д. Результатом разрешения отмеченных противоречий является обретение индивидом профессионально важных качеств, влияющих на эффективность интеллектуального труда, и ценностных ориентаций, интереса определяющих отношение специалиста к избранной профессии, к ее содержанию удовлетворяются в ее процессе.

Обеспечение информационно-технологической подготовленности специалиста наука сравнительно молодая и вместе с тем интенсивно развивающаяся как в самой науке, так и педагогике. Ее предмет и объект исследования, совокупность методических приемов описания задач и функций инструментальных средств определились окончательно лишь в последние десятилетия.

При этом особенно весомым был вклад современных ученых-программистов: Гейтса Б. (1955) -разработчика в области электронно-вычислительной техники, основателя ведущей компании в мире в области программного обеспечения Microsoft; Джобса С. (1955) - получившего широкое признание в качестве пионера эры ITтехнологий; Касперского Е.В. (1965), одного из основателей «Лаборатории Касперского»; Мацумото Ю. (1965) японского разработчика свободного ПО, создателя языка программирования Ruby; Рошал Е.(1972) - российского программиста, автор известного архиваторов RAR и WinRAR, особенно популярных в России и странах СНГ; Торвальдса Л. (1969) - создателя известной во всем мире операционной системы Linux, которые продолжали и развивали традиции программистов мировой известности: Тьюринга А. (1912 - 1954), Геделя К. (19061978), Неймана Дж. (1903 - 1957) Цузе К. (1910 - 1995), Ершова А.П. (1931 - 1988, Вирта Н.(1934), восходящие к трудам: Шиккарда В. (1592 - 1635), который в 1623 году построил первый механический калькулятор, мог выполнять базовые арифметические операции над целыми числами; Лейбница Г.В. (1646 - 1716), изобретавшего систему двоичной арифметики в 1679 г., опубликованную в 1701 году.

В свете сказанного становится очевидным, что именно эти вклады великих программистов человечества дают мощный мотивационный заряд современной системе профессионального образования всех уровней к подготовке специалиста по направлению ИСТ.

Этот факт становится еще более значимым и актуальным с учетом разнообразия среднего и профессионального учебных заведений, когда социальный заказ общества ориентируется на дипломированного специалиста, владеющего широким спектром фундаментальных знаний, компетентного в проектировании и практическом осуществлении автоматизированных систем в производственном процессе и управленческой деятельности.

В настоящее время в Кыргызстане как никогда возрастает роль информационных систем в экономических науках. В принятом 30сентября 1999 году Закон «Об информатизации» регулирует основные правовые, экономические и организационные отношения, необходимые для развития процесса информатизации в стране. Целью опубликованного Закона является создание благоприятных условий для удовлетворения информационных потребностей граждан, учреждений, организаций и органов государственного управления и др. [1, с. 1].

Здесь в числе благоприятствующих условий в профессиональной подготовке специалистов в вузе, естественно, следует назвать обеспечение единства обучения и воспитания. Идейная убежденность, компетентность, глубокие профессиональные 
знания, творческий подход к делу, инициатива и активность - таковы требования, которым в наши дни должен отвечать выпускник высшей школы. Большие резервы кроются в углублении и расширении собственных знаний по моделированию и программированию, всех форм самостоятельности в учебной работе.

В настоящее время непрерывно идет обновление содержания обучения. Главную роль в этом обновлении играют новые учебные планы и программы, постоянно модернизируемые с учетом достижений (ИСТ). При этом дальнейшая профессионализация обучения на факультетах информационных технологий (ФИТ) в вузе осуществляется только путем глубокого усвоения студентами фундаментальных математических и компьютерных знаний.

Тем не менее, отдельной группой ученых республики было предложено «улучшение информационного и организационного обеспечения научно-технической деятельности молодежи» [5, с. 1]. Наряду с этим, очень важным моментом является «необходимость подготовки и привлечения молодых специалистов в сферы социально-экономической и управленческой деятельности в науке для повышения качества менеджмента науки и инноваций» [5, с. 1].

Такие важные моменты в принятых решениях ученых дает ключ к обеспечению возможностями применение информаций в компьютерах на более высоком уровне, чем до сих пор актуальна. Сегодня всему этому предстоит обучать и будущих бакалавров и магистров по избранному ими направлению ИСТ. Рабочий учебный план данного направления, следовательно, должен быть более гибким, давать возможности для оперативного осуществления процесса обучения при появлении новых запросов производственных предприятий.

С учетом требований по сокращению обязательных аудиторных занятий и других мероприятий, усиливающих самостоятельности обучающихся, в нашем факультете был разработан новый учебный план, по специальностям: экономика промышленности, производственный менеджмент, предпринимательство и коммерция, экономика и финансы, информационные системы в экономике. Важное место в новом учебном плане отводится усвоению студентами ряд профилирующих дисциплин: «Дискретная математика», «Математическая логика и алгоритмизация», «Компьютерные вычислительные системы», «Методы оптимизации», «Эконометрика», «Математическая моделирование в экономике» и использованию материала этих дисциплин при изучении специальных курсов с тем, чтобы добиться целенаправленного формирования у будущих специалистов современного информативного мышления, выработать у них предприимчивость и вычислительные навыки.

Предусмотрены также изучение технологического сочетания с широкими инструментальными средствами, направленными на расширения возможности информационных систем - систем сбора, хранения, анализа и графической визуализации необходимых данных и связанной с ними информации о необходимых объектах.

В общей структуре учебного плана одним из узловых является вопрос о месте и значении подготовки IT -специалистов на кафедре «Информационные системы в экономике». Подготовку такого специалиста в современных условиях можно определить по меньшей мере двумя особенностями.

Во-первых, развитость обучающих средств - непременное условие функционирования и динамичного проведения учебного процесса, главными ресурсами которых выступают: современная техническая база, увеличивающая объемов хранимой информации, создание банков данных и знаний, развитость каналов и систем связи, приводящие к большей доступности информации. Во-вторых, современные технологии обучения требуют у преподавателей соответствующих с базовым уровнем образованности, профессионально мобильных, обладающих обширными коммуникативными умениями и навыками.

В соответствии с этим в процессе обучения будущему информационному технологу необходимо дать более полный объем знаний по различным дисциплинам: 
защите и надежности информаций, компьютерному моделированию систем, идеологии CASE технологий [см. 2, 3, 4] для разработки информационных систем, такие программы как управления реляционными базами данных (РСУБД) Oracle Database, IBM DB2 и Microsoft SQL Server, C \#\# - объектно-ориентированное программирование - средство для создания его интерфейсной части.

Нельзя не учитывать, что производственные предприятия сегодня заинтересованы прежде всего в IT- специалистах с достаточной подготовкой по компьютерным технологиям, с глубоким знанием основ математических методов в экономике. В связи с этим изучение методов: дискретной оптимизации, «дерева решений», линейного программирования, двойственных задач, Модели Леонтьева и др. на инженерно-экономических факультетах должно вестись с позиций прогнозирования и измерения величины изменений в экономике.

Следует подчеркнуть, что IT-специалист прежде всего должен быть достаточно хорошо знаком со структурой автоматизированной системы управления предприятия, проектом которых он призван заниматься, уметь синтезировать в рамках своей специальности аналитические и фундаментальные компьютерные знания. Представление знаний в форме информационных моделей или извлечь знаний из этих моделей работа само по себе достаточно длительная и трудоемкая. В связи с этим становится очевидным, что при проведении лабораторных практикумов преподаватель ни в коей мере не должен подавлять студента, наоборот, активизировать весь его потенциал.

Действующие программы не всегда учитывают, что в нынешних условиях от ITспециалиста требуется гибкое мышление, умение в короткое время перестраивать свою работу; кроме того, содержание программ не отражает в необходимой степени перспективные направления развития профессиональной деятельности специалистов информационно - технологической службы. Поэтому при разработке новых программ должны быть отражены такие важные методические принципы, как междисциплинарная интеграция и перспективность обучения и т.д.

Перспективность обучения в вузе оценивается, как известно, по ее главному результату - умению выпускников самостоятельно выполнять определенные проективные действия, необходимые для самостоятельной работы по всем видам концептуального и информационного моделирования. Наиболее ответственную работу в этом аспекте должны выполнять профильные кафедры, несущие моральную ответственность за качество практической подготовки студентов.

Приведем пример. Выпускная квалификационная работа группы Ускенбаева Б.У. группы ИСТ(б)1-12 по теме «Информационная система (ИС) оценки кредитоспособности клиента ЗАО БТА банк» представлена следующим образом: анализ деятельности, структуры и управления банка, анализ существующих ИС «БТА банк, отличия существующей ИС от разработанной системы управления потребительскими кредитами. Проектирование ИС сопровождалось разработками жизненного цикла модели, концептуальным и информационным моделированием (модели As Is ,To Be), где они дают представления о бизнес процессах и документобороте, существующих в банке. Далее, описано главное меню программы атоматизированной ИС оценки кредитоспособности клиента ЗАО БТА банк, применением архитектуры «КЛИЕТСЕРВЕР» через инструменты прикладных программ SQL Server и Delfi7 как разработки программного обеспечения базы данных.

Очевидно, что подобный перечень обязательных навыков по специальности следует включить во все учебные программы. В таких перечнях необходимо отразить модель деятельности специалиста, квалификационную характеристику, а также богатый и разнообразный опыт подготовки, накопленный в различных вузах страны.

В настоящее время профессорско-преподавательским составом КГТУ им. И. Раззакова, ведущими специалистами Министерства образования и науки КР ведется улучшения новой квалификационной характеристики по специальности 710200 - 
информационные технологии и системы. Определены функции и назначение специалистов. Содержание квалификационной характеристики значительно обновлено и дополнено видами деятельности IT-специалиста с учетом перспективы развития информационной службы страны. Приведен также подробный перечень умений и навыков, которыми должен владеть выпускник факультет информационных технологий.

Усиление практической подготовки будущих специалистов может осуществляться не только путем широкого использования в качестве базовых промышленных предприятий как цветная металлургия и горнодобывающая, энергетика, тяжелая промышленность, транспорт, лёгкая промышленность текстильная промышленность, швейная промышленность, кожевенно-обувно-меховая промышленность и др. Оно должно вестись и через организацию учебно-производственных комплексов «кафедра — базовое предприятие». Соблюдая отдельные положения об информатизации, в электронных вариантах выпускники кафедры выполняют квалификационные работы (дипломные проекты) в вышеперечисленных базовых промышленных предприятиях, создавая программные продукты по автоматизации рабочих мест персонала предприятий.

Возрастающие требования к качеству подготовки (IT)-специалистов а также значительный и разнообразный опыт профильных кафедр зарубежных вузов в республике: АУЦА (Американский университет в центральной Азии), КРСУ им. Б. Ельцина (Кыргызско-Славянский университет) перевели в разряд первоочередных проблему унификации контроля текущих знаний студентов.

Результатом работы в этом направлении в КГТУ им. И.Раззакова явилось составление перечня типовых вопросов для экзамена по всем профилирующим и дисциплинам общетехнического цикла, которые загружены в тестовую систему «Training test» кафедры ИСЭ. Такая система с обучающими материалами была разработана преподавателями кафедры под руководством проф. Бабак В.Ф. (применяя инструментальные средства Delfi7 и Microsoft SQL Server), которая существенно скорректировала порядок и усовершенствовала содержание экзаменов, хотя ведущей формой итогового контроля по дисциплинам «Манасоведения», философии, культурологии, истории) до сих пор остается устный экзамен по билетам.

Принципиальным с этих позиций становится совершенствование процедуры государственных экзаменов с помощью тестовой системы Training test. Государственный экзамен сегодня должен быть технологичным и психологически разгруженным по форме, и, по содержанию являться логическим завершением всей подготовки студента.

Факультеты информационных технологий осуществляют широкопрофильную подготовку и могут выпускать будущих исследователей по управлению социальноэкономическим системам. Практический опыт кафедр по автоматизации контроля знаний убедительно свидетельствует о правильности такого подхода и высокой эффективности разработанных обучающих систем.

Не менее значимое место среди важных вопросов оптимизации и автоматизации учебного процесса повышения качества учебно-методических пособий, укрепление материально-технической базы занимает дальнейшее совершенствование всей системы подготовки, использования и повышения квалификации преподавателей.

Первостепенную важность здесь приобретают развитие магистратуры (аспирантуры) и докторантуры как ведущих форм подготовки научно-педагогических кадров. К сожалению, кафедры по информационным технологиям и программным обеспечениям компьютерных систем до сих пор не имеют аспирантских мест, не существует в КР по данной деятельности Совета по защите диссертаций.

Вывод. Таким образом, применяя индуктивные выводы по ранее опубликованным статьям, по группе известных соображений ученых, преподавателей вузов можно изыскать новые подходы по данной проблеме. Эта проблема к настоящему времени ещё недостаточно имеет решения, и является актуальной педагогической проблемой. 
1. Закон Кыргызской Республики «Об информатизации». Принят Законодательным собранием Жогорку Кенеша Кыргызской Республики. Бишкек 30 сентября 1999 г. [Электронный ресурс]. Режим доступа: http://base.spinform.ru/show_doc.fwx?rgn=13 1/ (дата обращения: 05.05.2017).

2. Маклаков C.B. BPwin и ERwin. CASE-средства разработки информационных систем / С.В. Маклаков. М.: ДИАЛОГ-МИФИ, 1999. 256 с.

3. Статья: BPwin и Erwin. CASE-средства для разработки информационных систем: Сергей Маклаков. [Электронный ресурс]. Режим доступа: http://programminglang.com/ru/comp_db/maklakov/0/j128.html/ (дата обращения: 05.05.2017).

4. Вендров A.M. CASE-технологии: Современные методы и средства проектирования информационных систем / А.М. Вендров. М.: ДИАЛОГ-МИФИ, 1999. 256 с.

5. Осмоналиев К.О., Каниметов Ж.К., Абылгазиев Р.И., Шариеналиева З.Ш., Султанкулова А.C. Основные проблемы развития кадрового потенциала науки в Кыргызской Республике. Материалы международной научно-практической конференции «Подготовка научных кадров высшей квалификации в условиях инновационного развития экономики. Региональные, межрегиональные и международные аспекты» / Под ред. И.В. Войтова. Минск: ГУ «БелИСА», 2007. 200 с. [Электронный ресурс]. Режим доступа: http://www.vivakadry.com/74.htm/ (дата обращения: 05.05.2017).

\title{
МЕТОДИЧЕСКИЕ ПРИЕМЫ РАБОТЫ НА ИНТЕРАКТИВНОЙ ДОСКЕ СРЕДСТВАМИ ПРОГРАММЫ SМАRТ NOTЕВООК Кюршунова В.В. Email: Kyurshunova1799@scientifictext.ru
}

\author{
Кюриунова Вероника Владимировна - кандидат педагогических наук, дочент, \\ кафедра теории и методики преподавания математики и ИКТ в образовании, \\ Петрозаводский государственный университет, г. Петрозаводск
}

\begin{abstract}
Аннотация: в настоящее время в практику работы образовательных учреждений активно внедряются интерактивные доски. Однако часто учителя используют новое оборудование в качестве демонстрационного средства, не реализуя всех его возможностей. В данной статье рассматриваются методические приемы работь с интерактивной доской на разных этапах урока с помощью популярного программного обеспечения SMART Notebook. Описанные приемы иллюстрируются на примере конкретных заданий для младших школьников, разработанных в среде данного программного продукта.
\end{abstract}

Ключевые слова: интерактивная доска, методический прием, обучение, программное обеспечение SMART Notebook.

\section{THE METHODICAL TECHNIQUE TO WORK WITH INTERACTIVE WHITEBOARD BY MEAN OF SMART NOTEBOOK APPLICATION Kyurshunova V.V.}

\footnotetext{
Kyurshunova Veronika Vladimirovna - PhD in Pedagogic, Associate Professor, DEPARTMENT OF THEORY AND TEACHING METHODOLOGY OF MATHEMATIC AND INFORMATION AND COMMUNICATION TECHNOLOGY IN EDUCATION, PETROZAVODSK STATE UNIVERSITY, PETROZAVODSK
} 
Abstract: in nowadays, interactive white boards are often used for teaching and training in educational institutions. But, teachers and trainers do not use all the possibilities of modern demonstration equipment. This article describes methodical technique of teaching (on different layers of lesson) with interactive whiteboard by means of widely used SMART Notebook software. Described technique are illustrated by examples of teaching works for junior high school students, that examples was created by mentioned software application.

Keywords: interactive whiteboard, methodical procedure, training, SMART Notebook software.

УДК 371.68

Вместе с компьютером и проектором в настоящее время в учебных заведениях широко применяются интерактивные доски. Для полноценной реализации на уроке всех возможностей этого средства учителю необходимо освоить специальное программное обеспечение для интерактивных досок, изучить его основные возможности. Часто при разработке учебных материалов для интерактивной доски используют программу SMART Notebook. Данный программный продукт обладает простым и понятным интерфейсом и позволяет создавать документы собственного формата, содержащие набор страниц (слайдов). На страницах может быть представлена различная информация: текст, графические объекты, анимация, аудио- и видеоматериалы, интерактивные задания, гиперссылки на объекты Интернет и др.

Чаще всего интерактивная доска на уроке используется в качестве средства фронтальной работы с учащимися и предполагает тщательную подготовку и разработку необходимого набора слайдов с учебными материалами и заданиями. На этапе проектирования слайдов в программе SMART Notebook важно заранее предусмотреть методические приемы работы с интерактивной доской на различных этапах урока.

\section{1. Прием «Напиши от руки».}

Данный прием очень прост и эффективен в работе, к тому же он не требует большой подготовки. С помощью инструмента Перо на слайдах можно различными цветами делать пометки, осуществляя графическое комментирование, записывать решения задач, примеров, вставлять пропущенные символы и слова.

Для начала необходимо создать заготовки заданий, в условиях которых детям предлагается использовать инструменты рисования: впиши, подпиши, подчеркни, нарисуй, обведи, соедини, установи связь и т.п. При подготовке заданий используются такие инструменты, как работа с текстом, линиями, фигурами, вставка рисунков и других объектов. Те объекты, которые должны быть статичными на странице, следует заблокировать (закрепить), чтобы случайно не сдвинуть их в процессе работы. Для этого нужно выбрать в контекстном меню объекта команду Блокировка - Закрепить.

На рис. 1 представлены примеры использования данного приема. В первом задании дети обводят в филворде найденные слова, во втором - исправляют ошибки красным цветом.

Найдите в филворде названия перелетных птиц

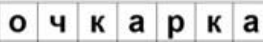

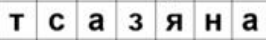

\begin{tabular}{llllllll}
$\boldsymbol{л}$ & $\mathbf{a}$ & $\mathbf{C}$ & $\mathbf{O}$ & $\mathbf{p}$ & $\mathbf{e}$ & $\boldsymbol{k}$ \\
\hline
\end{tabular}

$\begin{array}{lllllll}3 & \text { Д } & \text { К } & \text { В } & \text { M } & \text { L } & \text { B }\end{array}$

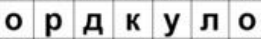

T) $\mathrm{C}$ о

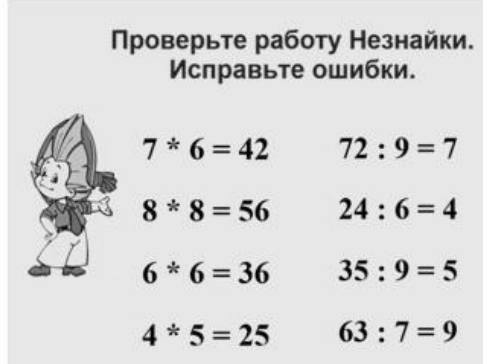

Проверьте работу Незнайки.

$7 * 6=42 \quad 72: 9=7$

$8 * 8=56 \quad 24: 6=4$

$6 * 6=36 \quad 35: 9=5$

$4 \div 5=25 \quad 63: 7=9$

Рис. 1. Прием «Напиши от руки» 


\section{2. Использование инструмента «Волшебное перо».}

Среди набора инструментов программы SMART Notebook следует выделить «Волшебное перо». Этот инструмент интересен тем, что записи, сделанные им, исчезают через 10 секунд. Это позволяет учителю делать временные пометки на слайде. Также можно использовать данный инструмент при выполнении одного и того же задания на интерактивной доске несколькими учениками поочередно. В этом случае нет необходимости стирать ластиком результат работы предыдущего ученика.

У данного инструмента есть еще одна очень интересная функция. Если нарисовать им окружность или овал, то все, что не попало в нарисованную область, будет затемнено. Таким образом, можно привлекать внимание учеников к нужному фрагменту страницы. Если же начертить волшебным пером квадрат или прямоугольник, то все, что оказалось внутри данной фигуры, увеличивается, что также позволяет акцентировать внимание на необходимом материале. За счет возможности перемещать и изменять размер выделенной области можно делать акцент на той или иной части объекта и более детально его рассматривать [1], [2].
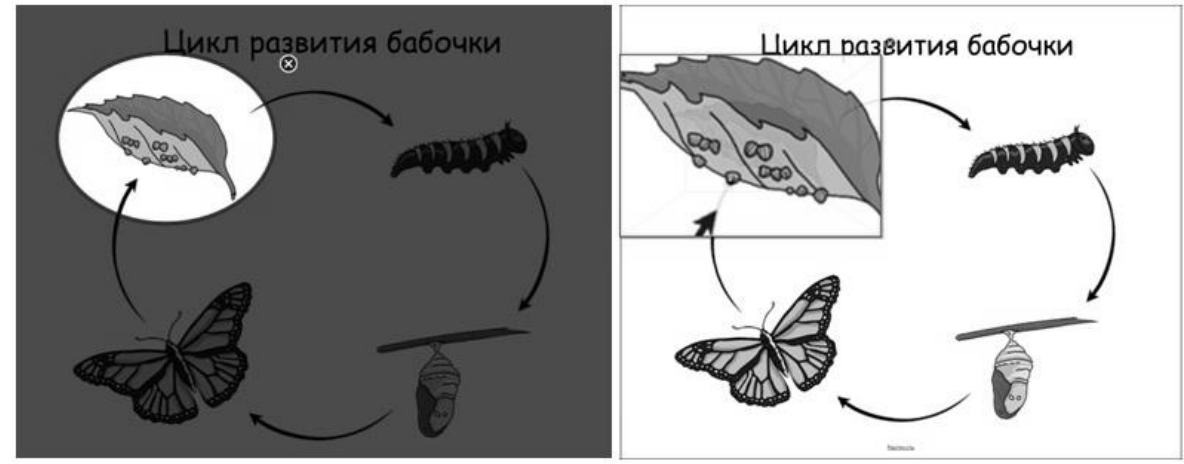

Рис. 2. Работа с «Волшебным пером»

\section{3. Прием «DragandDrop» («Перетащи и отпусти»).}

При помощи этой технологии любой объект на интерактивной доске рукой (или маркером) может быть перемещен в другое положение. Технология свободного перемещения объектов открывает широкие возможности для создания разнообразных заданий в любой предметной области. Она позволяет решить множество задач: передвигать объект из одного места на доске в другое, устанавливать соответствие между объектами, группировать, сортировать, восстанавливать правильную последовательность, располагать элементы в порядке возрастания или убывания, конструировать объекты из набора деталей. В качестве объектов могут выступать надписи, схемы, фигуры, рисунки, и т. д. Для реализации заданий такого типа требуется только разместить исходные элементы на слайде и выбрать их начальное положение. Объекты, которые не должны быть передвинуты, обязательно нужно закрепить, чтобы исключить возможность случайного их перемещения [2].

Данный прием можно использовать как для закрепления пройденного материала, так и при изучении новой темы.

\section{4. Использование «Утилиты множественного клонирования».}

Часто на уроке возникает необходимость использования некоторых объектов несколько раз. Копирование объектов, особенно если копий нужно много, отнимает много времени. Выходом из данной ситуации является «Утилита множественного клонирования», позволяющая автоматически создавать копии объектов бесконечное число раз. Для того, чтобы воспользоваться данной функцией, необходимо выделить нужный объект и через контекстное меню выбрать команду «Утилита множественного клонирования». Теперь при перетаскивании объекта, перемещается его копия, а оригинал остается на месте. 
Использование этой утилиты позволяет учителю экономить время на уроке за счёт того, что объекты в необходимом количестве уже есть на доске, достаточно их только перемещать в нужное место. Такая технология очень удобна и в том случае, когда заранее неизвестно (или учитель не хочет демонстрировать), сколько раз будет использоваться объект-оригинал [2]. Эту функцию можно использовать при изучении нового материала (например, для демонстрации приема сложения однозначных чисел с переходом через десяток), для отработки навыков и для закрепления изученного материала, для проверки усвоения устного материала, при организации эмоциональной рефлексии.

В примере на рис. 3 ученики собирают из частей квадрата, к которым была применена «Утилита множественного клонирования», фигурки путем перетаскивания частей.

\section{Танграм}

\section{Составьте фигурки из частей квадрата}

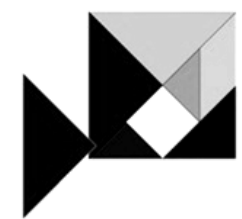

Pис. 3. Использование «Утилиты множественного клонирования» и приема «DragandDrop»

\section{5. Использование анимации.}

К любым объектам на слайде в программе SMART Notebook можно применить анимацию. Для этого нужно выделить объект и на вкладке «Свойства» на боковой панели нажать на кнопку «Анимация объекта». Далее в списках можно выбрать тип анимации, направление, события, скорость и повторы. Анимация запускается щелчком по объекту, поэтому работать с ней можно в любой последовательности, как в PowerPoint при использовании триггеров [2].

Описанный прием можно использовать при изучении нового, а также при закреплении пройденного материала. Например, в задании требуется найти лишнее слово (рис. 4). В процессе обсуждения это слово исчезает при касании его вызвавшимся учеником (применен эффект анимации - исчезание), а остальные остаются на доске. Часть материала на слайде прикрыта шторкой (см. далее), чтобы не отвлекать внимание.

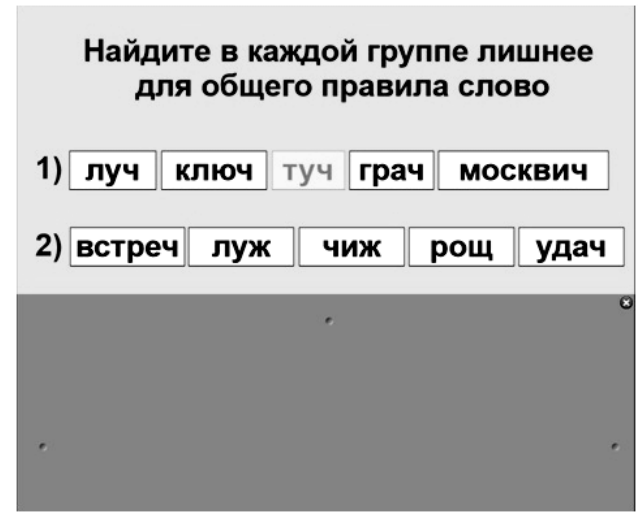

Рис. 4. Использование анимачии и иторки

\section{6. Прием «Рентген».}

Данный прием, разработанный А.Б. Розенфельдом, реализует идею рентгеновского аппарата, позволяющего заглянуть под оболочку некоего объекта. 
Сначала нужно подготовить 2 изображения одинакового размера - фоновое и то, которое будет проявляться под «рентгеном». Далее на слайд помещается фоновое изображение - иллюстрация внешнего вида изучаемого объекта (например, системный блок). Затем создается ячейка таблицы нужного размера и заливается изображением, которое мы будем рассматривать под «рентгеном» (для нашего примера - внутреннее устройство системного блока). Для заливки выделяем ячейку таблицы и на вкладке «Свойства» на боковой панели выбираем Эффекты заливки - Заливка изображением - нужный рисунок.

Таким же образом можно создать иллюзию просмотра нескольких слоев, когда ряд отдельных ячеек заливаются нужными изображениями, на время закрываются шторкой и открываются по мере необходимости. Необычный инструмент создаёт яркий зрительный образ и побуждает запоминать информацию.

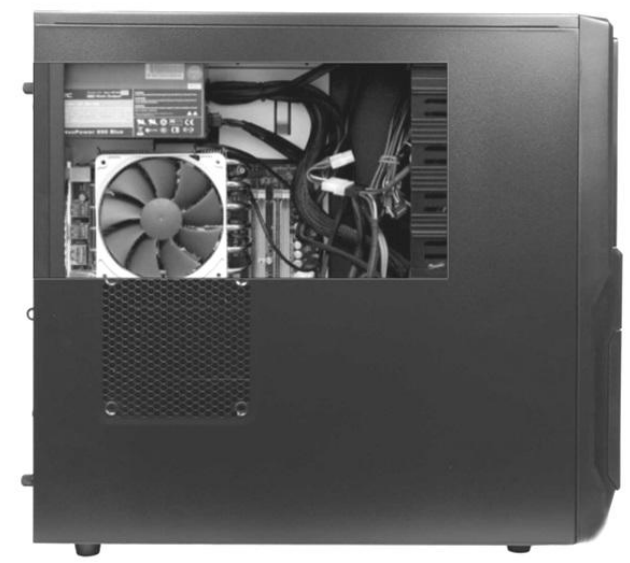

Рис. 5. Использование приема «Рентген»

\section{7. Приемы временного скрытия информации.}

Эту технологию, позволяющую предъявлять материал в нужный момент, учителя часто применяют для проверки правильности решения или для постепенного вывода информации на слайд. Существует целый ряд приемов скрытия информации. Рассмотрим некоторые из них.

\section{а) Использование инструмента «Затенение экрана».}

Данный инструмент закрывает необходимый фрагмент слайда прямоугольной областью. Его использование дает возможность организовать как поэтапное изложение материала, так и его проверку. Чтобы спрятать содержимое слайда за шторкой, достаточно выбрать соответствующую кнопку на панели инструментов. Если требуется частично прикрыть экран, следует уменьшить размер шторки, потянув за ее границы. При работе со слайдом шторка постепенно открывается маркером или рукой, предъявляя ту порцию материала, которая в это время необходима. Использовать инструмент можно и для отдельных ячеек таблицы. Для этого нужно выделить ячейку, содержимое которой требуется скрыть, и в контекстном меню выбрать команду «Добавить затенение ячейки».

Этот прием эффективен на любом этапе урока. Например, при изучении нового материала, закрыв шторкой весь слайд, постепенно открывают его по мере надобности. При закреплении изученного и проверке домашнего задания шторкой можно скрыть часть экрана (к примеру, ответы) и в нужный момент их демонстрировать. С помощью затенения ячейки в таблице возможно спрятать тему урока, задание или ответ [2]. В моменты, когда учитель не пользуется интерактивной доской, шторкой можно закрыть всю поверхность экрана, чтобы материал не отвлекал учеников [1]. 
На рис. 6 представлен пример задания с использованием данного приема. В ходе проверки учитель щелкает по затененной ячейке и ответ становится виден.

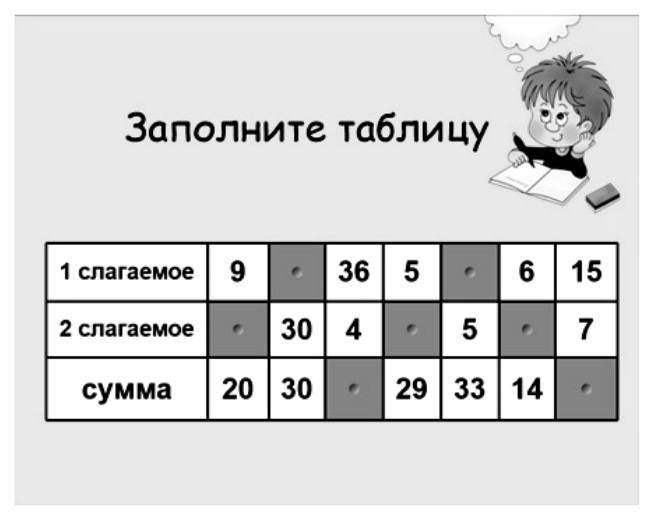

Рис. 6. Использование инструмента «Затенение»

\section{b) Использование инструмента «Ластик».}

Суть приема: для того, чтобы скрыть текстовый или графический объект на слайде, его закрашивают инструментом «Перо» или «Художественное перо», а показывают спрятанное с помощью ластика. Например, закрасив ответы цветом фона или любым другим так, чтобы их не было видно при выполнении задания, при проверке стирают ластиком «закраску» (это можно делать в произвольной последовательности). При использовании ластика необходимо обязательно закрепить на слайде объекты, чтобы случайно не сдвинуть их и не открыть ответы [2].

С помощью этого инструмента можно разнообразить проверку, создавать игровые ситуации. Данная технология применима при фронтальном опросе, закреплении изученного, проверке домашнего задания. В задании, представленном на рис. 7, в ходе обсуждения кляксы стираются и производится проверка.

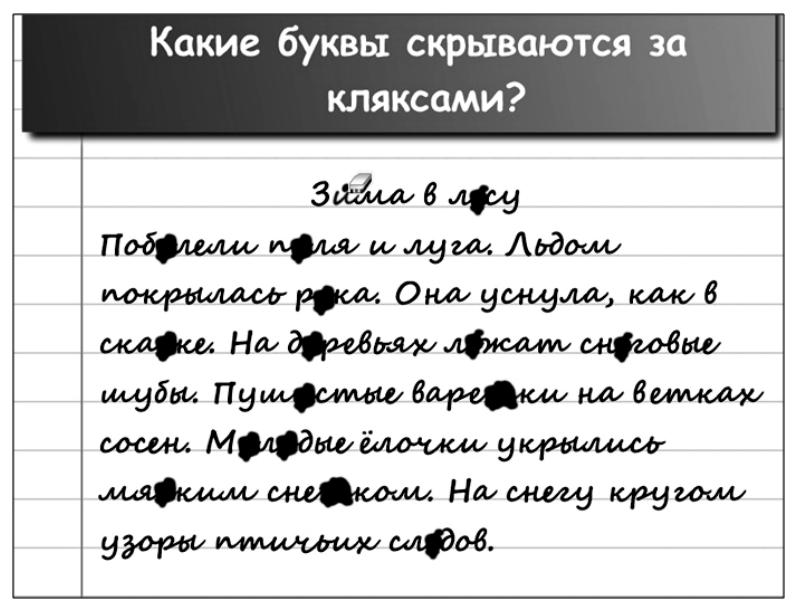

Рис. 7. Использование инструмента «Ластик»

\section{с) Использование фона и порядка объектов.}

Прием заключается в том, что текст, написанный цветом фона и потому невидимый, «волшебно» появляется в нужный момент на другом контрастном фоне. Чтобы сделать проверку более наглядной и зрелищной, нужно создать фигуру проверочный элемент (лупа, труба, бочка и пр.). Таким образом скрывают пропущенные буквы в словах или ответы в математических примерах, а при проверке 
с «волшебной лупой» (когда лупу наводят на скрытый ответ) или «волшебной трубой» (когда объекты перемещаются через трубу) все становится видным.

При использовании этой технологии необходимо продумать порядок размещения информации на слайде. Ответы обязательно нужно предварительно поместить на передний план (в контекстном меню объекта выбрать Порядок - На передний план), чтобы проверочный элемент не закрыл их при наведении.

Также можно спрятать объект, нарисовав поверх него любую геометрическую фигуру с цветной заливкой или просто картинкой. Сдвигая закрывающее ответ изображение, осуществляют проверку. Картинка, закрывающая ответ, может нести смысловую нагрузку.

C этой же целью можно использовать и средства встроенной Коллекции SMART Notebook в форме прямоугольника, круга, треугольника, звезды, воздушного шарика (на боковой панели выбираем вкладку Коллекция, далее выбираем раздел LAT 2.0-RU - Средства - Интерактивные средства и мультимедиа и перетаскиваем на слайд нужный объект). У фигуры можно поменять цвет и размер. При нажатии на такой объект он становится прозрачным, и появляются спрятанные за ним ответы.

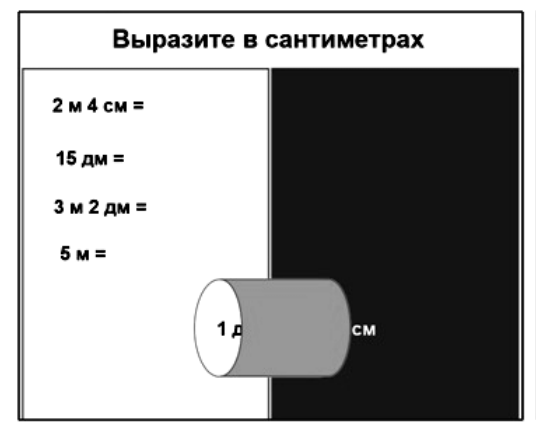

Найдите закономерность и продолжите ряд

1) \begin{tabular}{|l|l|l|l|}
\hline 38 & 40 & 42 & 44 \\
\hline
\end{tabular}

2) \begin{tabular}{l|l|l|l|l|}
\hline 88 & 85 & 82 & 79 \\
\hline
\end{tabular}

3) \begin{tabular}{|l|l|l|l|}
\hline 5 & 10 & 15 & 20 \\
\hline
\end{tabular}

4) \begin{tabular}{|l|l|l|l|}
\hline 91 & 81 & 71 & 61 \\
\hline
\end{tabular}

Рис. 8. Использование фона и порядка объектов

Этот прием можно использовать при фронтальном опросе, при проверке домашнего задания, при закреплении изученного материала. На рис. 8 показаны примеры использования данного приема. В первом случае дети работают устно, для проверки учитель проводит выражение через «волшебную трубу». Во втором задании дети записывают решение на доске по цепочке и осуществляют проверку с помощью «волшебной лупы».

d) Вынесение объектов за край слайда.

Сначала готовится слайд с заданием и ответами. Чтобы впоследствии было удобнее искать и доставать спрятанные блоки из-за края слайда, нужно сделать «язычок», за который их можно будет выдвинуть. Такие блоки можно нарисовать с помощью инструментов Фигуры и Текст и затем сгруппировать их. А можно воспользоваться язычками из встроенной Коллекции SMART Notebook (на боковой панели выбираем вкладку Коллекция, далее выбираем раздел LAT 2.0-RU - Графики - Язычки - Рисунки, перетаскиваем на слайд нужный объект и вписываем в него текст). После этого сгруппированный объект необходимо переместить таким образом, чтобы он скрылся за краем слайда, а на виду был только «язычок». 


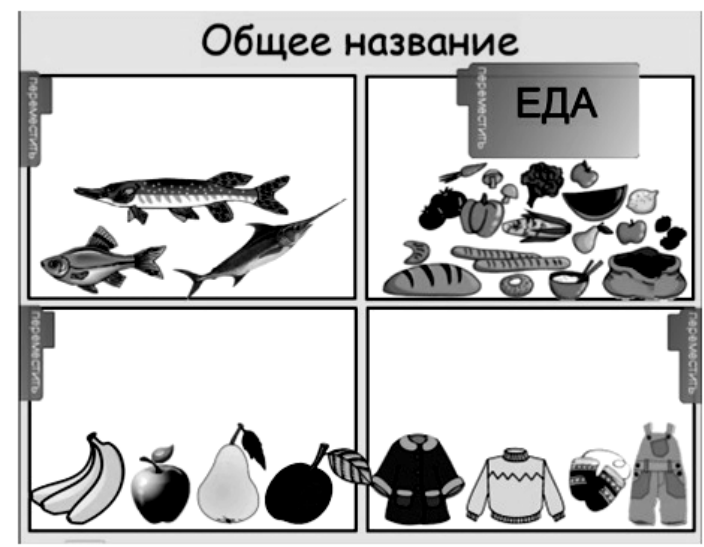

Рис. 9. Прием вынесения объектов за край слайда

Таким образом, можно прятать не только ответы к заданиям, но и дополнительный теоретический материал, а также сами задания, чтобы не перегружать слайд. В нужный момент достаточно потянуть за «язычок», выдвинув блок с материалом из-за края слайда.

е) Прием «Волшебная таблица».

Этот прием использует два свойства. Первое - это свойство ячейки таблицы подгонять размер фигуры, помещенной в него, под размер ячейки. Второе - свойство объекта Фигура при уменьшении размера скрывать часть текста (если этот текст создан в фигуре с помощью двойного щелчка), а также скрывать часть изображения, если используется заливка фигуры изображением. Для использования приема необходимо создать ячейку таблицы и фигуру с ответом, которую мы будем перемещать в ячейку, одинаковых размеров. Затем уменьшить фигуру так, чтобы ответ (или его часть) не был виден. На этапе проверки при перетаскивании в ячейку таблицы фигуры, размер последней восстанавливается и можно увидеть ответ.

С помощью данной технологии можно создавать контейнеры с информацией, уменьшая их до минимального размера, а в нужный момент использовать, помещая в ячейку таблицы и предъявляя тем самым материал. Этот прием удобно применять при фронтальном опросе, изучении нового и закреплении изученного материала.

В примере на рис. 10 ученики перетаскивают в ячейку таблицы устройства ввода. При правильном ответе под устройством появляется надпись «Верно», при неправильном «Неверно». Прямоугольники с соответствующей заливкой и надписью были подготовлены заранее и уменьшены так, чтобы надпись было не видно.

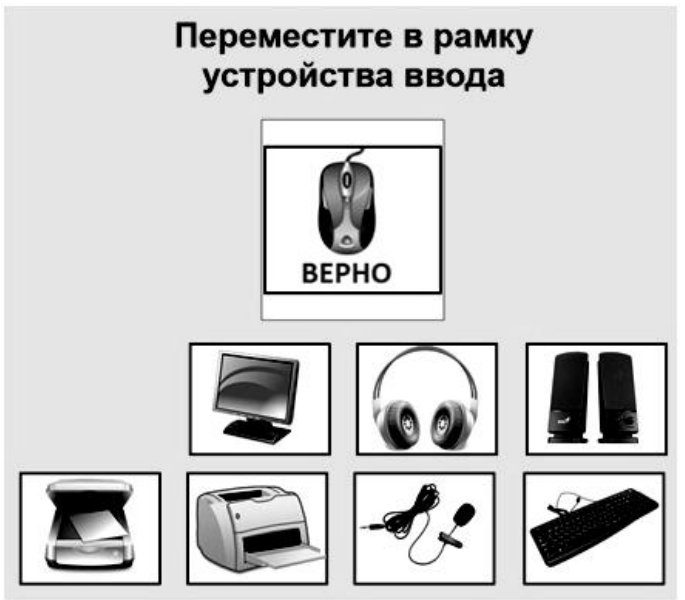

Рис. 10. Использование «Волшебной таблицы» 


\section{8. Использование «Коллекции» SMART Notebook.}

Встроенная коллекция заготовок насчитывает несколько тысяч элементов, размещенных по темам на вкладке Коллекция на боковой панели. Необходимый элемент коллекции перемещается на страницу способом перетаскивания или двойным щелчком по объекту коллекции.

Коллекцию SMART Notebook можно использовать при объяснении нового и закреплении изученного материала. Например, при подготовке к уроку математики учитель может воспользоваться коллекцией разнообразных математических объектов (объемные и плоские фигуры, углы, координатные прямые и плоскость и т. д.) и инструментов (линейка, транспортир, циркуль и др.).

Особенно интересна коллекция интерактивных объектов на русском языке LAT 2.0, которая подробно описана в работе А.Б. Розенфельда [3]. Средства данной коллекции позволяют учителю на основе готовых шаблонов создавать разнообразные интерактивные задания, которые можно использовать на всех этапах урока. На рис. 11 представлено интерактивное задание, выполненное с помощью шаблона «Выбор изображения». На этапе подготовки учитель заполняет шаблон, используя заранее подготовленные картинки. В процессе работы эти изображения быстро сменяют друг друга в окне в случайном порядке. При щелчке по окну в нем остается одна картинка, а под ней - три варианта ответа, из которых нужно выбрать верный. Программа отреагирует либо зеленой галочкой, либо красным крестиком. После этого смена картинок продолжится. К доске можно пригласить другого ученика.

\section{Определи у предметов общий признак.}

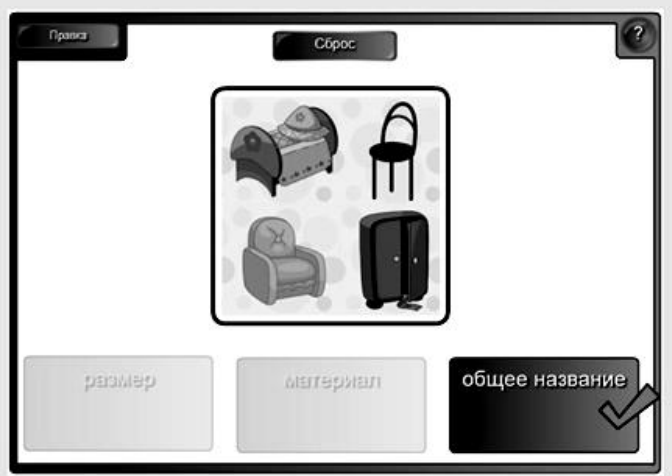

Рис. 11. Пример использования интерактивного средства «Выбор изображения»

\section{Сиисок литературы / References}

1. Аствачатуров Г.О., Кочегарова Л.В. Эффективный урок в мультимедийной образовательной среде (практическое пособие). М.: Национальный книжный центр. ИФ «Сентябрь», 2015. 176 с.

2. Иванова И.И. Методические рекомендации по использованию интерактивной доски в учебном процессе / И.И. Иванова. Под ред. Е.М. Ганичевой. Вологда: ВИРО, 2012. $32 \mathrm{c}$.

3. Розенфельд А.Б. Коллекция LAT 2.0. [Электронный ресурс]: А.Б Розенфельд, 2010. 37 c. Режим доступа: http://sc48.ru/files/collection_LAT\%202.0.pdf/ (дата обращения: 20.04.2017). 


\title{
СУЩНОСТЬ И КЛАССИФИКАЦИЯ ИННОВАЦИОННЫХ ТЕХНОЛОГИЙ В РЕЧЕВОМ РАЗВИТИИ ДЕТЕЙ ДОШКОЛЬНОГО ВОЗРАСТА Зотова И.В. ${ }^{1}$, Вовк С.А. ${ }^{2}$ Email: @ scientifictext.ru
}

\author{
${ }^{1}$ Зотова Ирина Васильевна - кандидат педагогических наук, дочент; \\ ${ }^{2}$ Вовк Светлана Александровна - студент, \\ кафедра дошкольного образования и педагогики, \\ Крымский инженерно-педагогический университет, \\ г. Симферополь
}

\begin{abstract}
Аннотация: в статье идет речь о путях повышения качества речи дошкольников, посредством использования инновачионных технологий, а именно: мнемотехники, моделирования, сказкотерапии, синквейна, приводятся достоинства и недостатки рассматриваемых технологий. Показано, что обучение с помощьюю инновационных технологий обеспечивает и ускоряет прочесс развития речи каждого ребенка, а значит, способствует улучшению качества образования. В представленной публикации поднят вопрос о сущчности и классификации инновационных технологий образования.
\end{abstract}

Ключевые слова: инновационные технологии, речевое развитие, дошкольный возраст.

\section{ESSENCE AND CLASSIFICATION OF INNOVATIVE TECHNOLOGIES IN SPEECH DEVELOPMENT OF PRESCHOOL CHILDREN Zotova I.V. ${ }^{1}$, Vovk S.A. ${ }^{2}$}

\author{
${ }^{I}$ Zotova Irina Vasil'evna - PhD in Pedagogy, Associate Professor; \\ ${ }^{2}$ Vovk Svetlana Aleksandrovna - Student, \\ DEPARTMENT OF PRESCHOOL EDUCATION AND PEDAGOGY, \\ CRIMEAN ENGINEERING-PEDAGOGICAL UNIVERSITY, \\ SIMFEROPOL
}

\begin{abstract}
: the article deals with the ways to improve the quality of preschool children through the use of innovative technologies, namely, mnemonics, modeling, fairy tale therapy, sinquan are the advantages and disadvantages of the considered technologies. It is shown that learning through innovative technology secures and accelerates the process of speech development of each child, and thus contributes to improving the quality of education. In the publication raised the question of the nature and classification of innovative educational technologies.
\end{abstract}

Keywords: innovative technologies, speech development, preschool age.

УДК 372.461

Сегодня перед педагогами дошкольных образовательных учреждений встает главная проблема: формирование речевых умений ребят. Воспитатели должны сформировать условия, в которых дошкольники смогут свободно овладеть разговорной речью, поэтому необходим поиск эффективных методов и приемов обучения, дающих возможность любому ребенку проявить себя в речевой активности. С каждым днем актуальным становится введение в обучение детей дошкольного возраста инновационных технологий, способствующих развитию речи, формированию мышления, улучшению гибкости памяти, фантазии, воображения.

Ученые: А.М. Бородич, В.В. Гербова, М.М. Конина, В.И. Логинова, Г.М. Лямина, Ф.А. Сохин, О.С. Ушакова ввели обязательные занятия в детском саду. Разработали 
технологии проведения занятий по развитию речи. Усовершенствовали программы по развитию речи такие

Современные ученые в области развития речи: М.М. Алексеева, А.Г. Арушанова, В.В. Гербова, О.С. Ушакова, В.И. Яшина укрепили теоретические основы технологий, нашли формы и методы развития речи вне занятий, развили идеи коммуникативнодеятельностного подхода.

В условиях реализации ФГОС ДО принципиально новой является необходимость решения речевых задач в контексте детской деятельности (игр, детского исследования, труда, экспериментирования), не переводя ее в учебную по форме и методам воздействия. Это требует новых технологий речевого развития дошкольников.

Инновация - означает нововведение, новшество [6].

Инновационные технологии - это новые способы, методы, приемы взаимодействия преподавателей и учащихся, обеспечивающие эффективное достижение результата педагогической деятельности [6].

Так мы понимаем под этим внедрение преподавателем следующих инновационных технологий: мнемотехнику, моделирование, сказкотерапию, синквейн.

Сперва необходимо рассмотреть такую технологию как мнемотехника. Значение слов «мнемотехника» и «мнемоника» обозначают одно и то же - техника запоминания. Считается, что это слово придумал Пифагор Самосский (6 век до н.э.) [5, с. 5]. Данную методику применял Цицерон, для запоминания своей речи. Он выстраивал определенный путь по комнатам, связывая с предметами или местами различные изречения. Это помогало вспомнить их при выступлении перед публикой, пройдя этот путь уже в своей голове, собирая «разложенные» по местам факты и слова.

Мнемотехника - является системой разных приемов, дающих возможность легче запоминать и увеличивать объем памяти через создание дополнительных ассоциаций. Подобные приемы имеют особое значение для дошкольников, потому что наглядный материал усваивается намного лучше вербального [5, с. 5].

Часто встречаются ошибки в грамматике детей дошкольного возраста, к ним относится неправильное использование предлогов и окончаний в падежах. Данные недостатки с возрастом исчезают. Взрослые играют важную роль в устранение этих ошибок. Развитию речи ребят помогает применение мнемотехники. Ученые дают ей разные названия. В.К. Воробьёва называет эту методику сенсорно-графическими схемами, Т.А. Ткаченко - предметно-схематическими моделями, Т.В. Большева коллажём, Л.Н. Ефименкова - схемой составления рассказа [1, с. 86].

Особенности технологии заключаются в использовании не изображенного предмета, а знаков с целью опосредованного запоминания. Это существенно упрощает дошкольникам отбор и усвоение слов. Знаки максимально приближены к речевому материалу, к примеру с целью обозначения диких животных используют елку, домашних животных обозначают домом.

Мнемоника всегда создается на основе работы от простого к сложному. Нужно приступать к работе, начиная с простых мнемоквадратов, затем переходя к мнемодорожкам, и далее - к мнемотаблицам, потому что у дошкольников в памяти закрепляются отдельные образы: кошечка - пушистая, клубничка сладкая. Потом - затруднять либо замещать другой заставкой - показать персонажа в графическом варианте. Информация, которую запоминают, применяя мнемомику, похожа на расположение папок в компьютере. Однако вместимость каждой «папки» не так уж и велика [5].

Следующая технология приобрела большое использование в обучения дошкольников знаково-символической деятельности (моделирования). Данный способ может помочь воспитателям четко отметить простые взаимосвязи и взаимоотношения с объектами действительности.

Модели очень результативны при разучивании произведения в стихотворной форме. Содержание состоит в следующем: главное слово либо сочетание слов в 
любой строке стихотворения «кодируется» в похожей картинке, поэтому, все стихотворение состоит полностью из иллюстраций. Далее дошкольники то, что запомнили, смотря на иллюстрации, воссоздают полностью. На первом этапе предлагается готовый план-схема, затем в ходе изучения они создают собственную схему. Кодирование можно производить от простого вида к сложному. В исследовании С.Н. Карповой и И.Н. Колобовой написано о том, что дети дошкольного возраста не всегда могут осознанно отделять языковые элементы: особенно слова, которые не имеют предметное содержание (предлоги и др.), тяжелее морфемы [4].

Развивая речь дошкольников, применяются предметно - схематические модели. Формируя у детей дошкольного возраста представления о словах и предложениях, показывают графические схемы предложений. Воспитатель рассказывает им о том, что, предложение можно написать в виде схемы. Черточки в предложениях - слова. Дошкольникам предлагают составить предложение - «Пришла морозная зимушка. Задувает ледяная метель».

Графические схемы могут помочь дошкольникам наиболее точно почувствовать пределы слов и их раздельное написание в предложениях. В данной работе допускается применение различных иллюстраций и объектов.

Далее считается наиболее эффективным методом при работе с детьми, которые имеют речевые нарушения - сказка, оказывающая коррекционное воздействие.

Сказка является средством погружения ребенка в атмосферу той жизни и истории, которую проживает герой. Это «ключ» к ребенку и приобретению им новых знаний, накапливаемому им опыту [3]. Для того чтобы развить речь дошкольников воспитателем применяется методика сказкотерапии. Сказкотерапия проводится единожды в неделю. В младшей и средней группе сказкотерапия длится 15 - 20 минут. В старшей и подготовительной группе 25 - 30 минут. Проводя, сказкотерапию в младшей и средней группе применяют прием словесно-режиссерской игры, психогимнастики, словесного комментирования, совместной словесной импровизации - учат продолжению предложений педагога. В старшей группе применяют подобные методы, но с усложнением, занятно выполняют дошкольники пантомимические этюды, упражнения на ритмизацию и др.

Сказки влияют не только на эмоциональное состояние дошкольников, но и на их речевую активность. При использовании на занятиях сказкотерапии активизируется словарь детей. Ее применяют при нарушениях речи, а также работая над связной речью. В сказке заключаются речевые и коммуникативные функции: лексикообразная, потому что формируется языковая культура дошкольника; активизируется и развивается внутренняя слуховая память; слушая либо читая сказки, происходит преобразование вербально-знаковой формы сказок; развиваются коммуникативная и экспрессивная функции языка.

Все разновидности сказок можно преподнести в разном виде: анализе, рассказывании, сочинении, постановках и рисовании. Но необходимо помнить о том, что это делается с целью создания интереса и положительной мотивации ребят. Жизненные ценности, вот что является ядром сказкотерапии [3, с. 170].

Поэтому, становится возможным сделать вывод о том, что влияние сказкотерапии уникально в коррекционных целях, потому что другая деятельность не сможет оказать комплексное воздействие на речь дошкольника.

Если вы впервые услышите о следующей технологии, которая называется «синквейн», может показаться, что это название какого-то экзотического блюда или растения. Однако это всего лишь стихотворение, которое считается эффективным методом развития речи детей. В начале 20 века данный вид стихотворения разработала поэтесса американского происхождения - Аделаида Крэпси, опираясь на знакомые всем японские хайку и танка [7]. 
Легкость синквейна позволяет быстро его составить, однако это может не сразу получиться. Для того чтобы он получился правильным, необходимо обратить внимание на его структуру построения [2]. Синквейн строится из пяти строк. По своей форме он похож на елку: одно слово, два слова, три слова, четыре слова, одно слово.

У некоторых детей могут возникнуть трудности в написании синквейна. Устранить эту проблему можно, разделив детей по парам. Назвав тему синквейна, им дается шесть-восемь минут на его написание. Далее оба партнера поворачиваются друг к другу и из своих частей составляют один синквейн. Это предоставит им возможность проанализировать, написанное и прийти к общему решению задачи, которая перед ними стоит. В результате вся группа может прослушать синквейны каждой пары. Для лучшего понимания детьми того, что от них требуется лучше привести пример нескольких готовых синквейнов.

При составлении синквейна обогащается и расширяется словарь дошкольников. Их знакомят с таким понятием, как «слово, которое обозначает предмет» либо «слово, которое обозначает действие». Таким образом, закладывается «фундамент» для дальнейшей работы над предложением. Далее усваивают понятия «живой и неживой» предмет. Дошкольники свои работы могут оформить графически либо в виде сочинений.

Синквейн помогает успешно корректировать всю речевую систему: активизируется и обогащается речевая лексика, усваиваются навыки образования слов, развивается умение описания предметов и составления синквейна по картине, использования в речи различных по составу предложений.

Из выше сказанного, следует вывод о том, что инновационные технологии являются ключевым средством развития образования в целом и дошкольного учреждения в частности. Тем более, решая задачи формирования речевой активности дошкольников, которая основана на знаниях, невозможно без перехода образовательной системы на путь инноваций. Инновации затронули все компоненты образовательной деятельности целиком и полностью.

\section{Сиисок литературы / References}

1. Григорьева А.А. Качество дошкольного образования: интеграция науки и практики / А.А. Григорьева, Л.В. Николаева, Т.И. Никифорова, Л.С. Ядрихинская. Якутск: МЦНИП, 2013. 543 с.

2. Душка Н.Д. Синквейн в работе с дошкольниками» / М.Д. Душка // Журнал «Логопед», М.: «ТЦ Сфера», 2005. № 5. С. 85-91.

3. Зинкевич-Евстигнеева Т.Д. Тренинг по сказкотерапии // Т.Д. ЗинкевичЕвстигнеева. СПб.: «Речь», 2006. 176 с.

4. Карпова С.Н. Особенности ориентировки на слово у детей / С.Н. Карпова, И.Н. Колобова. М., 1978. 281 с.

5. Козаренко B.A. Учебник мнемотехники // Система запоминания «Джордано» [Электронный ресурс], 2007. Режим доступа: http://mnemonikon.ru (дата обращения: 10.03.2017).

6. Студопедия. [Электронный ресурс]. Режим доступа: http://studopedia.ru/ (дата обращения 10.03.2017).

7. Википедия. [Электронный ресурс]. Режим доступа: https://ru.wikipedia.org/ (дата обращения 10.03.2017). 


\title{
ОСОБЕННОСТИ РАЗВИТИЯ КОММУНИКАТИВНЫХ И РЕЧЕВЫХ НАВЫКОВ ДЕТЕЙ СТАРШЕГО ДОШКОЛЬНОГО BOЗРАСТА \\ Зотова И.В. ${ }^{1}$, Могилка Д.В. ${ }^{2}$ Email: Zotova1799@ scientifictext.ru
}

${ }^{1}$ Зотова Ирина Васильевна - кандидат педагогических наук, доцент;

${ }^{2}$ Могилка Диана Вадимовна - студент,

кафедра дошкольного образования и педагогики,

Крымский инженерно-педагогический университет,

2. Симферополь

\begin{abstract}
Аннотация: в данной статье рассмотрена проблема речевого развития $u$ коммуникации детей старшего дошкольного возраста. Рассмотрень понятия "речевой навык», «коммуникативный навык». Представлены особенности развития коммуникативных и речевых навыков старших дошкольников. Раскрыты формы общения дошкольников со сверстниками: эмоционально-практическое общение, ситуативно-деловая форма, внеситуативно-деловая форма. Показан ряд характерных особенностей общения дошкольников со сверстниками. Отражена специифика детских контактов на протяжении всего дошкольного возраста.

Ключевые слова: коммуникативные навыки, речевые навыки, старший дошкольный возраст.

\section{FEATURES OF DEVELOPMENT OF COMMUNICATIVE AND SPEECH SKILLS OF CHILDREN OF SENIOR PRESCHOOL AGE Zotova I.V. ${ }^{1}$, Mogilka D.V.}

\author{
${ }^{I}$ Zotova Irina Vasilevna - PhD in Pedagogy, Associate Professor; \\ ${ }^{2}$ Mogilka Diana Vadimovna - Student, \\ CRIMEAN ENGINEERING-PEDAGOGICAL UNIVERSITY, \\ SIMFEROPOL
}

DEPARTMENT OF PRESCHOOL EDUCATION AND PEDAGOGY,
\end{abstract}

\begin{abstract}
: this article discusses the problem of speech and communication development of children of senior preschool age. Discusses the concept of "speech skills", "communication skill". The peculiarities of development of communicative and linguistic skills of senior preschool children. Disclosed forms of communication of preschool children with peers: emotional, practical communication, situational business form, unhesitating-business form. Shows a number of characteristic features of communication of preschool children with peers. Reflects the specificity of children's contacts throughout preschool age.
\end{abstract}

Keywords: communicative skills, language skills, senior preschool age.

УДК 372.461

Актуальность проблемы развития коммуникативных и речевых навыков у старших дошкольников заключается в том, что количество контактов со взрослыми и сверстниками у ребенка в современном мире постоянно увеличивается, а эффективность и успешность таких взаимодействий зависит непосредственно от уровня речевого развития детей.

На данный момент показатели речевого развития многих современных дошкольников не соответствуют возрастной норме. Основная причина этого - разрыв коммуникативных связей между миром детей и миром взрослых: взрослые отчуждаются от детей, дети лишаются содержательных (живых, эмоциональных) способов общения. 
Коммуникативные и речевые умения исследовали многие отечественные и зарубежные ученые. К ним относятся: А.А. Бодалев, Л.П. Буева, Я.Л. Коломинский, А.А. Леонтьев, А.Н. Леонтьев, М.И. Лисина, В.М. Соковкин и др.

Проблемой развития коммуникативных способностей занимались многие ученые: Н.А. Асадулаева, Дж. Брунер, Л.С. Выготский, В.М. Григорьев, С.В. Григорьев, К. Монтенегро, С.Л. Новоселова, М.А. Норбашева, Н.Н. Палагина, А.Н. Фролова, С.А. Шмаков, А.П. Юсупова, Д.Б. Эльконин и многие другие.

Цель статьи заключается в рассмотрении особенностей развития коммуникативных и речевых навыков детей старшего дошкольного возраста.

Проблемы развития коммуникации сегодня особенно актуальны в старшем дошкольном возрасте, так как именно этот возраст считается отечественными психологами и педагогами (Л.А. Венгером, В.С. Мухиной, Н.Н. Поддъяковым и другими) как сензитивный. То есть это максимально чувствительный период, который обладает благоприятными условиями для формирования определенной способности или типа деятельности организма [7].

Такие ученые как Л.С. Выготский, М.И. Лисина и другие, занимавшиеся проблемой развития коммуникации старших дошкольников, считают, что главным условием для становления психических способностей и качеств ребенка, а именно речи, воображения, мышления, самооценки, является общение ребенка со взрослым. Такое общение приобщает детей к опыту человечества. Дошкольники посредством такого общения обмениваются знаниями, обогащают свой жизненный опыт [2].

Как мы успели заметить, современные дети неохотно идут на контакт, не могут понятно для окружающих выразить свою мысль, у таких детей слабо разработан речедвигательный аппарат. Коммуникативные способности необходимы, так как все мы находимся в социуме и так или иначе взаимодействуем с ним.

Зачастую взрослые не понимают всей важности звучащего слова в развитии и воспитании детей раннего возраста. Общение взрослого с ребенком сегодня вряд ли можно назвать общением. В современном мире это общение чаще кратковременное, формальное и поверхностное: проявляется в виде замечаний, указаний, инструкций. В том случае, когда у малыша не удовлетворилась потребность в общении со взрослыми, начинают проявляться всевозможные отклонения в поведении дошкольников: неуверенность при новых начинаниях, тяжелая адаптация в дошкольном учреждении, огромное количество страхов, тревожность и агрессивность, снижение показателей их речевой и познавательной активности.

ФГОС ДО выделяет такие образовательные области как «Речевое развитие» и «Социально-коммуникативное развитие». Сегодня данные области играют важнейшую роль для развития ребенка не только в плане речи, но и для личности в целом.

Сформировать речевой навык - это значит обеспечить необходимые условия для того, чтобы дошкольник мог правильно построить и реализовать высказывание. Для того, чтобы общение было полноценным, необходимо, чтобы мы, педагоги, сами умели пользоваться речевыми навыками для самостоятельного выражения своих мыслей, чувств, намерений, переживаний; если этого не будет, то речевая деятельность сформируется только лишь частично.

Коммуникативный навык - это навык взаимодействия с другими людьми, умение находить компромисс, умение слушать и высказывать свое мнение.

Известный психолог М.И. Лисина отмечала, что, начиная от раннего и до конца дошкольного возраста общение между детьми проходит значительные изменения по всем категориям: меняются содержание, потребности, мотивы и средства общения. От двух до семи лет выделяются два перелома; первый отмечается приблизительно в четыре года, второй - около шести лет [3].

Первый перелом мы можем наблюдать тогда, когда в жизни ребенка большую роль начинают играть другие дети. В этот период дошкольники начинают открыто предпочитать одиночную игру либо общество других детей взрослому. 
Во время второго перелома, по мнению М.И. Лисиной, происходит появление избирательных привязанностей, дружбы; возникают более устойчивые и глубокие отношений между дошкольниками.

Эти переломы можно считать временными границами 3-х этапов в развитии общения детей. Эти этапы (также как и этапы со сферой общения со взрослым) получили название «формы общения дошкольников со сверстниками».

По мнению М.И. Лисиной, первой формой является эмоционально-практическое общение со сверстниками (второй-четвертый годы жизни). На втором году у дошкольников мы замечаем заинтересованность к другому ребенку, дошкольник уделяет повышенное внимание к действиям сверстника, а к концу второго года возникает желание привлечь внимание сверстника к себе, показать свои результаты и увидеть его ответную реакцию. На представленном этапе дети общаются без предметных действий, общение происходит само по себе [4].

Вторая форма общения сверстников, которую выделяет М.И. Лисина, ситуативно-деловая. Данная форма складывается приблизительно к четырем годам и до шести лет. Сюжетно-ролевая игра уже коллективная - дошкольники преимущественно играют вместе, а не по одному. В процессе ситуативно-делового общения дети заняты совместным делом, они согласовывают свои действия с действиями партнеров и учитывают активность сверстников для достижения общей цели. Такое взаимодействие между детьми получило название сотрудничества.

По мнению М.И. Лисиной, к концу дошкольного возраста у многих (но не у всех) детей дошкольного возраста появляется новая форма общения, которая получила название «внеситуативно-деловая». К шести-семи годам значительно увеличивается количество внеситуативных контактов. Дети начинают рассказывать друг другу о том, где они отдыхали и что нового увидели, делятся своими впечатлениями и эмоциями [4].

Итак, социальная ситуация развития старшего дошкольника усложняется и дифференцируется. Взрослый человек остается главным в жизни ребенка, но взаимоотношения с ним кардинально меняются. В раннем возрасте ребенок общается исключительно с близкими взрослыми, как только ребенок немного подрастает, он вступает в отношения с более широким социальным миром. Появляется новая сфера социальных контактов ребенка - его отношения со сверстниками.

Общение дошкольников со сверстниками можно описать рядом характерных особенностей, которые отличают его от общения со взрослыми.

Как отмечает Е.О. Смирнова, первой и самой важной отличительной чертой является огромное разнообразие коммуникативных действий. Ребенок может спорить со сверстником, навязывать свою волю, успокаивать и т.д. Такие сложные формы поведения, как симулирование, стремление сделать вид, выразить обиду впервые появляются именно в общении с другими детьми.

Вторая яркая черта общения сверстников, как считала Е.О. Смирнова, состоит в его особо яркой эмоциональной насыщенности. При общении со сверстниками мы наблюдаем у дошкольника намного больше эмоций, чем при общении со взрослым, это самые разнообразные эмоциональные состояния - от злостного негодования до бурной радости, от нежности и сочувствия до агрессии [6].

Третья отличительная особенность контактов детей состоит в том, что они нестандартны. Если при взаимодействии со взрослым даже малыши соблюдают определенные общепринятые нормы поведения, то при общении со сверстником дошкольники не соблюдают нормы поведения. Они могут использовать самые неожиданные действия и движения: дети скачут, изображают различные позы, делают гримасы и т.д.

Еще одной особенностью общения сверстников является то, что инициативные действия берут верх над ответными. Особенно отчетливо это замечается, когда невозможно продолжить и развить диалог, так как отсутствует ответная реакция партнера. 
Для дошкольника намного важнее его собственное действие или высказывание, а инициативу сверстника он чаще всего не замечает и не поддерживает [6].

Таким образом, рассмотренные выше особенности общения раскрывают специфику детских контактов на протяжении всего дошкольного возраста.

Итак, понимание коммуникации подводит педагогов к пониманию того, что всетаки необходимо прикладывать все усилия для становления, формирования и развития у дошкольников коммуникативных умений и навыков.

Немаловажную роль в данном процессе играют также принципы и методы развития детской коммуникации. Ведь только правильная организация методологии развития процесса способна дать эффективный результат.

\title{
Сиисок литературы / References
}

1. Арушанова А.Г. Речь и речевое общение детей / А.Г. Арушанова. М.: Мозаика. Синтез, 2002. 272 c.

2. Выготский Л.С. Вопросы детской психологии : учеб.пособие / Л.С. Выготский. Изд. «Союз», 2007. $110 \mathrm{c.}$

3. Лисина М.И. Проблемы онтогенеза общения: учеб. пособие / М.И. Лисина. М.: «Педагогика», 2007. 160 с.

4. Лисина М.И. Общение детей со взрослым и сверстником: общее и различное / М.И. Лисина. М., 2005. 38 с.

5. Мухина В.С. Под ред. Венгера Л.А. Детская психология: Учеб. для студентов пед. ин-тов. 2-е изд., перераб. и доп. М.: Просвещение, 1985. 272 с.

6. Смирнова E.O. Особенности общения с дошкольниками: учеб. пособие для студ. сред. пед. учеб. заведений / Е.О. Смирнова. М.: Издательский центр «Академия», 2000. $160 \mathrm{c}$.

7. Сензитивный период / Психология личности // Психология и психиатрия: сайт практикующих психологов. [Электронный ресурс]. Режим доступа: http://psihomed.com/sensitivnyiy-period/ (дата обращения: 12.03.2017).

\section{ВЛИЯНИЕ ЗРИТЕЛЬСКИХ ПРЕДПОЧТЕНИЙ СТУДЕНТОВ НА ВЫБОР ТРАЕКТОРИИ ВНЕУЧЕБНОЙ ДЕЯТЕЛЬНОСТИ Красушкина А.В. ${ }^{1}$, Басова Д.Н. ${ }^{2}$ Email: Krasushkina1799@scientifictext.ru}

\author{
${ }^{1}$ Красушкина Анна Викторовна - кандидат филологических наук, дочент, \\ ${ }^{2}$ Басова Диана Николаевна - студент, \\ кафедра дошкольного образования, \\ Череповецкий государственный университет, \\ 2. Череповеи
}

\begin{abstract}
Аннотация: статья посвящена изучению интереса современных студентов к современному телевизионному контенту. Отмечается степень влияния медиасреды на интересы современной молодежи, приводятся данные опроса студентов 1 курса на предмет их зрительских предпочтений, выявляются связи между их ответами и заявленными интересами в сфере внеучебной деятельности (траектории "Спорт и здоровый образ жизни», «Волонтерство и сочиальная работа», «Международная деятельность», «Наука и инновации», «Бизнес и предпринимательство» и другие).

Ключевые слова: медиаобразование, зрительские предпочтения, воспитательная работа, внеучебная деятельность.
\end{abstract}




\title{
INFLUENCE OF STUDENT'S VISUAL PREFERENCES FOR THE SELECTION OF TRAJECTORY OF NON-TRAFFIC ACTIVITIES Krasushkina A.V. ${ }^{1}$, Basova D.N. ${ }^{2}$
}

\author{
${ }^{1}$ Krasushkina Anna Viktorovna - PhD of Philology, the associate professor; \\ ${ }^{2}$ Basova Diana Nikolaevna - Student, \\ DEPARTMENT OF PRESCHOOL EDUCATION, \\ CHEREPOVETS STATE UNIVERSITY, \\ CHEREPOVETS
}

\begin{abstract}
: the article is devoted to studying the interest of modern students in modern television content. The degree of influence of the media environment on the interests of modern youth is noted, the data of the 1st year students 'survey is given on their viewers' preferences, the links between their responses and declared interests in the field of extracurricular activities (trajectory "Sport and a healthy lifestyle", "Volunteering and social work" "International activity", "Science and Innovations", "Business and entrepreneurship" and others).
\end{abstract}

Keywords: media education, viewer preferences, educational work, extra-curricular activities.

УДК 378.184

Духовное здоровье молодежи сегодня является не только социокультурной потребностью, но и важной государственной задачей. Рост творческого, научного и профессионального потенциала молодежи - именно такая задача была поставлена Президентом РФ перед различными общественными институтами еще в 2009 году. Как отмечают современные исследователи, «сегодня стало очевидным, что театры, выставки и концертные залы больше не привлекают современного подростка, и опасения о постепенном отчуждении подрастающего поколения от ценностей отечественной и мировой культуры далеко не беспочвенны. Например, педагоги и библиотечные работники свидетельствуют о резком снижении читательского интереса среди молодежи» [3; с. 120]. Чем заменяется чтение, становится понятным после изучения статистики просмотра ТВ, использования ресурсов интернета молодежью. «Средства массовой информации, в частности телевидение, сегодня с полной уверенностью можно назвать одним из способов воздействия массовой культуры на сознание человека. В особенности, на молодежь, так как сознание молодых людей находится в стадии формирования и легко поддается различным влияниям, как позитивным, так и негативным», - отмечают студенты СибГИУ, РФ Зорин В.О и Киселева В.Е. в статье «Исследование влияния телевидения на жизнь молодежи» [2]. Если еще в 2000 году досугом молодежи являлся активный отдых, посещение культурных, спортивных и образовательных учреждений, то в 2014 году большинство молодых респондентов предпочитали провести вечер за просмотром телепередач или фильмов, за виртуальным общением [4].

В этих условиях закономерно, что современные высшие учебные заведения ставят перед собой важную задачу не только обучать, но и развивать творческий, научный и профессиональный потенциал студенчества, что, например, в ЧГУ реализуется через траектории внеучебной деятельности. Для внеучебной работы вуза актуальным является формирование общекультурных компетенций студентов в условиях развития университетской социокультурной среды. Программа, реализуемая в 2015 - 2020 гг. основана на принципах создания развивающей среды, единства воспитательной и учебной деятельности университета, формирования общекультурных компетенций, непрерывности опыта студентов и соуправления. К внеучебным траекториям относятся: профессиональная карьера, наука и инновации, лидерство и управление, 
международная деятельность, волонтерство и социальное проектирование, культура и искусство, бизнес и предпринимательство, спорт и здоровый образ жизни - их целью является создание условий для личностного и профессионального развития обучающихся, осознанного выбора и реализации их жизненных стратегий.

Целью данной работы является выявление связей между зрительскими предпочтениями студентов 1 курса кафедры дошкольного образования очной формы обучения и выбранной ими траекторией внеучебной деятельности.

Для того чтобы понять, насколько серьезной сегодня является проблема зависимости молодежи от просмотра телепередач, мы провели опрос среди студентов. В опросе, проведенном в социальной сети «ВКонтакте» с 19 по 25 марта 2017 года, приняли участие 55 человек в возрасте от 17 до 19 лет. Респондентам предлагалось ответить на ряд вопросов, например, сколько времени в день вы отводите на просмотр фильмов, телепередач; какие телеканалы предпочитаете смотреть; фильмы каких жанров, каких производителей вы предпочитаете; считаете ли вы, что просмотр телевизора наносит вред здоровью и другие.

Результаты показывают, что более 50\% респондентов смотрят телевизор от 2 до 4 часов в день. 6 человек ответили, что смотрят телевизор до 2 часов в день. Среди предпочитаемых молодежью телевизионных каналов указаны развлекательные (50 человек), информационные (36 человек), образовательные (10 человека), никто не указал спортивные каналы. Более половины респондентов (55\%) предпочитают телеканалы развлекательного характера, что подтверждается результатами ответов на вопрос о жанрах предпочитаемых фильмов. Молодежь выбирает комедийные, военные и исторические фильмы, драмы и фантастику. Примечательно, что в основном, эти фильмы (73\% респондентов отметили этот факт) оказываются зарубежного производства. Обратим внимание на то, что 64\% респондентов считают, что просмотр телевизора, скорее всего, вредит здоровью. Однако, как показывают ответы на первый вопрос, ни один из респондентов не отказывается от просмотра ТВ. Тем не менее, осознание потенциальной опасности дает возможность предположить, что с повышением уровня критического мышления и образования молодые люди способны будут выбирать для себя более полезные увлечения.

На вопрос о том, как студенты предпочитают проводить свободное время, мы получили следующие ответы: просмотр телевизора - 10 человек, общение в интернете - 30 человека, чтение книг - 30 человек, хобби (кружки, секции) - 40 человека, прогулки - 45 человек. Однако в личной беседе, студенты признаются, что на прогулках они активно пользуются гаджетами (смартфонами, планшетами) для виртуального общения.

Итак, даже небольшая выборка позволяет увидеть, что студенты в большой мере зависят от медиасреды и телевидения и ощущают эту зависимость. Они много времени тратят на просмотр различных телепередач; смотрят больше развлекательных каналов, чем образовательных; предпочитают проводить свое свободное время на прогулке, но при этом находятся онлайн.

Полученные данные мы сравнили с результатами университетского анкетирования студентов 1 курса, проведенного в октябре 2016 года, которые показывают, какие траектории внеучебной деятельности выбрали первокурсники. Траекторию «Профкарьера» выбрали 42\% студентов, «Волонтерство и соцпроект» - 28\%, «Лидерство и управление» - 28\%, «Наука и инновации» - 70\%, «Спорт и здоровый образ жизни» - 42\%, «Культура и творчество» - 56\%. Никто не выбрал траектории: «Бизнес» и «Международная деятельность». Таким образом, можно предположить, что зрительские предпочтения студентов 1 курса не влияют на выбор ими траекторией внеучебной деятельности. Так, предпочитая смотреть развлекательные передачи на ТВ, для направления своей внеучебной деятельности студенты выбирают науку и инновации; не выбирая на ТВ спортивные каналы, многие респонденты указали траекторию «Спорт и здоровый образ жизни»; просматривая в больших 
количествах фильмы зарубежного производства, студенты не выбирают траекторию «Международная деятельность».

Итак, исследование показало, что первокурсники сами не ощущают связи между зрительскими предпочтениями и траекторией собственного саморазвития. Являясь активными потребителями медиапродуктов различного типа, они не используют медиасреду для получения знаний в выбранной области деятельности, для расширения своего кругозора или получения важной информации. Телевизор для них, как и для большинства современных зрителей, - прежде всего - способ снять эмоциональное напряжение, получить удовольствие, развлечься.

\title{
Сиисок литературы / References
}

1. Журин А.А. Школа, подростки, средства массовой информации, Монография. - М.: ЮНПРЕСС, 2000. [Электронный ресурс]. Режим доступа: http://www.ynpress.ru/cgi-bin/main.cgi?action=show\&dir=metodbiblioteka\&file=26/ (дата обращения: 19.03.2017).

2. Зорин В.О., Киселева В.Е. Исследование влияния телевидения на сознание молодежи // Молодежный научный форум: Гуманитарные науки: электр. сб. ст. по материалам XIII студ. междунар. заочной науч.-практ. конф. М.: «МЦНО», 2014. № 6 (13) [Электронный ресурс]. Режим доступа: https://nauchforum.ru/archive/MNF_humanities/6(13).pdf/ (дата обращения: 10.03.2017).

3. Красушкина A.B. Медиаграмотность как компетенция современного специалиста дошкольного образования // Череповецкие научные чтения, 2015. Материалы Всероссийской научно-практической конференции (11-12 ноября 2015 г). Часть 2: педагогика, психология, методика преподавания, художественное образование. Череповец, 2016. С. 120-121.

4. Сайт лаборатории воспитания нравственно-этической культуры ГосНИИ семьи и воспитания. [Электронный ресурс]. Режим доступа: http://ethos.narod.ru/vospit.htm/ (дата обращения: 02.04.2017).

\section{РАЗВИТИЕ ИНТЕЛЛЕКТУАЛЬНО-ЯЗЫКОВЫХ СПОСОБНОСТЕЙ ДЕТЕЙ СТАРШЕГО ДОШКОЛЬНОГО BO3PACTA \\ Зотова И.В. ${ }^{1}$, Зосенко Е.А. ${ }^{2}$ Email: Zotova1799@scientifictext.ru}

\footnotetext{
${ }^{\text {I} З о т о в а ~ И р и н а ~ В а с и л ь е в н а ~-~ к а н д и д а т ~ п е д а г о г и ч е с к и х ~ н а у к, ~ с т а р и и и ̆ ~ п р е п о д а в а т е л ь ; ~}$

${ }^{2}$ Зосенко Екатерина Александровна - студент,

кафедра дошкольного образования и педагогики,

Крымский инженерно-педагогический университет,

г. Симферополь
}

\begin{abstract}
Аннотация: в данной статье раскрываются содержание и структура интеллектуально-языковых способностей с позиций различных исследователей в области педагогики и психологии. Также широко раскрыты особенности интеллектуально-языковых способностей возрастного и индивидуального развития у детей старшего дошкольного возраста, выделены основные проблемы развития. Отдельное внимание уделено методам и приемам работь по развитию интеллектуально-языковых способностей детей в условиях дошкольного образовательного учреждения.
\end{abstract}


Ключевые слова: интеллектуально-языковые способности, особенности, компоненты, формирование, развитие, требования программ, методы, приемь pаботьл.

\title{
THE DEVELOPMENT OF INTELLECTUAL AND LANGUAGE ABILITIES OF CHILDREN OF SENIOR PRESCHOOL AGE Zotova I.V. ${ }^{1}$, Zosenko E.A. ${ }^{2}$
}

\author{
${ }^{I}$ Zotova Irina Vasilivna - PhD in Pedagogy; \\ ${ }^{2}$ Zosenko Ekaterina Aleksandrovna - Student, \\ DEPARTMENT OF PRESCHOOL EDUCATION AND PEDAGOGY, \\ CRIMEAN ENGINEERING-PEDAGOGICAL UNIVERSITY, \\ SIMFEROPOL
}

\begin{abstract}
: this article reveals the content and structure of intellectual and linguistic abilities from the positions of various researchers in the field of pedagogy and psychology. The features of the intellectual and linguistic abilities of the age and individual development in children of the senior preschool age are also widely disclosed, and the main problems of development are highlighted. Special attention is paid to methods and methods of work on developing the intellectual and linguistic abilities of children in pre-school educational institutions.
\end{abstract}

Keywords: intellectual-language abilities, features, components, formation, development, requirements, programs, methods, practices.

УДК 372.32

Постановка проблемы. Интеллектуально-языковое развитие в дошкольной педагогике имеет особое значение, поскольку данное направление является основополагающим для подготовки дошкольников к школьному обучению. Интеллектуально-языковая способность выступает компонентом языковой и интеллектуальной способностей и оказывает значительное воздействие на формирование личности в целом. В настоящее время в дошкольной педагогике уделяется огромное внимание интеллектуальному и языковому развитию детей. Это нашло свое отражение в таких документах, как: Закон «Об образовании в Российской Федерации» [8], «Федеральный государственный образовательный стандарт дошкольного образования» [7], так же широко раскрыты задачи интеллектуального и языкового развития в современных дошкольных образовательных программах. Многие программы дошкольного образования, построенные с учетом требований ФГОС ДО [7], уделяют большое внимание интеллектуальному и языковому развитию дошкольников. Данное направление отображено в рамках взаимодополнения образовательных областей «Социально-коммуникативное развитие», «Речевое развитие» и «Познавательное развитие». Несмотря на разработанность данного вопроса, в современной педагогической литературе нет четкого определения методов и приемов интеллектуально-языкового развития дошкольников, которые отвечали бы требованиям современных программ дошкольного образования, и включали в себя структуру последовательного развития всех направлений интеллектуально-языкового развития, выдвинутых современными требованиями к организации дошкольного образования, что ставит перед исследователями задачу поиска эффективных методов и средств развития указанных способностей дошкольников.

Цель статьи. В данной статье раскрыты содержание и структура интеллектуально-языковых способностей, а также методы и приемы работы по развитию интеллектуально-языковых способностей детей в условиях ДОУ.

Изложение основного материала. Состав интеллектуально-языковой способности, по мнению Т.Б. Филичевой [9], включает в себя несколько компонентов, состоящих их фонетических, лексических, морфологических, синтаксических, семантических 
составляющих, связанных определенными правилами, позволяющими осуществлять выбор функциональных элементов для реализации коммуникативных потребностей.

Поскольку речь непосредственно связана с мышлением, структура интеллектуально-языковой способности в этой связи, включает в себя интеллектуальный (общий) и специальный - лингвистический (состоящий из языковой и речевой частей) - компоненты [10]. Каждый компонент интеллектуальноязыковой способности состоит из определенных умений и способностей:

- интеллектуальный компонент: логическое мышление (владение логикоязыковыми операциями анализа, синтеза, обобщения, абстрагирования, классификации, дифференциации); образное мышление (умения сопоставлять словесные, живописные, музыкальные образы).

- языковой компонент: осмысление языковой теории (семантики языковых понятий, смысла лингвистических текстов); восприимчивость к семантике языковых единиц, к грамматическим значениям.

Центром языковой способности является «чувство языка», языковая интуиция.

Каждый компонент интеллектуально-языковой способности обладает определенной структурой, состоящей из умений и способностей, ключевыми из которых выступают, по мнению Р.Е. Левина [5]: способность адекватно воспринимать и оценивать вербально выраженное содержание и выражать в слове собственные мысли в соответствии с темой и замыслом высказывания; способность к оценочному восприятию чужих и собственных речевых произведений и корректировке плана содержания и плана выражения своего речевого произведения;- способность к вероятностному прогнозированию, к планированию своих речевых действий при восприятии и создании текста.

Формирование данных компонентов является необходимым на всех возрастных этапах дошкольного образования, однако особую актуальность приобретает данное направление работы со старшими дошкольниками, на этапе подготовки к дальнейшему обучению в школе.

Таким образом, интеллектуально-языковые способности представляют собой многоуровневую организованную функциональную систему, компоненты которой позволяют осуществлять выбор функциональных элементов для реализации коммуникативных потребностей человека.

К старшему дошкольному возрасту, согласно Д.Б. Эльконину [10], ребенок достигает такого уровня освоения языка, когда язык становится не только полноценным средством общения и познания, но и предметом сознательного изучения.

Интеллектуально-языковая способность детей старшего дошкольного возраста зависит от нескольких причин, к которым, по словам А.Н. Гвоздева [2], можно отнести следующие: качество и количество жизненного опыта детей, способы ознакомления с окружающими явлениями, особенности общения взрослых с детьми, наличие стимулирующих к рассуждению вопросов взрослых. Трудности формирования интеллектуально-языковой способности обусловлены структурной сложностью и незнанием детьми специальных языковых средств связи смысловых частей речевого высказывания.

Основываясь на интеллектуально-языковых особенностях детей старшего дошкольного возраста, а также учитывая требования современных программ дошкольного воспитания, организацию работы с детьми в данном направлении стоит реализовывать в следующих направлениях:

- развивать логическое мышление детей;

- развивать образное мышление;

- расширять словарный запас;

- формировать грамматический строй речи;

- развивать восприимчивость к семантике языковых единиц, к грамматическим значениям; 
- развивать навыки словотворчества;

- формировать умения строить связное высказывание, обогащать речь детей тропами, фигурами речи;

- формировать умения использовать в речи средства интонационной выразительности.

С этой целью можно организовать различные методы работы, к которым могут быть отнесены:

- создание необходимых условий для интеллектуально-языкового развития;

- организацию предметно-развивающего пространства, в котором должны располагаться центры речевой активности детей, а также разнообразный практический материал для организации речевых игр и занятий с детьми (картотеки для проведения артикуляционных гимнастик; комплексы пальчиковых игр; игрушки и игровые пособия для развития правильного речевого дыхания, тематические альбомы; дидактические игры, художественная литература, настольно-печатные игры и др.).

- использовать в работе различные методы, приемы и технологии обучения;

- организация работы с родителями.

Приемами работы по развитию интеллектуально-языковых способностей детей могут выступать:

- общение (беседы, подведение итогов, речевые игры), игры (сюжетно-ролевые, дидактические, подвижные, театрализованные и т.п.), экскурсии [3];

- ТРИЗ. Организовывают в форме диалога, используются вопросы, которые побуждают детей к сравнению, к установлению сходства и различия (по какому признаку похожи, отличаются предметы? и т.п.) [4];

- приемы мнемотехники Т.А. Ткаченко [6] предлагает применять для составления описательных рассказов мнемотаблицы, с опорой на которые дети составляют более содержательные рассказы;

- метод экспериментирования. В процессе проведения эксперимента с детьми пополняется словарный запас, развиваются умения классифицировать предметы, активно развивается речь-рассуждение [1].

Вывод. Организованное применение в работе с детьми перечисленных методов и приемов, а так же целенаправленная, планомерная и последовательная работа педагога в данном направлении в полной мере будет способствовать эффективному развитию у дошкольников интеллектуально-языковых умений.

\section{Список литературы / References}

1. Баранова Э. Учимся задавать вопросы. [Текст] / Э. Баранова // Дошкольное воспитание, 2012. № 12. С. 12-20.

2. Гвоздев А.Н. Вопросы изучения детской речи. [Текст] / А. Н. Гвоздев. М.: Знание, $1961.667 \mathrm{c}$.

3. Каджаспирова Г.М. Использование технических средств в дошкольном образовании. [Текст]: / Г.М. Каджаспирова. М.: Просвещение, 2001. 128 с.

4. Кудряшова О.В. ТРИЗ: волшебные кольца Луллия. [Текст] // Дошкольное воспитание, 2007. № 3. С. 46.

5. Левина P.E. Воспитание правильной речи у детей. [Текст] / Р.Е. Левина. М.: Просвещение, 2008. 329 с.

6. Ткаченко T.A. Схемы для составления описательных рассказов. [Текст] / Т.А. Ткаченко. М.: АРКТИ, 2009. 87 с.

7. Федеральный государственный образовательный стандарт дошкольного образования. [Электронный ресурс]: Утвержден приказом Министерством образования и науки Российской Федерации 2013 г. Режим доступа: http://www.firo.ru/wp-content/uploads/2013/11/ FGOS_DO.pdf/ (дата обращения: 05.05.2017). 
8. Федеральный закон от 29.12.2012 N 273-Ф3 (ред. от 21.07.2014) «Об образовании в Российской Федерации» (с изм. и доп., вступ. в силу с 01.01.2015) [Электронный peсурс]. Режим доступа: http://www.consultant.ru/document/cons_doc_LAW_165887/ (дата обращения: 05.05.2017).

9. Филичева Т.Б. Особенности формирования речи у детей дошкольного возраста. [Текст] / Т.Б. Филичева-М.: РИЦ «Альфа» МГОПУ им. М.А. Шолохова, 2000. 350 с.

10. Эльконин Д.Б. Психология развития в детском возрасте. [Текст] / Д.Б. Эльконин. М.: Просвещение, 1997. 395 с.

\title{
К ВОПРОСУ О СОДЕРЖАНИИ ПРОФЕССИОНАЛЬНОЙ ПЕРЕВОДЧЕСКОЙ КОМПЕТЕНТНОСТИ ПРИ ПОДГОТОВКЕ ПЕРЕВОДЧИКОВ ПРОФЕССИОНАЛЬНО ОРИЕНТИРОВАННЫХ ТЕКСТОВ Киселева O.M. Email: Kiseleva1799@ scientifictext.ru
}

\author{
Киселева Оксана Михайловна - преподаватель, \\ кафедра иностранных языков, \\ Рязанский государственный медицинский университет им. академика И.П. Павлова, г. Рязань
}

\begin{abstract}
Аннотация: в статье затрагивается проблема профессиональных компетенций, которыми должен обладать письменный переводчик профессионально ориентированных текстов факультета дополнительного образования «Переводчик в сфере профессиональной коммуникации». В статье приводятся различные подходы отечественных и зарубежных исследователей к установлению навыков и умений профессиональной компетентности. Делается попытка сформулировать объем основополагающих профессиональных компетенций, a вместе $c$ тем $u$ классифицировать основные компетенции, которые будут необходимы будущему переводчику для реализации личного потенциала в профессии и карьере.
\end{abstract}

Ключевые слова: переводчик в сфере профессиональной коммуникации, компетенция, письменный перевод, объем, умения.

\section{TO THE QUESTION OF THE CONTENT OF PROFESSIONAL TRANSLATION COMPETENCE IN THE TRAINING OF TRANSLATORS OF PROFESSIONALLY ORIENTED TEXTS Kiseleva O.M.}

\author{
Kiseleva Oxana Michaylovna - Lecturer, \\ FOREIGN LANGUAGES DEPARTMENT, \\ RYAZAN STATE I.P. PAVLOV MEDICAL UNIVERSITY, RYAZAN
}

\begin{abstract}
: the article reveals the problem of defining professional translation competence, to be gained by translators of professionally oriented texts, trained at the faculty of additional education "translator in the sphere of professional communication". It represents a variety of approaches to establishing skills and professional competence. The article reports of an attempt to specify a particular volume of main professional competences and along with that an effort to classify the main competences to be needed to future translators for realization of personal potential in his profession and career.
\end{abstract}

Keywords: translator in the sphere of professional communication, competence, translation, volume, skills. 
Медицина - такая область науки, которая требует постоянного обновления и интеграции знаний. Современный врач должен быть не только профессионалом в своей области, но и отлично владеть иностранным языком, для того, чтобы идти в ногу со стремительно развивающимися технологиями во всем мире. По этой причине курс дополнительного образования «Переводчик в сфере профессиональной коммуникации» требует модификации переводческих компетенций, создания особых условий преподавания ИЯ, и вместе с тем разработки иного содержания, которое обеспечит эффективную и конкурентоспособную деятельность переводчика.

Перевод и письмо вещи родственные, в том смысле, что их создание (письменного текста и создание переводного текста) зависит от того как человек умеет предугадывать, создавая письменный текст перевода. Его автор должен быть уверен, что он отвечает на вопросы предполагаемого читателя, в той последовательности, в какой они могут поступать. Если переводчик способен предугадывать, то процесс перевода становится более экономичным и эффективным.

Вопросы переводческой компетентности структуры, а также ее содержания изучаются отечественными лингвистами (В.Н. Комиссаров А.В. Хуторский, Н.Н. Гавриленко) а также зарубежными специалистами (А.Д. Швейцер, К. Норд, Р. Белл, М. Пресас). Вместе с тем, анализ лингвометодической литературы показывает, что единого мнения касательно объема компетентности письменного переводчика до сих пор не существует. Многоплановость переводческой компетентности позволяет исследователям по-разному видеть не только необходимые умения, но и ключевые компетенции. Компетентность переводчика составляет владение соответствующей компетенцией [7, с. 29], а также определенным набором навыков и умений. В.Н. Комиссаров выделяет следующие умения:

-умение выполнять действия одновременно на двух языках;

- умение понимать внутренний смысл высказывания;

- умение оставаться как можно ближе к исходному тексту;

- умение выбирать и правильно преодолевать трудности, связанные с лексическими, фразеологическим, грамматическими и стилистическим особенностями исходного текста;

- умение анализировать текст оригинала.

Швейцер А.Д. выделяет такие составляющие профессиональной переводческой компетентности как:

- владение технологией перевода;

- способность интерпретации исходный текст по-переводчески;

- творческие способности к переводу;

- определенный минимум фоновых знаний (знание предмета) [7, с. 87].

Некоторые исследователи предпринимают попытку сгруппировать ключевые компетенции, как это сделал, например, М. Пресас. Исследователь акцентирует внимание на языковую компетенцию [5, с. 34]. К. Норд к базовым компетенциям относит лингвистическую и культурную компетенции [4, с. 198]. Р. Белл выделяет грамматическую, социолингвистическую, дискурсивную и стратегическую компетенции [1, с. 64]. Н.Н. Гавриленко, исследуя профессиональную компетентность переводчика профессионально ориентированных текстов, выделяет интегративную компетенцию [2, с. 112], что означает способность эффективно применять полученные знания по своей специальности. Как видно из вышесказанного, профессиональная компетентность переводчика явление весьма сложное по своему содержанию и может включать коммуникативную, предметную, дискурсивную, социокультурную, социальную, грамматическую и стратегическую компетенции [6].

В силу того, что переводоведение включает данные большого числа смежных дисциплин, профессиональная компетентность переводчика профессионально 
ориентированных текстов, на наш взгляд, должна включать тот объем компетенций, который будет отвечать требованиям не только целям и задачам обучения, но и соответствовать его этапам.

Нам представляется целесообразным уточнить объем профессиональных компетенций письменного переводчика медицинских текстов, обучающегося на факультете «Переводчик в сфере профессиональной коммуникации».

Прежде всего, следует включить языковую компетенцию, так как переводчику требуется знание как минимум двух языков. Переводчик необходимо уметь адаптироваться к любой конкретной ситуации общения. Данное умение реализуется в коммуникативной компетенции. Компетентному переводчику необходимо знать особенности социального и речевого поведения страны языка оригинала, что достигается при помощи социокультурной компетенщии. Умение осуществлять переводческие трансформации, знать стратегии перевода реализуется при помощи технической компетенции. Ровно, как и способность, создавать тексты в зависимости от ситуации и коммуникативной задачи, что достигается при помощи текстообразующей компетенции. Вместе с тем, в современном мире невозможно представить работу письменного переводчика без применения интернет технологий, переводческих модулей памяти, специализированных электронных словарей, что говорит о необходимости владения информационно-технологической компетенциией. Предполагаем, упомянутые выше три компетенции являются базовыми для письменного переводчика профессионально ориентированных текстов. Одну из самых главных ценностей представляет, на наш взгляд, умение письменного переводчика угадывать, предвидеть предполагаемый результат перевода, что достигается при помощи глубоких знаний своей специальности и накопленного переводческого опыта в данной области. Формирование упомянутого умения включает необходимость владения специально-переводческой компетенцией. Вместе с тем, знания об окружающем мире, контексте речевого акта реализуются посредством экстралингвистической компетенции. Интегративная компетенция - позволяет актуализировать полученные знания по основной специальности, что является необходимым условием для успешной работы письменного переводчика. И наконец, личностная компетенция, которая включает качества и характеристики переводчика, позволяющий осуществлять деловой подход к профессиональной деятельности.

Приведенную выше классификацию можно представить в виде таблицы 1.

Таблиия 1. Профессиональная компетентность письменного переводчика

\begin{tabular}{|c|}
\hline $\begin{array}{c}\text { Профессиональная компетентность переводчика профессионально- } \\
\text { ориентированных текстов }\end{array}$ \\
\hline Языковая компетенция \\
\hline коммуникативная компетенция \\
\hline Социокультурная компетенция \\
\hline Техническая компетенция \\
\hline Интегративная компетенция \\
\hline Текстообразующая компетенция \\
\hline Информационно-технологичекая компетенция \\
\hline Специально-переводческая компетенция \\
\hline Личностная компетенция \\
\hline Экстралингвистическая компетенция \\
\hline
\end{tabular}

Безусловно, что компетентный переводчик профессионально ориентированных текстов, должен не только хорошо знать иностранный язык, но и владеть переводческими стратегиями и приемами, разбираться в культурных особенностях социального и речевого поведения носителей иностранного языка. Таким образом, еще до начала обучения переводчика профессионально ориентированных текстов 
нужно четко понимать объем каких навыков и умений должен быть сформирован к концу обучения.

Приведенный анализ позволил как изучить, так и уточнить основной объем профессиональной компетентности письменного переводчика в сфере профессиональной коммуникации, что позволит ему обеспечить эффективную и конкурентоспособную деятельность.

\section{Сиисок литературы / References}

1. Bell R.T. Translation and Translating. L.: Longman, 1991. 298 p.

2. Гавриленко Н.Н. Обучение переводу в сфере профессиональной коммуникации: Монография. М.: РУДН, 2008. 175 с.

3. Комиссаров В.Н. Современное переводоведение. М: Издательство «ЭТС», 2001. $424 \mathrm{c}$.

4. Nord C. Text Analysis in Translator Training, Dollerup C et A. Loddegaard (eds), Teaching Translation and Interpreting. Amsterdam et Philalphie: John Benjamins, 1992. $274 \mathrm{p}$.

5. Presas M. Investigating Translation: Selected papers from the $4^{\text {th }}$ International on Translation, Barcelona, 1998. 294 p.

6. Хуторский А.В. Ключевые компетенции и образовательные стандарты. Интернетжурнал «ЭДОС». [Электронный ресурс]. Режим доступа: http://www.eidos.ru/journal/2005/0910-12.htm/ (дата обращения: 17.04.2017).

7. Швейцер А.Д. Теория перевода: Статус проблемы, аспекты. М.: Наука, 1988. 215 с. 


\section{СОВЕРШЕНСТВОВАНИЕ СИСТЕМЫ ОКАЗАНИЯ СПЕЦИАЛИЗИРОВАННОЙ ОНКОЛОГИЧЕСКОЙ ПОМОЩИ НАСЕЛЕНИЮ КЫРГЫЗСКОЙ РЕСПУБЛИКИ \\ Айдарбекова А.А. ${ }^{1}$, Сулайманова А.А. ${ }^{2}$, Соодонбеков Э.Т. ${ }^{3}$, Миненков Г.О. ${ }^{4}$, Тургунбаев У.А. ${ }^{5}$ Email: Aidarbekova1799@scientifictext.ru}

${ }^{1}$ Айдарбекова Айжана Азаматовна - доктор медииинских наук, профессор, ученый секретарь;

${ }^{2}$ Сулайманова Аида Анаркуловна - заведующая отделением, организационно-методическое отделение;

${ }^{3}$ Соодонбеков Энвербек Тентиевич - кандидат медицинких наук, руководитель отдела, отдел эпидемиологии злокачественных новообразований,

Национальный центр онкологии;

${ }^{4}$ Миненков Геннадий Олегович - доктор медичинских наук, профессор, заведующий отделением, отделение компьютерной томографии, клиника «Тотех»;

${ }^{5}$ Тургунбаев Уланбек Айтбаевич - кандидат медицинских наук, старший научный сотрудник, отделение химиотерапии,

Национальный центр онкологии,

г. Бишкек, Кыргызская Республика

Аннотация: в статье представлены данные о ситуации с оказанием онкологической помощи в Кыргызской Республике. Отражены данные заболеваемости и смертности от злокачественных новообразований в КР, а такюе даны рекомендации о путях решения сложившихся проблем.

При проф. осмотре было выявлено 889 (16,0\%) онкологических больных, по регионам от 0\% до 69,4\%. Около 50\% онкологических больных, впервые взятых на учет, погибают, не дожив 1 года. Одной из причин высокой одногодичной летальности является позднее обращчение больных к врачам, отсутствие квалифицированных кадров в поликлиниках, снижение онкологической настороженности врачей и населения республики, отсутствие смотровых кабинетов в поликлиниках и др.

Ключевые слова: злокачественные опухоли, рак, заболеваемость, смертность, онкологическая служба.

\section{IMPROVEMENT OF THE SYSTEM OF RENDERING SPECIALIZED ONCOLOGICAL CARE TO THE POPULATION OF THE KYRGYZ REPUBLIC \\ Aidarbekova A.A. ${ }^{1}$, Sulaimanova A.A. ${ }^{2}$, Soodonbekov E.T. ${ }^{3}$, Minenkov G.O. ${ }^{4}$, Turgunbaev U.A. ${ }^{5}$}

\footnotetext{
${ }^{I}$ Aidarbekova Aijana Azamatovna - doctor of medical sciences, professor, scientific secretary;

${ }^{2}$ Sulaimanova Aida Anarkulovna - head of the department, ORGANIZATIONAL AND METHODICAL DEPARTMENT;

${ }^{3}$ Soodonbekov Enverbek Tentievich - candidate of medical sciences, head of the Department, DEPARTMENT OF EPIDEMIOLOGY OF MALIGNANT NEOPLASMS,

NATIONAL CENTER OF ONCOLOGY;

${ }^{4}$ Minenkov Gennadyi Olegovich - doctor of medical sciences, professor, head of the department, COMPUTED TOMOGRAPHY DEPARTMENT, THE TOMEX CLINIC;

${ }^{5}$ Turgunbaev Ulanbek Aitbaevich - candidate of medical sciences, researcher, DEPARTMENT OF CHEMOTHERAPY, NATIONAL CENTER OF ONCOLOGY, 
Abstract: the article presents data on the situation with the provision of cancer care in the Kyrgyz Republic. The data of morbidity and mortality from malignant neoplasms in the $K R$ are reflected and also recommendations on ways of the decision of the developed problems are given.

With preventive examination 889 (16.0\%) of cancer patients were diagnosed, and in regions from $0 \%$ to $69.4 \%$. About $50 \%$ of cancer patients, first taken into account die, not surviving 1 year. One of the reasons for the high one-year mortality is the late treatment of patients to doctors, the lack of qualified personnel in the polyclinic, the reduction of oncological alertness of doctors and the population of the republic, the lack of observation rooms in polyclinic.

Keywords: malignant tumors, cancer, morbidity, mortality, oncological service.

УДК 616-006.04

На сегодняшний день для повсеместного развития и процветания любого государства очень важно уделять особое значение человеческому фактору, особенно в отношении здоровья населения страны. Именно забота о человеческих ресурсах позволяет странам иметь развитую экономику [2]. Особый интерес к сохранению и поддержанию здоровья населения отмечен в странах с социально ориентированной рыночной экономикой.

Очень важно уделять достаточное внимание всем без исключения факторам, таким как медицинские, состоянию экологии, социальным, экономическим, поскольку без этого мы будем наблюдать неукоснительное снижение уровня жизни нашего населения. Государство должно понимать, что без его пристального внимания к состоянию здоровья населения невозможно продвижение вперед и здесь, необходимо больший акцент придавать, прежде всего, профилактическим мероприятиям [1]. Ежегодный рост числа людей с различного вида утратой трудоспособности, а также низкая продолжительность жизни населения отодвигает возможность экономического рывка вперед.

Особое место в такой ситуации занимают злокачественные опухоли, которые относятся к основным причинам инвалидизации и смертности населения во всем мире и в Кыргызстане в частности. На сегодня,смертность среди населения от злокачественных опухолей занимает одно из ведущих мест в структуре общей смертности, что говорит о глобальной проблеме человечества.

В каждой стране должна функционировать онкологическая служба, включающая в себя сеть различного уровня учреждений. В развитых странах, там, где государство финансово обеспечивает ведущие онкологические учреждения, существует строгая вертикаль. Именно головные учреждения обеспечивают и контролируют в своих странах оказание специализированной онкологической помощи. В этих странах помимо головного учреждения имеются подконтрольные ему специализированные онкологические институты.

В настоящее время наблюдается неуклонный рост числа онкологических заболеваний, и данная тенденция затронула также и Кыргызскую Республику [3]. В Кыргызстане, по официальным данным в 2014 г. было впервые взято на учет 5552 онкологических больных и данная цифра с каждым годом только увеличивается.

В Кыргызстане, как и во многих странах мира, основным фактором возникновения нетрудоспособности, а также высокой заболеваемости и смертности являются неинфекционные заболевания, к которым относятся злокачественные опухоли, что отражено в статистических данных Республиканского медико-информационного центра за 2011 год.

Онкологическая служба КР представлена следующими медицинскими учреждениями: Национальный центр онкологии (НЦО) на 400 коек, Ошский межобластной центр онкологии (ОМОЦО) - 100 коек, онкологические отделения в г. 
Джалал-Абад - 30 коек, в Иссык-кульской области - 10 коек, в Чуйской области 15 коек. Всего 555 коек.

Таблииа 1. Сеть онкологических учреждений в Кыргызстане

\begin{tabular}{|c|c|c|c|}
\hline Сеть онкологических учреждений в КР & $\mathbf{1 9 8 0}$ & $\mathbf{1 9 9 6}$ & $\mathbf{2 0 1 4}$ \\
\hline НИИ и Центры & 1 & 1 & 2 \\
\hline Онкодиспансеры & 3 & 3 & 0 \\
\hline Онкоотделения & 2 & 1 & 3 \\
\hline Онкокабинеты & 57 & 66 & 40 \\
\hline Число онкокоек & 1050 & 720 & 555 \\
\hline Обеспеченность онкокойками на 10000 населения & 2,8 & 1,58 & 1,0 \\
\hline Число врачей-онкологов в ЦСМ КР & 50 & 50 & 14 \\
\hline Число смотровых кабинетов & 63 & 63 & 17 \\
\hline
\end{tabular}

При этом только Национальный центр онкологии при МЗ КР (г. Бишкек) обеспечивает лечение онкологических больных в полном объеме, соответственно международным протоколам лечения.

Для описания ситуации, в которой находится сейчас онкологическая помощь в стране, приведем лишь часть данных. Так, в 2014 г. по КР впервые было взято на учет 5552 онкологических больных, из них по республике умерло 3219 больных, т.е. больше половины.

Показатель заболеваемости злокачественными новообразованиями (3Н) в КР увеличился (табл. 2) и составил в 2012 г. - 89,1 на 100 тыс. населения (\%), в 2013 г. $89,6 \%$ и в 2014 г. - 95,1\%. Отмечается рост заболеваемости по республике в целом, а также некоторым регионам: в Чуйской, Таласской, Нарынской, Джалал-Абадской областях и г. Ош.

Таблица 2. Заболеваемость злокачественными новообразованиями основных локализаций на 100000 населения КР за 2012 - 2014 г2.

\begin{tabular}{|c|c|c|c|c|c|c|c|c|c|c|c|}
\hline & 产 & 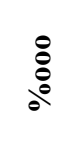 & 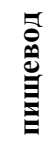 & 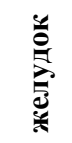 & 苞 & 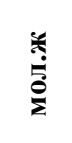 & 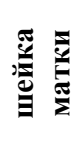 & 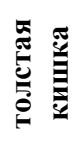 & 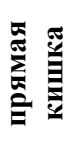 & 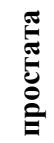 & 烁 \\
\hline 可 & 2012 & 89,1 & 2,8 & 11,9 & 8,3 & 9,7 & 8,4 & 2,5 & 2,8 & 1,7 & 4,2 \\
\hline${ }_{0}^{0}$ & 2013 & 89,6 & 2,4 & 12,2 & 9,0 & 10,9 & 7,7 & 2,3 & 3,0 & 1,6 & 3,8 \\
\hline D & 2014 & 95,1 & 2,3 & 12,8 & 8,9 & 19,3 & 18,1 & 3,0 & 2,9 & 3,3 & 4,8 \\
\hline
\end{tabular}

Смертность по республике составила в 2014 г. - 55,1\%, в г. Бишкек - 62,7\%. Первое место в структуре смертности по КР занимает рак желудка $(9,6 \%)$, на 2 месте - рак молочной железы $(9,2$ \%) и на 3 -м - рак шейки матки $(7,7 \% 000)$. Аналогичная картина наблюдается по регионам республики.

Распределение больных по стадиям заболевания представлено в таблице 3. В плане ранней диагностики самое плохое положение при раке пищевода (1-2 ст.$12,6 \%)$, желудка (15,2\%), легкого (15,7\%).

Высокая онкологическая заболеваемость в республике связана с рядом причин и среди них, низкий уровень проводимых профилактических мероприятий [3]. Статистические данные говорят о слабом охвате населения республики профилактическими осмотрами на наличие онкологической патологии (табл. 4). 
Таблица 3. Распределение больных по стадиям заболевания, локализаџии проиесса за 2014 год

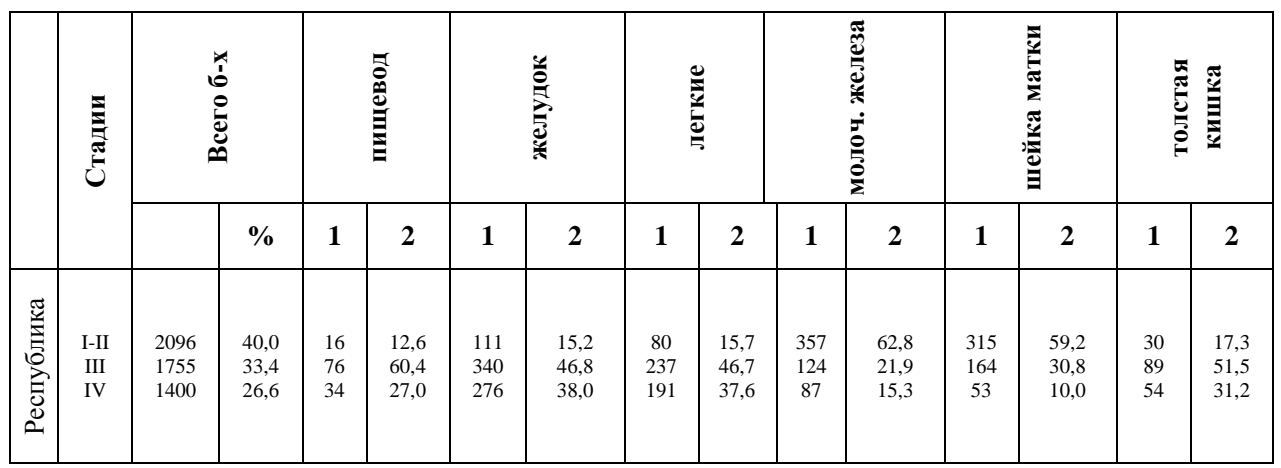

Таблица 4. Профилактический осмотр и запущенность онкологических заболеваний в КР за 2014 г.

\begin{tabular}{|c|c|c|c|c|}
\hline \multirow{2}{*}{ Регионы } & \multicolumn{2}{|c|}{ Просмотр (\%) } & \multicolumn{2}{c|}{ Запущенность ІVст. } \\
\cline { 2 - 5 } & \multirow{2}{*}{ абс.ч. } & \% & \multirow{2}{*}{ абс.ч } & \% \\
\hline Чуйская область & 182 & 15,4 & 377 & 32,0 \\
\hline Таласская область & 15 & 7,1 & 46 & 21,8 \\
\hline Ошская область & 32 & 3,6 & 248 & 32,9 \\
\hline Иссык-Кульская область & 9 & 1,5 & 173 & 30,2 \\
\hline Джалал-Абадская область & 508 & 69,4 & 223 & 30,5 \\
\hline Нарынская область & 49 & 15,1 & 61 & 27,4 \\
\hline Баткенская область & - & - & 53 & 19,2 \\
\hline г.Ош & 23 & 8,6 & 76 & 28,5 \\
\hline г.Бишкек & 71 & 6,3 & 131 & 14,9 \\
\hline Республика & 889 & 16,0 & 1400 & 26,6 \\
\hline
\end{tabular}

Исходя из представленных данных можно сделать вывод, что:

1. Около 50\% онкологических больных, впервые взятых на учет погибают, не дожив 1 года. Одной из причин высокой одногодичной летальности является позднее обращение больных к врачам, отсутствие квалифицированных кадров в ЦСМ, снижение онкологической настороженности врачей и населения республики, отсутствие смотровых кабинетов в ЦСМ и др.

2. Все отрицательные результаты связаны с отсутствием ранней диагностики рака. Диагностика рака зависит от первичного звена здравоохранения (ГСВ).

3. Добиться ранней диагностики рака можно при правильной постановке диспансеризации больных предраковыми заболеваниями, формировании групп высокого риска среди них. Необходимо проведение селективного скрининга.

4. При проф. осмотре в КР было выявлено 889 (16,0\%) онкологических больных, по регионам от $0 \%$ до 69,4\%. Эти показатели свидетельствуют о том, что проф. осмотры (флюорография, гинекологическое и др. обследования) проводятся редко.

5. Руководящим органам МЗ КР необходимо решить кадровый вопрос. В каждом ЦСМ должен работать врач-онколог, а не совместители. Это должно улучшить диагностику, качество учета и отчетность.

6. Необходимо утвердить и внедрить Национальную программу по борьбе со злокачественными опухолями (Национальная программа противораковой борьбы), чтобы ежегодно проводить, согласно плану, мероприятия по снижению заболеваемости раком. 
В то время, как отмечается рост числа заболеваемости и смертности от онкологических заболеваний, в республике не налажена работа онкологической службы. Остро ощущается нехватка квалифицированных кадров, нет современного диагностического и лечебного оборудования, отсутствует преемственность в оказании онкологической помощи населению, не хватает стационаров, существующий Закон об онкологической помощи не работает. И это при том, что лечение онкологических заболеваний относится к разряду высокозатратных методов лечения.

Таким образом, в настоящее время назрела острая необходимость изменить систему управления специализированной помощью с созданием строго системной вертикали. Нужно, чтобы в республике были созданы все условия для нормальной и полноценной работы, необходимо создать в республике специализированные медицинские учреждения с достаточным оснащением. После развала СССР диспансеры, находящиеся в регионах, потеряли свою специализацию, перестали функционировать, и были прикреплены к стационарам общего профиля. Сейчас необходимо в срочном порядке восстановить преемственность в оказании специализированной онкологической помощи больным онкологическими заболеваниями. При этом важным условием качественного предоставления специализированной онкологической помощи является материально-техническая база этих учреждений, куда входит не только наличие самого современного оборудования, но и обеспеченность лекарственными препаратами и др. Также важным условием является наличие квалифицированных специалистов, наличие информационно развитого обеспечения, взаимосвязь с общей сетью лечебных учреждений и т.д.

\section{Сиисок литературы / References}

1. Масленникова Г.Я. Неинфекционные заболевания как глобальная проблема здравоохранения, роль ВОЗ в ее решении // Профилактическая медицина, 2015. № 18 (1). С. 9-13.

2. Самутин К.А. Здоровье населения как составной элемент экономической политики государства // Российское предпринимательство, 2012. № 11 (209). С. 131-136.

3. Соодонбеков Э.Т., Бейшембаев М.И., Сулайманова А.А., Айдарбекова А.А. Некоторые проблемы онкологической службы в Кыргызской Республике // Журнал Вестник онкологии Кыргызстана, 2013. Т. 2. С. 5-13. 


\title{
ОСОБЕННОСТИ ФУНКЦИОНИРОВАНИЯ СЕРДЕЧНО-СОСУДИСТОЙ СИСТЕМЫ У ЮНЫХ СПОРТСМЕНОВ, ЗАНИМАЮЩИХСЯ В УСЛОВИЯХ ЖАРКОГО КЛИМАТА Усманходжаева А.А. ${ }^{1}$, Высогорцева О.Н. ${ }^{2}$, Нуруллаев Б.А. ${ }^{3}$ Email: Usmankhodjaeva1799@scientifictext.ru

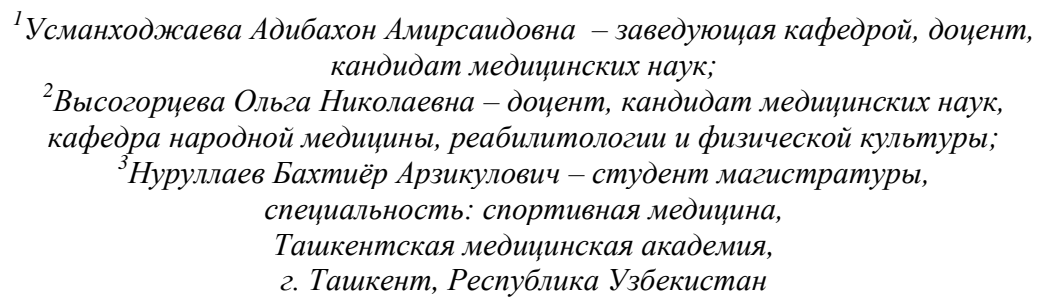

Аннотация: иелью исследования явилось изучение особенностей функционирования сердечно-сосудистой системы юных спортсменов, занимающихся в условиях жаркого климата, с иелью выбора оптимального объема и интенсивности тренировочных нагрузок и контроля рациональности того или иного тренировочного режима в жарких климатических условиях. Были выявлены достоверные отличия, зарегистрированные в жаркий период года: увеличение частоты встречаемости неблагоприятных реакиий сердечно-сосудистой системы на физическую нагрузку, снижение показателей выносливости, повышение влияния симпатической нервной системы, увеличение частоты и степени постнагрузочного утомления.

Ключевые слова: юные спортсмены, сердечно-сосудистая система, сухой и жаркий климат, тренировочный пароцесс.

\section{FUNCTION OF CARDIOVASCULAR SYSTEM IN YOUNG ATHLETES INVOLVED IN HOT CLIMATES Usmankhodjaeva A.A. ${ }^{1}$, Vysogortseva O.N. ${ }^{2}$, Nurullayev B.A. ${ }^{3}$

\author{
${ }^{1}$ Usmankhodjaeva Adibakhon Amirsaidovna-Head of department, PhD; \\ ${ }^{2}$ Vysogortseva Olga Nikolaevna - Docent, PhD, \\ DEPARTMENT OF FOLK MEDICINE, PHYSICAL THERAPY AND PHYSICAL CULTURE; \\ ${ }^{3}$ Nurullayev Bakhtiyor Arzikulovich - Graduate Student, \\ SPORTS MEDICINE, \\ TASHKENT MEDICAL ACADEMY, \\ TASHKENT, REPUBLIC OF UZBEKISTAN
}

\begin{abstract}
: the aim of the research was to study of the functioning of the cardiovascular system of young athletes involved in hot climates, in order to select the optimal volume and intensity of training loads and control the rationality of a training regime in hot climates. Significant differences registered in the hottest period of the year have been identified: an increase in the incidence of adverse reactions of the cardiovascular system to physical stress, decline in endurance, increase the influence of the sympathetic nervous system, increasing the frequency and extent of post-exercise fatigue.
\end{abstract}

Keywords: young athletes, cardiovascular system, hot and dry climate, training process.

УДК: 612.13+61:796/799

Введение. Особенностью подготовки юных спортсменов в нашей республике является тот факт, что тренировки проходят в условиях жаркого климата. Особенности климата нашего региона (среднегорье, высокие среднесуточные 
температуры, низкая влажность воздуха и др.) имеют определенное влияние на ведущие системы организма, которые обеспечивают выполнение физических нагрузок, что необходимо учитывать в процессе тренировок. Чрезмерно форсированные тренировки в детско-юношеском возрасте, особенно в условиях жаркого и сухого климата, быстрое наращивание их объема и интенсивности без достаточного научного обоснования и критериев оценки функционального состояния сердца могут вызвать его перенапряжение (Карпман В.Л, 2010) и оказать серьезное неблагоприятное воздействие на организм (А.Г. Сухарев, 2009) и тем самым ограничить дальнейшее совершенствование в избранном виде спорта.

Цель исследования - изучить особенности функционирования сердечнососудистой системы юных спортсменов, занимающихся в условиях жаркого климата, с целью выбора оптимального объема и интенсивности тренировочных нагрузок и контроля рациональности того или иного тренировочного режима в жарких климатических условиях.

Материалы и методы. В исследовании участвовали 130 юных спортсменов, занимающихся в спортивных школах г. Ташкента и в Чирчикском колледже олимпийского резерва, в возрасте от 15 лет до 18 лет. Из них 26 занимались циклическими видами спорта, 13 - игровыми видами спорта и 91 представителей единоборств мужского пола; средний возраст 16,02 $\pm 1,14$ лет. Спортивный стаж составлял от 6 до 10 лет.

Проводились следующие методы обследования: антропометрия, соматоскопия, изучение спортивного анамнеза, общеклинические и функциональные методы исследования (ЭКГ в покое и после нагрузки, проба Мартине, определение тренированности методом Гарвардского степ-теста, оценка вегетативного статуса с помощью вычисления вегетативного индекса Кьердо-Кардю). Характер тренировок изучался при врачебно-педагогическом наблюдении (ВПН). По данным протокола ВПН оценивалось утомление по внешним признакам: цвет кожных покровов, потоотделение, координация и равновесие, реакция спортсмена на команды тренера, оцениваемые по 3-балльной системе; баллы суммировались и устанавливалась степень утомления (Макарова Г.А., 2003).

Исследование проводилось в течение годичного цикла, охватывая тренировочный процесс и соревновательный период, в различных климатических условиях, условно разделялось на нежаркий (октябрь-апрель) и жаркий (май-сентябрь) периоды.

Полученные результаты и обсуждение. При сравнительном анализе характера тренировочного процесса было выявлено, что тренировки проводились в одно и то же время дня, количество в неделю и продолжительность занятий были одинаковыми. Температура окружающей среды в жаркий период во время утренних тренировок составляла $33,2 \pm 1,56^{\circ} \mathrm{C}$, влажность $40 \%$; во время вечерних тренировок соответственно $36,63 \pm 1,72^{\circ} \mathrm{C}$ и $38 \%$.

Распределение нагрузок в ходе тренировок в жаркий период времени отличалось: в утренние часы преобладали общеразвивающие и на выносливость упражнения при малом проценте специализированных, в вечерние часы процент специализированных нагрузок увеличивался и максимально отмечался в предсоревновательный период. Двигательная плотность занятий в жаркий период времени снизилась в среднем на $3 \%$.

При сравнении показателей гемодинамики юных спортсменов, полученных в ходе тренировочного процесса в разные периоды года, в состоянии покоя достоверных отличий не отмечалось.

При сравнительном анализе гемодинамических показателей в покое отмечалась тенденция к повышению частоты сердечных сокращений (ЧСС) и систолического артериального давления (САД), достоверно повысился вегетативный индекс КьердоКардю (ВИ) $(\mathrm{P}<0,05)$ (таблица 1). 
Таблица 1. Клиническая характеристика обследуемого контингента (эркин кураш) в различных климатических условиях

\begin{tabular}{|c|c|c|}
\hline Показатели & $\begin{array}{c}\text { Нежаркий период } \\
\mathbf{M} \pm \mathbf{m}\end{array}$ & $\begin{array}{c}\text { Жаркий период } \\
\mathbf{M} \pm \mathbf{m}\end{array}$ \\
\hline Возраст & $15,5 \pm 1,80$ & $15,5 \pm 1,80$ \\
\hline Рост & $163,6 \pm 8,91859$ & $163,6 \pm 8,92$ \\
\hline ЧСС0 & $11,63 \pm 1,26$ & $13,28 \pm 1,63$ \\
\hline САД0 & $106,3 \pm 8,117$ & $116,6 \pm 8,17$ \\
\hline А ДАД0 & А $62,14 \pm 4,074$ & А $64,24 \pm 4,74$ \\
\hline ВИ & $9,1423 \pm 1,463$ & $14,93 \pm 8,63 *$ \\
\hline
\end{tabular}

*достоверность различий $\mathrm{P}<0,05$.

По результатам пробы Мартине, проведенной у спортсменов в ходе тренировочного процесса в различные периоды года, частота встречаемости нормотонического типа реакции снизилась с $72 \%$ до $49 \%$, повысилась частота регистрации неудовлетворительных реакций ССС на физическую нагрузку: гипертонического на 5\%, дистонического - на 10\%, ступенчатого типа - на $3 \%$ (рисунок 1 ).

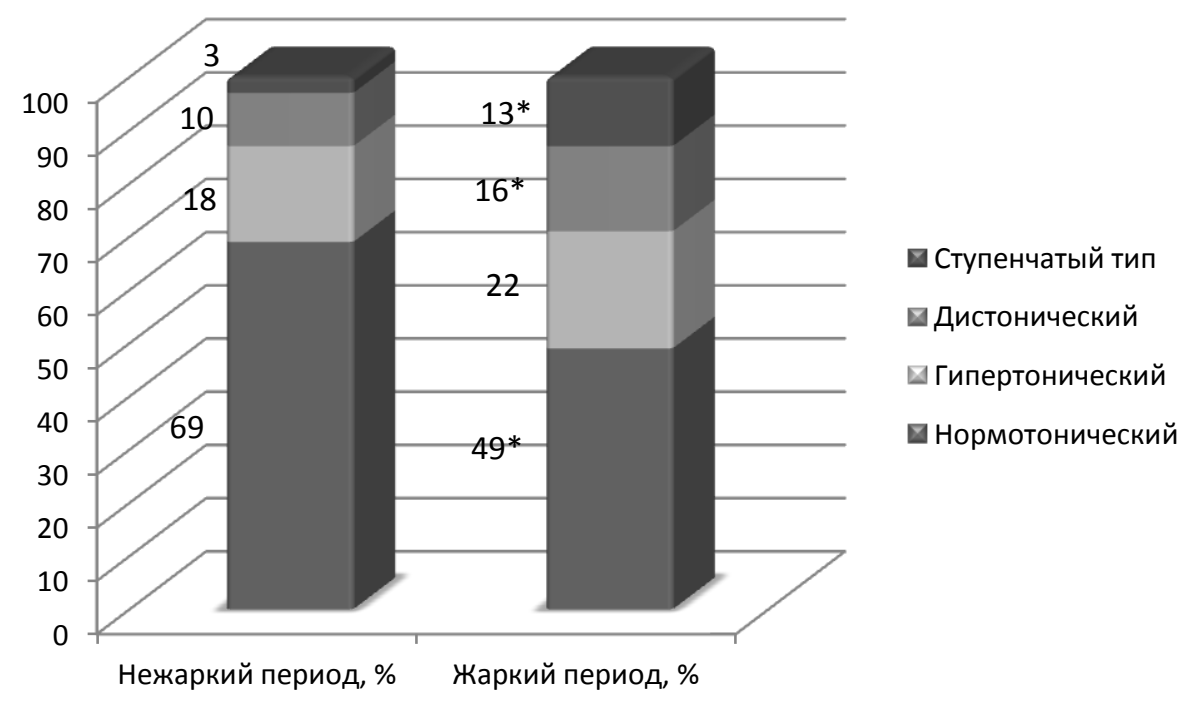

Рис. 1. Распределение типов реакиии на физическую нагрузку по данным пробы Мартине у юных спортсменов, тренирующихся в различных климатических условиях

Примечание: *- достоверность различий $\mathrm{P}<0,05$.

При изучении степени тренированности по данным Гарвардского степ-теста средний показатель индекса Гарвардского степ-теста (ИГСТ) достоверно снизился в жаркий период года по сравнению с нежарким. Показатели тренированности снизились: процент спортсменов, демонстрировавших в нежаркий период отличную и хорошую тренированность, снизился на $21 \%(\mathrm{p}<0,05)$, в жаркий период показатели стали средними и выше средних (таблица 2). 
Таблица 2. Сравнительные результаты Гарвардского степ-теста у юных спортсменов в различные климатические периоды года

\begin{tabular}{|c|c|c|}
\hline \multirow{2}{*}{ Оценка степени выносливости } & \multicolumn{2}{|c|}{ Количество обследованных, \% } \\
\cline { 2 - 3 } & нежаркий период & жаркий период \\
\hline ИГСТ $(\mathrm{M} \pm \mathrm{m})$ & $83,26 \pm 3,63$ & $62,47 \pm 3,72^{*}$ \\
\hline Плохая, \% & 1 & 1 \\
\hline Ниже средней, \% & 2 & 3 \\
\hline Средняя, \% & 5 & $12^{*}$ \\
\hline Выше средней, \% & 12 & $25^{*}$ \\
\hline Хорошая, \% & 63 & $50^{*}$ \\
\hline Отличная, \% & 17 & $9^{*}$ \\
\hline
\end{tabular}

Примечание: *достоверность различий $\mathrm{P}<0,05$.

При сравнительном анализе степени утомления юных спортсменов, тренирующихся в различных климатических условиях, было выявлено, что в условиях жаркого климата частота спортсменов с признаками утомления увеличилась, достоверно повысилась степень выраженности таких показателей, как цвет кожных покровов и степень потоотделения (таблица 3 ).

Таблица 3. Сравнительная оченка степени утомления юных спортсменов, тренирующихся в различных климатических условиях

\begin{tabular}{|c|c|c|}
\hline Показатели & $\begin{array}{c}\text { Баллы в нежаркий } \\
\text { период }\end{array}$ & $\begin{array}{c}\text { Баллы в жаркий } \\
\text { период }\end{array}$ \\
\hline $\begin{array}{c}\text { Цвет кожных покровах } \\
\text { (в баллах 1-3) }\end{array}$ & $1,56 \pm 0,13$ & $2,68 \pm 0,43^{*}$ \\
\hline $\begin{array}{c}\text { Потоотделение } \\
\text { (в баллах 1-3) }\end{array}$ & $1,27 \pm 0,83$ & $2,83 \pm 0,64 *$ \\
\hline $\begin{array}{c}\text { Координация и равновесие } \\
\text { (в баллах 1-2) }\end{array}$ & $1,68 \pm 0,46$ & $1,98 \pm 0,67$ \\
\hline $\begin{array}{c}\text { Реакция на команды тренера } \\
\text { (в баллах 1-2) }\end{array}$ & $1,16 \pm 0,32$ & $2,12 \pm 0,46$ \\
\hline
\end{tabular}

Примечание: *достоверность различий $\mathrm{P}<0,05$.

Исследование показало, что перечисленные изменения параметров гемодинамики, тренированности и постнагрузочного восстановления непосредственно связаны с влиянием сухого жаркого климата. Под воздействием высокой температуры окружающей среды возбуждаются корковые и подкорковые центры терморегуляции, что приводит к торможению двигательных зон центральной нервной системы, следствием чего и является снижение мышечной работоспособности $[1,2,3]$.

Снижение работоспособности развивается в основном за счет трех факторов: перегревание организма, быстрой дегидратации, снижением кислород-транспортных возможностей сердечно-сосудистой системы $[1,2,3]$.

Интенсивное потоотделение приводит к снижению общего объема циркулирующей крови, повышению ее вязкости, уменьшению сердечного выброса. Уменьшение объема крови лишь на 3\% приводит к снижению спортивной работоспособности, ухудшению самочувствия спортсменов. При этом развитие дегидратации приводит к прогрессирующему повышению температуры тела и увеличению нагрузки на функциональные системы организма, что проявляется в повышении частоты сердечных сокращений. Параллельно с этим уменьшается систолический объем. У спортсменов наблюдается ухудшение кровоснабжения работающих мышц из-за увеличения доли сердечного выброса, направленного в кожные сосуды для усиления теплоотдачи. В результате значительно дегидратации происходит уменьшение объема межклеточной и внутриклеточной жидкостей. В 
клетках с пониженным содержанием воды и изменением равновесия электролитов нарушается нормальная жизнедеятельность [4, 5].

Это подтверждается усиленным расходованием гликогена и накоплением в мышцах молочной кислоты. Кроме этого, потеря воды приводит к перегреванию организма и вызывает усиление кровотока в коже, при одновременном уменьшении его во внутренних органах, что ведет к развитию гипоксии, затрудняет сердечную деятельность и сгущение крови $[1,2]$.

Во время тренировок в условиях жаркого климата вместе с потом теряются важные для организма электролиты. Большие потери с потом натрия, калия и других хлоридов могут привести к повреждениям миокарда.

Поэтому в процесс физической подготовки и занятий спортом в условиях жаркого климата следует внести ряд изменений. Прежде всего необходимо увеличить потребление жидкости в виде воды и специальных напитков, включающих минеральные соли и микроэлементы. Питание должно быть дробным, 5-6-разовым и включать легкоусвояемые продукты: каши, творог, куриное мясо, рыбу, овощи, фрукты и т.д. [6, 7].

Также следует изменить характер тренировочного процесса:

1. перенести время тренировок на более ранние утренние часы (например, 7:009:00) и более поздние вечерние (например, 17:00-19:00);

2. уменьшить процент силовых нагрузок;

3. включать короткие перерывы смены вида физической деятельности.

В распоряжении медицинского персонала, осуществляющего мед обеспечение, должны быть средства для оказания помощи в случае тепловых травм: средства для реанимации, пакеты со льдом и вентиляторы для охлаждения, специальные пункты с напитками.

Повышению устойчивости к жаре способствует и рационально построенное питание. Наряду с адекватным потреблением жидкости и электролитов в рационе питания следует снизить количество белков, поскольку их сжигание связано с образованием большого количества тепла по сравнению со сжиганием других веществ. Повышению тепловой толерантности способствует и дополнительное применение аскорбиновой кислоты (250-500 мг) [5].

\section{Выводы:}

1. При активной мышечной деятельности в условиях жаркого климата развиваются гипертермические реакции эндо- и экзогенной природы, приводящие к резким функциональным расстройствам в первую очередь сердечно-сосудистой системы и выраженному снижению физической работоспособности спортсменов.

2. Сравнительный анализ показателей гемодинамики юных спортсменов, тренирующихся в различных климатических условиях, показал достоверные отличия, зарегистрированные в жаркий период года: увеличение частоты встречаемости неблагоприятных реакций сердечно-сосудистой системы на физическую нагрузку, снижение показателей выносливости, повышение влияния симпатической нервной системы, увеличение частоты и степени постнагрузочного утомления.

\section{Сиисок литературы / Reference}

1. Бабкин А.П. Консервативные методы коррекции тепловой (физической) адаптации и акклиматизации спортсменов к жаркому и влажному климату // Вестник спортивной науки, 2007. № 1. С. 50-51.

2. Кузнецьов И.А. Физическая выносливость как фактор повышения неспецифической устойчивости личного состава к жаркому климату. // Научно-теоретический журнал «Ученые записки», 2006. № 22. С. 15-18.

3. Лавриченко В.В., Артемьева Н.К., Лавриченко С.П., Ермаков В.В. Особенности влияния специализированных продуктов на процессы восстановления в организме 
юношей футболистов 17-19 лет в летне-осеннем сезонном периоде года. // Научный журнал КубГАУ, 2013. № 86 (02), С. 3-4.

4. Панина Н.Г., Ушанов Г.А., Кльчккова О.В. Изучение влияния физической и тепловой нагрузок на организм спортсменов. // Известия ВолгГТУ, 2015. № 2 (155). С. 211-214.

5. Спортивная медицина: национальное руководство / Под ред. акад. РАН и РАМН С.П. Миронова, проф. Б.А. Поляева, проф. Г.А. Макаровой. М.: ГЭОТАР-Медиа, 2012. C. $450-471$.

6. Rowland T. Fluid replacements for child athletes. Sports Med., 2011: 41 (4): P. 279-288.

7. Sally S., Anderson J., Harris S., Steven J. Care of young athletes. American Academy of Orthopedic Surgeons, 2010. 612 p.

\title{
ФЕТАЛЬНАЯ ЭКГ (STAN) В ДИАГНОСТИКЕ ИНТРАНАТАЛЬНОЙ ГИПОКСИИ ПЛОДА Филиппова Я.Д. ${ }^{1}$, Ившин А.А. ${ }^{2}$, Иванова Н.А. ${ }^{3}$ Email: Filippova1799@scientifictext.ru
}

\author{
${ }^{1}$ Филиппова Яна Дмитриевна - студент; \\ ${ }^{2}$ Ивиин Александр Анатольевич - кандидат медицинских наук, доцент; \\ ${ }^{3}$ Иванова Наталья Александровна - кандидат медицинских наук, ассистент; \\ кафедра акушерства и гинекологии, дерматовенерологии, \\ Медицинский институт \\ Петрозаводский государственный университет, \\ г. Петрозаводск
}

\begin{abstract}
Аннотация: в статье очениваются эффективность и безопасность трансабдоминальной электрокардиографии (STAN) при интранатальной гипоксии плода. Целью научной работь была оценка эффективности и безопасности фетальной ЭГК в акушерстве (STAN). Для достижения цели исследования поставлены следующие задачи: выявить значимые факторы риска интранатальной гипоксии плода, установить эффективность и оценить безопасность STAN, сопоставить полученные данные $c$ данными литературы, сформулировать практические рекомендации по применению STAN в акушерстве.

Ключевые слова: гипоксия плода, трансабдоминальная ЭКГ, электрокардиография плода, ST-анализ, STAN, кардиотокография, фетальная иеребральная пульсоксиметрия, допплер, лактат, рН-метрия.
\end{abstract}

\section{FETAL ECG (STAN) IN DIAGNOSTICS OF INTRANATAL HYPOXIA Filippova J.D. ${ }^{1}$, Ivshin A.A. ${ }^{2}$, Ivanova N.A. ${ }^{3}$ \\ ${ }^{\text {I}}$ Filippova Yana Dmitrievna - Medical Student; \\ ${ }^{2}$ Ivshin Aleksandr Anatolyevich - PhD MD, Associate Professor; \\ ${ }^{3}$ Ivanova Natalya Aleksandrovna - PhD MD, Assistant Professor, DEPARTMENT OF OBSTETRICS AND GYNECOLOGY, DERMATOLOGY, MEDICAL INSTITUTE \\ PETROZAVODSK STATE UNIVERSITY, PETROZAVODSK}

Abstract: the paper assesses the efficacy and safety of transabdominal electrocardiography
(STAN) in intrapartum fetal hypoxia. The aim of research work was to evaluate the efficacy
and safety of fetal EGC in obstetrics (STAN). To achieve the objectives of the study the
following objectives: to identify significant risk factors for intrapartum fetal hypoxia to 
determine the efficacy and evaluate the safety STAN, to compare the obtained data with literature data to formulate practical recommendations for the use of STAN in obstetrics.

Keywords: fetal hypoxia, transabdominal electrocardiography, fetal electrocardiography, ST analysis, STAN, cardiotocography, fetal cerebral pulse oximetry, doppler, lactate, ph-meters.

УДК: 618.5-07

Интранатальная гипоксия плода является актуальной проблемой акушерства [1-7]. При ведении родов с интранатальной гипоксией возникает прямая угроза жизни плода. Роды должны быть безопасными для матери и плода. Главная задача при гипоксии - своевременное и адекватное родоразрешение наиболее оптимальным способом. В настоящее время существует несколько методов диагностики гипоксии плода в родах, целью которых является выявление признаков гипоксии и профилактика еe осложнений [3]. Одним из таких методов является трансабдоминальная ЭКГ плода (STAN) $[1-3,6,7]$. В литературе имеются данные о том, что в ответ на острую или хроническую гипоксию у плода нарушаются функции проводимости и сократимости сердечной мышцы, которые эффективно выявляются по результатам морфологического анализа элементов ЭКГ плода $[5,6]$. Технология получения ЭГК плода основана на ее выделении из общего трансабдоминального сигнала, в котором доминирует электрическая активность от сердца матери. Применение этого метода позволило в значительной степени сократить число необоснованных оперативных родоразрешений, снизить уровень перинатальной смертности и число заболеваний, вызванных интранатальной гипоксией плода [2].

Целью научной работы была оценка эффективности и безопасности STAN в акушерстве. Для достижения цели исследования были поставлены следующие задачи: выявить значимые факторы риска интранатальной гипоксии плода, установить эффективность и оценить безопасность STAN, сопоставить полученные данные с данными литературы, сформулировать практические рекомендации по применению STAN в акушерстве. Исследование выполнено в Республиканском перинатальном центре. Нами был проведен ретроспективный анализ 33 истории родов и 33 истории новорожденных за 2016-2017 годы. Критериями включения в группу наблюдения стали интранатальная гипоксия плода, патологическая КТГ, доношенный срок, наличие одного плода в матке и его головное предлежание. Для диагностики гипоксии плода использован кардиотокограф и STAN. B ходе исследования был накоплен массив данных и к ним применены непараметрические методы медицинской статистики.

На первом этапе научной работы дана клинико-анамнестическая характеристика группы и проведена оценка преконцепционных и антенатальных факторов риска гипоксии плода в родах. Основной контингент пациенток представлен социально благополучными женщинами. Однако, обращает на себя внимание большой процент безработных и одиноких женщин, что может указывать на неблагоприятные социальноэкономические условия их жизни и социальную дезадаптацию. Большинство женщин были старше 30 лет, с высшим образованием, нормального конституционного типа, в основном без вредных привычек, страдающими заболеваниями сердечно-сосудистой системы, печени, желчевыводящих путей и заболеваниями желудочно-кишечного тракта, повторнобеременными, повторнородящими, с частыми абортами и выкидышами, с воспалительными заболеваниями органов малого таза, патологией шейки матки, с осложненным течением беременности анемией, инфекционными заболеваниями, угрозой прерывания беременности, преэклампсией и задержкой роста плода. В большинстве случаев роды были срочными. Чаще роды заканчивались без применения оперативных пособий. Однако, в 13\% случаев акушерская тактика потребовала наложения вакуумэкстрактора, а у каждой четвертой роженицы роды были завершены операцией кесарева сечения. Показанием к кесареву сечению стали острая или прогрессирующая гипоксия плода, аномалии родовой деятельности, преэклампсия и преждевременная отслойка нормально расположенной плаценты. Чаще рождались девочки. Новорожденные были со 
средним росто-весовым коэффициентом, в состоянии асфиксии, по шкале Апгар 5 и 7 баллов на 1 и 5 минуте соответственно.

На втором этапе работы проводилась оценка эффективности фетальной ЭКГ. При установлении взаимосвязи между STAN и результатами оценки новорождённого по шкале Апгар выявлена обратная зависимость - чем выше T/QRS, тем ниже оценка по Апгар. При проведении корреляционного анализа между результатами STAN и одноканальной КТГ с оценкой кардиотокограммы по шкале FISHER нам не удалось установить надёжную взаимосвязь. При установлении взаимосвязи между результатами КТГ и оценкой новорождённого по шкале Апгар достоверной корреляции не обнаружено. На заключительном этапе работы проводилось сопоставление полученных результатов с данными отечественной и зарубежной литературы.

Ведущими преконцепционными факторами риска интранатальной гипоксии были: неблагоприятный социально-экономический статус и возраст женщин старше 30 лет. Среди антенатальных факторов риска следует подчеркнуть железодефицитную анемию, инфекционные заболевания, угрозу прерывания беременности, преэклампсию и плацентарную недостаточность с формированием задержки роста плода. При установлении взаимосвязи между результатами STAN и оценкой новорождённого по шкале Апгар выявлена обратная зависимость - чем выше T/QRS, тем ниже оценка по Апгар, что говорит о высокой эффективности метода. При проведении STAN не выявлено осложнений. Артефакты, ложноположительные и ложноотрицательные результаты не наблюдались.

Таким образом, трансабдоминальная ЭКГ является эффективным и безопасным методом оценки функционального состояния плода в родах. Полученные в ходе исследования результаты подтверждают данные литературы о применении этого метода в акушерстве.

\section{Список литературы / References}

1. Вихарева О.Н., Баев О.Р., Воеводин С.М., Кан Н.Е., Клименченко Н.И., Тетруашвили Н.К., Тютюнник В.Л., Шмаков Р.Г. Применение STAN в родах. / Вихарева О.Н., Баев О.Р., Воеводин С.М., Кан Н.Е., Клименченко Н.И., Тетруашвили Н.К., Тютюнник В.Л., Шмаков Р.Г. // Акушерство и гинекология № 4, 2015. С. 13.

2. Гудков Г.В., Пенжоян Г.А., Филиппов Е.Ф., Дурлештер М.В. Трансабдоминальная электрокардиография в диагностике критических состояний плода при плацентарной недостаточности. / Г.В. Гудков, Г.А. Пенжоян, Е.Ф. Филиппов, М.В. Дурлештер // Вестник МУЗ ГБ № 2, 2014. № 1 (31). С. 1-20.

3. Еремина О.В., Шифман Е.М., Баев О.Р., Гус А.И. Методы изучения сердечной гемодинамики плода в родах: от стетоскопа до оксиметрии / О.В. Еремина, Е.М. Шифман, О.Р. Баев, А.И. Гус // Акушерство и гинекология. М., 2011. № 7-1. C. 11-15.

4. Еремина О.В., Шифман Е.М., Баев О.Р., Александрова, Н.В. Исследование крови из предлежащей части плода в оценке его состояния в родах / О.В. Еремина, Е.М. Шифман, О.Р. Баев// Акушерство и гинекология. М., 2011. № 8. С. 16-20.

5. Doret M., Constans A., Gaucherand P. Physiologic basis for fetal heart rate analysis during labour / M. Doret, A. Constans, P. Gaucherand // J. Gynecol. Obstet. Biol. Reprod. (Paris), 2010. Vol. 39, 4. P. 276.

6. Velayo C., Sato N., Ito $T$. et al. Understanding congenital heart defects through abdominal fetal electrocardiography: case reports and clinical implications // J. Obstet. Gynaecol. Res., 2011; 37(5): P. 428-435.

7. Westerhuis M.E., Visser G.H., Moons K.G., Zuithoff N., Mol B.W., Kwee A. Cardiotocography plus ST analysis of fetal electrocardiogram compared with cardiotocography only for intrapartum monitoring: a randomized controlled trial // Obstet. Gynecol, 2011; 117(2 Pt 1): 406-407. 


\title{
«ПРОБЛЕМНЫЕ ВОПРОСЫ» КАК УСТАНОВКА ФОРМЫ \\ TОК-ШОУ \\ Орлова К.E. Email: Orlova1799@scientifictext.ru
}

Орлова Кристина Евгеньевна - магистр,

кафедра электронных СМИ и новых медиа, факультет журналистики,

Кубанский государственный университет,

2. Краснодар

\begin{abstract}
Аннотация: форма ток-шоу зависит от поставленного вопроса, он бывает открытого и закрытого типа. Вопрос, заданный в начале эфира, обобщающий тему и подводящий зрителей к уже сформированному мнению, дает старт всей беседе и делит участников и зрителей на два лагеря. И им уже остается "сражаться» за свою точку зрения. Важность формулировки вопроса - это основа ток-цоу, так как от того, насколько четко будет задан подводящий вопрос и насколько открытто или закрыто он будет сформулирован, зависит информаџионная наполненность токшоу. После того, как ведущий озвучил вопрос, у него под контролем находится весь информационный поток или информационная среда, в которой находятся все присутствующие. Отсюда следует, что «Проблемные вопросы» также выступают одним из средств манипуляции аудитории.
\end{abstract}

Ключевые слова: ток-шоу, вопросы, программа, ведущчй, проблемная программа, структура, обсуждение, тема, участники, цель, позиция, дискуссия, конфликт, открытый тип, закрытый тип, проблемный вопрос, участники ток-шоу, манипуляции, способ манипуляцฺии, аудитория, зритель, привлечение аудитории, скандальв в студии.

\section{"PROBLEMATIC ISSUES" LIKE SETTING UP A TALK SHOW FORM Orlova K.E.}

\author{
Orlova Kristina Evgenievna - Master, \\ DEPARTMENT OF ELECTRONIC MEDIA AND NEW MEDIA, FACULTY OF JOURNALISM, \\ KUBAN STATE UNIVERSITY, KRASNODAR
}

\begin{abstract}
: the form of the talk show depends on the question, it is open and closed type. The question asked at the beginning of the broadcast, generalizing the topic, and bringing the audience to the already formed opinion, gives a start to the whole conversation and divides the participants and spectators into two camps. And they already have to "fight" for their point of view. The importance of the wording of the question, this is the basis of the talk show, since the question is asked clearly and how open or closed it will be formulated, the information content of the talk show depends. After the presenter voiced the question, he under control is the entire information flow or information environment, in which are all present. It follows that "Problematic issues" also serve as one of the means of manipulating the audience.

Keywords: talk show, questions, program, presenter, problem program, structure, discussion, topic, participants, goal, position, discussion, conflict, open type, closed type, problem issue, talk show participants, manipulation, manipulation method, The audience, the viewer, attracting the audience, scandals in the studio.
\end{abstract}


Сегодня ток-шоу относительно молодой и развивающийся вид программы. Свое начало берет на американском телевидении еще в 60х годах. Фил Донахью стал инициатором процесса развития ток-шоу. Есть легенда, что интервьюируя гостя в прямом эфире, у него закончились вопросы, после чего Фил подошел к одному из зрителей и спросил, есть ли у него вопрос к гостю. Их оказалось много, это и стало началом развития ток-шоу. Намного позже жанр ток-шоу пришел в Россию. Первый телемост в эфире Центрального телевидения состоялся в 1986 году. Зрители Советского Союза и США общались между собой и задавали друг другу любые интересующие их вопросы. Фил Донахью и Владимир Познер были ведущими телемоста. Успешный проект, так как в студиях обсуждались важные и актуальные для обеих стран вопросы [1].

Фил задал один вопрос и после стали появляться другие, благодаря которым токшоу получило такое развитие. Сегодня в статье я решила рассмотреть именно «проблемные» вопросы, в результате которых завязывается дискуссия, кипят страсти, вопросы, не требующие ответа, но определяющие настрой и позицию зрителей к той или иной ситуации.

«Сложные» вопросы, это те вопросы, которые формируют тему проводимого токшоу. Важно правильно сформулировать в заданном вопросе проблему, чтобы интервьюируемый не чувствовал дискомфорт [2].

Также формулировка проблемы в программе имеет вопросительный вопрос [3]. Формулировка вопроса происходит после обозначения ведущим темы эфира. Это определяет структуру обсуждения, ракурс рассматриваемой проблемы, состав участников:

«Автомобили, какой марки востребованы сегодня на рынке в России?»

«Конкурентоспособен ли сегодня отечественный автопром в сравнении с зарубежным?»

Эта тема звучит примерно так « Проблемы отечественного автопрома», но оба вопроса раскрывают ее по-разному. Итак, есть 2 вопроса, суть которых, в принципе, одна и та же. И как же будет проводиться ток-шоу и в первом, и во втором случае? Будем это анализировать.

В первом случае, целью ток-шоу будет представление различных марок автомашин, существующих сегодня на дорогах в России - вместе со всеми плюсами и минусами каждой марки. Вопрос, стимулирующий такое развитие дискуссии открытого типа с вопросительным словом «Какой?».

Цель второго ток-шоу - вынести вердикт отечественному автопрому - быть ему или не быть.

Из исходящего вопроса, зрители и участники принимают ту или иную позицию, и на протяжении всей программы защищают ее. Первоначальный вопрос заводит дискуссию - он закрытого типа, альтернативный, по сути. То есть в формулировке вопроса уже существует ответ, а участникам необходимо только определиться «за» или «против», выдержит ли конкуренцию автопром или нет.

В основном на современном телевидении используется вторая форма ток-шоу, где альтернативный вопрос лежит в основе.

Конфликт задает динамику такой программе, он скрыт уже в самой формулировке вопроса. И участники, разделившись на два лагеря, доказывают свою правоту. Это можно проследить в таких программах, как «Пусть говорят», «Прямой эфир». В любой из этих программ эфиры проходят достаточно насыщено, некорректные высказывания, драки, на эмоциональном уровне встречается многое. Но все происходит только после того, когда ведущий задаст сакраментальный вопрос.

В таком ток-шоу главное, как в спорте, например в борьбе, чтобы противоборствующие стороны были в одной весовой категории и сумели наиболее полно раскрыть и представить свою позицию. 
Ток-шоу первой формы, в основе которой вопрос открытого типа, также эффективно присутствует в телеэфире. «Культурная революция» Михаила Швыдкого или «Времена» Владимира Познера - яркие представители программы такой формы.

Формирующий вопрос открытого типа может быть раскрыт в программе только с помощью разных мнений участников. Сложность в проведении такого типа ток-шоу заключается в приглашении участников дискуссии высокого уровня, с интересными мнениями для зрителя.

«Проблемные» вопросы обоих типов, это база при создании эфира. Какой бы ни прозвучал вопрос, в начале ток-шоу, он является синтезатором всех идей, мыслей и разных точек зрения присутствующих, участников и зрителей. От поставленного основного вопроса зависит проведение всего ток-шоу, с какой подачей, эмоциями и бывает, с агрессией будут высказывать свое мнение люди. «Проблемные вопросы» это одна из основных составляющих удачного ток-шоу на телевидении.

Таким образом, ток-шоу относительно молодой жанр на отечественном телевидении. Он прошел этап становления, но его жанровое определение представляет определенную проблему в современной науке. Классификация жанра может быть весьма разнообразной, если учесть многообразие классифицирующих критериев.

На нынешнем этапе ток-шоу относятся к числу самых рейтинговых передач, поэтому их авторы заинтересованы в поддержании и сохранении аудитории. Для достижения этой цели используются разные способы и «Проблемные вопросы» это тоже одна из ступеней привлечения зрителей. Так как поставленный вопрос определит форму ток-шоу и информационную наполненность эфира. После того, как ведущий озвучил вопрос, он взял под контроль информационный поток или информационную среду, в которой находятся все присутствующие. Все их мысли были направлены в одно русло, из которого выходят разные мнения. Отсюда следует еще один вывод «Проблемные вопросы» также являются одним из средств манипуляции аудитории.

\section{Сиисок литературы / References}

1. Вартанов А.C. Актуальные проблемы телевизионного творчества на телевизионных подмостках. Москва, 2003. 320 с. С. 20-21.

2. Вартанов А.C. Актуальные проблемы телевизионного творчества на телевизионных подмостках. Москва, 2003. 320 с. С. 27.

3. Телевизионная журналистика. Учебник. Под ред. Кузнецова Г.В., Цвик В.Л, Юровского А.Я. Москва, 2002. 304 с. С. 198. 


\title{
СПЕЦИФИКА МОЛОДЁЖНОЙ ИНТЕРНЕТ-АУДИТОРИИ Осипов К.В. Email: Osipov1799@scientifictext.ru
}

\author{
Осипов Кирилл Владимирович - студент, \\ кафедра электронных СМИ, факультет журналистики, \\ Кубанский государственный университет, г. Краснодар
}

\begin{abstract}
Аннотация: в статье раскрываются типь молодежной аудитории интернет-СМИ. Даются определения медиаповедения (индифферентное, осознанное). Рассказывается о предпочтениях аудитории, и даётся их объяснение. Делается вывод, что современная интернет-аудитория является в крайней степени неоднородной и с большим трудом поддается формализации.

Объектом данного исследования являются интернет-СМИ и другой информационноразвлекательный интернет-контент. В роли предмета исследования выступают молодежная интернет-аудитория, её специфика, предпочтения и особенности.

Были подробно изучены интернет-СМИ, информачионно-развлекательный интернет-контент. С помощьью метрики, статистики просмотров и отзывов были учтень предпочтения аудитории. Опираясь на исследования предчественников, были выявлены типь медиаповедения, психология и причины предпочтений $u$ заинтересованности аудитории.
\end{abstract}

Ключевые слова: медиаповедение, контент, интернет-СМИ, блогер, неожурналистика, аудитория.

\section{THE SPECIFICITY OF THE YOUTH OF THE INTERNET AUDIENCE Osipov K.V.}

\author{
Osipov Kirill Vladimirovich - Student, \\ DEPARTMENT OF ELECTRONIC MEDIA, FACULTY OF JOURNALISM, \\ KUBAN STATE UNIVERSITY, KRASNODAR
}

\begin{abstract}
Defines mediapointe (indifferent, conscious). Describes preferences of the audience, and gives them an explanation. The conclusion is that the modern Internet audience is extremely heterogeneous, and difficult to formalize.

The object of this research is the online media and other informational and entertainment Internet content. The role of the subject of the research is youth Internet users, its specificity, preferences and characteristics.

Studied online media, information and entertainment content on the Internet. Using metrics, statistics of views and opinions were taken into account the preferences of the audience. Based on the research of predecessors, identified the types of mediapointe, psychology and the reasons for the preference and interest of the audience.
\end{abstract}

Keywords: mediabehaviour, content, online media, blogger, neo-journalism. audience.

УДК 316.77:001.12/.18

В условиях информационного и технологического взрыва существенно трансформировались все социальные общности. Особенно многослойным стало понятие «молодежь». В сущности, оно утратило свою смысловую определенность, поскольку даже возраст сегодня не позволяет однозначно охарактеризовать эту социальную группу. Сюда могут смело войти люди от 8 до 28 лет, однако, самыми активными являются пользователи в возрасте от 14 до 25 лет. Именно их мы и взяли за основу. 
Что есть молодежное СМИ на сегодняшний день? Для одних - это красиво упакованный глянец, пустой и бессмысленный по содержанию, несущий в себе исключительно развлекательную функцию. Отчасти, в этом замечании есть доля правды, поскольку в большинстве своём, молодёжные СМИ, будь то печатные издания, или же красочная игровая программа на специализированном кабельном канале, не несут в себе какой-то образовательной и воспитательной функции. Но с другой стороны, молодёжный сегмент СМИ активно развивается, многие журналисты, понимая, что рынок перенасыщен, а конкуренция сильна, ищут иные способы заинтересовать молодого зрителя [5, с. 1]. С тех пор, доля программ и печатных изданий заметно увеличилась. То, чем раньше занимались такие легендарные издания, как «Наука и техника», нынче выполняют образовательные ролики, наподобие «5 фактов о...».

Говоря о молодёжных СМИ, мы подразумеваем интернет. Безусловно, есть молодёжное телевидение, пресса и даже радио, однако они не имеют и толики популярности и аудитории, которые есть у онлайн-СМИ. Что характерно, интернет-журналы пользуются большой популярностью, в отличие от своих печатных аналогов.

Однако, самым распространённым и популярным каналом связи является интернет-телевидение. На просторах таких платформ, как YouTube по разным данным находится до 30000 различных интернет-каналов, которые предоставляют зрителю продукт разного качества. Но даже несмотря на свою дистанцированность от основных каналов, молодежные СМИ - это, безусловно, отрасль современной журналистики. Но со своими большими особенностями. Дело не только в том, что она сориентирована на молодежь, но и в специфической функциональной нагрузке. Одна из важнейших задач молодежных СМИ - это воспитание подрастающего поколения, включение молодого человека в общество. Поэтому к содержанию таких СМИ относиться нужно особо: качественный продукт способен существенно повлиять на настроения и судьбы целого поколения. Нельзя также забывать и об остальных функциях молодежной прессы, которые являются общими для всех СМИ: идеологическая, социально-ориентирующая, организаторская, культурнообразовательная, рекламно-справочная и рекреативная .

Молодёжная аудитория - самая многочисленная и активная в сети интернет. По данным ВЦИОМ 2011 года установлено, что в России насчитывается примерно 51 миллион работающих компьютеров. Каждый третий житель страны - пользователь сети интернет. Среди них около 8 миллионов - дети и подростки до 14 лет. 36\% авторов текстов в глобальной сети в возрасте от 14 до 25 лет [2, с. 2].

Молодых пользователей интернет стал не столько средством коммуникации, сколько отдельной социальной средой, чьё отличие только в том, что она существует в виртуальной форме. Здесь свои законы, свои негласно принятые нормы поведения. Своего рода, это отдельное общество, самостоятельный организм, где главным продуктом является, так называемый интертеймент. Здесь протекает постоянная связь, с помощью социальных сетей. Возможно, эта связь ещё более плотная и полная, чем в реальном мире. Чувства, эмоции, знания - всё это теперь можно найти на просторах онлайн.

В условиях комфортной для молодого человека цифровой среды, он быстро и легко адаптируется к ней, принимает ее правила существования. При этом с одной стороны, новые медиа влияют на молодых пользователей, с другой, медиа сами порождаемы цифровым поколением.

Для молодежи интернет - это естественная среда обитания, а любая информация, будь то новости или демотиваторы являются своеобразным воздухом, которым эта молодёжь дышит. А вот какой этот воздух чистый, или безнадёжно испорченный - зависит от потребностей и воспитания не только потребителя, но и изготовителя медиапродукта. 
В большинстве случаев изготовители интернет-СМИ подстраиваются под вкусы и предпочтения зрителя. Попытка перевоспитать, как правило, сводится к тому, что большая часть публики теряется. Разумеется, можно создавать контент, интересный малому кругу обывателей. При наличии грамотного, качественного и самое главное, регулярного материала каналу обеспечена стабильная, хоть и небольшая посещаемость. Беда в том, что большинство онлайн-ресурсов, существуют за счёт добровольных пожертвований (доннатов) и рекламы. Разумеется, у каналов с большей посещаемостью большая прибыль. В нём нет таких денежных вливаний, бюджет интернет-канала в разы меньше бюджета крупного телеканала. Помимо всего прочего, так называемая «живучесть» канала зависит не от количества рекламы, не от вливаемых в него средств, а от аудитории и от количества просмотров. Интернетжурналистика - совсем молодое явление, и потому еще не крепко стоит на ногах. Многие интернет-каналы носят любительский характер, и осуществляют свою деятельность за счет спонсорских вливаний и рекламы. Как правило, подобное финансированиезначительно, однако известны и обратные примеры, когда крупные компании (как правило, так или иначе связанные с онлайн-средой) заключают крупные спонсорские контракты с различными интернет-СМИ.

Что относить можно отнести к определению «молодёжные интернет-СМИ»? Вопрос сложный, потому как интернет позволяет практически беспрепятственно получить любую доступную информацию. Молодёжь не интересуется жизнью звёзд, как это было в популярных 15 лет назад глянцевых журналах вроде «Cool». Спектр их интересов широк и огромен, от культуры и научно-познавательных ресурсов, до материалов, затрагивающих современную, сформировавшуюся недавно интернеткультуру, состоящую из «мемов» (крылатых выражений) и пранков (постановочных розыгрышей). Молодёжная аудитория сильно привязана к так называемым авторитетам - людям, блогерам, ведущим, которые раз за разом делают выпуски одних и тех же, или близких по стилистике программ. Узнаваемые, и зарекомендовавшие себя блогеры вызывают интерес у аудитории.

У современного молодого зрителя есть ещё одна особенность - он не гонится за зрелищным, красочным материалом. Для него гораздо важнее наполнение, иначе каналы современных видеоблогеров, иронично рассказывающих о своём мнении и взглядах на жизнь набирают сотни тысяч просмотров. А интернетжурналы, ориентированные на прогрессивную молодёжную публику («Метрополь», «ВOC», «BroDude», «FurFur») не имели бы той колоссальной популярности, которой позавидовали бы многие отечественные глянцевые издания. Это ещё раз отсылает нас к «авторитетам».

Таким образом, формируется целая система мировоззрений и жизненных взглядов, воспитывающая молодёжь. Государство могло бы использовать подобный опыт для создания воспитательных и патриотических интернет-ресурсов, однако эти попытки не обвенчались успехом, ведь недостаточно подготовить материал, важно сделать его интересным для потенциального зрителя, завоевать его внимание. У блогеров и онлайн-журналистов это получается как минимум потому, что описанная ими точка зрения близка молодежи, они разговаривают на одном языке со зрителем. Даже научный материал должен подаваться легко, включать в себя хотя бы немного интертеймента, и соответствовать знаменитой концепции Оскара Уайльда об искусстве - поучая развлекай.

Большинство ресурсов избрало своеобразным «ключом» к зрительскому вниманию юмор. Даже если речь идет о трансляции игрового процесса c Twitchканала или статье о гибридных двигателях. Доступный адекватный юмор, в купе с высокой информативностью подкупает зрителя больше, нежели сплетни.

Стоит отметить одну важную особенность интернет-сообщества, и общества в целом. Это живучесть информации. Сенсация в онлайн-сообществе, без подпитки и новых фактов живет меньше, чем в других видах СМИ. Поэтому. Актуальность и 
своевременность являются секретом успеха видеоблоггера. Программа, сделанная раньше других, всегда наберет больше просмотров. Если же новость устарела, то она привлечет меньший интерес. Точно подсчитать срок жизни новости в интернеттелевидении невозможно. Все зависит от самой новости, вызванного резонанса. Зритель всегда хочет быть в центре резонанса.

Одним из самых главных преимуществ сетевой журналистики является её бесспорная гибкость, касаемо критики, отзывов и предложений со стороны зрителей. Всегда можно оставить комментарий, обсудить материал с другими зрителями, и оценить продукт путем системы «лайков» и «дизлайков». И что самое главное, создатели действительно прислушиваются к мнению зрителей, делают выводы, и подстраивают свой материал с учетом вкусов и предпочтений аудитории. Во многом это происходит потому, что по своим масштабам сетевая журналистика сильно уступает обычным СМИ.

У молодежи, как и у любой другой социальной группы во взаимодействии с медиа прослеживается определенное медиаповедение, которое характеризует ее как часть стратифицированного сообщества. Медиаповедение аудитории не сводится к медиапотреблению, как это часто наблюдается в медиаиндустрии, где аудитория является предметом купли-продажи [2, с. 3]. Медиаповедение - это все то, что человек делает или не делает по отношению к медиа. Бездействие и низкий рейтинг это тоже своего рода критика.

Самым распространённым является индифферентное медиаповедение, когда молодой человек проявляет полное отсутствие интереса к источникам информации. Молодёжная аудитория, сильнее другой способна действовать под влиянием инстинктов и потребностей. Этим и обуславливается выбор продукта. В свою очередь, существует осознанное медиаповедение - аудитория, имеющая достаточно высокий уровень медиаинформационной грамотности и способная критически отнестись к контенту, который ей предлагает медиасреда. Именно они формируют современные классы и субкультуры в онлайн-пространстве и в жизни (например, хипстеры).

Аудитория карйне неоднородна по своим интересам. Большой круг аудитории относит себя к молодым интеллектуалам, ценящим высокое искусство, инди-музыку, любящее читать книги. В большинстве своём, они составляют аудиторию интернетпрессы . Кроме того, есть широкий круг любителей маргинального и нестандартного контента. Остальные, преимущественно выбирают классический развлекательный контент, который отчасти смешался с информационным. Однако нередки случаи, когда наблюдается смешение интересов провести какую-либо градацию просто невозможно. Интеллектуалы посещают новостные сайты, и смотрят и популярные развлекательные шоу. Чаще всего, список интересов определяется образом жизни, потребностями, широкой рекламой и общей доступностью готового материала.

Сегодня оно выражается в самодеятельном творчестве непрофессиональных авторов по созданию массового информационного продукта, который носит неформальный, внеэкономический, социальный характер и рождается из коммуникаций с другими людьми. Этот процесс происходит вне рамок формальных медиаорганизаций, результатом неформального медиаповедения индивида становится неформальная нео-журналистика. К ней можно отнести практически всю блогосферу, за исключением блогов профессиональных журналистов, бесчисленное множество постов информальных авторов, комментариев, твиттов, SMS-сообщений и других форматов медиатекстов.

Молодежная аудитория в высокой степени неформальна, её очень сложно подвергнуть какой бы то ни было формализации. Духовное, нормативно-правовое медиапроизводство, попытки манипулировать мнением для непопулярных с гражданской точки зрения целей (как то агитация и политическая пропаганда) вызывает волну раздражения. 
Современная молодежная интернет-аудитория с большим трудом поддаётся формализации. Понятие «молодёжь сильно трансформировалось, и включает в себя большую группу людей в возрасте от 8 до 28 лет [5, с. 4]. Аудитория, по своим интересам весьма неоднородна. Встречаются как интеллектуалы, так и большая группа аудитории с маргинальными предпочтениями, и те, кто предпочитает контент развлекательного характера.

Чаще всего, список интересов определяется образом жизни, потребностями, широкой рекламой и общей доступностью материалов онлайн-продукта.

\section{Список литературы / References}

1. Борусяк Л. Чтение как ценность в среде молодых российских интеллектуалов, Вестник общественного мнения, 2010. № 3.

2. Жилавская И.В. «Медиаповедение молодежной аудитории в условиях дивергенции» Московский государственный гуманитарный университет им. М.А. Шолохова, 2012.

3. Жилавская И.В. «Медиаповедение личности. Обретение смысла». Медиаскоп. № 2, 2011.

4. Косолапова Ю.И. Аудитория молодежных СМИ. Характер информационных потребностей вчера, сегодня и завтра, Московский гуманитарно-экономический институт. Кировский филиал, 2010.

5. Роджерс К. Взгляд на психотерапию. Становление человека. М., 1994.

6. Пронин Е.И. Психологические проблемы современной журналистики, Вестн. Моск. ун-та. Сер. 10. Журналистика, 2001. № 3.

7. Амзин A. Новостная интернет-журналистика. [Электронный ресурс]. Режим доступа: http://kebati.ru/ journ/j ourn.pdf./ (дата обращения: 25.04.2017). 


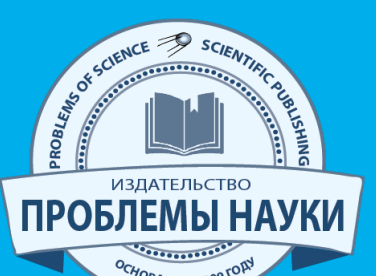

НАУЧНО-МЕТОДИЧЕСКИЙ ЖУРНАЛ

«ПРОБЛЕМЫ СОВРЕМЕННОЙ НАУКИ И ОБРАЗОВАНИЯІ

PROBLEMS OF MODERN SCIENCE AND EDUCATION»

http://www.ipi1.ru

ISSN 2304-2338(Print)

ISSN 2413-4635(Online)

ИЗДАТЕЛЬСТВО «ПРОБЛЕМЫ НАУКИ» http://scienceproblems.ru

э POCKOMHАДЗОР

СВИДЕТЕЛЬСТВО ПИ № ФС 77-47745

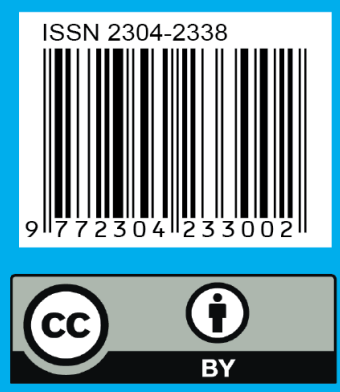

